\title{
Numerical Modeling and Field Monitoring of Overburden Response during Geologic Sequestration
}

\author{
Raj Kumar Gondle \\ West Virginia University
}

Follow this and additional works at: https://researchrepository.wvu.edu/etd

\section{Recommended Citation}

Gondle, Raj Kumar, "Numerical Modeling and Field Monitoring of Overburden Response during Geologic Sequestration" (2010). Graduate Theses, Dissertations, and Problem Reports. 4598.

https://researchrepository.wvu.edu/etd/4598

This Dissertation is protected by copyright and/or related rights. It has been brought to you by the The Research Repository @ WVU with permission from the rights-holder(s). You are free to use this Dissertation in any way that is permitted by the copyright and related rights legislation that applies to your use. For other uses you must obtain permission from the rights-holder(s) directly, unless additional rights are indicated by a Creative Commons license in the record and/ or on the work itself. This Dissertation has been accepted for inclusion in WVU Graduate Theses, Dissertations, and Problem Reports collection by an authorized administrator of The Research Repository @ WVU.

For more information, please contact researchrepository@mail.wvu.edu. 


\title{
Numerical Modeling and Field Monitoring of Overburden Response during Geologic Sequestration
}

\author{
Raj Kumar Gondle \\ Dissertation submitted to the \\ College of Engineering and Mineral Resources \\ at West Virginia University \\ in partial fulfillment of the requirements \\ for the degree of
}

Doctor of Philosophy

in

Civil \& Environmental Engineering

Hema J. Siriwardane, Ph.D., Chair

H. Ilkin Bilgesu, Ph.D.

Grant S. Bromhal, Ph.D.

John D. Quaranta, Ph.D.

Roger C. Viadero, Ph.D.

Thomas H. Wilson, Ph.D.

Morgantown, West Virginia

2010

Keywords: Sequestration; Deformation; Numerical Modeling; Tiltmeters 


\section{ABSTRACT \\ Numerical Modeling and Field Monitoring of Overburden Response during Geologic Sequestration}

\section{Raj Kumar Gondle}

Atmospheric levels of carbon dioxide $\left(\mathrm{CO}_{2}\right)$ have increased at a rate of about 1 to 2 parts per million (ppm) per year to its current level of approximately 388 ppm. Mitigation efforts are being deployed around the world in all possible ways to combat these accelerating levels of carbon dioxide. The study presented in this dissertation deals with the ground response caused by geologic sequestration of carbon dioxide. The ground response can be used as a tool for longterm monitoring of carbon storage in geological formations.

Unmineable coal seams have been identified as promising reservoirs for large-scale sequestration of carbon dioxide. A sequestration field site located in West Virginia and in the northern Appalachian basin has been used in this study. The field project is intended for geologic sequestration of carbon dioxide in a deep unmineable coal seam. The objective of the current study is to monitor any field-scale deformations resulting from the injection of carbon dioxide into a coal seam. Thirty six high-precision tiltmeters and two GPS receivers (absolute and remote) have been installed at the site to monitor surface deformations during the injection of $\mathrm{CO}_{2}$. Moreover, a multi-layered, three-dimensional, single-phase, coupled flow-deformation finite element model has been developed to investigate surface deformations during the injection. The model incorporates the topographical challenges and field-specific details. A finite difference based reservoir modeling approach was used to investigate the multi-phase fluid flow behavior in the coal seam by considering sorption/desorption properties and coal swelling/shrinkage. The results from multi-phase reservoir modeling were integrated in the finite element based geomechanical models. Tiltmeter measurements show the extent of deformations at the field site. The comparison of measurements and modeling results helps in calibrating numerical models that can be used to study reservoir response during large-scale injection of carbon dioxide. Results obtained from this study are useful in understanding the migration of fluid and pressure changes in the reservoir that helps in developing monitoring technologies. 
This QDissentation work is dedicated to

my Samily,

especially

my Wham, OPramila OBai Gondle

(6)

my Oad, Marsing ORas Gondle

Pox theirs Olove, Gare and Oluppont

iii 


\section{ACKNOWLEDGEMENTS}

Graduate education at West Virginia University has been a wonderful and a memorable journey of my learning. I would like to take this excellent opportunity given to me to thank several people who have helped, supported and encouraged me during my graduate studies at West Virginia University. First and foremost, I offer my special and sincere thanks to my dissertation advisor Professor Hema Siriwardane. He was the backbone to my success. Dr. Siriwardane has always persuaded me, helped me, supported me and provided me with an insight to problem solving from the day one of graduate life. I am indebted to have such a wonderful person, great teacher, outstanding researcher and a superb mentor as my graduate advisor.

I wish to extend my sincere and immense gratitude to my committee members - Dr. Grant Bromhal, Dr. Thomas Wilson, Dr. Roger Viadero, Dr. Ilkin Bilgesu and Dr. John Quaranta for serving on my Ph.D. committee, reviewing my dissertation and for bringing the best out of me through their expertise. Dr. Grant Bromhal has been a part of this research project providing valuable guidance and constructive comments. My experience with him as a committee member and as a co-researcher has made my learning productive and stimulating. I offer my sincere appreciation to Dr. Thomas Wilson, who has been a helping hand behind the scene. Dr. Thomas Wilson has been a continuous support providing assistance with my dissertation research work. Also, I enjoyed working with him as an active member of WVU ZERT team. I am heartfully thankful to Dr. Roger Viadero for having him as one of my committee members. Dr. Viadero is a nice, kind and knowledgeable person to work with and provided help whenever I needed during my research completion. I offer my warm and deepest admiration to Dr. Ilkin Bilgesu and Dr. John Quaranta for their assistance, enthusiasm and remarkable ideas in my research work.

I gratefully acknowledge the financial support provided through a graduate research assistantship by West Virginia University through a project funded by the United States Department of Energy as a subaward (G137-05-W0221, Prime award DE-FC-26-04NT42262) through Montana State University under its ZERT program. 
The field site used in the current research work is operated by CONSOL Energy. I acknowledge CONSOL Energy for providing access to the field site and field data. I am thankful to Consol Energy's team, especially Richard Winschel, Roy Scandrol, Ravi Srivastava, James Locke and Adam Goodell for providing assistance at the field site and with pertinent field data. This field study would not have been possible without their help and assistance. Field monitoring of ground response by using tiltmeters was performed with assistance from Pinnacle Technologies. I would like to offer my special thanks to Zeno Philip, John Sullivan, Glenn McColpin, Mike Jordan, Jeff Mueller and Will Roadarmel of Pinnacle Technologies for their assistance. I am also thankful to Dr. Richard Bajura for leading WVU ZERT team with conference calls and research meetings. Moreover, I thank members of WVU ZERT team for their active participation and valuable discussions.

I gratefully acknowledge the use of reservoir simulation software provided by Computer Modeling Group (CMG). I offer my special thanks to Jim Erdle, Bob Brugman and K. Patel for providing assistance and training to CMG software. I also acknowledge WV GIS Technical Center for providing GIS data and Will Ravenscroft for helping with GIS software.

It's a pleasure for me to recognize Professor Darrell Dean as well. He has always given me a great motivation and moral support to my performance. I am fortunate to know Mr. \& Mrs. Moloy Gupta. Perhaps, their interaction has lead to my success. Words are not enough, but it's the only way I can pour out my thoughts to extend my thanks and share this happiness with all my family members on this big achievement. In a university or work place, nothing is possible without your buddies, friends and well wishers. The road to any success is not seen without getting a little help from friends. You always want to celebrate party, drink and share your achievement with them. It's true in my story. My heartful thanks to all of you - Rupesh Gondle, Suhasini Kalluru, Kalyan Varma Bhupathiraju, Benjamin Bowes, Sai Varre, Laura Sesack, Andrew Dietz, Nathaniel Burgett, Sumanth Gundagatti, Jeremi Stawovy, Rajesh Tolikonda, Srikanth Mantri, Hemachandar Mada, Arun Sivaraman, Ramakanth Mettu, Rajesh Vuppala, Divya Doma, Shilpa Bollineni, Preethi Vantaram, Himanshu Bhatt and Samarth Bharadwaj for helping me when I am in need. Inadvertently, if I have missed someone in my list, I would like to apologize and thank you for all your help, care and support. Love and cheers to all of you. 


\section{TABLE OF CONTENTS}

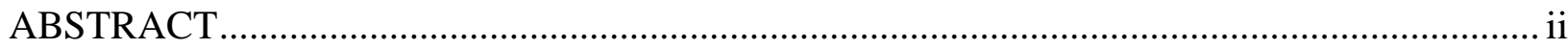

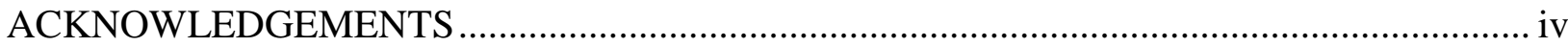

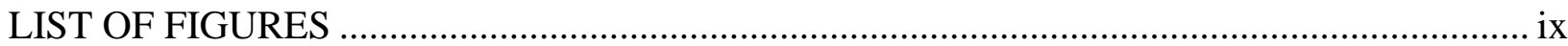

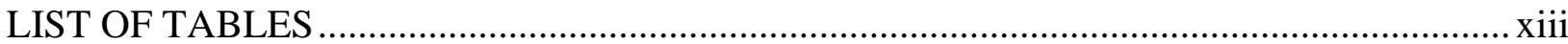

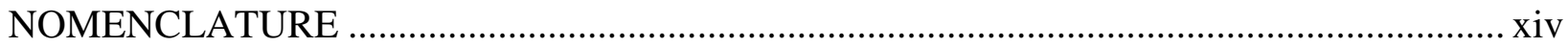

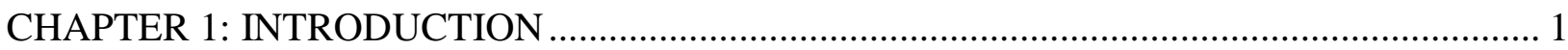

1.1 Introduction to greenhouse gas effect ………………….................................................. 1

1.2 Carbon sequestration in geologic formations................................................................ 2

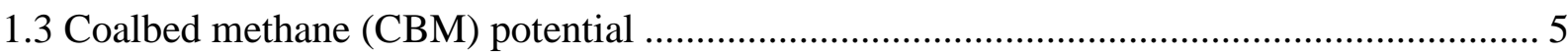

1.4 Sequestration potential of $\mathrm{CO}_{2}$ in coal seams ………...................................................... 6

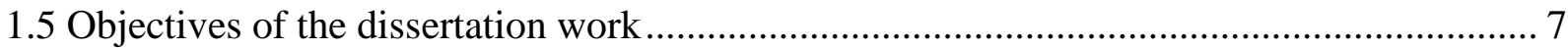

CHAPTER 2: OVERVIEW OF CBM RECOVERY AND $\mathrm{CO}_{2}$ SEQUESTRATION ................... 9

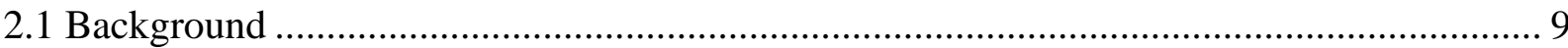

2.2 Gas storage mechanism in coal seams ............................................................................ 10

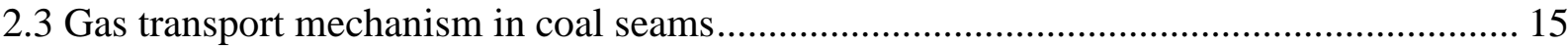

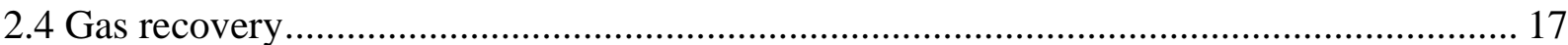

$2.5 \mathrm{CO}_{2}$ sequestration in coal seams .................................................................................. 20

2.6 Factors affection $\mathrm{CBM}$ recovery and $\mathrm{CO}_{2}$ sequestration ................................................... 21

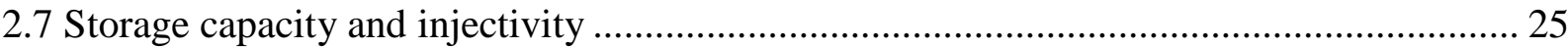

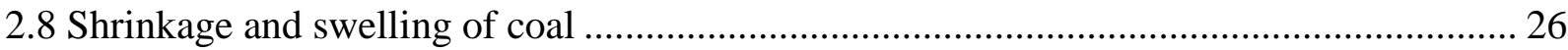

2.9 Geomechanics ............................................................................................................ 33

CHAPTER 3: DESCRIPTION OF CO ${ }_{2}$ SEQUESTRATION FIELD SITE .................................. 34

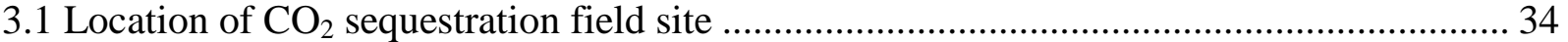

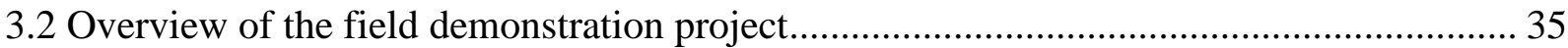

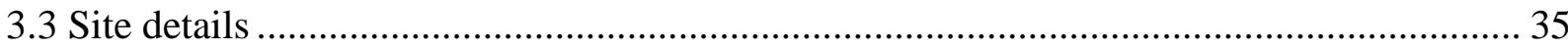

3.4 Geologic characterization and structural geology ……....................................................... 41 
3.5 Gas content and adsorption/desorption properties ............................................................. 51

3.6 Production and injection details ....................................................................................... 57

CHAPTER 4: FIELD MONITORING OF SURFACE DEFORMATIONS DURING $\mathrm{CO}_{2}$

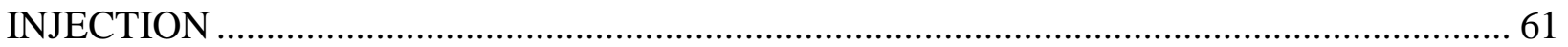

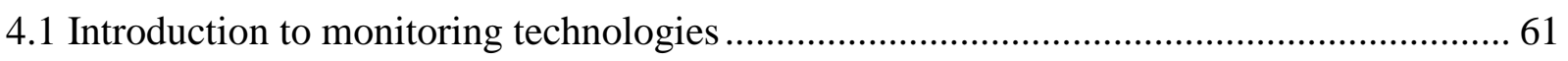

4.2 Advantages and disadvantages of InSAR and tiltmeters ...................................................... 61

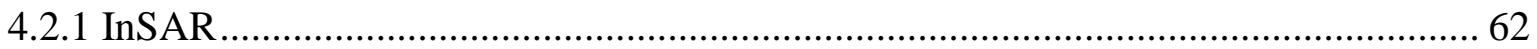

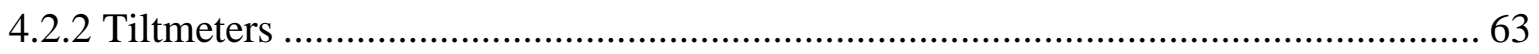

4.3 Ground monitoring objectives at the field site ................................................................... 64

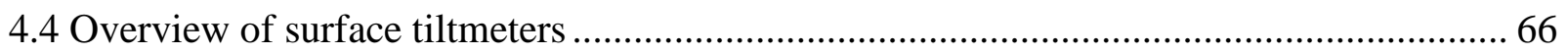

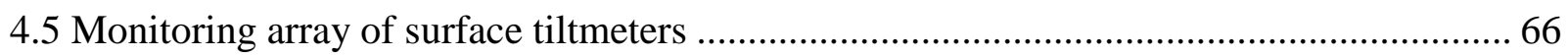

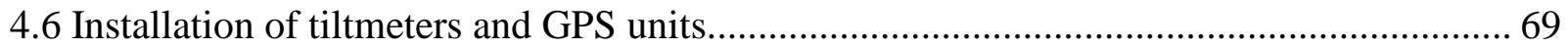

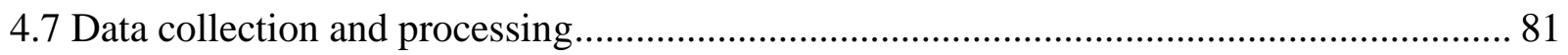

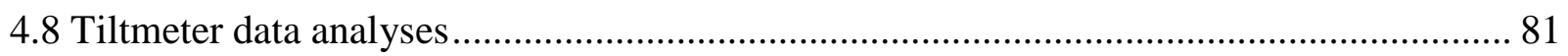

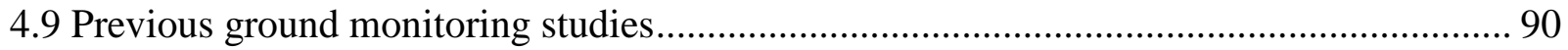

4.10 Tiltmeter monitoring results at the field site ………………........................................... 93

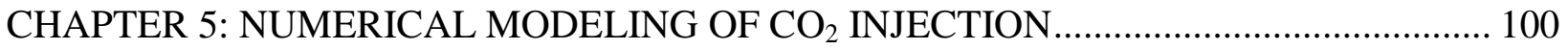

5.1 Objectives of numerical modeling .............................................................................. 100

5.2 Numerical methodology …………………………….................................................. 101

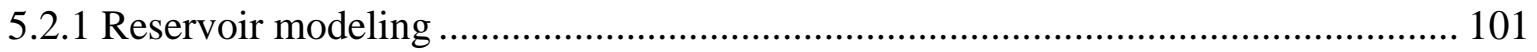

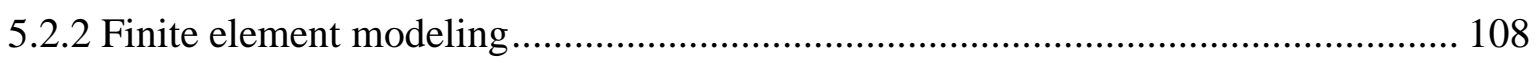

5.3 Mathematical formulations for coupled flow-deformation analyses ................................. 112

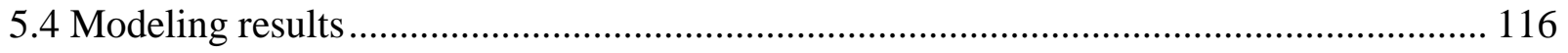

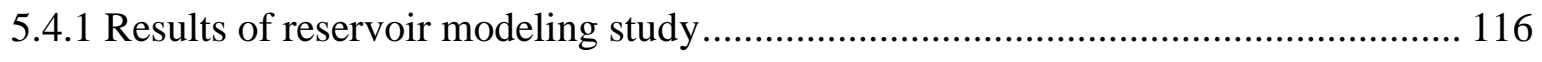

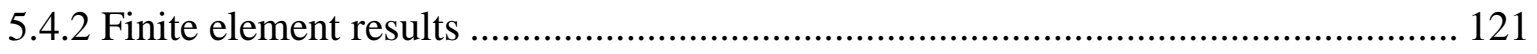

5.4.3 Comparison of computed and measured surface displacements............................... 125

5.4.4 Correlation of measured and computed ground displacements ................................ 125

5.4.5 Pressure comparison from reservoir modeling and finite element modeling............ 125 
CHAPTER 6: PRESSURE RESPONSE IN A OVERBURDEN MONITORING LAYER ...... 129

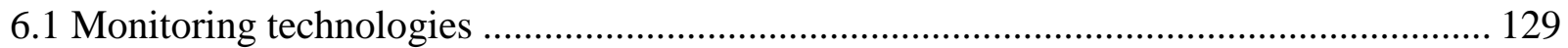

6.2 Numerical methodology used in the caprock fracture study ...................................... 130

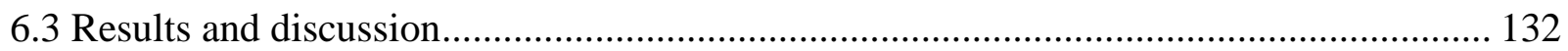

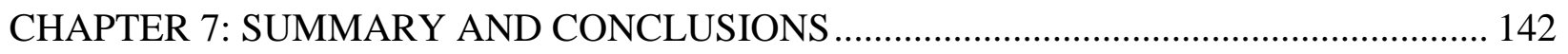

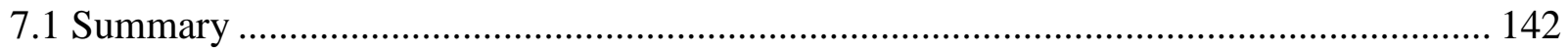

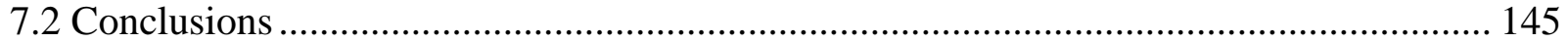

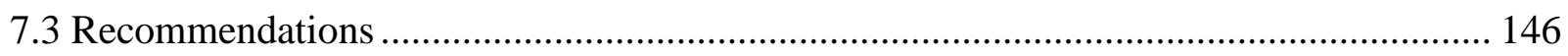

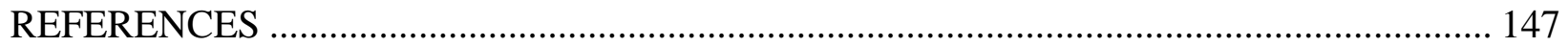




\section{LIST OF FIGURES}

Figure 1.1: Geologic sequestration of $\mathrm{CO}_{2}$ into potential reservoirs ..............................................

Figure 1.2: Major coal basins of the United States of America......................................................6

Figure 2.1: Micropores and macropores of a typical coal..............................................................9

Figure 2.2: A typical Langmuir isotherm curve.....................................................................11

Figure 2.3: Comparison of typical isotherm curves based on raw, dry and dry-ash free basis ....15

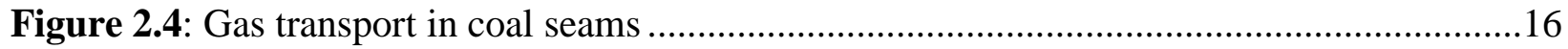

Figure 2.5: Gas and water production curves from conventional and CBM reservoirs.................18

Figure 2.6: Interpretation of a typical Langmuir isotherm curve..................................................19

Figure 2.7: Cleat openings as a result of coal shrinkage............................................................27

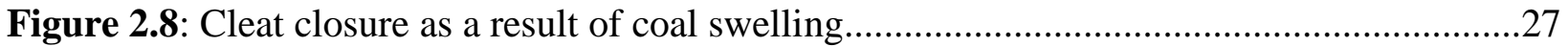

Figure 3.1: Location of $\mathrm{CO}_{2}$ sequestration field site used in the current study .............................34

Figure 3.2: Pittsburgh coal seam and Upper Freeport coal seam at the field site...........................36

Figure 3.3: A perspective view of production wells, injection wells and access wells .................38

Figure 3.4: Aerial view of well configurations with respect to ground topography ......................39

Figure 3.5: Well configuration and well names in both coal seams .............................................40

Figure 3.6: Injection site surrounded by thick vegetation and hilly terrain ....................................42

Figure 3.7: Stream located near the field site...........................................................................42

Figure 3.8: One of the producer wells in the region .................................................................43

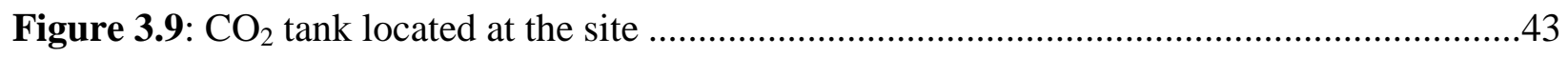

Figure 3.10: Generalized stratigraphic sequence of the northern Appalachian coal basin ............44

Figure 3.11: Thickness map for Pittsburgh coal seam (feet) ………………………….................47

Figure 3.12: Thickness map for Upper Freeport coal seam (feet) ..................................................48

Figure 3.13: Depth to Pittsburgh coal seam (feet) ………….......................................................49

Figure 3.14: Depth to Upper Freeport coal seam (feet) ……........................................................49

Figure 3.15: 3-D perspective of coal seams with individual well configurations...........................50

Figure 3.16: Gas Content map for Pittsburgh coal seam (SCF/ton) ...............................................52

Figure 3.17: Gas Content map for Upper Freeport coal seam (SCF/ton) ......................................53

Figure 3.18: Isotherm curves of Pittsburgh coal seam................................................................55 
Figure 3.19: Adsorption curves of Pittsburgh coal seam ....................................................55

Figure 3.20: Isotherm curves of Upper Freeport coal seam.................................................56

Figure 3.21: Adsorption curves of Upper Freeport coal seam ................................................56

Figure 3.22: Comparison of gas production for all wells ...................................................58

Figure 3.23: Time-line of $\mathrm{CBM}$ production and $\mathrm{CO}_{2}$ injection .............................................59

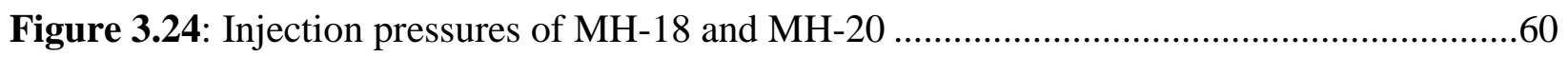

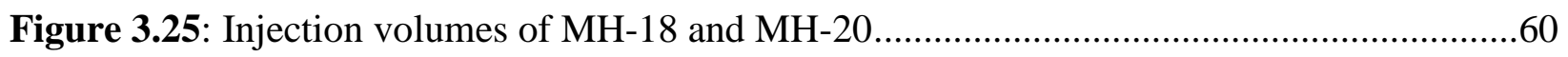

Figure 4.1: Tilt measurements due to earth tides ................................................................65

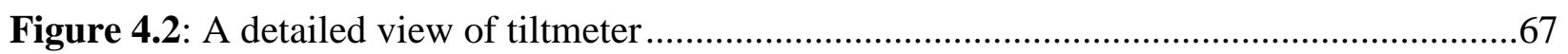

Figure 4.3: A schematic diagram of tiltmeter monitoring array ............................................68

Figure 4.4: Surveying and positioning of potential tiltmeter locations...................................70

Figure 4.5: Rough terrain at the field site ....................................................................... 70

Figure 4.6: Ground topography around the injection wells ...............................................71

Figure 4.7: 3D-view of installed tiltmeters at the field site ...............................................72

Figure 4.8: Tiltmeter monitoring array with a projected view of wells on the ground surface ....73

Figure 4.9: Aerial view of 36 tiltmeters and 2 GPS receivers installed at the field site ..............74

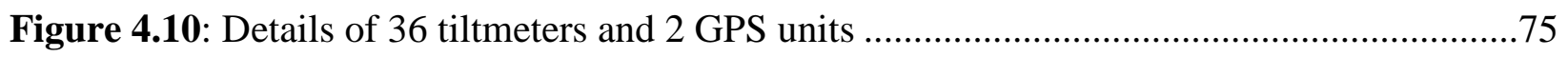

Figure 4.11: Installation details of a tiltmeter at the field site ...............................................77

Figure 4.12: A few tiltmeter stations located at the field site ...........................................78

Figure 4.13: Detailed view of absolute GPS station at the field site .......................................79

Figure 4.14: Central processing computer located with other field equipment ..........................80

Figure 4.15: An example of Delauney triangulation..........................................................83

Figure 4.16: Results of tiltmeter study reported at the Pump Canyon $\mathrm{CO}_{2}$ sequestration site .....91

Figure 4.17: InSAR results reported at the Pump Canyon $\mathrm{CO}_{2}$ sequestration site .....................91

Figure 4.18: InSAR results reported at the InSalah $\mathrm{CO}_{2}$ sequestration site..............................92

Figure 4.19: Raw data obtained from Tiltmeter 26...........................................................93

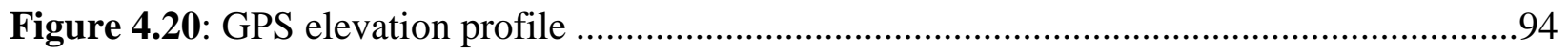

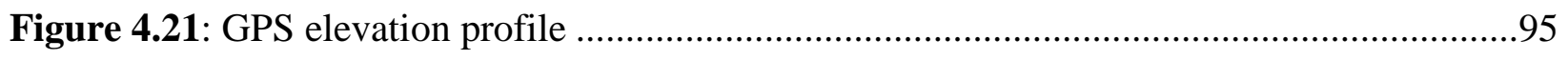

Figure 4.22: Surface deformation prior to injection of $\mathrm{CO}_{2}$ at the field site............................96

Figure 4.23: Surface deformation for a two week period of 08/16/2010 to 08/30/2010 .............97 
Figure 4.24: Long-term cumulative surface deformations from the beginning of $\mathrm{CO}_{2}$ injection (09/07/2009 to $08 / 30 / 2010)$

Figure 5.1: Reservoir geometry of Pittsburgh coal and Upper Freeport coal used in the study.103

Figure 5.2: Well configurations considered in the reservoir modeling study ..........................105

Figure 5.3: Stress-dependent permeability used in the study.............................................106

Figure 5.4: Geometry and mesh of the finite element model.............................................110

Figure 5.5: Idealized well configuration of $\mathrm{CO}_{2}$ injection wells ..........................................111

Figure 5.6: History matching results of CBM production from $\mathrm{MH}-12, \mathrm{MH}-5$ and $\mathrm{MH}-11$.....117

Figure 5.7: History matching results of production and $\mathrm{CO}_{2}$ injection of $\mathrm{MH}-18$ and $\mathrm{MH}-20 . .119$

Figure 5.8: Reservoir pressure distribution...................................................................120

Figure 5.9: Fluid pressure distribution in the lower coal seam at the end of injection period....121

Figure 5.10: Fluid pressure distribution in the reservoir and overburden layers ......................122

Figure 5.11: Computed surface displacements .................................................................123

Figure 5.12: Vertical displacements in overburden layers................................................124

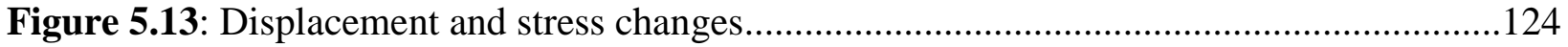

Figure 5.14: Ground topography, field measurements and computed surface displacements....126

Figure 5.15: Correlation of measured and computed surface displacements ..........................127

Figure 5.16: Comparison of pressure from reservoir modeling and finite element modeling....128

Figure 6.1: Multi-layered geologic profile of hypothetical $\mathrm{CO}_{2}$ injection site ........................130

Figure 6.2: 2-D and 3-D finite element models with multiple fractures ...............................131

Figure 6.3: Finite element mesh and location of fault in the caprock...................................132

Figure 6.4: Surface displacements with and without fracture............................................133

Figure 6.5: Signal change in surface deformations with time (at 210 days)...........................133

Figure 6.6: Pressure response in the monitoring layer with and without fracture ....................134

Figure 6.7: Influence of caprock permeability on overburden pressure response .....................135

Figure 6.8: Monitoring points above the caprock layer ....................................................136

Figure 6.9: Variations of pore pressure at various locations...............................................137

Figure 6.10: Variation of pore pressure in different layers ...............................................137

Figure 6.11: Influence of a fault on the pore pressure response in the monitoring layer ...........138

Figure 6.12: Influence of different fractures on the ground response...................................139 
Figure 6.13: Influence of different fractures on the pressure response .................................140

Figure 6.14: Two-dimensional finite element mesh used to simulate fault activation ..............140

Figure 6.15: Pressure response due to activation of simulated fault during $\mathrm{CO}_{2}$ injection ........141 


\section{LIST OF TABLES}

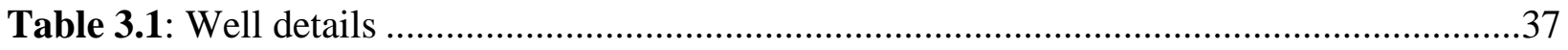

Table 5.1: Conventional and unconventional reservoir properties used in the study ................107

Table 5.2: Geomechanical properties used in the study ....................................................109 


$$
\begin{aligned}
& \mathrm{A}=\text { area of coal } \\
& \mathrm{b}=\text { Langmuir constant } \\
& \mathrm{B}=\text { slip factor } \\
& \mathrm{B}_{\mathrm{g}}=\text { gas volume factor } \\
& \mathrm{B}_{\mathrm{S}}=\text { Skempton's pore pressure coefficient } \\
& \mathrm{C}=\text { concentration of } \mathrm{CH}_{4} \text { in a unit volume of coal } \\
& \mathrm{C}_{\mathrm{D}}=\text { curvature of the Delauney triangulation line } \\
& \mathrm{C}_{\mathrm{f}}=\text { completion factor } \\
& \mathrm{C}_{\mathrm{f}}=\text { formation compressibility } \\
& \mathrm{C}_{\mathrm{m}}=\text { compressibility or compliance of coal matrix } \\
& C^{\text {sh }}=\text { shrinkage constant } \\
& C^{\text {sw }}=\text { swelling constant } \\
& \mathrm{D}=\text { diffusion coefficient } \\
& \mathrm{d} \text { = vector for the measured surface deformations } \\
& \mathrm{E}=\text { elastic modulus of coal } \\
& \hat{f}=\text { body forces per unit volume } \\
& \mathrm{f}=\mathrm{a} \text { fraction, usually between } 0 \text { to } 1 \\
& \mathrm{f}_{\mathrm{a}}=\text { ash content (fraction) } \\
& \mathrm{f}_{\mathrm{m}}=\text { moisture content (fraction) } \\
& g=\text { acceleration due to gravity } \\
& \mathrm{G}_{\mathrm{c}}=\text { gas content } \\
& \mathrm{H}=\text { finite difference approximation of the Laplace operator. } \\
& \mathrm{h}=\text { thickness of the coalbed } \\
& \mathrm{H}_{\mathrm{i}}=\text { elevation at start and end of Delauney triangulation line } \\
& \text { IGIP = initial gas-in-place } \\
& \mathrm{J}=\text { ratio of current volume to original volume } \\
& \mathrm{K}=\text { bulk modulus of coal } \\
& \mathrm{k}=\text { reservoir permeability }
\end{aligned}
$$


$\mathrm{k}_{0}=$ original reservoir permeability

$\mathrm{k}_{\infty}=$ permeability at infinite pressure

$\mathrm{k}_{\mathrm{rg}}=$ gas relative permeability

$\mathrm{k}_{\mathrm{rg} 0}=$ endpoint relative permeability to gas

$\mathrm{k}_{\mathrm{rw}}$ = water relative permeability

$\mathrm{k}_{\mathrm{rw} 0}=$ endpoint relative permeability to water

$\mathrm{K}_{\mathrm{u}}$ = bulk modulus at undrained condition

$\mathrm{L}=$ length of the Delauney triangulation line

$\mathrm{M}=$ constrained axial modulus

$n=$ porosity of the porous media

$n_{t}=$ porosity of fluid trapped

$n_{w}=$ porosity of free fluid at a point

$\mathrm{n}_{\mathrm{g}}=$ exponent of the gas relative permeability curve

$\mathrm{n}_{\mathrm{w}}=$ exponent of the water relative permeability curve

$\mathrm{p}=$ pore pressure

$\mathrm{P}=$ reservoir pressure

$\mathrm{P}_{\mathrm{C}}=$ critical desorption pressure

PGIP = producible gas-in-place

$\mathrm{P}_{\mathrm{i}}=$ initial or original reservoir pressure

$\mathrm{P}_{\mathrm{L}}=$ Langmuir pressure

$\mathrm{P}_{\mathrm{m}}=$ mean reservoir pressure

$\mathrm{P}_{\mathrm{sc}}=$ pressure at standard conditions

$\mathrm{q}=$ gas flow rate through macropores of the coal

$\mathrm{q}^{\prime}=$ gas flow rate through micropores of the coal

$\mathrm{R}_{\mathrm{f}}=$ Recovery factor

$\mathrm{s}=$ vector for changes in the pore fluid volume of the individual reservoir block

$\mathrm{S}_{\mathrm{E}}=\mathrm{CO}_{2}$ storage efficiency factor (fraction)

$\mathrm{S}_{\mathrm{g}}=$ average gas saturation

$\mathrm{S}_{\mathrm{gc}}=$ irreducible gas saturation

$\mathrm{S}_{\mathrm{w}}=$ average water saturation

$\mathrm{S}_{\mathrm{wc}}=$ irreducible water saturation 
$t=$ surface tractions per unit area

$\mathrm{T}=$ temperature

$\mathrm{T}_{\mathrm{i}}=$ surface tilts caused due to change in the pore fluid volume

$\mathrm{T}_{\mathrm{sc}}=$ temperature at standard conditions

$\mathrm{u}_{\mathrm{i}}=$ surface displacements caused due to change in the pore fluid volume

$\mathrm{V}_{\text {(adsorbed) }}=$ volume of gas adsorbed

$\mathrm{V}_{\text {(coalbed) }}=$ volume of gas in coalbed reservoir

$\mathrm{V}_{\text {(conventional) }}=$ volume of gas in a conventional reservoir

$\mathrm{V}_{\text {(free state) }}=$ volume of gas in free state

$\mathrm{V}_{\mathrm{i}}$ = adsorption volume of gas component, $\mathrm{i}$

$\mathrm{V}_{\mathrm{L}}=$ Langmuir volume

$V_{a}=$ volume of the gas adsorbed

$V_{d}=$ volume of the gas desorbed

$\mathrm{x}_{\mathrm{i}}=\operatorname{vector}\left(\mathrm{x}_{1}, \mathrm{x}_{2}, \mathrm{x}_{3}\right)$

$\beta=$ grain compressibility

$\beta^{2}=$ smoothness factor

$\theta=$ tilt oriented in the direction of Delauney triangulation line

$\mu=$ gas viscocity

$v=$ Poisson's ratio

$\phi_{0}=$ initial or original reservoir porosity

$\phi=$ porosity of coalbed reservoir

$\delta v=$ virtual velocity field

$\Delta v_{\text {est }}=$ inverted distribution of fluid volume changes

$\Delta v(\varsigma)=$ ratio of mass change per unit volume to fluid density at reference state

$\alpha=$ poroelastic constant

$\rho_{w}=$ fluid density

$\rho=$ density of coal

$\rho_{w}=$ density of the wetting liquid

$\varepsilon_{l}=$ maximum strain 
$\varepsilon_{i j}=$ strain tensor

$\varepsilon_{k k}=$ volumetric strain

$\varepsilon_{v}^{s h}=$ volumetric shrinkage strain

$\varepsilon_{v}^{s w}=$ volumetric swelling strain

$\delta \varepsilon=$ virtual rate of deformation

$\sigma_{i j}=$ stress tensor

$\sigma=$ true stress (Cauchy stress)

$\sigma_{v}=$ total vertical stress

$\sigma_{v}=$ effective vertical stress

$\sigma_{k k}=$ mean stress

$\sigma_{\mathrm{i}}=$ initial effective stress

$N^{N}=$ interpretation function

$I^{N}=$ Internal load array

$P^{N}=$ External load array

$g_{i}^{*}(x, \varsigma)=$ Green's function due to point source

$u_{w}=$ pore fluid pressure

$u_{a}=$ pore-air pressure 


\section{CHAPTER 1: INTRODUCTION}

\subsection{Introduction to greenhouse gas effect}

Increasing concentrations of greenhouse gases in earth's atmosphere are believed to have a substantial influence on many physical and biological ecosystems (Chu, 2009). Such gases are produced by the combustion of fossil fuels (oil, natural gas, and coal), deforestation, and livestock fermentation. Mainly, carbon dioxide $\left(\mathrm{CO}_{2}\right)$, methane $\left(\mathrm{CH}_{4}\right)$, nitrous oxide $\left(\mathrm{N}_{2} \mathrm{O}\right)$, and fluorocarbons (FC's) are the constituents in the atmosphere that trap heat. $\mathrm{CO}_{2}$ is considered to be the major contributor to the greenhouse gas effect (Chu, 2009). In the Unites States of America, $\mathrm{CO}_{2}$ alone constitutes almost $80 \%$ of total greenhouse gas emissions (U.S. D.O.E., 2007). It has been reported that concentration levels of atmospheric $\mathrm{CO}_{2}$ have risen to approximately 388 parts per million (ppm) from a pre-industrial value of about $280 \mathrm{ppm}$ accelerating at a rate of about 1-2 ppm per year (www. $\mathrm{CO}_{2} \mathrm{NOW}$.org; IPCC, 2007). Also, it is believed that the global surface temperature has increased by about $0.74 \pm 0.18{ }^{0} \mathrm{C}(1.33 \pm 0.32$ ${ }^{0} \mathrm{~F}$ ) during the last century, partly due to the greenhouse gas effect (IPCC, 2007).

Mitigation efforts are being deployed by several national and international organizations to combat carbon dioxide emissions. The target goal of the United States Department of Energy is to develop technologies for fossil fuel conversion systems that could allow $90 \%$ of $\mathrm{CO}_{2}$ to be captured and $99 \%$ of $\mathrm{CO}_{2}$ to be stored with less than $10 \%$ hike in the energy prices by 2012 (U.S. D.O.E., 2006). Several other countries and international collaborations are also working towards the goal of reducing $\mathrm{CO}_{2}$ emissions (U.S. D.O.E., 2010; IPCC, 2007).

Several options are reported for minimizing greenhouse gas emissions (U.S. D.O.E., 2010; IPCC, 2007; Reeves 2003; Bruant, 2002; Beecy and Kuuskraa, 2001; Lewis and Shinn, 2001; Reeves, 2001; Audus, 1997; Blunt et al., 1993; Koide et al., 1992; Van der Meer, 1992). These options include: 


\section{Conservation of energy:}

a. by improving the efficiency of power plants to reduce pollutants

b. by increasing emission-free and fuel efficient automobiles and appliances

c. by changing individual lifestyle and business practices.

\section{Reliance of renewable energy:}

a. by exploring, changing or converting to clean energy resources

b. by use of solar, wind, tidal, ocean, geothermal energies or hydrogen fuel cells

3. Capture and storage technologies for carbon:

a. by capturing the atmospheric carbon and storing into geologic formations, terrestrial ecosystems or oceans.

Carbon capture and storage (CCS) is a mitigation plan to capture carbon dioxide $\left(\mathrm{CO}_{2}\right)$ from large power plants before it is released into the atmosphere and subsequently sequester it in geologic formations or terrestrial ecosystems. The present study deals with some aspects of carbon dioxide storage in geological formations.

\subsection{Carbon sequestration in geologic formations}

Several studies have been reported in published literature with options of sequestering carbon dioxide into deep geologic sinks, repositories or reservoirs (Bachu et al, 2007; White et al., 2005; Reeves 2003; Bachu, 2002; Bruant, 2002; Beecy and Kuuskraa, 2001; Lewis and Shinn, 2001; Holt, 1995). Figure 1.1 illustrates a few options to store $\mathrm{CO}_{2}$ in different geologic formations. These underground formations are believed to have large storage capacities and have the ability to securely store carbon dioxide for a long period of time. The storage potential and economics of geologic sequestration in different reservoirs have been evaluated and can be found elsewhere (Bachu et al, 2007; Beecy and Kuuskraa, 2001). In order to determine potential sites for $\mathrm{CO}_{2}$ sequestration, several factors such as structural geology, hydrocarbon potential, basin 
history, and nearby infrastructure such as pipelines and power plants need to be addressed (Bachu, 2002).

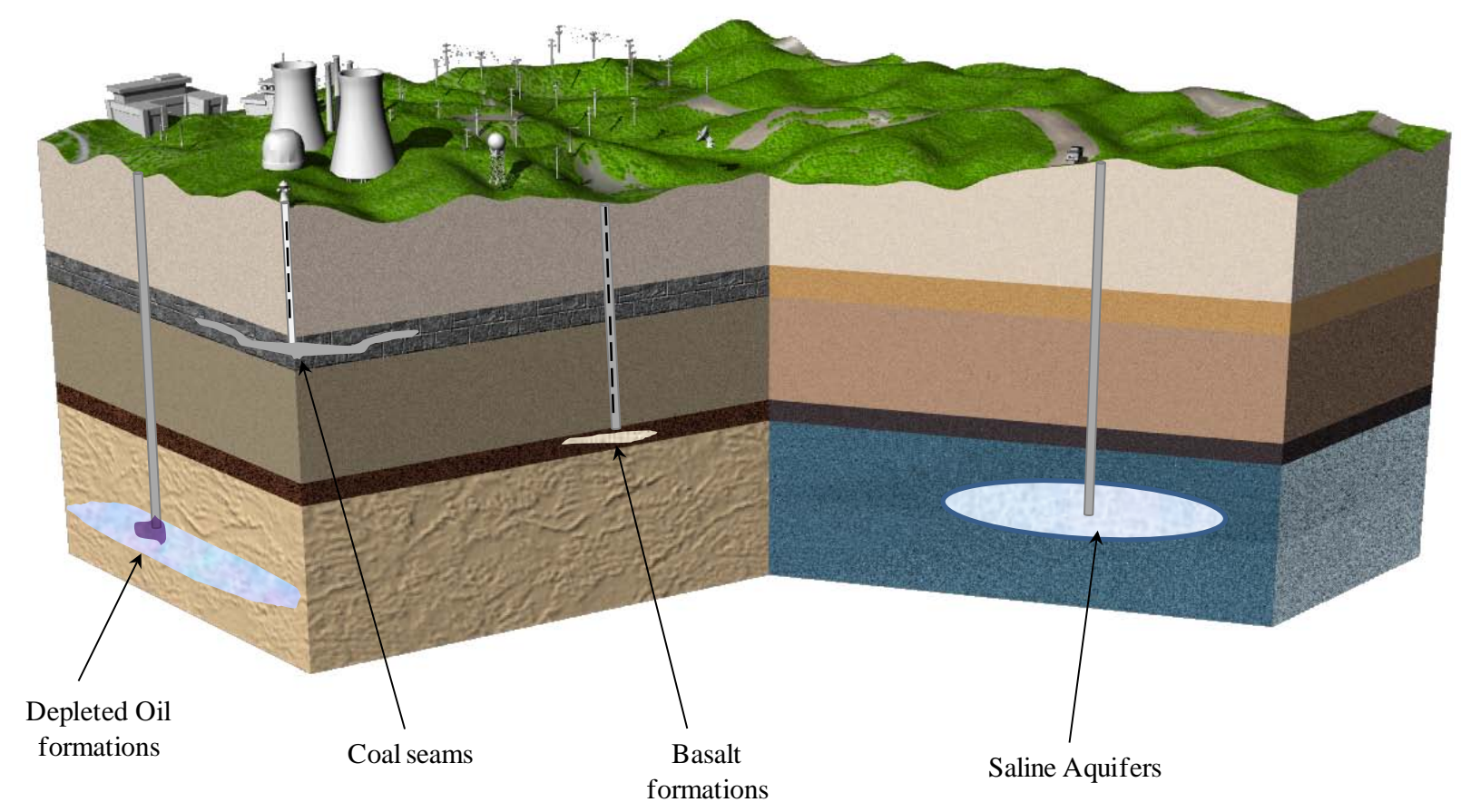

Figure 1.1: Geologic sequestration of $\mathrm{CO}_{2}$ into potential reservoirs

A few potential geologic reservoirs are listed below with some added advantages (U.S. D.O.E., 2008, U.S. D.O.E., 2006):

Depleted oil and gas reservoirs: Several research plans have been developed to evaluate the potential of $\mathrm{CO}_{2}$ storage in petroleum reservoirs with enhanced oil recovery (Blunt et al, 1993). Oil and gas reservoirs are porous rock formations overlain with layers of low permeability rock acting as a seal. Such formations have well established geologic properties and offer a great potential for $\mathrm{CO}_{2}$ storage. Also, the storage of $\mathrm{CO}_{2}$ in depleted oil and gas fields has an added advantage due to vast experience and established geologic data (Stevens et al, 2001).

Unmineable coal seams: The process of coalbed methane recovery and geologic sequestration of $\mathrm{CO}_{2}$ in deep unmineable coal seams has been identified as one of the feasible and profitable options (Gale and Fruend, 2001). Coals have an affinity to sorb massive amounts 
of carbon dioxide and desorb large amounts of coalbed methane that are present in numerous microstructures of the coal matrix. Several studies have shown enhanced production of coalbed methane due to $\mathrm{CO}_{2}$ injection into deep unmineable coal seams (White et al, 2005; Sams et al, 2002). Several recent studies (Siriwardane et al, 2009; Oudinot et al, 2008; White et al, 2005; Bromhal, 2004; Reeves 2003; Sams et al, 2002) have addressed different aspects of storage of carbon dioxide in deep unmineable coal seams.

Saline aquifers: Saline formations are found in large geographic areas making deep brine aquifers an excellent candidate for $\mathrm{CO}_{2}$ sequestration in terms of storage capacity and long-term potential storage (Braunt et al, 2002; Bergman and Winter, 1995; Birkholzer et al, 2009). These formations are overlain by an impermeable caprock which makes it have a perfect seal and is therefore more attractive to trap $\mathrm{CO}_{2}$ for a long period of time.

Basalt formations: Basalt formations are another type of geologic formation that could be used for $\mathrm{CO}_{2}$ sequestration (U.S. D.O.E., 2010). The injected $\mathrm{CO}_{2}$ is believed to chemically react with basalt minerals like calcium, magnesium and iron, converting minerals into calcite. Calcite is a solid carbonate mineral generally found in limestone. Thus, this chemical process is anticipated to help sequester $\mathrm{CO}_{2}$ in basalt rocks and permanently isolate $\mathrm{CO}_{2}$ from reaching the atmosphere.

Shales: Shale formations have also become an attractive option for $\mathrm{CO}_{2}$ sequestration. Shales are the most abundant sedimentary rocks. They are stratified or laminated with thin individual horizontal layers and extremely low permeability in the vertical direction. Many types of shale are composed of less than $5 \%$ organic material. The injected $\mathrm{CO}_{2}$ is adsorbed and stored similar to adsorption in coal seams. Research is being continued to investigate economic viability of $\mathrm{CO}_{2}$ storage in low permeable deep oil and gas shales (U.S. D.O.E., 2008).

Deep Oceans: Oceans are considered to have the largest storage potentials. In deep oceans, the density of $\mathrm{CO}_{2}$ is greater than that of ocean water, therefore allowing $\mathrm{CO}_{2}$ to settle to the bottom of the ocean (Bachu, 2002). Storage of $\mathrm{CO}_{2}$ in deep oceans is reported to entail 
several uncertainties such as environmental, economical, social and political issues (Bachu, 2002).

The current dissertation work mainly deals with the coalbed methane recovery and injection of $\mathrm{CO}_{2}$ in deep unmineable coal seams at a sequestration site. More details of the study are presented in later sections.

\subsection{Coalbed methane (CBM) potential}

Coal is a major contributor to the nation's energy supply. Coal reserves in the United States are abundant and cover about 25\% percent of the world's coal reserves (U.S.D.O.E., 2010). Coal has been a major energy source for many years. Coal contains large quantities of methane gas which is a serious threat to underground coal mining. Coalbed methane, often

referred to as CBM, is a promising natural gas produced from coal reserves and transported in pipelines to nearby power plants to generate electricity. Figure 1.3 shows the major coal basins of the United States of America (www.eia.doe.gov). About 400 to 700 trillion cubic feet (TCF) of methane is believed to be available from these major coal basins (White el al, 2005).

Some of the large gas producing basins include the San Juan basin of New Mexico and Colorado, the Power River basin of Wyoming and Montana, the Warrior basin of Alabama, the Raton basin of New Mexico and Colorado, the Greater Green River basin of Wyoming, Colorado and Utah, and the Uinta-Piceance basin of Colorado and Utah (Byrer et al, 1987; Rogers, 1994; Pashin et al, 2001; Reeves, 2001; Carroll and Pashin, 2003; Pashin and McIntyre, 2003; White et al, 2005; Koperna et al, 2009). Coalbed methane also exists in the coal reserves of the Cherokee, the Forest City, the Arkoma and the Appalachian basins, but the resources are untapped (Byrer et al, 1987). Significant CBM potentials have been reported for coal basins of Piceance, Northern Appalachian, Central Appalachian, and Powder River (Byrer et al, 1987). For the past several years, studies related to coals of Warrior basin, San Juan basin, Piceance basin, Raton Mesa basin, Northern and Central Appalachian basins have been of particular interest in the natural gas industry (Byrer et al, 1987). 
The Northern Appalachian coal is believed to have the second highest underlain coal area of 43,700 square miles with an estimated methane volume of 61 trillion cubic feet, TCF (Adams et al, 1984; Byrer et al, 1987; Lyons, 1998; Rogers, 1994; White et al, 2005; Kelafant and Boyer, 1988). Development of CBM from the Pittsburgh coal seam of the northern Appalachian coal basin reportedly began in the 1930's (Byrer et al, 1987). However, the CBM sources from the Northern Appalachian coal basins have been untapped and are reported to be abundant (Lyons, 1998). In the current study, a sequestration field site located in the Northern Appalachian coal basin is selected to evaluate CBM recovery and sequestration potential.

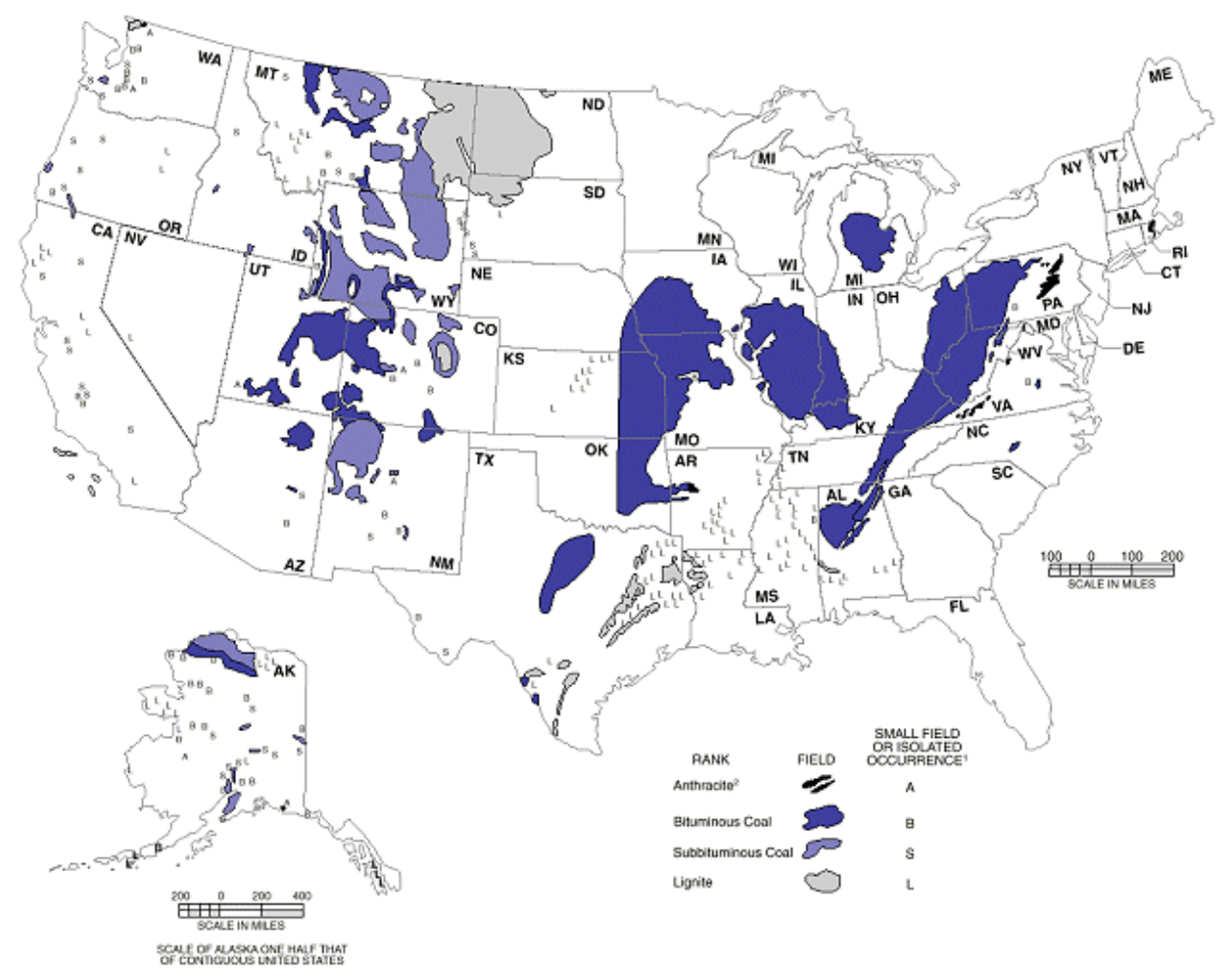

Figure 1.2: Major coal basins of the United States of America. (Source: www.eia.doe.gov)

\subsection{Sequestration potential of $\mathrm{CO}_{2}$ in coal seams}

Unlike other conventional gas reservoirs, coals have the unique characteristic of adsorbing large amounts of carbon dioxide and desorb structurally trapped coalbed methane from 
numerous micropores of the coal matrix. Recent studies (Siriwardane et al, 2009; Oudinot et al, 2008; White et al, 2005; Bromhal, 2004; Reeves 2003; Sams et al, 2002) have addressed some aspects of the storage of carbon dioxide in coal seams. In addition to benefits of long-term storage of carbon in coal sinks, the enhanced coalbed methane recovery has drawn a huge interest in the natural gas industry. Several studies have shown improved production of coalbed methane due to sequestration of $\mathrm{CO}_{2}$ into deep unmineable coal seams (White et al, 2005; Sams et al, 2002). Thus, dual greenhouse gas benefits can be attained by long-term storage of carbon dioxide in unmineable coal seams. However, long-term consequences of enhanced coalbed recovery and geologic sequestration of $\mathrm{CO}_{2}$ in deep unmineable coal seams have not been fully understood.

\subsection{Objectives of the dissertation work}

For the success of large-scale $\mathrm{CO}_{2}$ sequestration, some uncertainties such as the flow behavior of the injected carbon dioxide in the reservoir and overburden pressure response due to geologic sequestration need to be investigated. In the current dissertation work, an actual $\mathrm{CO}_{2}$ sequestration field project and several hypothetical $\mathrm{CO}_{2}$ injection scenario's have been selected to study the flow behavior of injected fluid in the reservoir and overburden response of the system. The field site is located in the Northern Appalachian coal basin and the objective of the field study is to evaluate CBM recovery in the region and to demonstrate the sequestration potential of $\mathrm{CO}_{2}$ in unmineable coal seams. The field site consists of horizontal wells covering large areal extents (Winschel et al, 2010). More details of the field project are presented in the subsequent chapters.

Real-time monitoring is a key to determining the sequestration stability and the migration of injected $\mathrm{CO}_{2}$. In addition to other monitoring techniques located at the site, high precision ground monitoring instruments were installed to monitor any field-scale ground deformations caused by injection of carbon dioxide. A network of high-precision tiltmeters and GPS units were used to investigate the ground response due to injection of carbon dioxide and to determine the migration of fluid flow in the reservoir. In addition to field monitoring at the site, reservoir modeling was performed and integrated with multi-layered, three-dimensional finite element 
analyses to investigate the fluid flow and ground response due to injection of carbon dioxide. Such field monitoring techniques along with numerical modeling can be useful in developing an understanding of fluid flow and overburden response that will help in planning large scale $\mathrm{CO}_{2}$ sequestration and storage operations.

The dissertation work is focused towards the field monitoring and numerical modeling of fluid flow and overburden response during geologic sequestration of $\mathrm{CO}_{2}$. In brief, the objectives of the dissertation work are given below:

- Monitor any field-scale ground deformations caused by the injection of $\mathrm{CO}_{2}$ at a field site by using a network of tiltmeters and GPS stations.

- Investigate the influence of reservoir properties and geomechanical properties such as permeability on the overall response.

- Perform geomechanical modeling of ground response and fluid flow during $\mathrm{CO}_{2}$ injection.

- Compare field measurements with modeling results.

- Investigate the influence of a hypothetical fracture/fault in the caprock on the overburden pressure response.

The research work is reported in several chapters. Chapter 2 describes characteristics of coal and technical background of CBM production and sequestration potential. Chapter 3 provides details of the field site, structural geology, and basin history. Various field monitoring techniques and the use of high-precision ground monitoring instruments for $\mathrm{CO}_{2}$ sequestration benefits are presented in Chapter 4. The numerical methodology used to investigate the fluid flow and overburden response is reported in Chapter 5. Chapter 6 demonstrates hypothetical injection scenarios and models of fractures/fault to investigate $\mathrm{CO}_{2}$ leakage pathways. A summary and conclusions of this research work are presented in Chapter 7. 


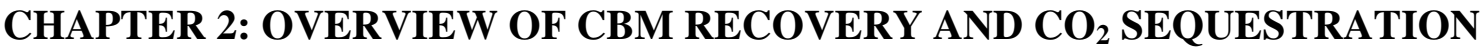

\subsection{Background}

Coalbed methane (CBM) is the clean and economical byproduct of the coalification process (Cervik, 1969). Production of coalbed methane is not only a source of energy from coal seams but also helps improve the safety of coal mining. When compared with other conventional gas reservoirs, CBM reservoirs have distinct characteristics. In nature, coal is a dual-porosity geologic formation associated with micropores (matrix) and macropores (fracture) as shown in Figure 2.1.

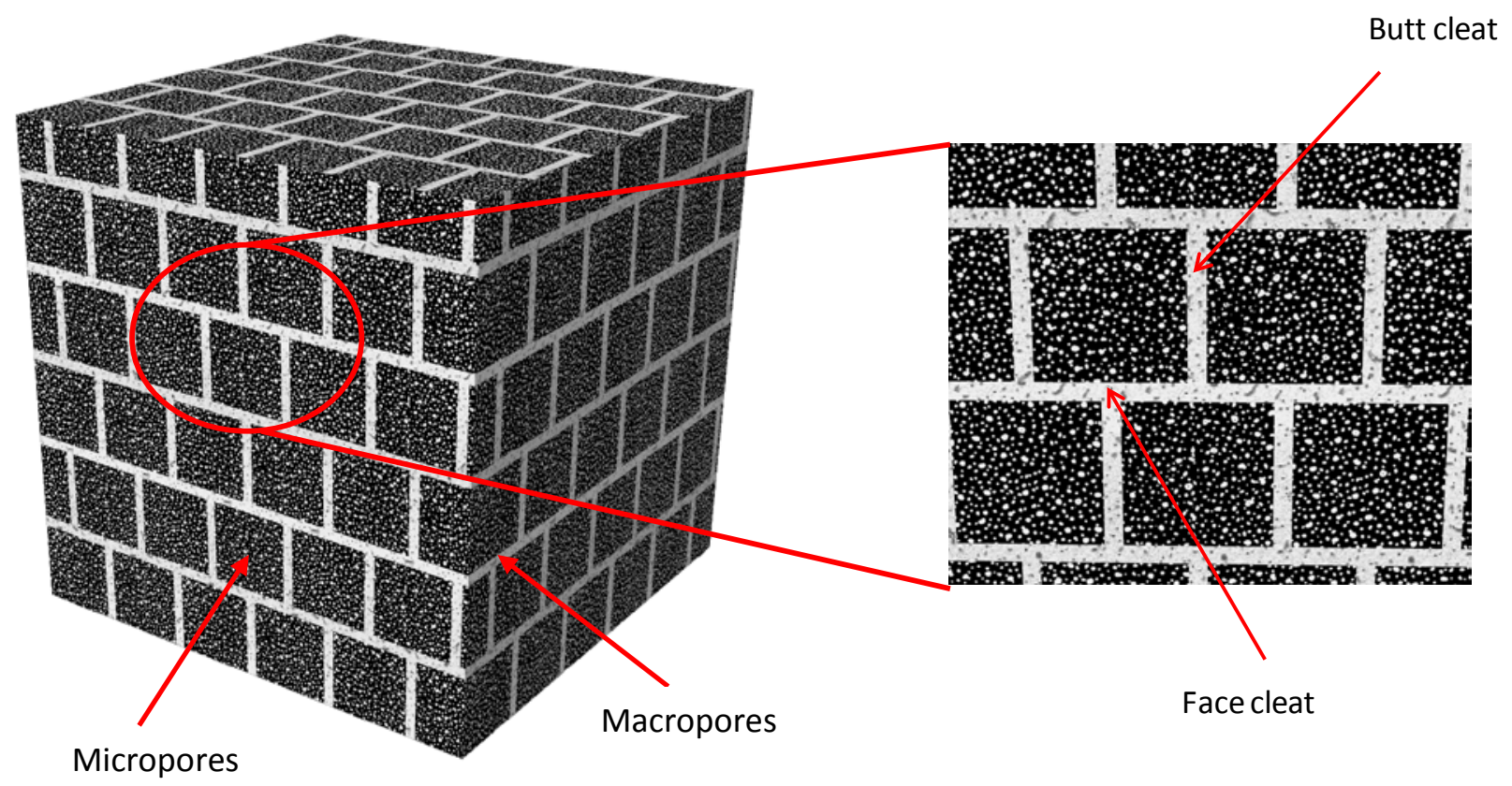

Figure 2.1: Micropores and macropores of a typical coal

Macropores associated with coal are usually regular, closely and uniformly spaced naturally fractured planar fissures/conduits which are commonly known as cleats (Rogers, 1994). Mainly, face cleats (primary cleats) and butt cleats (secondary cleats) are the two cleat network systems that control gas and fluid flow. In general, face cleats are orthogonal to butt cleats and normally more pronounced continuous fissures with wider fracture openings (Rogers, 1994). Gas 
flows faster through face cleats resulting in anisotropic permeability in coalbeds where the cleat orientation determines the direction of highest permeability in the reservoir. Therefore the permeability and orientation of these fractures influence the coalbed methane production and storage of carbon dioxide in coal seams. Micropores are a set of pores associated within the coal matrix where majority of coalbed methane is usually stored as a free gas or held on internal surfaces of the coal matrix.

The mechanism of gas storage and gas transport in a coalbed reservoir is different from conventional gas reservoirs, and henceforth coal seams are also referred to as unconventional gas reservoirs. In a conventional gas reservoir, gas is stored due to formation pressure and the released gas flows according to Darcy's law as a function of the pressure gradient. Most of the gas in coal seams is stored in sorbed state in the micropores of the coal. During the production stage, the reservoir pressure is reduced and the gas is desorbed to flow through the naturally fractured cleat system to a well bore. The gas transport in the coalbed takes place according to both, Fick's law and Darcy's law. More details on the gas storage mechanism and gas transport process are presented in subsequent sections.

\subsection{Gas storage mechanism in coal seams}

In nature, coal seams are heterogeneous and naturally fractured geologic reservoirs. In a coalbed reservoir, coalbed methane is structurally trapped within the coal and is stored by a process called 'adsorption'. Adsorption is a process in which gas particles are held on the internal surface of numerous micropores of a coal matrix. Micropores in the coal matrix constitute a surface area in the order of 1 million square feet per pound mass (McElhiney et al, 1989). Therefore, the gas stored by this mechanism (adsorption process) under certain conditions exceeds the gas storage in other conventional reservoirs, particularly shallow reservoirs, due to the larger surface area of coal micropores.

The amount of gas storage and gas release in coalbed reservoirs is described by a relationship between pressure and gas storage capacity called the Langmuir isotherm. The Langmuir isotherm assumes that gas particles adhered on the surface of the coal matrix exist as a 
single layer of molecules in a condensed, near liquid state (Langmuir, 1918). Hence, at low pressures, a larger volume of gas is stored by adsorption than by compression. Figure 2.2 shows a typical Langmuir isotherm curve demonstrating the maximum amount of gas contained in the coal at equilibrium conditions. Langmuir volume $\left(\mathrm{V}_{\mathrm{L}}\right)$ and Langmuir pressure $\left(\mathrm{P}_{\mathrm{L}}\right)$ are the two parameters that control the storage capacity of coalbed methane and are critical to all calculations. A relationship between the gas content, pressure, Langmuir volume and Langmuir pressure is expressed in Equation (2.1) as given below (Rogers, 1994):

$$
G_{c}=\frac{V_{L} P}{P_{L}+P}
$$

where

$\mathrm{G}_{\mathrm{c}}=$ gas content at pressure, $\mathrm{P}$

$\mathrm{P}=$ pressure

$\mathrm{V}_{\mathrm{L}}=$ Langmuir volume

$\mathrm{P}_{\mathrm{L}}=$ Langmuir pressure

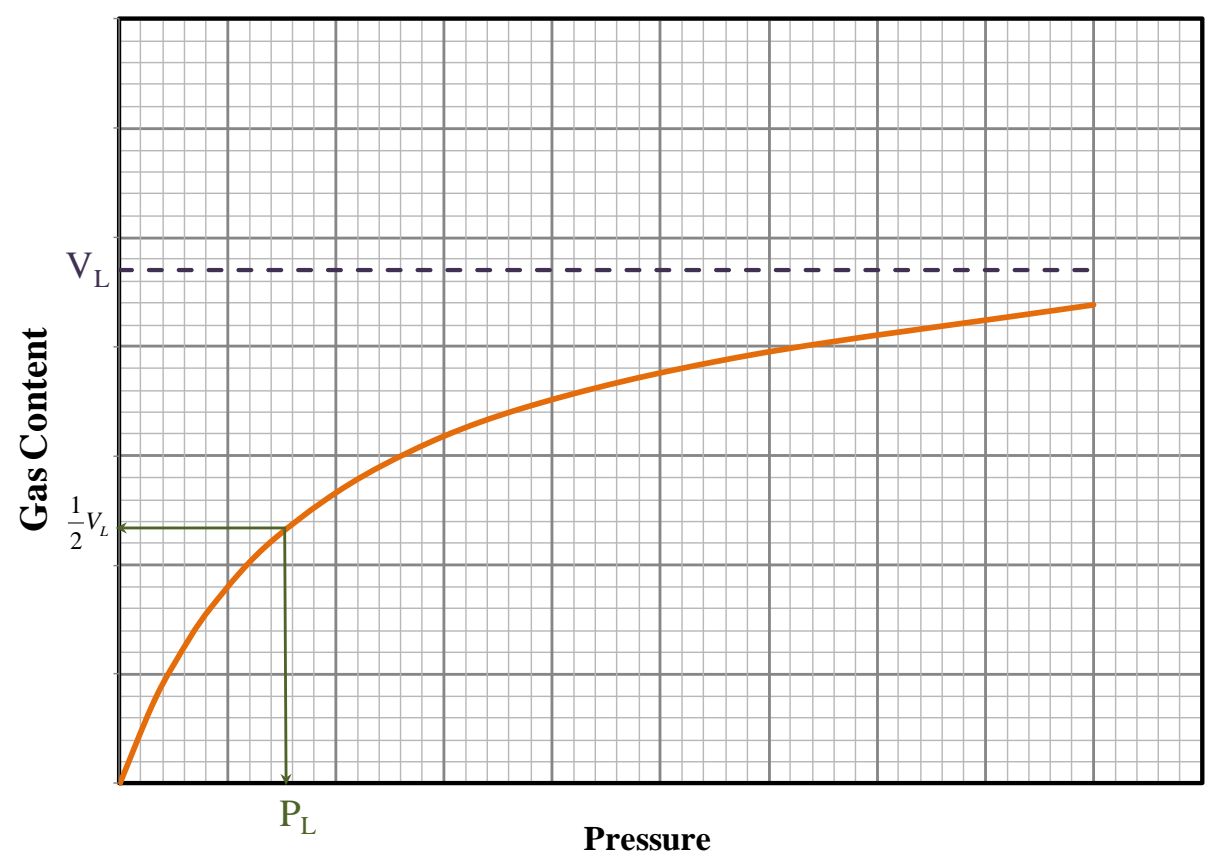

Figure 2.2: A typical Langmuir isotherm curve 
Langmuir volume $\left(\mathrm{V}_{\mathrm{L}}\right)$ is defined as the maximum volume of gas that can be adsorbed on the surface of micropores per unit mass of coal matrix at infinite pressures. The pressure at which half of this volume is adsorbed is referred to as Langmuir pressure $\left(\mathrm{P}_{\mathrm{L}}\right)$ as shown in Figure 2.2. A asymptotic behavior of the coal is reported if the surface is completely adsorbed and is not suitable for adsorption of any additional gas constituents (Bachu et al, 2007). Published literature (White et al, 2005) describes that the gas storage capacity in coal seams is dependent on various factors such as degree of coalification (coal rank), in-situ temperature conditions and water fraction in coal. Henceforth, the sorption isotherms based on the dry, ash free basis at field conditions is considered for calculations. The modified relationship for gas content accounting for ash content and moisture content at dry conditions can be seen in Equation (2.2) as given below (White et al, 2005):

$$
G_{\text {Adsorbed }}=\left(1-f_{a}-f_{m}\right) \frac{V_{L} P}{P_{L}+P}
$$

where

$$
\begin{aligned}
& f_{a}=\text { ash content (fraction) } \\
& f_{m}=\text { moisture content (fraction) }
\end{aligned}
$$

The total amount of the gas present in the coal reservoir is calculated by combining the adsorbed gas adhered on the coal surface and the free gas present in the cleat system as shown in Equations (2.3) and (2.4) (King et al, 1986; White et al, 2005). However, the volume of gas present in a typical conventional reservoir is calculated differently and is presented in Equations (2.5) and (2.6). In a conventional gas reservoir, most of the gas is present in the free state at standard pressure and temperature conditions. Also, it is reported that coalbed reservoirs possess higher amounts gas at lower pressures in comparison to a classic conventional gas reservoir (Rogers, 1994). More details on the sorption isotherms can be found elsewhere (Langmuir, 1918; King et al, 1986; King, 1990; White et al, 2005). 


$$
V_{(\text {coalbed })}=V_{(\text {adsorbed gas })}+V_{(\text {freestate })}
$$

where

$\mathrm{V}_{\text {(coalbed) }}=$ volume of gas in coalbed reservoir

$\mathrm{V}_{\text {(adsorbed) }}=$ volume of gas in coalbed reservoir

$\mathrm{V}_{\text {(free state) }}=$ volume of gas in coalbed reservoir

$$
V_{(\text {coalbed })}=\left(\frac{V_{L} P}{P_{L}+P}\right)(\rho A h)+\frac{\phi A h\left(1-S_{W}\right)}{B_{g}}
$$

where

$\mathrm{V}_{\text {(coalbed) }}=$ volume of gas in coalbed reservoir

$\mathrm{P}=$ pressure

$\mathrm{V}_{\mathrm{L}}=$ Langmuir volume; $\mathrm{P}_{\mathrm{L}}=$ Langmuir pressure

$\rho=$ density of coal

$\mathrm{A}=$ area of coalbed reservoir

$\mathrm{h}=$ thickness of the coalbed

$\phi=$ porosity of coal

$\mathrm{S}_{\mathrm{w}}=$ water saturation

$\mathrm{B}_{\mathrm{g}}=$ gas volume factor

$$
V_{(\text {conventional reservoir })}=V_{(\text {free state })}
$$

where

$\mathrm{V}_{\text {(conventional) }}=$ volume of gas in coalbed reservoir

$\mathrm{V}_{\text {(free state) }}=$ volume of gas in coalbed reservoir 


$$
V_{\text {(conventional) }}=\frac{\phi A h\left(1-S_{W}\right)}{B_{g}}=\phi A h\left(1-S_{W}\right) \frac{P T_{S C}}{Z P_{S C} T}
$$

Equation (2.6)

where

$$
\begin{aligned}
& \mathrm{V}_{\text {(conventional) }} \text { = volume of gas in a conventional reservoir } \\
& \mathrm{P}=\text { pressure } \\
& \mathrm{A}=\text { area of coalbed reservoir } \\
& \mathrm{h}=\text { thickness of the coalbed } \\
& \phi=\text { porosity of coal } \\
& \mathrm{S}_{\mathrm{w}}=\text { water saturation } \\
& \mathrm{B}_{\mathrm{g}}=\text { gas volume factor } \\
& \mathrm{T}=\text { temperature } \\
& \mathrm{T}_{\mathrm{sc}}, \mathrm{P}_{\mathrm{sc}}=\text { temperature and pressure at standard conditions }
\end{aligned}
$$

Gas composition, reservoir temperature, water saturation and ash content are the driving factors that determine the shape of the isotherm curve. Adsorption is a phenomenon in coalbed reservoirs that determines the affinity of different gases to coal. Usually, carbon dioxide has a greater affinity for coal than coalbed methane (Burruss, 2003). Another important parameter that influences gas storage is the reservoir temperature. The amount of gas adsorption decreases and increases with the increase and decrease of temperature, respectively. Cleat porosity in the coalbed reservoir is reported to be less than $5 \%$ and may often contain large amounts of water (Rogers, 1994; White et al, 2005). The amount of water present in the macropore and micropore structures reduces or prohibits the flow of methane that comes from the coal seam. Initially, an undersaturated coalbed reservoir is fully saturated. Therefore, water is produced from the coal seams before any successful CBM production. Moreover, ash content also controls the gas adsorption capacity of coals. In nature, ash contained in the coal hinders gas adsorption. Thus, gas content obtained based on tests performed by dry ash-free basis provides comparatively higher values to tests performed on raw coal samples. Figure 2.3 shows the comparison of typical isotherm curves for tests performed using raw basis and dry-ash free basis. 


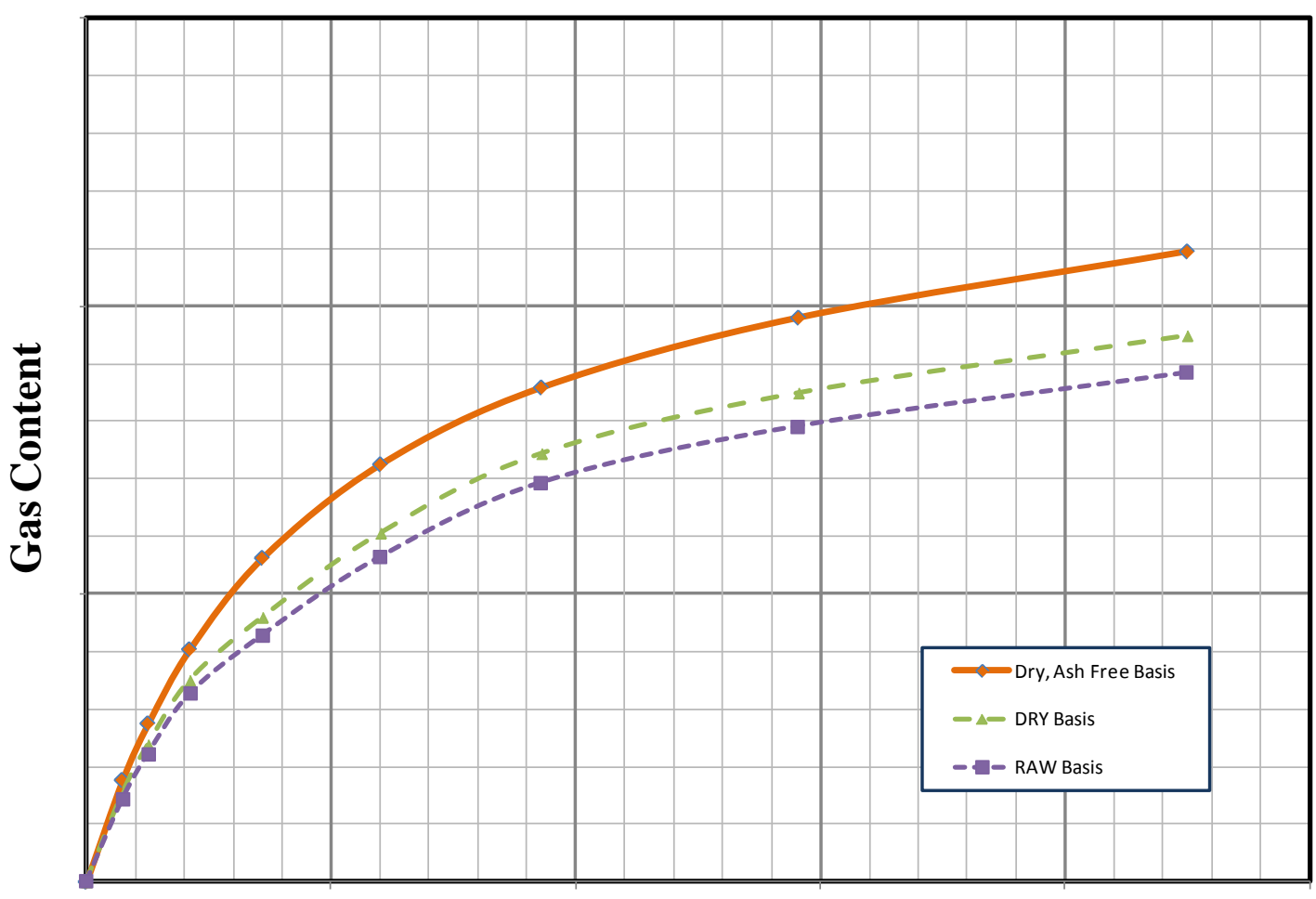

Pressure

Figure 2.3: Comparison of typical isotherm curves based on raw, dry and dry-ash free basis

\subsection{Gas transport mechanism in coal seams}

Gas transport in a CBM reservoir is a complex mechanism (Rogers, 1994). Gas transport from the surface of coal micropores to the well bore occurs in three steps - (1) Desorption process, (2) Diffusion process and (3) Convection process.

(1) Desorption process: Methane desorption is controlled by the hydrostatic head of the aquifer. By dewatering or by draining the water out from the reservoir, the hydrostatic head is dropped and the reservoir pressure is reduced. This reduced pressure allows methane to desorb from adsorbed surfaces of numerous micropores.

(2) Diffusion process: The desorbed methane is then diffused through the coal matrix to the cleat network as shown in Figure 2.4. This is referred to as single-phase gas diffusion 
through a coal matrix. Diffusion is a process in which particulates move from one system to another as a consequence of random molecular motion. The process of gas transport of this adsorbed gas in the coal seams is governed by Fick's law (Cervik, 1969), and is driven by concentration gradient as seen in Equation (2.7). Fick's law for gas flow rate in coal has been expressed as (Cervik, 1969):

$$
q^{\prime}=-D A \frac{d C}{d L}
$$

where

$\mathrm{q}^{\prime}=$ gas flow rate through micropores of the coal

$\mathrm{D}=$ diffusion coefficient

$\mathrm{A}=$ cross-sectional area

$\mathrm{C}=$ concentration of $\mathrm{CH}_{4}$ in a unit volume of coal

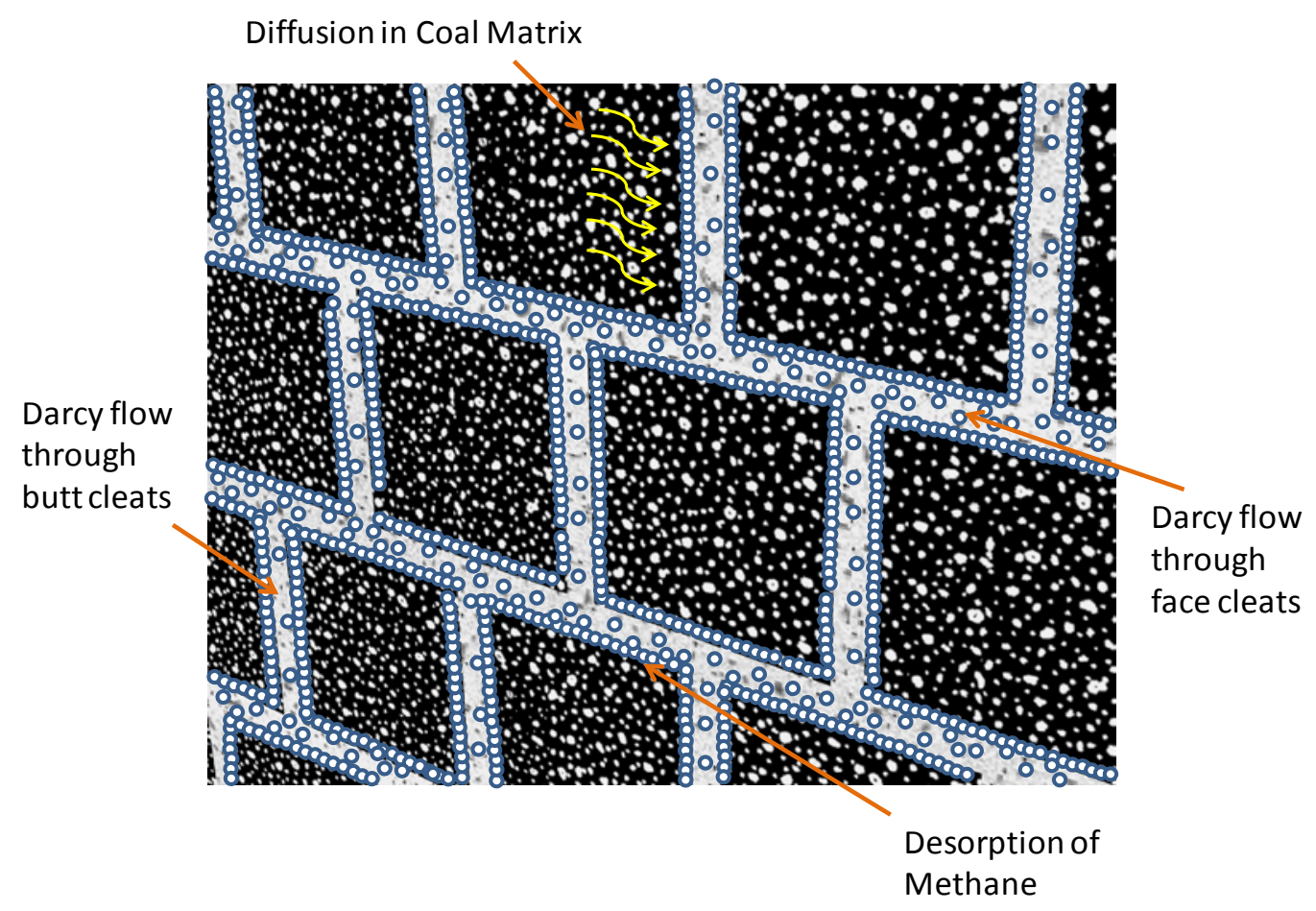

Figure 2.4: Gas transport in coal seams 
(3) Convection process: Gas and water (two-phase) flow through the cleat network by following Darcy's law to the well bore as shown in Figure 2.4. Typically, gas flows in the horizontal direction with the majority of flow going through face cleats. Equation (2.8) demonstrates the gas transport through the macropores (cleat system), which is governed by Darcy's law and is driven by the pressure gradient (Cervik, 1969).

$$
q=-\frac{k A}{\mu} \frac{d P}{d L}
$$

where

$$
\begin{aligned}
& \mathrm{q}=\text { gas flow rate through macropores of the coal } \\
& \mathrm{k}=\text { fracture permeability } \\
& \mathrm{A}=\text { cross-sectional area } \\
& \mu=\text { gas viscocity } \\
& \mathrm{P}=\text { pressure } \\
& \mathrm{L}=\text { length }
\end{aligned}
$$

\subsection{Gas recovery}

Figure 2.5 shows the differences in the gas and water production curves for a typical conventional gas reservoir and a coalbed reservoir. As stated in previous sections, most coalbed methane reservoirs normally contain large of amounts of water in the beginning. Initially, the amount of water contained in the pore spaces of coal (micropores and macropores) prohibits the production of gas from the coal seam. Also, the pressure in the cleat system and gas concentration in the matrix is in equilibrium at this stage. Therefore, withdrawal of water is required before a stable amount of gas can be produced (Rogers, 1994). As soon as dewatering is complete, the reservoir pressure is lowered and the gas production starts, reaching new equilibrium. The gas will not start to flow until the reservoir pressure reaches critical desorption pressure of the reservoir. Once the dewatering stage is complete and critical pressure is reached, gas starts producing at a stable rate up to a certain pressure regime as shown in Figure 2.5. Beyond certain pressure conditions, gas production declines with time and reaches abandonment 
conditions. Figure 2.6 illustrates an example of a sorption isotherm curve with a demonstration of initial reservoir conditions, critical desorption pressure, maximum gas release and abandonment conditions of pressure and gas content.

\section{Coalbed reservoir}
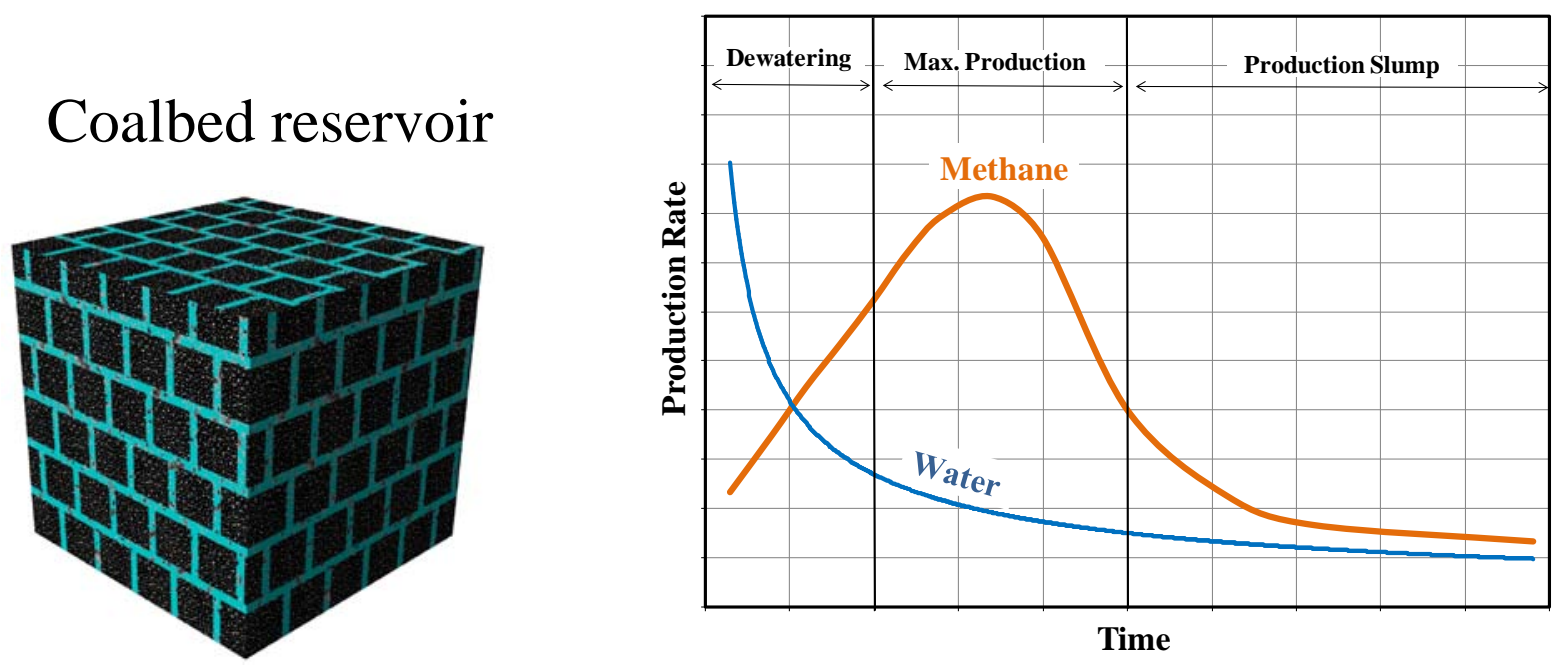

(a) CBM (unconventional) reservoir
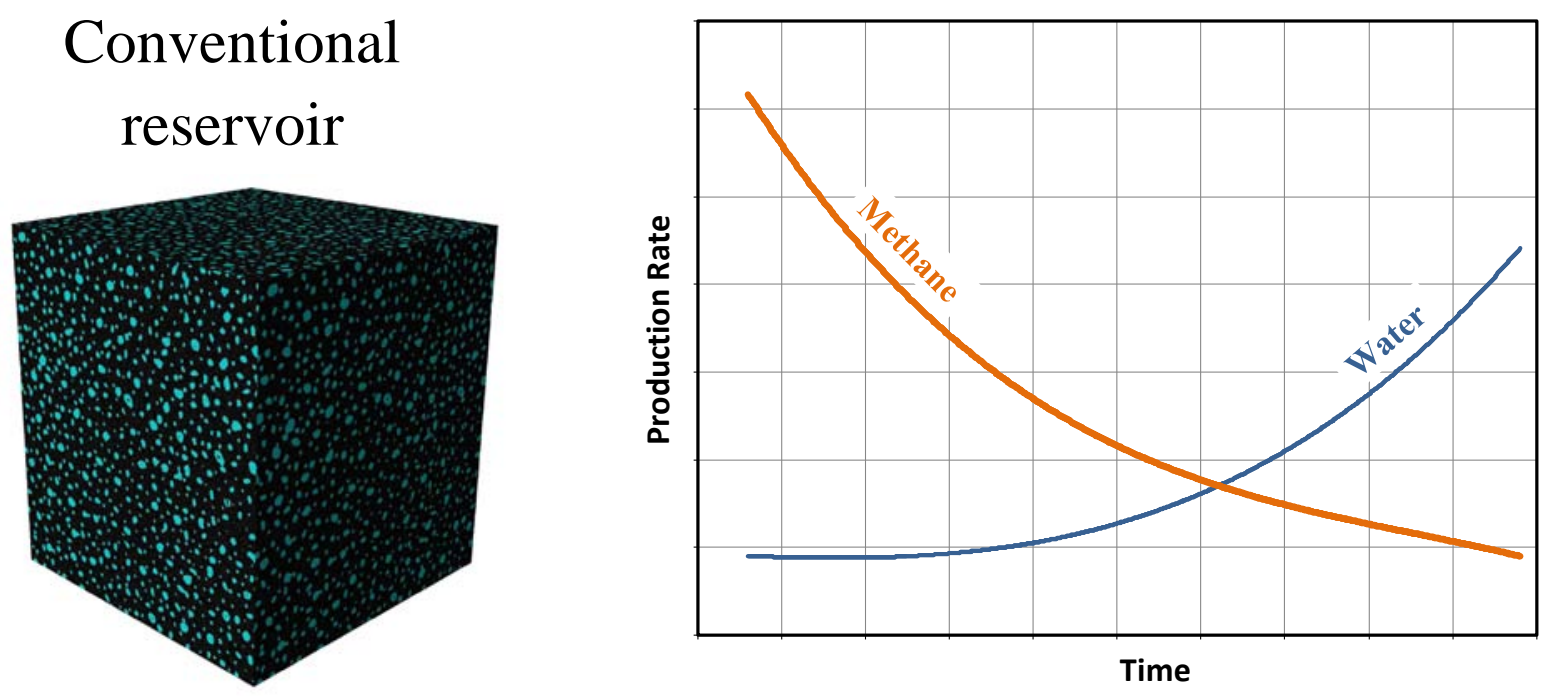

(b) conventional reservoir

Figure 2.5: Gas and water production curves from conventional and CBM reservoirs 


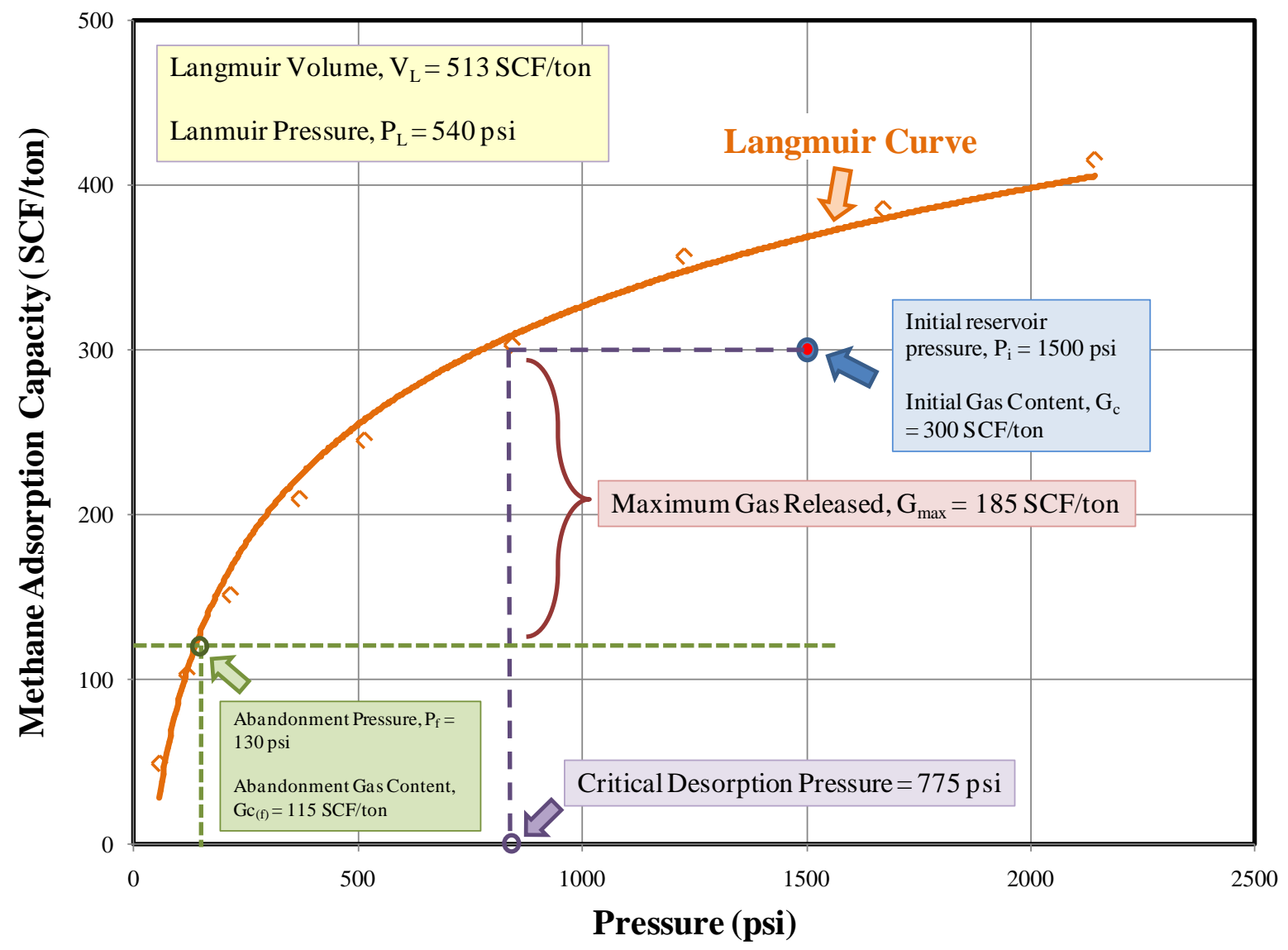

Figure 2.6: Interpretation of a typical Langmuir isotherm curve

Published literature also shows modification of simple single-gas sorption isotherm to multi-component sorption isotherm in order to accurately predict the affinity of coal towards other gases such as carbon dioxide and nitrogen. It is believed that these gases contend among each other to occupy the adsorption sites on the coal surface resulting in lower adsorption rates (Burruss, 2003). Sorption and desorption of coalbed methane is important for natural gas extraction; however, the multi-component sorption theory helps in determining the sequestration potential of $\mathrm{CO}_{2}$ and the enhanced coalbed methane recovery. Several studies have been conducted to develop the understanding of adsorption and desorption of $\mathrm{CH}_{4}, \mathrm{CO}_{2}$ and other gases (McCulloch and Diamond, 1976; Ruppel et al, 1973; McElhiney et al, 1989). Several reports have stated that coal has a greater affinity for $\mathrm{CO}_{2}$ than $\mathrm{CH}_{4}$ (Reucroft and Patel, 1986; Burruss, 2003; Chikatamarla et al, 2004). Equation (2.9) describes the pressure and volumetric 
relationship of multi-component gases using an Extended Langmuir isotherm. More details on the Extended Langmuir isotherm can be found elsewhere (Rogers, 1994).

$$
V_{i}=V_{L_{i}} \frac{b_{i} p_{i}}{1+\sum_{j=1}^{n_{c}} b_{j} p_{j}}
$$

where

$\mathrm{V}_{\mathrm{i}}=$ adsorption volume of gas component, $\mathrm{i}$

$\mathrm{V}_{\mathrm{Li}}=$ sorption adsorption volume constant of gas component, $\mathrm{i}$

$\mathrm{p}=$ pressure

$\mathrm{b}=$ Langmuir constant

$\mathrm{n}=$ number of gas components

Also, several research studies have been conducted to evaluate CBM recovery and to investigate storage potential (Byrer et al, 1987; Pashin et al, 2001; Reeves, 2001; Carroll and Pashin, 2003; Sams et al, 2003; Reeves and Oudinot, 2005; White et al, 2005). History matching and sensitivity calculations can be performed on CBM recovery to entail some uncertainties of reservoirs (Siriwardane et al, 2009; Koperna et al, 2009).

\section{$2.5 \mathrm{CO}_{2}$ sequestration in coal seams}

Geologic storage of $\mathrm{CO}_{2}$ in abandoned or unmineable coal seams can be promising. Unmineable coal seams are uneconomic and infeasible for successful mining operations due to many reasons such as unsatisfactory thickness of coal seam, unfavorable geology, reduced quality and extreme depths (Winschel and Scandrol, 2007). $\mathrm{CO}_{2}$ is injected into coal seams not to repressurize the reservoir, but to store large amounts of $\mathrm{CO}_{2}$ as it provides greater affinity towards coal. Therefore, cleat permeability and coal adsorption properties influence the success of $\mathrm{CO}_{2}$ sequestration. It is reported in the literature that the permeability of coals depend on the depth and overburden effective stress (Bachu et al, 2007; Gray, 1987). Effective stress increases with depth resulting in a permeability decrease. Hence, for successful CBM production and $\mathrm{CO}_{2}$ 
sequestration, permeability values of greater than 1 milli-Darcy $(\mathrm{mD})$ are reported to be desired for the reservoir (Bachu et al, 2007). Furthermore, the injection of $\mathrm{CO}_{2}$ may reduce the coal permeability due to coal swelling.

Several pilot studies have been demonstrated to study the sequestration potential and economic viability of $\mathrm{CO}_{2}$ injection into coal seams. Some of these include - the Allison unit located on the border of New Mexico and Colorado, Pump Canyon pilot site located in the San Juan basin of New Mexico, RECOPOL project, Poland and Ishikari coal basin, Japan (Byrer et al, 1987; Rogers, 1994; Pashin et al, 2001; Reeves, 2001; Reeves et al, 2003; Carroll and Pashin, 2003; Pashin and McIntyre, 2003; Shi and Durucan, 2003; White et al, 2005; van Wageningen and Mass, 2007; Onuma et al, 2008; Koperna et al, 2009; van Wageningen et al, 2009). Technical issues related to geologic sequestration have also been addressed in several published reports (Bromhal et al., 2003; Mavor et al., 2004; Gorucu et al., 2005; Reeves and Oudinot, 2005; Siemons et al, 2007; Karacan, 2007; Saghafi et al, 2007; Viete and Ranjith, 2007). Swelling and shrinkage of coal is one of the major issues. During the large-scale geologic sequestration of $\mathrm{CO}_{2}$ into coal, coal swelling has a significant influence on injection operations by reducing the permeability of coal. A comprehensive evaluation of reservoir history, reservoir potential, reservoir feasibility, and storage stability is mandatory for successful promotion of large-scale sequesration of $\mathrm{CO}_{2}$ into unmineable coal seams.

\subsection{Factors affection $\mathrm{CBM}$ recovery and $\mathrm{CO}_{2}$ sequestration}

In most of the underground repositories, $\mathrm{CO}_{2}$ is stored as a supercritical fluid based on the phase diagram of $\mathrm{CO}_{2}$ at different temperature and pressure conditions (Bachu, 2002). More details on phase behavior and transport properties of carbon dioxide at different temperatures and pressures can be found elsewhere (NIST, 2010; Altunin and Sakabetdinov, 1972; Avuduevskii et al, 1973). In-situ pressures and temperatures along with coal adsorption/desorption properties also influence the storage potential of $\mathrm{CO}_{2}$ (Bachu et al, 2007; White el al, 2005). 
Coal permeability has significant influence on CBM recovery and sequestration potential of $\mathrm{CO}_{2}$ into coal seams (Rogers, 1994). In the current report, cleat permeability is referred to as coal permeability. Coal permeability depends on various factors such as cleat spacing, depth of the coal seams, water saturation, coal swelling and shrinkage, and in-situ stresses. Various tests such as core tests, slug tests, and injection/fall-off tests are performed at the field site to investigate the permeability of the reservoir (Rogers, 1994). However, it can be accurately determined by performing reservoir simulations to history match CBM production, water production and $\mathrm{CO}_{2}$ injection. The permeability of the reservoir is primarily influenced by production of water and natural gas from the reservoir and then by injection of $\mathrm{CO}_{2}$ into the reservoir. The reservoir pressure in coal seams decreases during the production of water and natural gas and vice-versa during the injection of $\mathrm{CO}_{2}$. When the reservoir pressure is reduced due to extraction of coalbed methane and water from coal seams, the permeability of the coalbed is influenced by three different mechanisms (Rogers, 1994):

(1) Klinkenberg effect: Pressures in the coal seams are relatively low when compared to other conventional reservoirs such as sandstone reservoirs. As a result, higher gas flow rates are possible due to slippage of adjacent layers in the coal seam in contradiction to Darcy's law, which assumes that the gas layer closest to the fracture is inert. This mechanism is known as the Klinkernberg effect (Rogers, 1994). When, the reservoir pressure is reduced due to large production of methane and water from the coal seams, the Klinkernberg effect dominates by increasing the effective permeability of the reservoir. Equation (2.10) shows the corrected gas permeability at low pressures due to the Klinkernberg effect (Rogers, 1994).

$$
k=k_{\infty}\left(1+\frac{B}{P_{m}}\right)
$$

where

$\mathrm{k}$ = corrected permeability due to Klinkernberg effect

$\mathrm{k}_{\infty}=$ permeability at infinite pressure

$\mathrm{B}=$ slip factor

$\mathrm{P}_{\mathrm{m}}=$ mean reservoir pressure 
(2) Shrinkage of coal matrix: During production of coalbed methane, pressure in the microporous structure of the coal is reduced. The reduced pressure shrinks the coal matrix, widening the fracture apertures by increasing the permeability of the reservoir. More details on the coal shrinkage is discussed in the subsequent sections of this chapter.

(3) In-situ effective stress: Dewatering, degasification or depressurization of a conventional or an unconventional reservoir results in reservoir compaction due to change in in-situ stress conditions, the result of which alters the reservoir properties and field pressure conditions of the overall system (Cui and Bustin, 2005; Chikatamarla et al, 2004; Harpalani and Chen, 1997; Levine, 1996; Gray, 1987).

Cleat porosity also plays a significant role in the $\mathrm{CBM}$ recovery and $\mathrm{CO}_{2}$ injection. In the current research work, the cleat porosity proposed by Palmer and Mansoori (1996) has been used. The relationship between cleat porosity and the permeability of the reservoir proposed by Palmer and Mansoori (1996) is shown in Equation (2.11) as given below (Palmer and Mansoori, 1996; Pekot and Reeves, 2003).

$$
\left(\frac{k}{k_{0}}\right)=\left(\frac{\phi}{\phi_{0}}\right)^{n}
$$

where

$\mathrm{k}_{0}=$ Initial reference permeability $(\mathrm{mD})$;

$\mathrm{k}=$ final permeability $(\mathrm{mD})$

$\phi_{0}=$ initial reference porosity;

$\phi=$ final porosity

$\mathrm{n}=$ exponent (usually, 3 for most coalbeds)

The relative permeability of the reservoir is also critical to CBM production from coal repositories. Since the coal transports two-phase gas and water flow through the cleat network, the relationship between effective permeability and absolute permeability is of significant 
interest to the coal industry. Relative permeability is saturation dependent, and can be defined as a ratio of effective permeability to absolute permeability. Laboratory experiments or field tests can be very ambiguous to establish relative permeability curves, hence, history matching is used mostly as a methodology to obtain appropriate relative permeability curves for a particular coalbed reservoir. Few relationships of relative permeability of gas and water are presented in Equations (2.12) and (2.13) as given in published literature:

$$
\begin{aligned}
& \frac{k_{r g}}{k_{r g 0}}=\left(\frac{\bar{S}_{g}-S_{g c}}{1-S_{w c}-S_{g c}}\right)^{n_{g}}, \bar{S}_{g} \geq S_{g c} \\
& \frac{k_{r w}}{k_{r w 0}}=\left(\frac{\bar{S}_{w}-S_{w c}}{1-S_{w c}}\right)^{n_{w}}, \bar{S}_{g} \geq\left(1-S_{w c}\right)
\end{aligned}
$$

where:

$\mathrm{k}_{\mathrm{rg}}=$ gas relative permeability

$\mathrm{k}_{\mathrm{rg} 0}=$ endpoint relative permeability to gas

$\mathrm{k}_{\mathrm{rw}}=$ water relative permeability

$\mathrm{k}_{\mathrm{rw} 0}=$ endpoint relative permeability to water

$\mathrm{n}_{\mathrm{w}}=$ exponent of the water relative permeability curve

$\mathrm{n}_{\mathrm{g}}=$ exponent of the gas relative permeability curve

$\mathrm{S}_{\mathrm{g}}=$ average gas saturation

$\mathrm{S}_{\mathrm{gc}}=$ irreducible gas saturation

$\mathrm{S}_{\mathrm{w}}=$ average water saturation

$\mathrm{S}_{\mathrm{wc}}=$ irreducible water saturation 


\subsection{Storage capacity and injectivity}

Calculations of storage capacity and injectivity are important in order to evaluate sequestration potential of $\mathrm{CO}_{2}$ into a reservoir (Bachu et al, 2007). Coal thickness, areal extent, $\mathrm{CO}_{2}$ adsorption isotherms, production history, water saturation and well configuration are some of the influencing factors in these calculations (Bachu et al, 2007). Estimates of CBM recovery and $\mathrm{CO}_{2}$ storage capacity are based on CBM gas-in-place, completion and recovery factors such as fraction of gas that can be produced and stored within the drilled regions of coal seams (Bachu et al, 2007; White el al, 2005). Given below (Equations (2.14) and (2.15)) provide the are the relationships used to estimate initial gas-in-place (IGIP) and producible gas-in-place (PGIP) based on the published literature (Bachu et al, 2007; White el al, 2005):

$$
I G I P=A h \rho G_{c}\left(1-f_{a}-f_{m}\right)
$$

where

$\mathrm{A}=$ area of coal that outlines for calculation purpose

$\mathrm{h}=$ effective thickness of the coal for which storage is calculated

$\rho=$ bulk density of the coal

$\mathrm{G}_{\mathrm{C}}=$ gas content of the coal basin

$f_{a}, f_{m}=$ fractions of ash content and moisture content corrected for the dry, ash-free coal

$$
P G I P=\left(R_{f}\right)(C)(I G I P)
$$

Equation (2.15)

where

$\mathrm{R}_{\mathrm{f}}=$ Recovery factor and $\mathrm{C}_{\mathrm{f}}=$ Completion factor.

The recovery factor provides the gas fraction that can be produced from coal seams and the completion factor delivers the estimates of coal within the drilled region. It is reported in the published literature that the initial stages of dewatering from coal seams could tremendously help 
improve the recovery factor (White el al, 2005). However, Equation (2.14) can be modified by replacing the recovery factor with a storage efficiency factor as shown in Equation (2.16) to calculate the storage capacity of $\mathrm{CO}_{2}$. Limited information is available on the storage efficiency factors in the published literature except an estimated range of 28 to 40\% (U.S.D.O.E., 2007). The modified volumetric estimates of $\mathrm{CO}_{2}$ can be expressed as (Bachu et al, 2007; U.S.D.O.E., 2007):

$$
G_{\mathrm{CO}_{2}}=A h \rho G_{c}\left(1-f_{a}-f_{m}\right) S_{E}
$$

where

A = area of coal that outlines for calculation purpose

$\mathrm{h}=$ effective thickness of the coal for which storage is calculated

$\rho=$ bulk density of the coal

$\mathrm{G}_{\mathrm{c}}=$ gas content of the coal basin

$f_{a}, f_{m}=$ fractions of ash content and moisture content corrected for the dry, ash-free coal

$\mathrm{S}_{\mathrm{E}}=\mathrm{CO}_{2}$ storage efficiency factor (fraction)

\subsection{Shrinkage and swelling of coal}

Swelling and shrinkage of coal is important to the geologic sequestration of $\mathrm{CO}_{2}$ into coal seams (Siriwardane et al, 2009; Kelemen et al, 2006; Mazumder et al, 2006 ; Mazumder et al 2006 ; Pan and Connell, 2005; Pan and Connell, 2007; Siriwardane et al, 2006; Shi and Durucan, 2003). Shrinkage of coal is observed with the desorption and release of coalbed methane, and swelling of coal is more dominant when injection of $\mathrm{CO}_{2}$ is carried over. $\mathrm{CH}_{4}$ released from the coal results in sorption induced strains and permeability changes (Harpalani and Chen, 1997; Cui and Bustin, 2005). Reservoir pressure is lowered to desorb methane and as a result, effective stresses are increased and the permeability of the reservoir increases with wider cleat openings as illustrated in Figure 2.7 (Siriwardane et al, 2009; Clarkson et al, 2008; Mitra and Harpalani, 2007; Pan and Connell, 2007; Karacan, 2007, Mazumder and Wolf, $2006^{\mathrm{C}}$; Shi and Durucan, 2003; Palmer and Mansoori, 1998; Gray, 1987). During the injection of $\mathrm{CO}_{2}$, volumetric swelling of coal is observed and the permeability of the reservoir is reduced with fractures 
tending to close as shown in Figure 2.8 (Clarkson et al, 2008; Chikatamarla et al, 2004, Mitra and Harpalani, 2007; Pan and Connell, 2007; Karacan, 2007, Mazumder and Wolf, 2008). As a consequence, additional stresses are induced on the coal seams with the injection of $\mathrm{CO}_{2}$. Reports show volumetric strains as high as $15-30 \%$ due to coal swelling (Harpalani and Scraufnagel, 1990; Levine, 1996; Roberston and Christiansen, 2005; Karacan, 2007; Mitra and Harpalani, 2007; Reucroft and Patel, 1986).
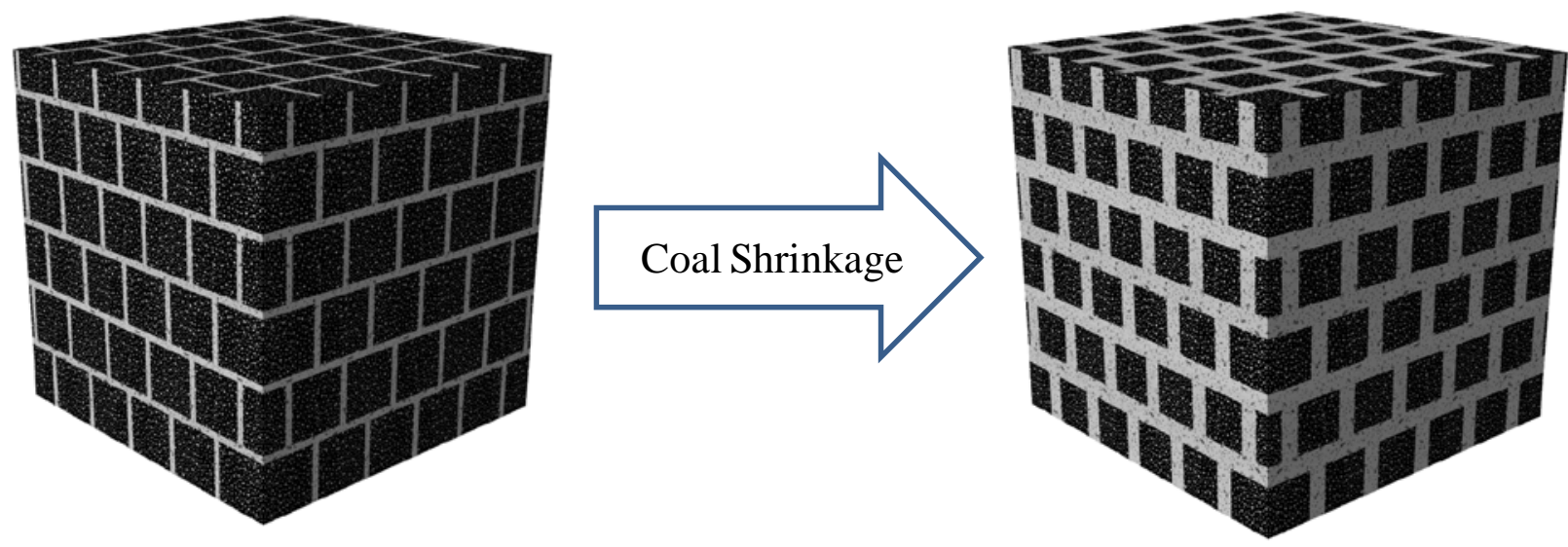

Figure 2.7: Cleat openings as a result of coal shrinkage
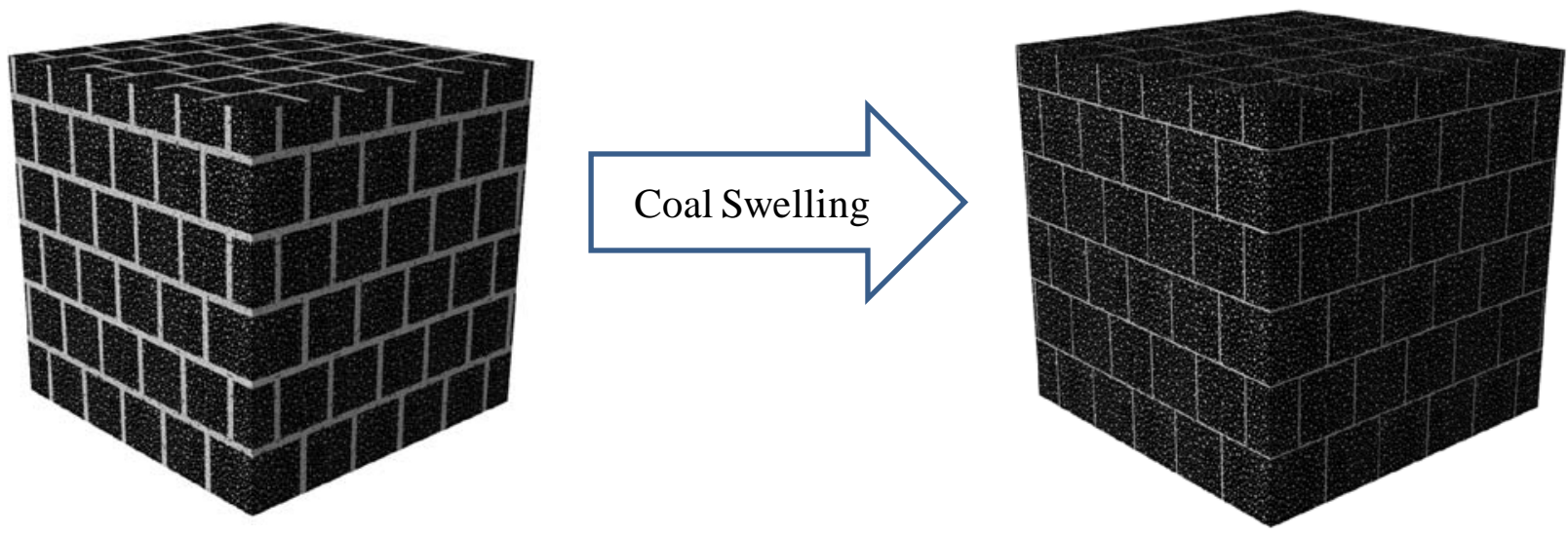

Figure 2.8: Cleat closure as a result of coal swelling

Coal swelling and shrinkage influence the injection or production along with other geomechanical parameters such as elastic modulus, cleat porosity and permeability of the reservoir. In recent years, several theories on coal swelling were proposed and most of these 
have been implemented into several conventional and commercially available reservoir simulators together with coal shrinkage and reservoir compaction (Siriwardane et al, 2009; Computer Modeling Group, 2009; Seidle and Huitt, 1995; Palmer and Manosoori, 1996; Seidle et al, 1992; Shi and Durucan, 2005). Some of these proposed models are discussed in this section (Seidle and Huitt, 1995; Palmer and Manosoori, 1996; Shi and Durucan, 2003; Siriwardane et al, 2009; Harpalani and Chen, 1997; Liu et al, 2010).

Gray (1987) related shrinkage of the coal with a reduced equivalent sorption pressure and derived the following relationship as shown in Equation (2.17) (Gray, 1987).

$$
\sigma-\sigma_{i}=-\frac{v}{1-v}\left(P-P_{i}\right)+\frac{E}{1-v} \frac{\Delta \varepsilon_{v}}{\Delta P_{v}} \Delta P_{v}
$$

where

$\mathrm{E}=$ elastic or Young's modulus of coal

$v=$ Poisson's ratio

$\mathrm{P}_{\mathrm{i}}=$ initial or original reservoir pressure; $\mathrm{P}=$ reservoir pressure

$\frac{\Delta \varepsilon_{v}}{\Delta P_{v}}=$ volumetric strain due to changes in equivalent sorption pressure

$\sigma_{\mathrm{i}}=$ initial or original effective stress; $\sigma=$ effective stress

Equation (2.18) and (2.19) illustrate the relationships proposed by Seidle and Huitt (1995) based on experimental tests for swelling and shrinkage of a coal matrix due to sorption and desorption of gas (Seidle and Huitt, 1995).

$$
c_{m}=\frac{\varepsilon_{\exp }+c_{p} P}{V_{m}\left(\frac{b P}{1+b P}\right)}
$$




$$
\frac{\phi}{\phi_{O}}=1+\left(1+\frac{2}{\phi_{O}}\right) c_{m}(1 E-06) V_{m}\left(\frac{b P_{i}}{1+b P_{i}}-\frac{b P}{1+b P}\right)
$$

Equation (2.19)

where

$$
\begin{aligned}
& \mathrm{C}_{\mathrm{m}}=\text { swelling coefficient } \\
& \phi_{0}=\text { initial or original reference porosity; } \phi=\text { final porosity } \\
& \mathrm{P}_{\mathrm{i}}=\text { initial or original reservoir pressure; } \mathrm{P}=\text { reservoir pressure } \\
& \mathrm{b}, \mathrm{V}_{\mathrm{m}}=\text { Langmuir pressure constant, Langmuir volume constant } \\
& \mathrm{C}_{\mathrm{p}}=\text { compressibility or compliance of coal matrix } \\
& \varepsilon_{\text {exp }}=\text { experimental strain }
\end{aligned}
$$

Later, Palmer and Mansoori (1996) discussed the proposed models of Seidle and Huitt (1995) and reported revisions to them. Theoretical models were developed for stress-dependent permeability caused by matrix shrinkage under uniaxial strain conditions (Palmer and Mansoori, 1996) as described in Equations (2.20) to (2.24) (Palmer and Mansoori, 1996):

$$
\begin{gathered}
\frac{\phi}{\phi_{0}}=1+\frac{c_{m}}{\phi_{0}}\left(P-P_{i}\right)+\frac{c_{0}}{\phi_{0}}\left(\frac{k}{M}-1\right)\left(\frac{b P}{1+b P}-\frac{b P_{i}}{1+b P_{i}}\right) \\
c_{m}=\frac{1}{M}-\left(\frac{K}{M}+f-1\right) \beta \\
\frac{M}{E}=\frac{1-v}{(1+v)(1-2 v)} \\
\frac{K}{M}=\frac{1}{3}\left[\frac{1+v}{1-v}\right]
\end{gathered}
$$


where

$\phi_{0}=$ initial or original reservoir porosity; $\phi=$ final porosity

$\mathrm{c}_{\mathrm{m}}=$ compressibility or compliance of coal matrix

b, $\mathrm{c}_{0}=$ Langmuir parameter to volumetric shrinkage

$\beta=$ grain compressibility

$\mathrm{E}=$ elastic modulus of coal; $\mathrm{K}=$ bulk modulus of coal; $\mathrm{M}=$ constrained axial modulus

$\mathrm{f}=\mathrm{a}$ fraction, usually between 0 to1

$\mathrm{P}_{\mathrm{i}}=$ initial or original reservoir pressure; $\mathrm{P}=$ reservoir pressure

$\mathrm{P}_{\mathrm{L}}=$ Langmuir pressure; $\mathrm{V}_{\mathrm{L}}=$ Langmuir volume

Geomechanical parameters such as elastic modulus, pore compressibility, cleat porosity and permeability in combination with swelling and shrinkage of coal were added to the model and the permeability of the porous rock was assumed to change according to the cubic equation as given below in Equation (2.24) (Palmer and Mansoori, 1996):

$$
k=k_{0}\left(\frac{\phi}{\phi_{0}}\right)^{3}
$$

where

$\phi_{0}=$ initial or original reservoir porosity; $\phi=$ final porosity

$\mathrm{k}_{0}=$ original reservoir permeability; $\mathrm{k}=$ final reservoir permeability

Assuming bundled matchstick geometry of coal, Shi and Durucan (2003) also proposed following relationships for cleat permeability and change in stress at different reservoir conditions as presented in Equations (2.25) to (2.28) (Shi and Durucan, 2003): 


$$
k=k_{0} e^{-3 c_{f}\left(\sigma-\sigma_{i}\right)}
$$

$$
\sigma-\sigma_{i}=-\frac{v}{1-v}\left(P-P_{i}\right), P_{C}<P \leq P_{i}
$$

$$
\sigma-\sigma_{i}=-\frac{v}{1-v}\left(P-P_{c}\right)+\frac{E}{3(1-v)} \varepsilon_{l}\left(\frac{P}{P+P_{\varepsilon}}-\frac{P_{c}}{P_{c}+P_{\varepsilon}}\right), 0<P \leq P_{c}
$$

$$
\sigma-\sigma_{i}=-\frac{v}{1-v}\left(P_{c}-P_{i}\right)
$$

where

$$
\begin{aligned}
& \mathrm{C}_{\mathrm{f}}=\text { formation compressibility } \\
& \mathrm{E}=\text { elastic or Young's modulus of coal } \\
& \mathrm{k}_{0}=\text { original reservoir permeability; } \mathrm{k}=\text { final permeability }(\mathrm{mD}) \\
& v=\text { Poisson's ratio } \\
& \mathrm{P}_{\mathrm{i}}=\text { initial reservoir pressure; } \mathrm{P}=\text { reservoir pressure; } \mathrm{P}_{\mathrm{C}}=\text { critical desorption pressure } \\
& \varepsilon_{\mathrm{l}}=\text { maximum strain } \\
& \sigma_{\mathrm{i}}=\text { initial effective stress; } \sigma=\text { effective stress }
\end{aligned}
$$

Based on the amount of gas adsorbed and desorbed, Siriwardane et al (2009) proposed volumetric strains caused due to coal swelling and coal shrinkage as shown in equations (2.29) and (2.30), respectively (Siriwardane et al, 2009):

$$
\begin{gathered}
d \varepsilon_{v}^{s w}=C^{s w} d V_{a} \\
d \varepsilon_{v}^{s h}=C^{s h} d V_{d}
\end{gathered}
$$


where

$\varepsilon_{v}^{s w}=$ volumetric swelling strain

$C^{s w}=$ swelling constant

$V_{a}=$ volume of the gas adsorbed due to coal swelling

$\varepsilon_{v}^{s h}=$ volumetric shrinkage strain

$C^{\text {sh }}=$ shrinkage constant

$V_{d}=$ volume of the gas desorbed due to coal shrinkage

The adsorption volumes and desorption volumes can also be expressed as functions of gas pressures as reported in Siriwardane et al (2009) and illustrated in equation (2.31) and (2.32):

$$
\begin{aligned}
& V_{a}=f_{1}(p) \\
& V_{d}=f_{2}(p)
\end{aligned}
$$

where

$V_{a}, V_{d}=$ volume of the gas adsorbed and desorbed due to coal swelling and shrinkage, respectively.

$\mathrm{p}=$ reservoir pressure

Equations (2.33) to (2.35) show the constitutive equations for the coal matrix in the incremental form as reported in Siriwardane et al (2009):

$$
d \sigma_{i j}=2 G d \varepsilon_{i j}+\left(K-\frac{2 G}{3}\right) d \varepsilon_{k k} \delta_{i j}+\alpha d p \delta_{i j}-C^{s w} f_{1}^{\prime}(p) d p K \delta_{i j}+C^{S H} f_{2}^{\prime}(p) d p K \delta_{i j}
$$




$$
\begin{gathered}
K=\frac{E}{3(1-2 v)} \\
G=\frac{E}{2(1+v)}
\end{gathered}
$$

where

$$
\begin{aligned}
& C^{\text {sh }}=\text { shrinkage constant; } C^{s w}=\text { swelling constant } \\
& \sigma_{i j}=\text { stress tensor; } \varepsilon_{i j}=\text { strain tensor } \\
& \mathrm{p}=\text { pore pressure } \\
& \mathrm{E}=\text { Elastic modulus or Young's Modulus of coal; } \mathrm{G}=\text { shear modulus; } \mathrm{K}=\text { bulk modulus } \\
& v=\text { Poisson's ratio } \\
& \alpha=\text { poroelastic constant }
\end{aligned}
$$

\subsection{Geomechanics}

The phenomenon of reservoir compaction and subsidence was first explained by Terzaghi's principle of effective stress (Terzaghi, 1936). Later, the deformation theory of isotropic and anisotropic poroelastic media using a compressible fluid was investigated by Biot (Biot, 1941; Biot, 1955; Biot, 1956a Biot, 1956 ${ }^{\mathrm{b}}$ ). Geertsma (1973) expanded these studies by proposing a few analytical and semi analytical solutions based on several simplified hypotheses to evaluate surface and near surface deformations due to reservoir depletion. Results of induced stresses and subsidence caused due to fluid extraction from an elastic half space were reported by Segall (1985), which was the beginning of geomechanics in the oil and gas industry. Several analytical models and mathematical formulations have been proposed in the published literature on the single-phase and multi-phase fluid flow in single and dual porosity geologic formations. Some of these related to coupled flow-deformation analyses used in the study are presented in following chapters. 


\section{CHAPTER 3: DESCRIPTION OF $\mathrm{CO}_{2}$ SEQUESTRATION FIELD SITE}

\subsection{Location of $\mathrm{CO}_{2}$ sequestration field site}

The Appalachian basin is a major source of coal in the United States (Bhatt, 1995; Rogers, 1994). The coal from the Appalachian region is reported to come mainly from four states West Virginia, Pennsylvania, Virginia and Eastern Kentucky (Bhatt, 1995). In the current research work, an actual sequestration field site located in the northern Appalachian basin and northern panhandle of West Virginia, U.S.A. has been selected. The objective of the field site is to evaluate the coalbed methane (CBM) recovery in the region and to demonstrate the sequestration potential of $\mathrm{CO}_{2}$ in an unmineable coal seam (Winschel et al, 2010). The pilot test site is located in Marshall County, West Virginia, U.S.A., as illustrated in Figure 3.1. Coal thickness, structural geology, site accessibility, nearby gas pipelines, and proximity to the field site were factors for selection of the demonstration site. The field site consists of dense woods and hilly terrain with a creek that flows through low lying areas of the site as seen in Figure 3.1.

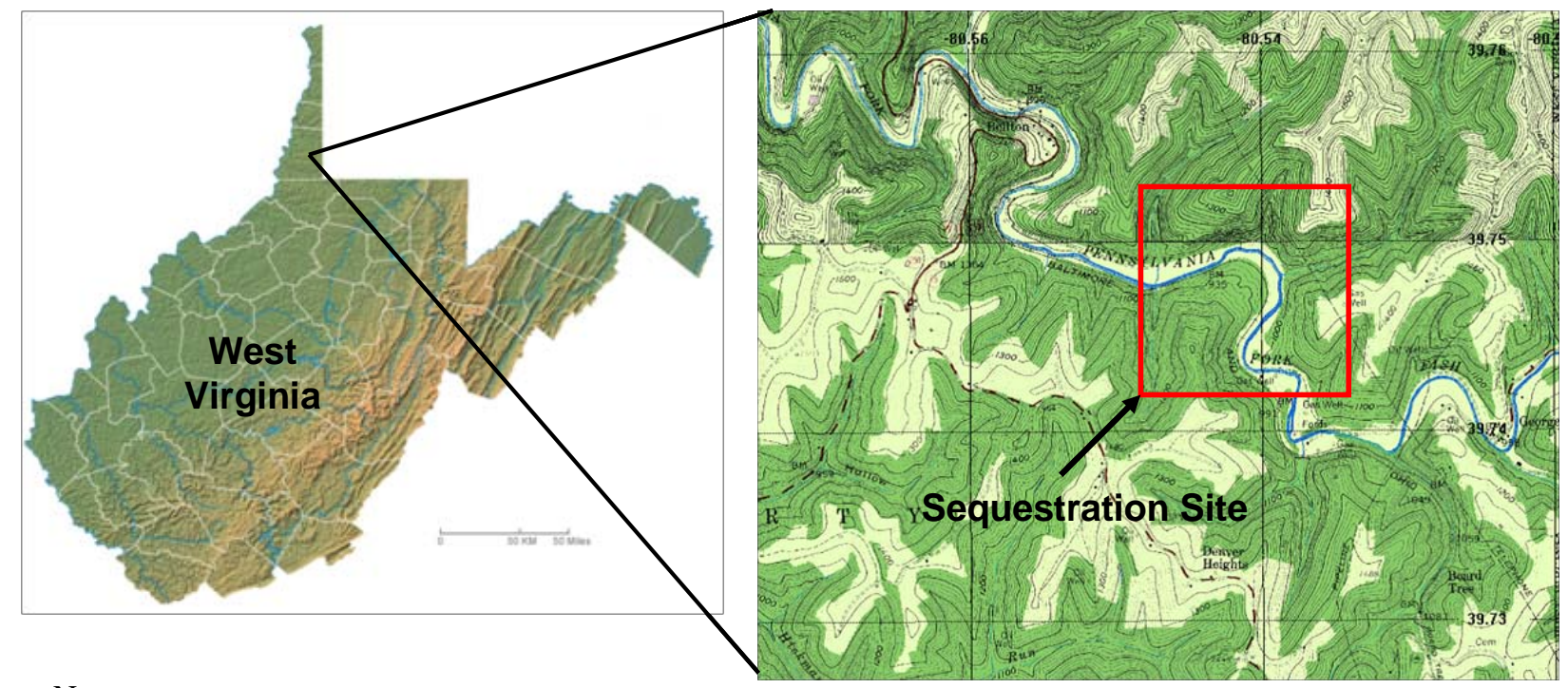

Note:

1. This map was generated based on site description provided by CONSOL Energy (Winschel et al, 2010).

2. The map of state of West Virginia was obtained from www.geology.com, and GIS data for project site was available from WV GIS technical center.

Figure 3.1: Location of $\mathrm{CO}_{2}$ sequestration field site used in the current study 


\subsection{Overview of the field demonstration project}

Several studies have classified unmineable coal seams as promising reservoirs for longterm storage of $\mathrm{CO}_{2}$. In the current field demonstration project site, the objective is to evaluate coalbed methane recovery in the region and to demonstrate the sequestration potential of $\mathrm{CO}_{2}$ into an unmineable coal seam (Winschel et al, 2010). Unmineable coal seams may be uneconomic and infeasible for successful mining operations due to many reasons such as unsatisfactory thickness of coal seam, unfavorable geology, reduced quality and extreme depths (Winschel and Scandrol, 2007). It has been reported that the pod-like distribution of Upper Freeport coal makes it unmineable (Wilson et al, 2003). Field operations on the site are carried out by a coal company, Consol Energy in collaboration with various researchers from National Energy Technology Laboratory, U.S. Department of Energy and West Virginia University (Winschel et al, 2010).

At the field site, pioneering technologies such as directional drilling techniques have been used to drill horizontal wells. As horizontal wells reach a large extent of coal reserves, it is believed that these wells have enormous potential to not only extract CBM but also to store large amounts of $\mathrm{CO}_{2}$ in the coal seam (Cairns, 2002). The uniqueness of this field site is that the CBM production and $\mathrm{CO}_{2}$ injection is carried out using horizontally drilled wells. Geophysical characterization was performed and several monitoring technologies have been employed to investigate sequestration stability and feasibility at the site (Winschel et al, 2010; Wilson et al, 2003). Some of the monitoring techniques include geophysical monitoring, gas and water sampling, shallow hydrogeologic monitoring, perfluorocarbon (PFC) tracers, and tiltmeters. The dissertation work reported here is focused on the use of ground monitoring technologies at the field site such as tiltmeters for geologic sequestration of $\mathrm{CO}_{2}$.

\subsection{Site details}

The field site consists of two coal seams - the Upper Freeport coal seam (lower/unmineable coal seam) and the Pittsburgh coal seam (upper/mineable coal seam), separated by about 600 feet (182 m) of shale and other rocks as illustrated in Figure 3.2. Coalbed 
methane was extracted from both the coal seams - unmineable (Upper Freeport coal) and mineable (Pittsburgh coal), and $\mathrm{CO}_{2}$ injection took place into the lower coal seam (Upper Freeport coal). The average depth to the upper coal seam (Pittsburgh coal - mineable) is about 700 feet $(213 \mathrm{~m})$ and the average depth to the lower coal seam (Upper Freeport coal unmineable) is about 1250 feet $(381 \mathrm{~m})$. Based on evaluation of one of the core samples, the average thickness of the Pittsburgh seam and the Upper Freeport seam were reported as 6.72 feet (2 m) and 4.25 (1.3 m) feet respectively (Winschel and Scandrol, 2007). However, depth and thickness of the coal seams vary spatially at the field site, which will be presented in the forthcoming sections. Surface and sub-surface characterization, basin history, structural geology, CBM estimates and storage potential at the site will be discussed in later sections.

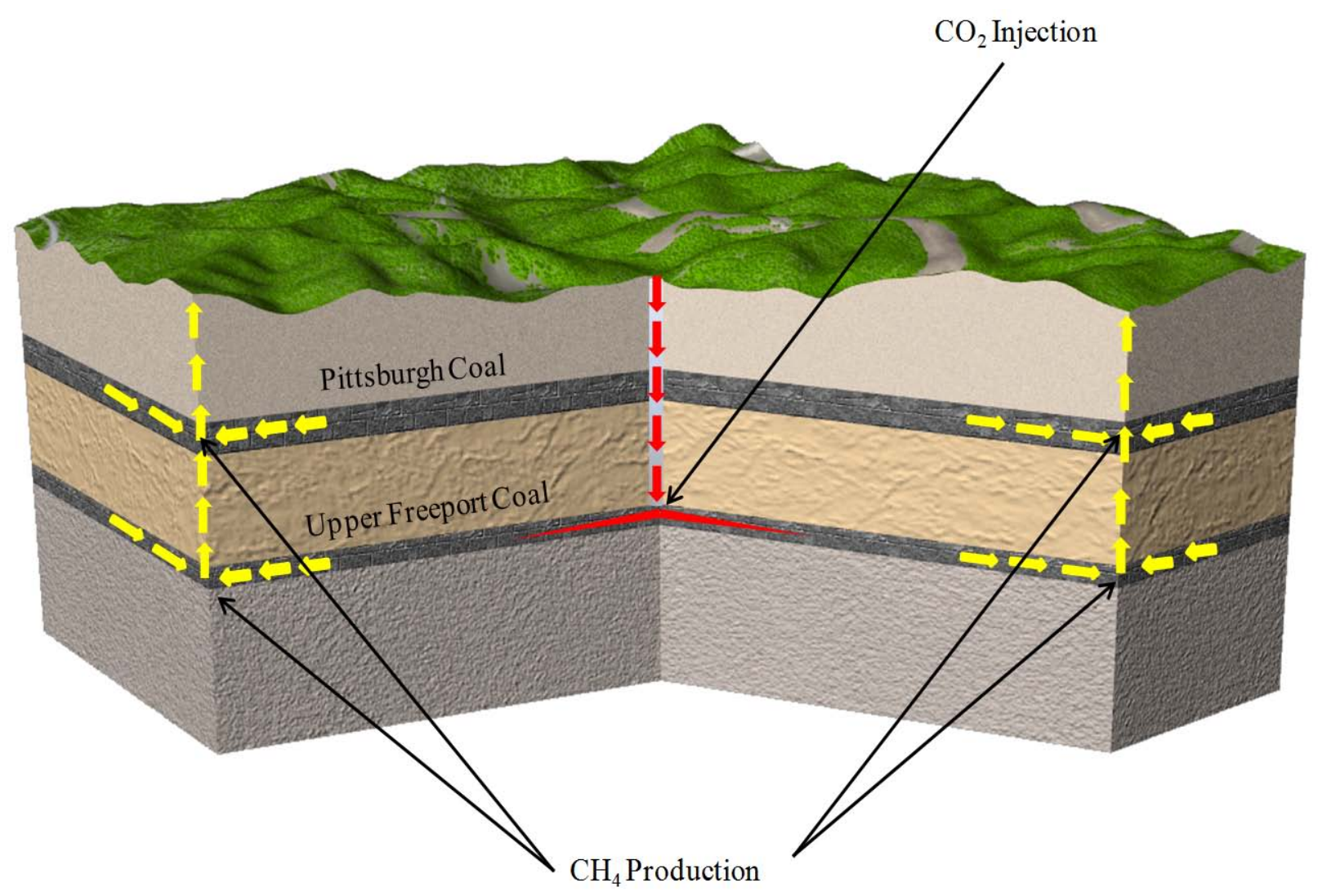

Note: This schematic diagram was generated based on field data and field details provided by CONSOL Energy at the field site (Winschel, 2009; Winschel et al, 2010).

Figure 3.2: Pittsburgh coal seam and Upper Freeport coal seam at the field site 
Table 3.1 provides details of the wells located and drilled at the field site in both coal seams. A three-dimensional perspective view of production wells, injection wells and access wells can be seen in Figure 3.3. Moreover, Figure 3.4 shows the aerial view of the horizontal wells in the Upper Freeport coal seam and Pittsburgh coal seam projected on ground topography. Well configuration and well names are outlined in Figure 3.5. Since 2004, most of these wells in both coal seams have been producing; however, the central production wells in the lower coal seam (Upper Freeport coal) have been converted to injection wells due to sufficient gas depletion from the reservoir.

Table 3.1: Well details

\begin{tabular}{|c|c|c|c|c|c|}
\hline \multirow[t]{2}{*}{ Well } & \multirow[t]{2}{*}{ Coal Seam } & \multirow[t]{2}{*}{ Comment } & \multirow[t]{2}{*}{ Well Type } & \multicolumn{2}{|c|}{$\begin{array}{l}\text { Length and directions } \\
\text { of horizontals, } \mathrm{ft} \text {. }\end{array}$} \\
\hline & & & & $\operatorname{leg} 1$ & $\operatorname{leg} 2$ \\
\hline \multicolumn{6}{|c|}{ North Site } \\
\hline $\mathrm{MH}-3$ & Pittsburgh & Slant hole well, one leg & Producer & 3,600 & NA \\
\hline $\mathrm{MH}-4$ & Pittsburgh & Slant hole well, one leg & Producer (shut-in) & 1,100 & NA \\
\hline $\mathrm{MH}-5$ & Upper Freeport & Slant hole well, one leg & Producer & 1,600 & NA \\
\hline MH-6 & Upper Freeport & Slant hole well, one leg, sealed & Producer (shut-in) & 1,248 & NA \\
\hline \multicolumn{6}{|c|}{ South Site } \\
\hline $\mathrm{MH}-11$ & Upper Freeport & Vertical well for $\mathrm{MH}-13$ & Producer & NA & NA \\
\hline $\mathrm{MH}-12$ & Pittsburgh & Vertical well for $\mathrm{MH}-15$ & Producer & NA & NA \\
\hline $\mathrm{MH}-13$ & Upper Freeport & Access well for $\mathrm{MH}-11$, two legs & Access Well & 2,115 & 794 \\
\hline MH-15 & Pittsburgh & Access well for $\mathrm{MH}-12$, two legs & Access Well & 2,933 & 3,477 \\
\hline \multicolumn{6}{|c|}{ Center Site } \\
\hline $\mathrm{MH}-18$ & Upper Freeport & Vertical well for $\mathrm{MH}-19$ & Injection Well & NA & NA \\
\hline MH-19 & Upper Freeport & Access well for $\mathrm{MH}-18$, two legs & Access Well & 866 & 806 \\
\hline $\mathrm{MH}-20$ & Upper Freeport & Vertical well for $\mathrm{MH}-21$ & Injection Well & NA & NA \\
\hline $\mathrm{MH}-21$ & Upper Freeport & Access well for $\mathrm{MH}-20$, two legs & Access Well & 1,100 & 1,124 \\
\hline \multicolumn{6}{|c|}{ West Site } \\
\hline $\mathrm{MH}-25$ & & & Monitoring Well & & \\
\hline $\mathrm{MH}-26$ & & & Monitoring Well & & \\
\hline $\mathrm{MH}-27$ & & & Monitoring Well & & \\
\hline
\end{tabular}

Note: Table was prepared based on the well details and well log information provided by CONSOL Energy (Winschel, 2009; Winschel et al, 2010). 
Figures 3.3, 3.4 and 3.5 show the square pattern configuration of horizontal wells (approximately 3,000 feet $(915 \mathrm{~m})$ ) drilled in the Pittsburgh coal seam. Directional drilling was used to complete these horizontal wells from two surface locations on the opposite corners of the square (as shown in Figure 3.3, 3.4 and 3.5). MH-3, MH-4 and two legs of MH-12 represent the square pattern configuration of wells in the Pittsburgh coal seam. These figures also illustrate the outside horizontal wells (MH-5, MH-6, and two legs of MH-11) completed in the Upper Freeport coal seam with a V-shaped well pattern and four horizontal legs drilled at the central site (2 legs of each MH-18 and MH-20). While legs of MH-18 extend toward the north and west, legs of MH-20 extend towards south and east as shown in Figures 3.4 and 3.5. Both injection wells are separated by a few feet as shown in Figures 3.4 and 3.5, and are approximately 800-900 feet long.

— Injection Wells (Upper Freeport Coal)

— Production Wells (Upper Freeport Coal)

- Production Wells (Pittsburgh Coal)

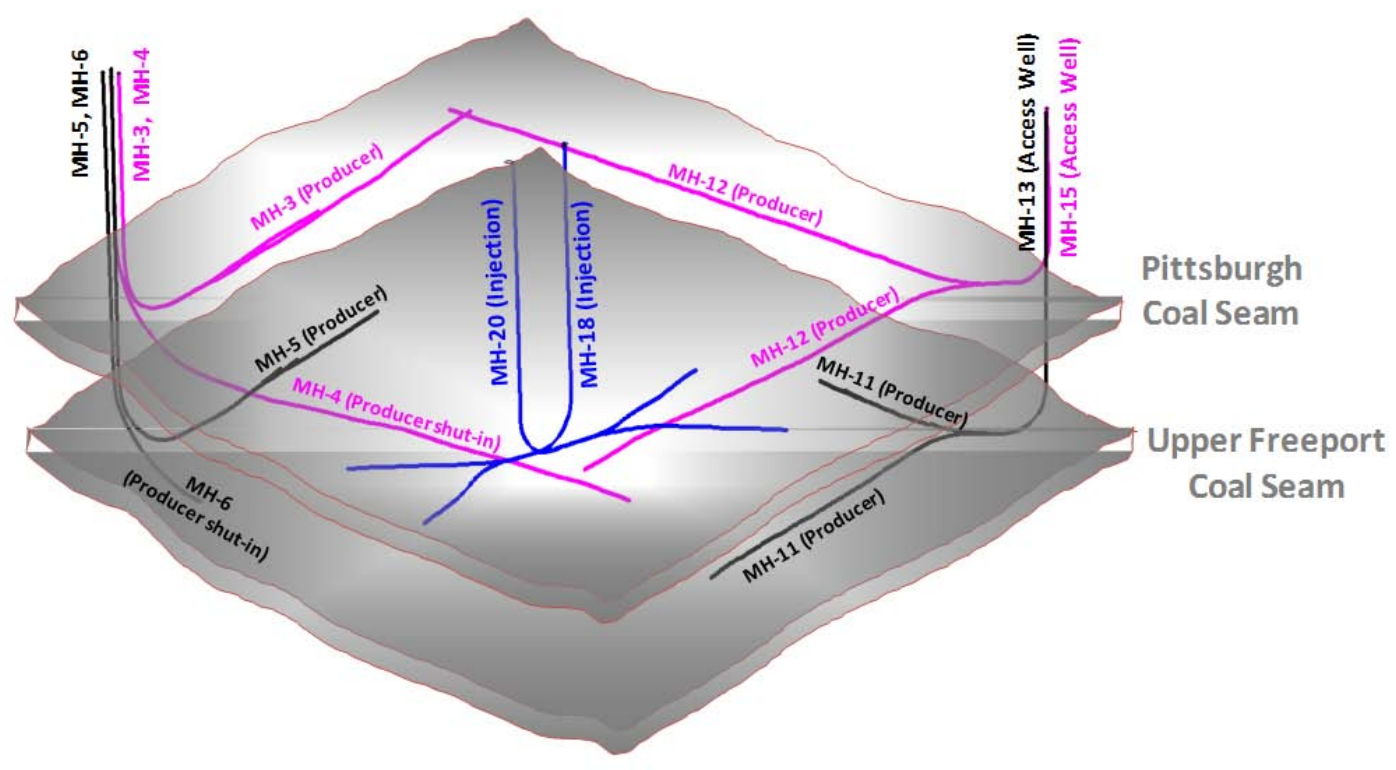

Note: This schematic diagram was generated based on field data and field details provided by CONSOL Energy at the field site (Winschel, 2009; Winschel et al, 2010).

Figure 3.3: A perspective view of production wells, injection wells and access wells 


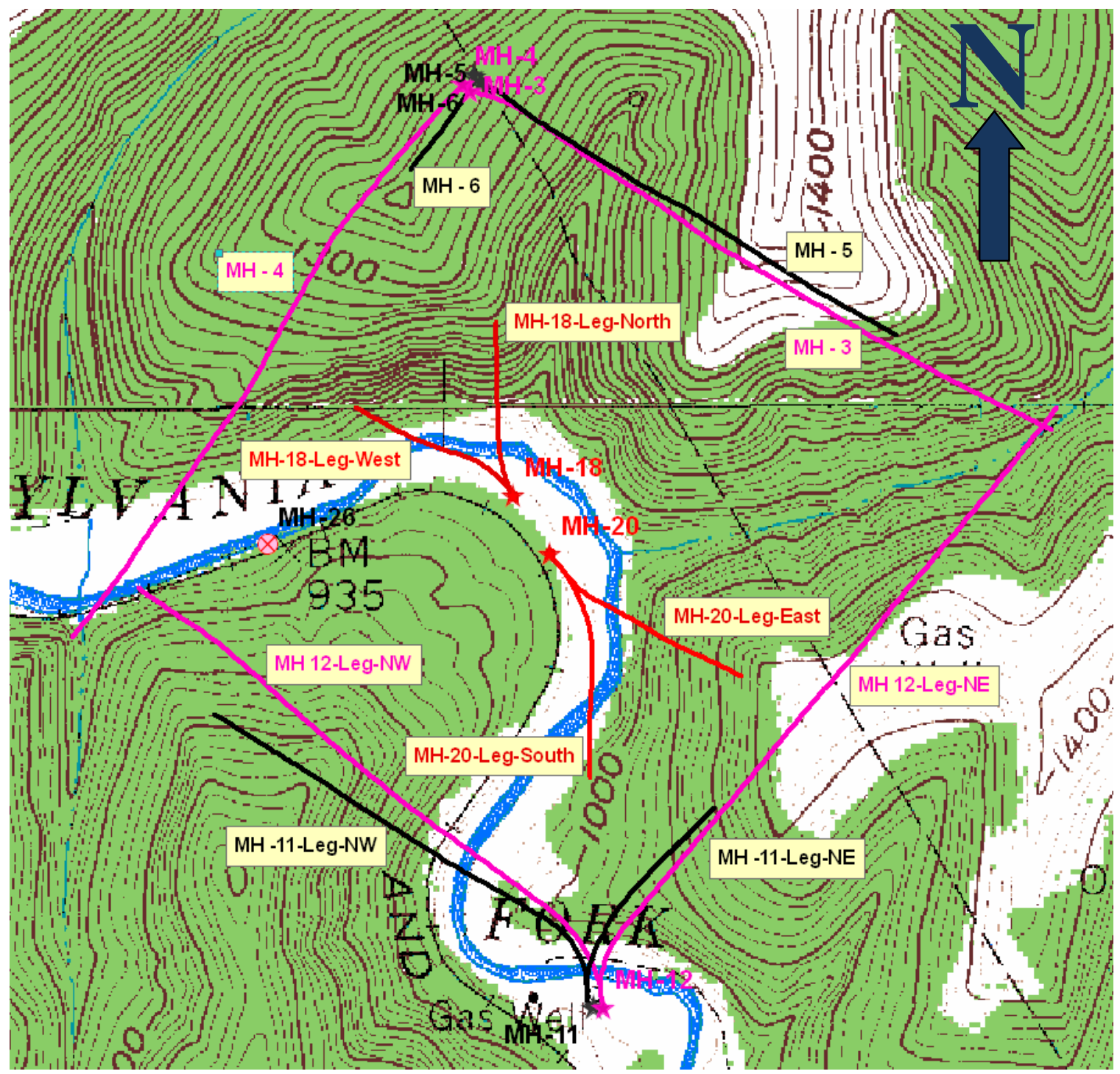

$\checkmark \quad$ Monitoring Wells

\section{_ Injection Wells (Upper Freeport Coal)}

\section{_ Production Wells (Pittsburgh Coal)}

\section{— Production/Injection Wells (Upper Freeport Coal)}

Note:

1. This figure was generated based on the field data and field details provided by CONSOL Energy at the field site (Winschel, 2009; Winschel et al, 2010).

2. GIS data was obtained from West Virginia GIS Technical Center (www.wvgis.wvu.edu).

Figure 3.4: Aerial view of well configurations with respect to ground topography 


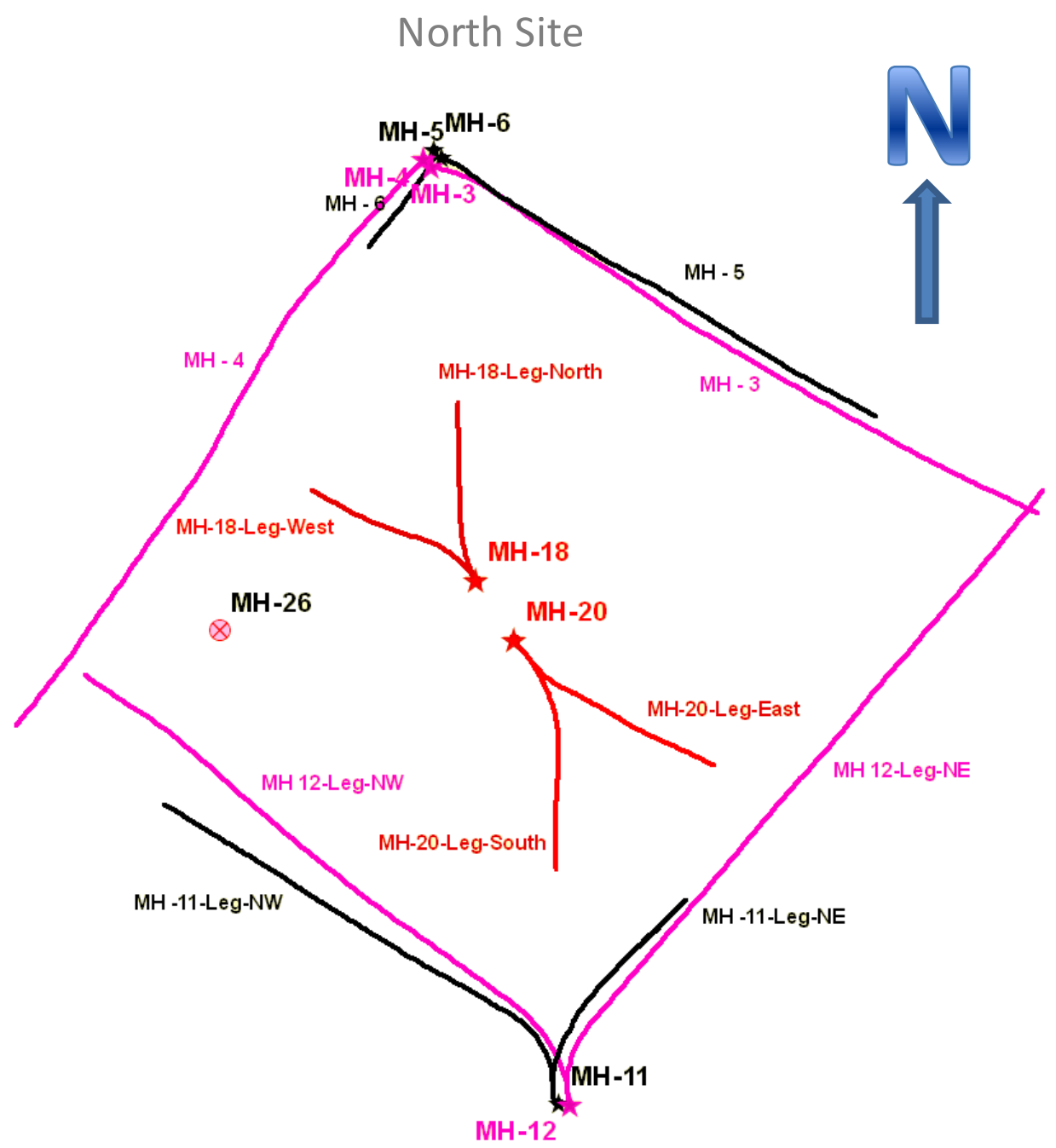

\section{South Site}

- Monitoring Wells

_ Injection Wells (Upper Freeport Coal)

_ Production Wells (Pittsburgh Coal)

\section{— Production/Injection Wells (Upper Freeport Coal)}

Note:

1. This figure was generated based on the field data and field details provided by CONSOL Energy at the field site (Winschel, 2009; Winschel et al, 2010).

2. Well details and well log information was provided by Consol Energy

Figure 3.5: Well configuration and well names in both coal seams 
About 20,000 tons of $\mathrm{CO}_{2}$ is planned for injection in the lower coal seam (Winschel et al, 2010). More details related to $\mathrm{CBM}$ production and $\mathrm{CO}_{2}$ injection are presented in subsequent sections. An area of approximately 200 acres is covered by the periphery of lateral production wells with an estimated 1,620,000 tons of coal in the Upper Freeport coal seam (Winschel et al, 2010). Large amounts of CBM reserves are expected from both coal seams with a $\mathrm{CO}_{2}$ storage potential of approximately 37,000 tons (Winschel, 2009). The calculations of these estimates were based on coal thickness, areal extent and average gas content of the lower coal seam. Furthermore, a few monitoring wells (MH-26 as seen in Figures 3.4 and 3.5) are completed to monitor $\mathrm{CO}_{2}$ migration.

Figures 3.6 through 3.9 show snap shots of the field site. Author strongly acknowledges Consol Energy for providing available field data and site access to this project site. Figure 3.6 shows the central injection site surround by thick vegetation and rough terrain. The stream flowing through low lying areas of the site can be seen in Figure 3.7. Figure 3.8 presents one of the production wells in the region and Figure 3.9 shows the $\mathrm{CO}_{2}$ tank placed at the site. The $\mathrm{CO}_{2}$ tank is capable of holding up to 50 tons of liquid $\mathrm{CO}_{2}$. The $\mathrm{CO}_{2}$ gets transferred through a vaporizer and is split into central injection wells. Flow meters, pressure transducers, pneumatic valves, and many other tools are equipped at the site. More details on field specific operations can be found elsewhere (Winschel et al, 2010).

\subsection{Geologic characterization and structural geology}

The coal seams of the northern Appalachian basin are categorized into five stratigraphic groups - the Pottsville, the Alleghany, the Conemaugh, the Monongahela, and the Dunkard as shown in Figure 3.10 (Kelafant and Boyer, 1988). The generalized stratigraphic sequence of the northern Appalachian coal basin was prepared based on available published sources (Kelafant and Boyer, 1988; Bruner; 1995; Lyons, 1998). The coal bearing groups of the Pennsylvanian age (the Pottsville, the Alleghany, the Conemaugh and the Monongahela) are known for gas recovery. However, the coal groups of the Dunkard group of the Permian age are reported to not be the best candidates for CBM recovery due to shallow subsurface (Kelafant and Boyer, 1988). 


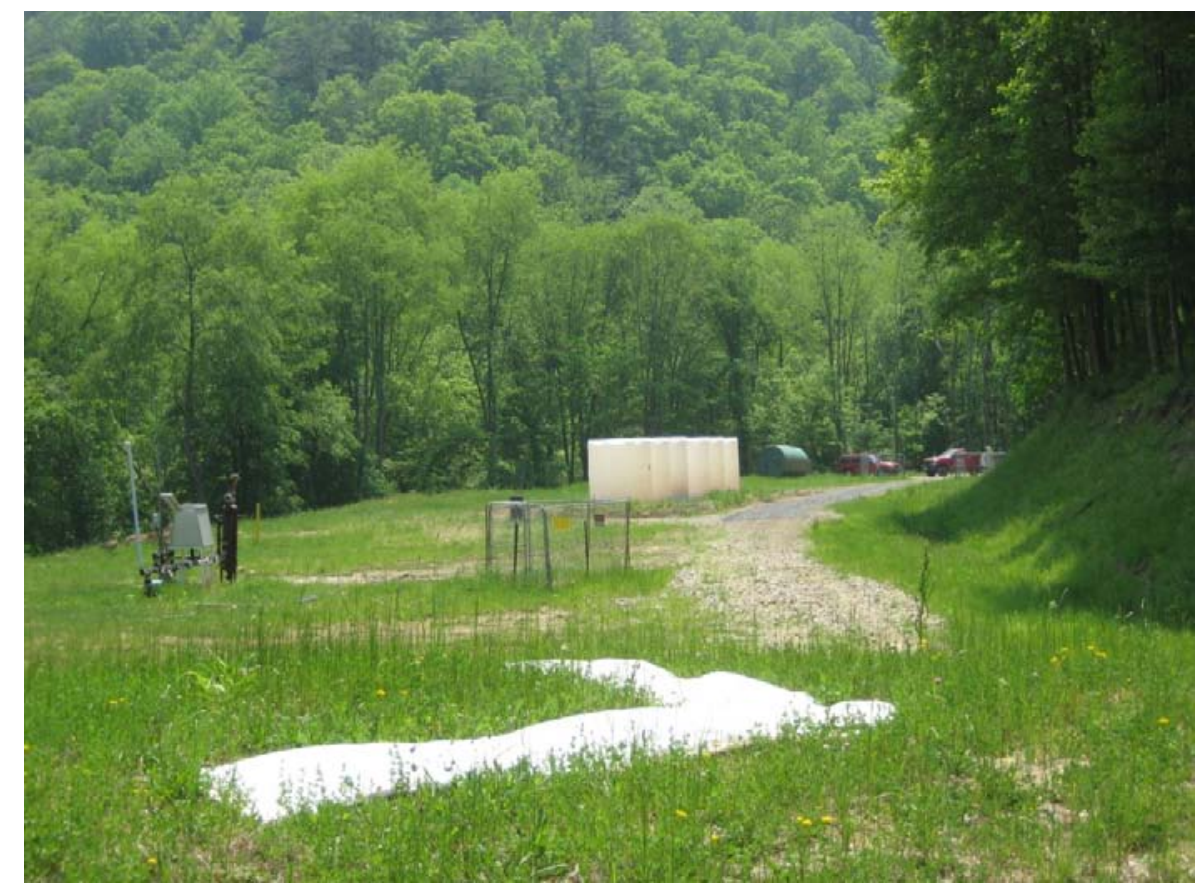

Note. Access to the field site was given by CONSOL Energy (Winschel, 2009).

Figure 3.6: Injection site surrounded by thick vegetation and hilly terrain

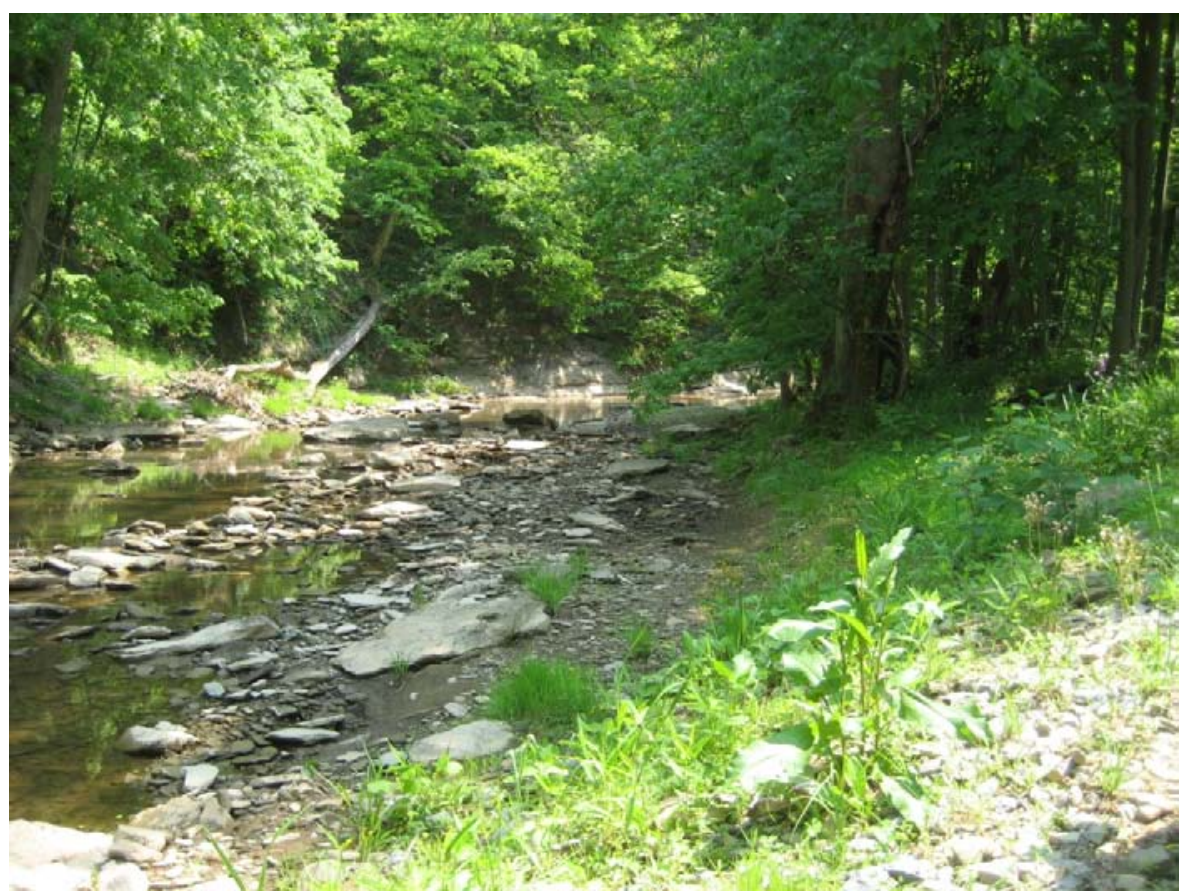

Note. Access to the field site was given by CONSOL Energy (Winschel, 2009).

Figure 3.7: Stream located near the field site 


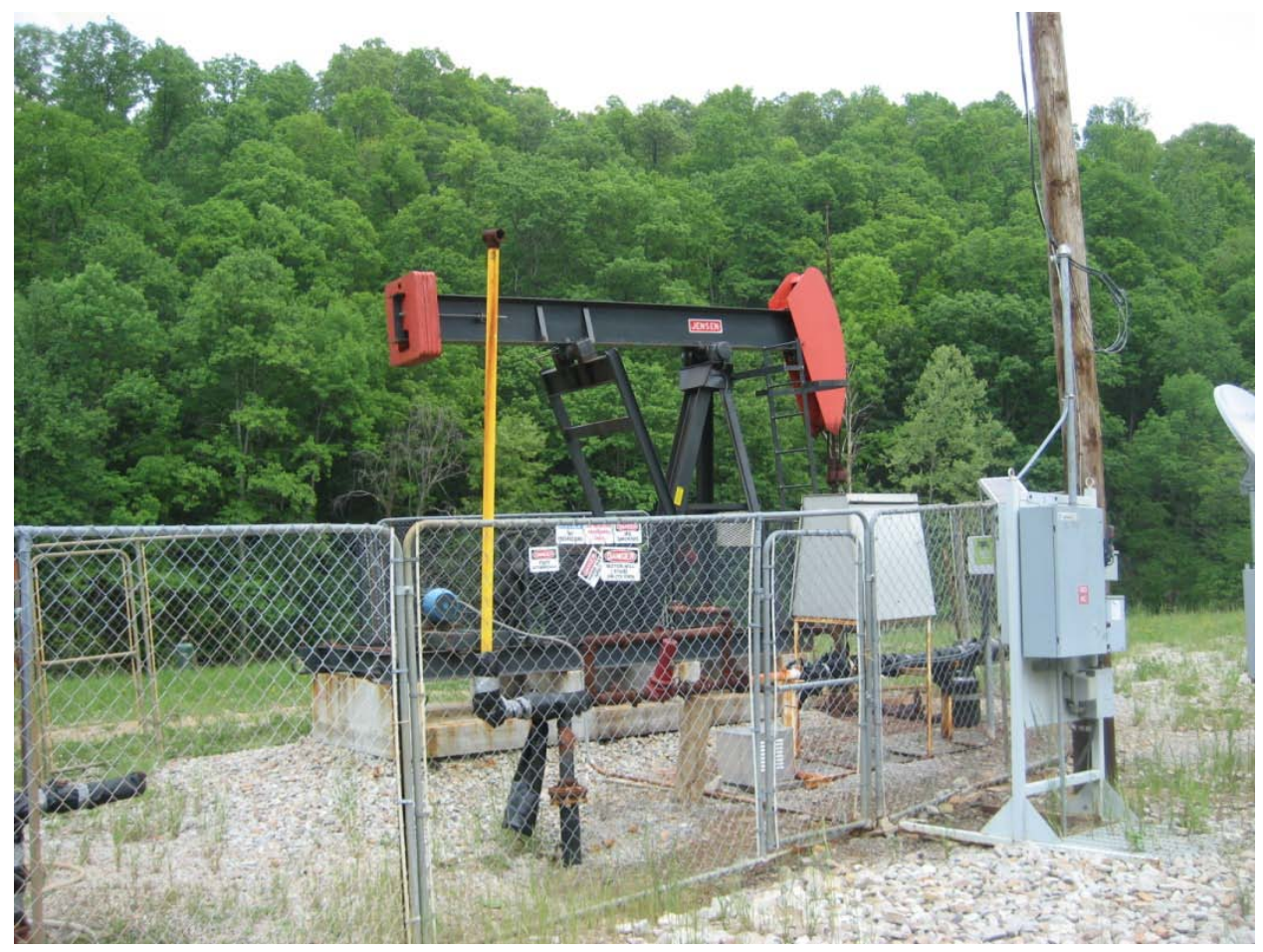

Note. Access to the field site was given by CONSOL Energy (Winschel, 2009).

Figure 3.8: One of the producer wells in the region

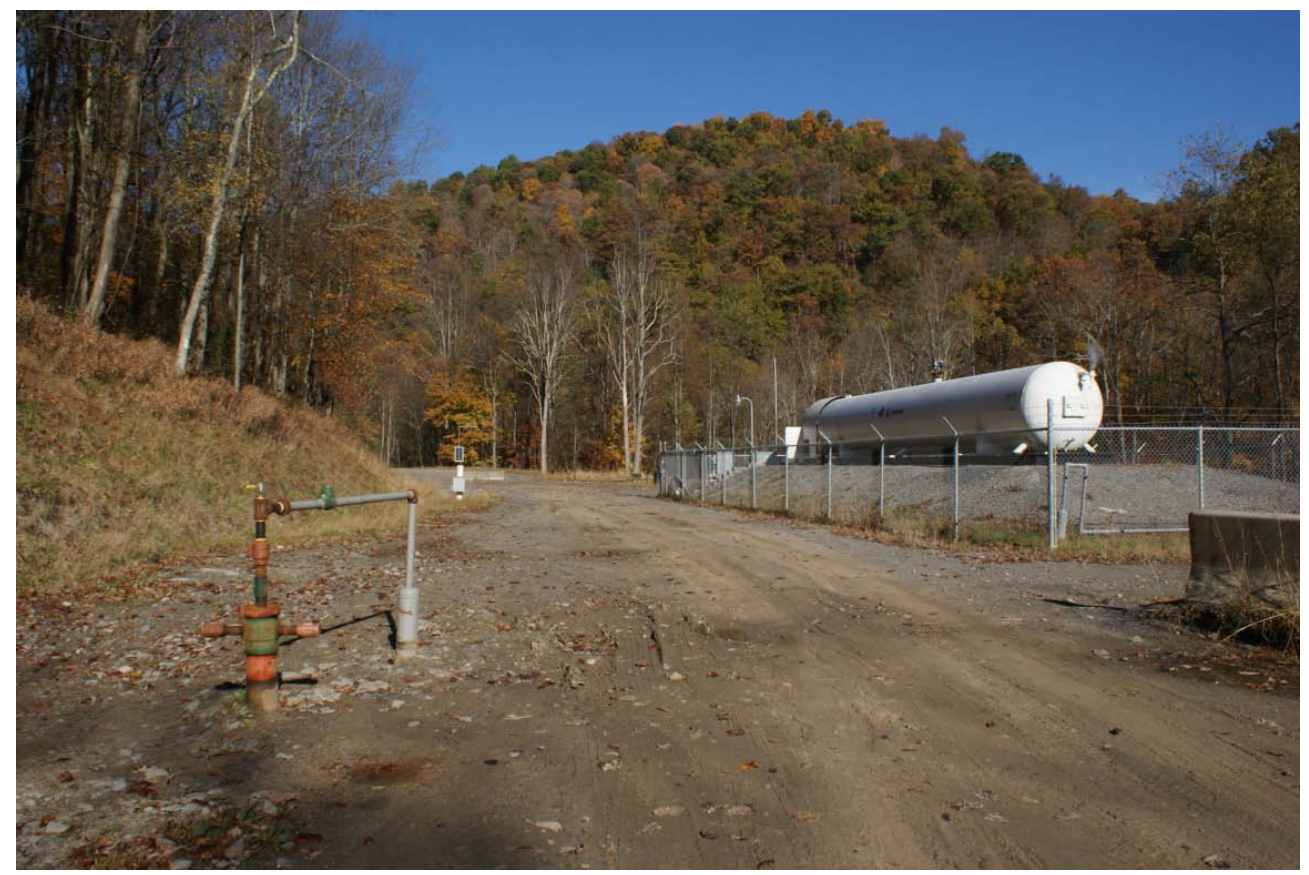

Note. Access to the field site was given by CONSOL Energy (Winschel, 2009).

Figure 3.9: $\mathrm{CO}_{2}$ tank located at the site 


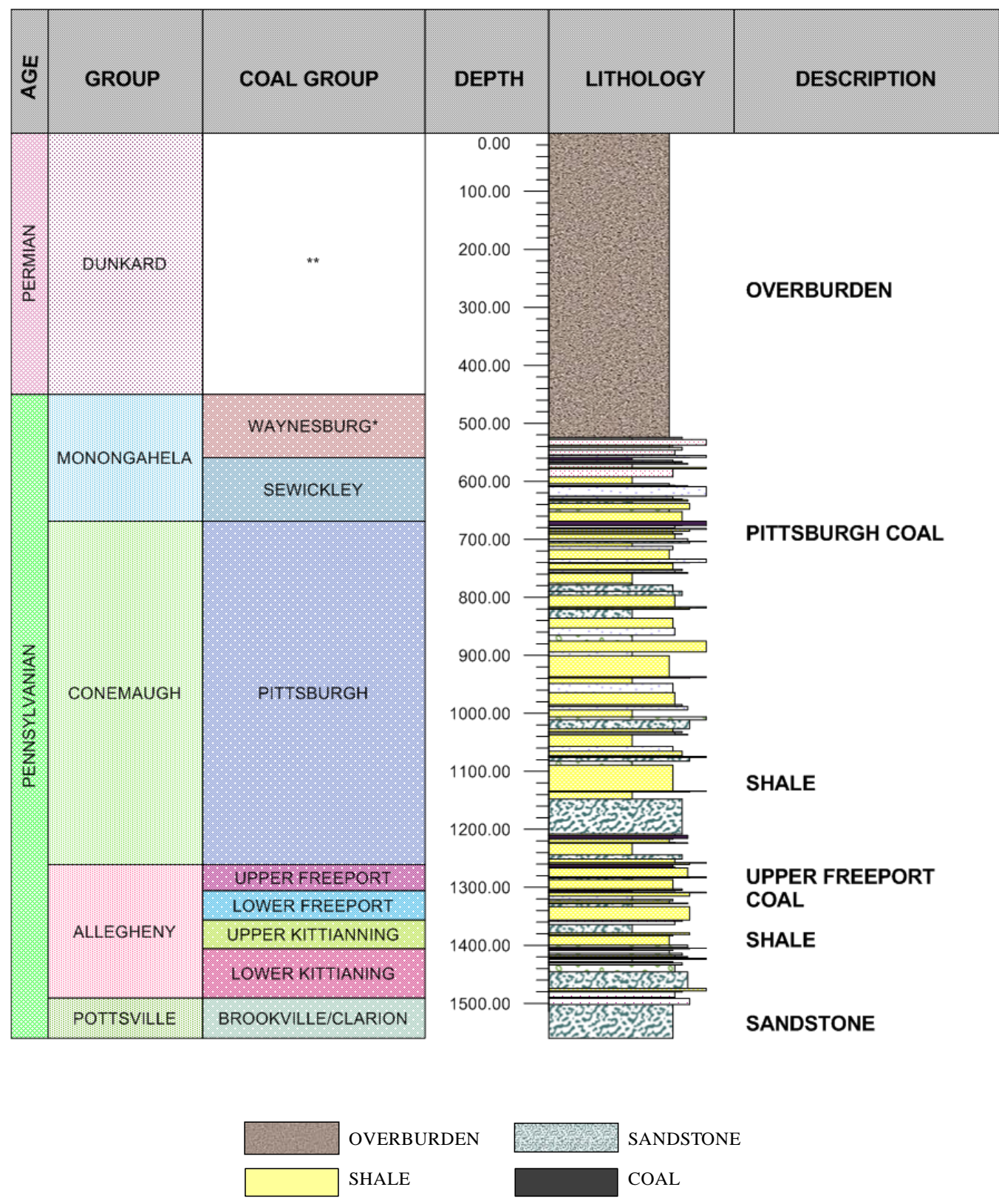

Note:

1. Depth to cover of Waynesburg coal was roughly obtained from Kelafant and Boyer (1988).

2. Limited data was available Dunkard Group.

3. Figure was generated based on collected geologic information near the site - available core hole and other published information (Kelafant and Boyer, 1988; Bruner, 1995).

4. Core hole data was obtained from CONSOL Energy (Winschel, 2009).

Figure 3.10: Generalized stratigraphic sequence of the northern Appalachian coal basin 
The Allegheny group consists of complex geology with a wide range of greywacke, gray colored shale and mudstone combined with clay and coal. The Kittanning and the Freeport are the major coal formations of the Allegheny group. The coals of the Allegheny group have a large areal extent, and vary from 2 to 6 feet in coal thickness. More details on the formation and geologic sequence of the Allegheny group can be found elsewhere (Kelafant and Boyer, 1988). The Conemaugh group which is next in the sequence generally extends from the top of the Upper Freeport coal formations to the bottom of the Pittsburgh coal as shown in the Figure 3.10. The Conemaugh group is dominated with red to light gray shales and mudstones with greywacke and discontinuous coal formations. The coal formations of the Conemaugh group are limited, and possess CBM potential depending on the local coal thickness (Kelafant and Boyer, 1988). The Monongahela group generally extends from the bottom of the Pittsburgh coal to the top of the Waynesburg coal. Coal groups of Pittsburgh, Redstone, Sewickley and Waynesburg with portions of gray shale and mudstone are the major formations of the Monongahela group. The coal seams (the Pittsburgh coal, the Redstone coal, and the Sewickeley coal) of Monongahela group are believed to be suitable for extraction of natural gas due to their gas potential, subsurface depth, lateral continuity and areal extents. More details on the individual coal groups can be found elsewhere (Lyons, 1998; Bruner, 1995; Kelafant, 1988; Diamond et al, 1986). For the present study, the Pittsburgh coal of Monongahela group and the Upper Freeport coal of Allegheny group are of particular interest.

The structural geology of the northern Appalachian coal basin is reported in published literature covering the project region (Wilson et al, 2003; Bruner, 1995; Kelafant and Boyer, 1988). The project site was selected based on core hole data and geologic information collected from Wetzel County and Marshall County in West Virginia (Cairns, 2002). Coal thickness, structural geology, surface topography, site accessibility, nearby gas pipelines and proximity to field operations were some of the driving factors for the selection of the site (Cairns, 2002). Based on data collected from one of the nearest core holes (MC-01-19) located at the site, a stratigraphic column corresponding to a generalized lithology is constructed as shown in Figure 3.10. Reconnaissance studies at the field site were performed and structural maps related to the northern Appalachian coal basin and region covering the project site can be found elsewhere (Kelafant and Boyer, 1988; Wilson et al, 2003). A bedding dip of less than 1 degree is reported 
at the site in the published literature (Wilson et al, 2003). Regional maps of structure contours for Pittsburgh coal and Upper Freeport coal can also be found elsewhere (Wilson et al, 2003). Orientation of approximately $\mathrm{N} 76^{0} \mathrm{~W}$ has been reported for face cleats near the field site in Marshall county, West Virginia (Wilson et al, 2003; Nickelsen and Hough, 1967). Also, similar cleat trends were observed near the area of interest in the northern Appalachian coals in published literature (McCulloch, 1974; Kulander, 1980; Kelafant and Boyer, 1988; Law, 1993; Bruner, 1995).

Subsurface characterization was carried out at the site by interpreting geophysical data and geologic data (Wilson, 2009). As a part of geophysical interpretation, 2D and 3D seismic surveys with well logging data are correlated. Several geologic analyses have been conducted in the past covering the region (Kelafant and Boyer, 1988; Bruner, 1995; Wilson et al, 2003). Some of these geologic assessments include regional cross-sections, area extents, coal structure, thickness, depth, rank and gas in place of various groups of coals. A series of isopach maps related to area of interest and overall Northern Appalachian coal basin can be seen elsewhere (Kelafant and Boyer, 1988; Wilson et al, 2003).

Well log information was collected in order to evaluate the subsurface geology and coal geometry at the project site. Based on the core hole information, Figures 3.11 and 3.12 show the maps of coal thickness generated for the Pittsburgh and Upper Freeport coal seams in and around the field site. While the thickness of the Pittsburgh coal appears to be very uniform, the Upper Freeport coal is observed to have approximately a one foot change in the thickness. Figures 3.13 and 3.14 represent the maps of depth to the top of the Pittsburgh coal and the Upper Freeport coal near the area of interest with respect to mean seal level. The average depth to the upper coal seam (Pittsburgh coal - mineable) is about 700 feet $(213 \mathrm{~m})$ and the average depth to the lower coal seam (Upper Freeport coal - unmineable) is about 1250 feet (381 m). By combining the ground surface and geometries of these coal seams, a vertically scaled perspective view of the surface and sub-surface geology is illustrated in Figure 3.15 for better interpretation of the subsurface geometry. Figure 3.15 also shows the well configurations of independent coal seams. Though depths to independent coals vary non-uniformly, they appear to be flat when compared to changes in surface elevations as shown in Figure 3.15. 


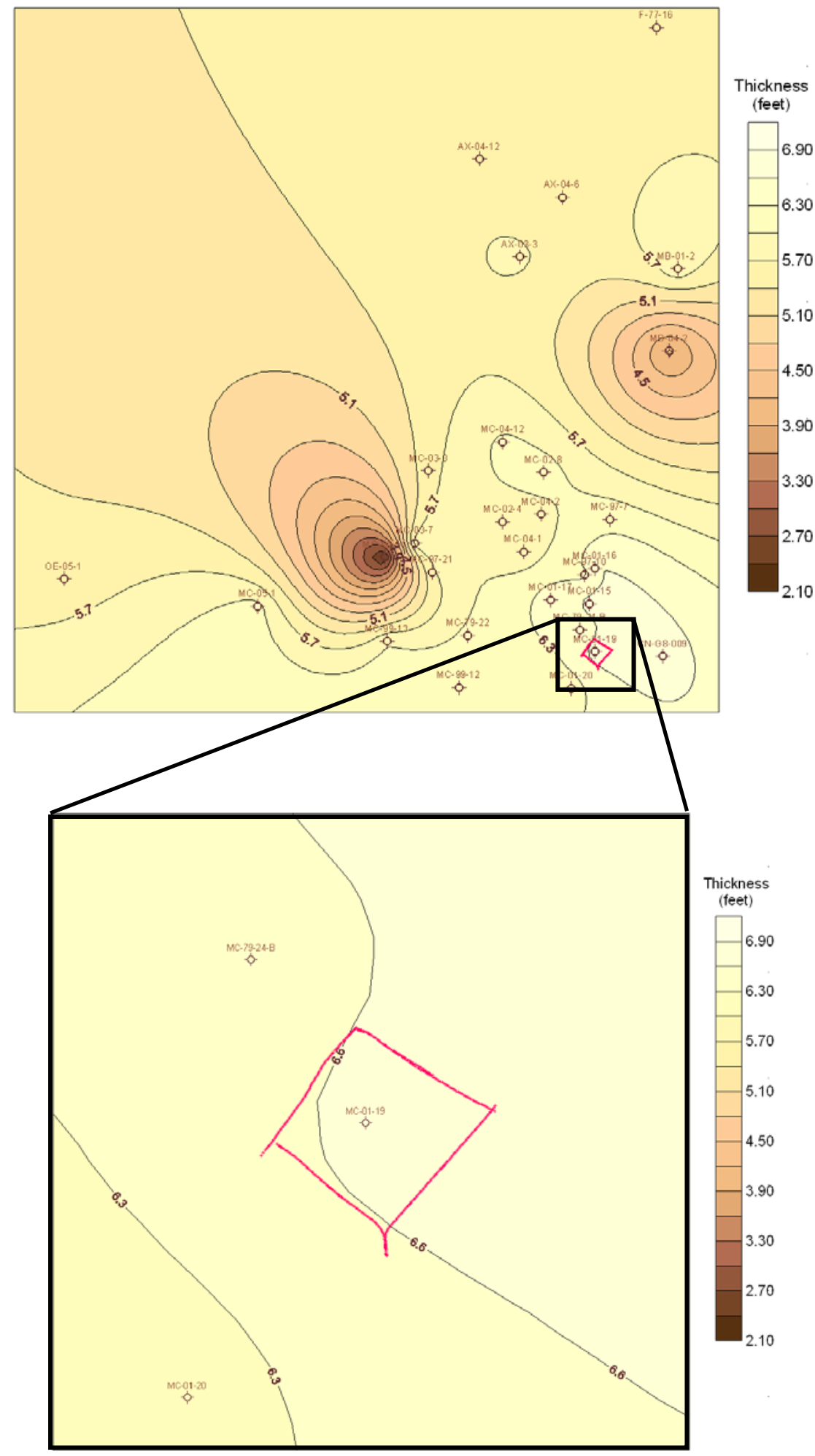

Note: Isopach maps were generated based on available field data from CONSOL Energy (Winschel, 2009).

Figure 3.11: Thickness map for Pittsburgh coal seam (feet) 


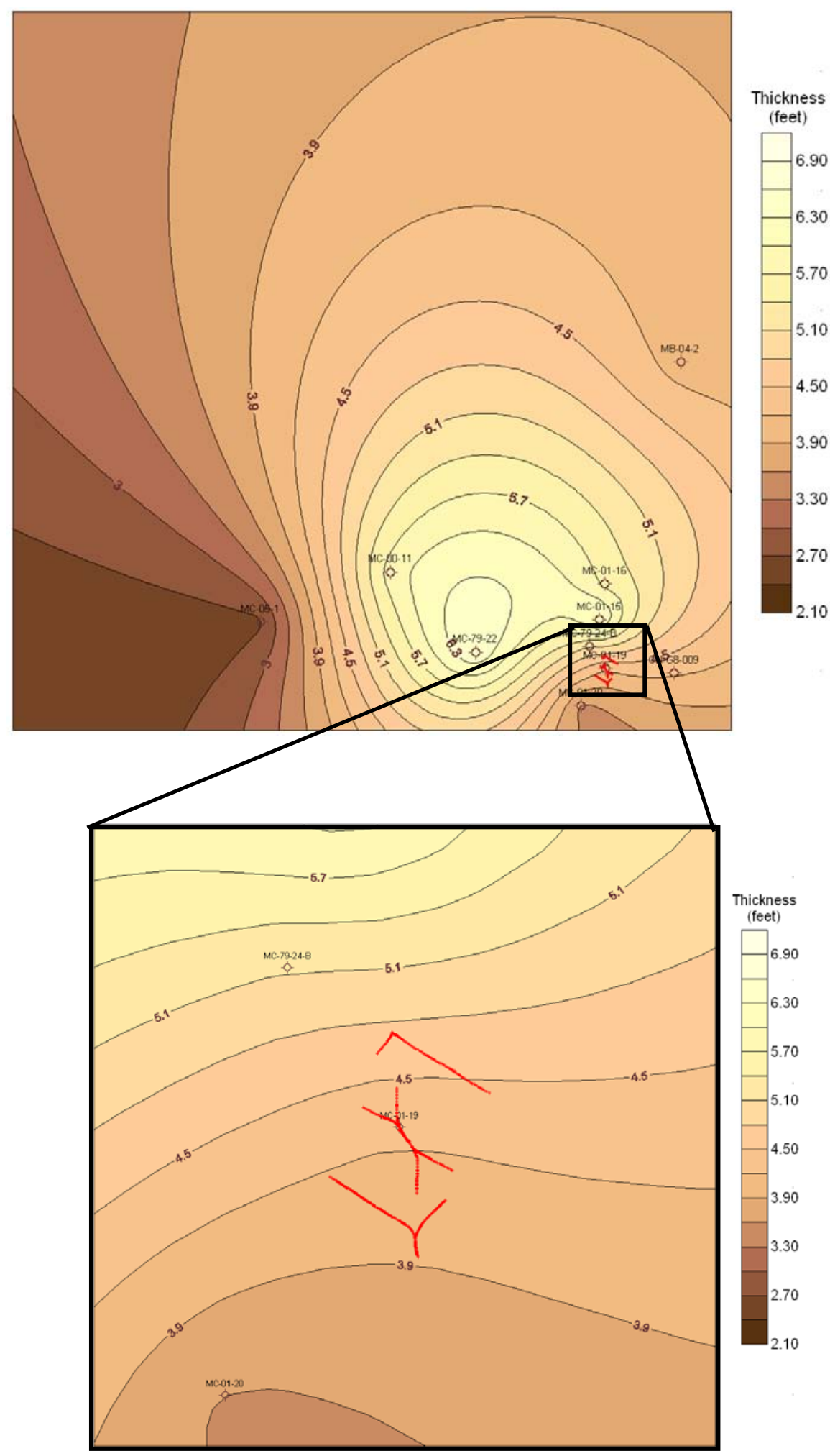

Note: Isopach maps were generated based on available field data from CONSOL Energy (Winschel, 2009).

Figure 3.12: Thickness map for Upper Freeport coal seam (feet) 


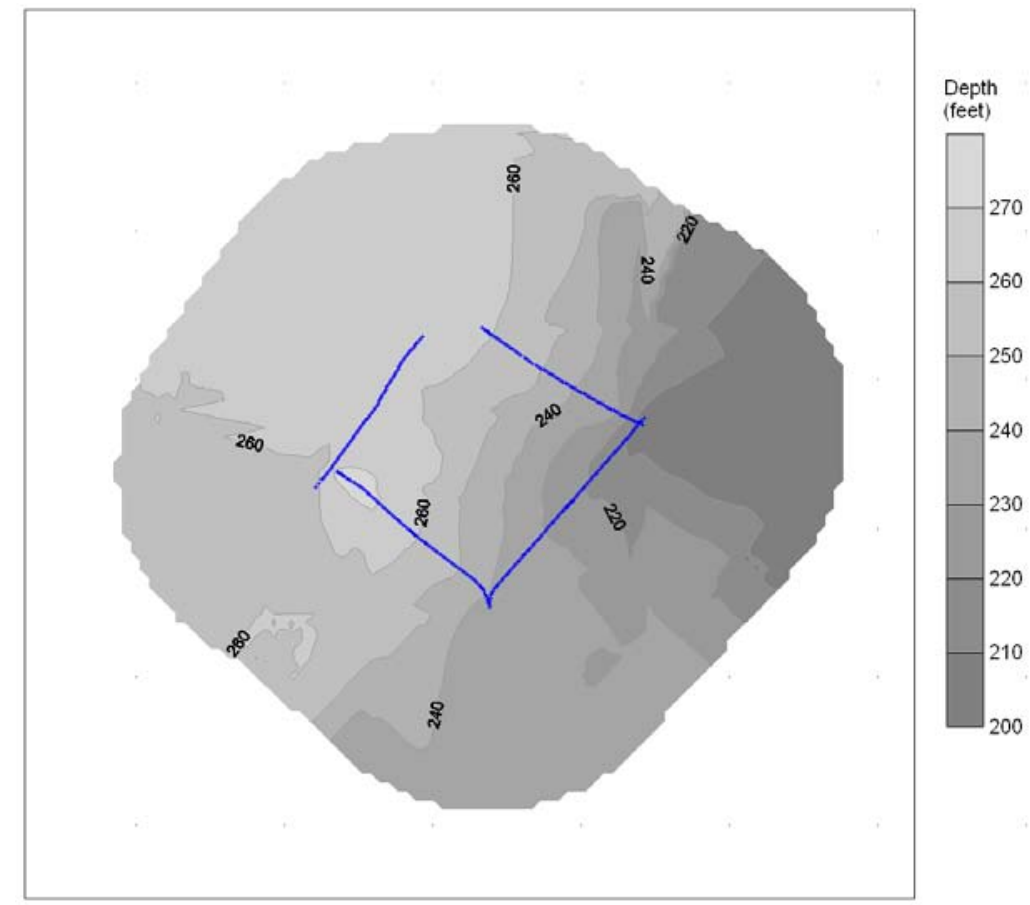

Note: Figure was generated based on available field data from CONSOL Energy (Winschel, 2009).

Figure 3.13: Depth to Pittsburgh coal seam (feet)

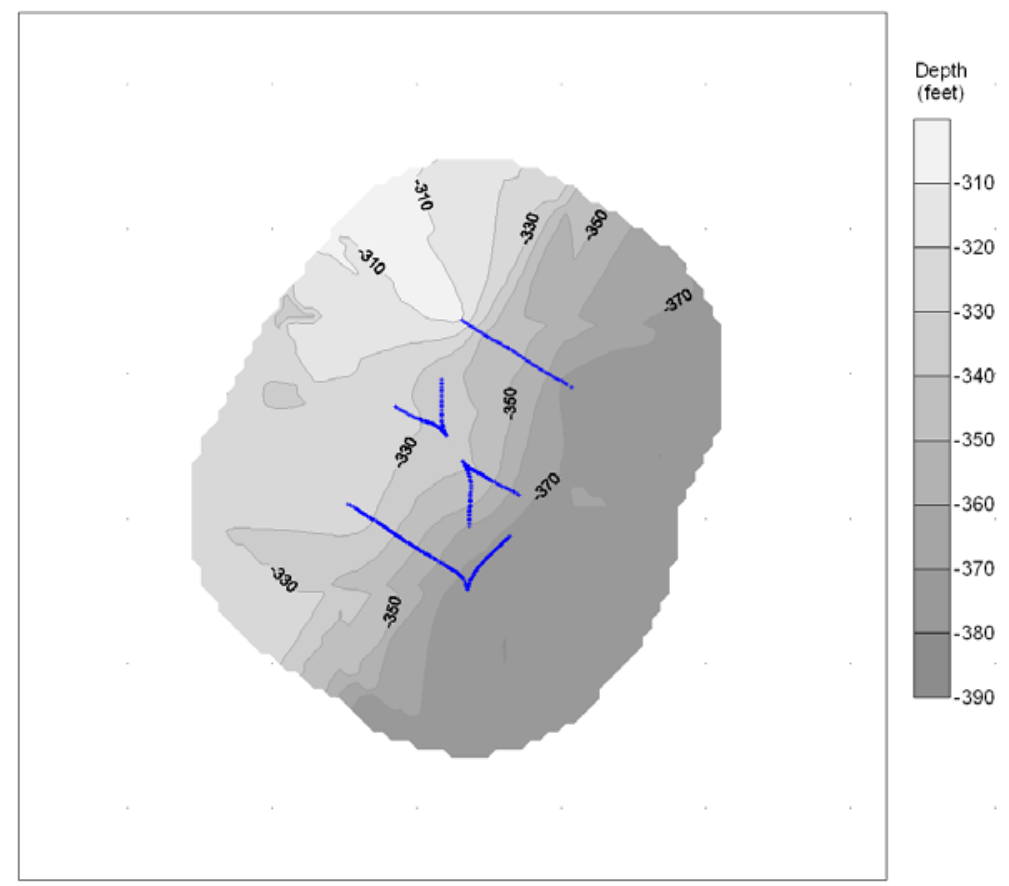

Note: Figure was generated based on available field data from CONSOL Energy (Winschel, 2009; Winschel, 2010).

Figure 3.14: Depth to Upper Freeport coal seam (feet) 


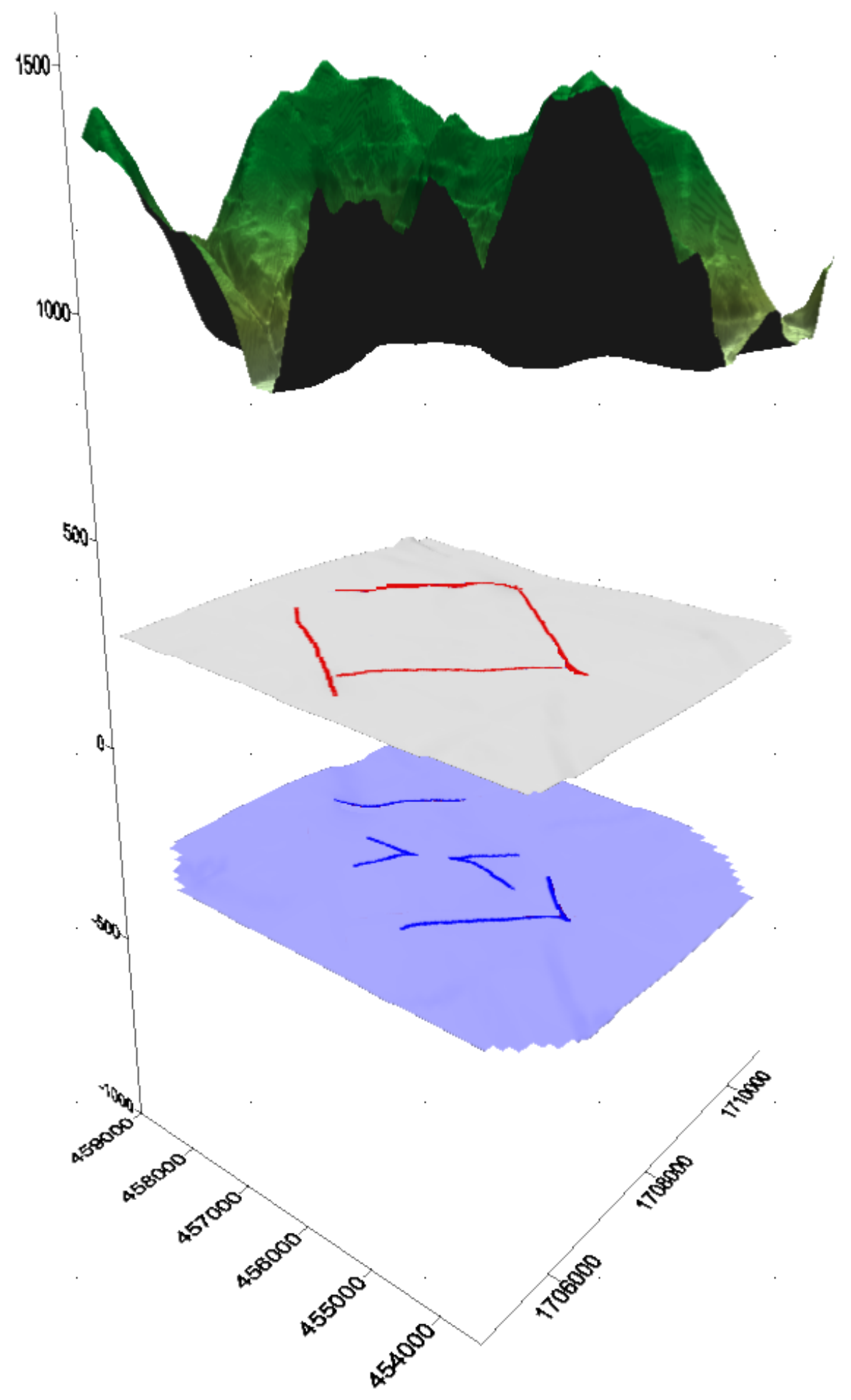

Note: Figure was generated based on available field data from CONSOL Energy (Winschel, 2009; Winschel, 2010).

Figure 3.15: 3-D perspective of coal seams with individual well configurations 


\subsection{Gas content and adsorption/desorption properties}

Several desorption tests were performed on coal samples and the data was made available by Consol Energy (Winschel, 2009). Based on the available data, gas content maps of Pittsburgh coal seam and Upper Freeport coal seam were generated and are presented in Figures 3.16 and 3.17, respectively. These gas content values are based on desorption tests performed on dry, ash free basis and include desorbed, residual and lost gases. On average, gas content values of 136 SCF/ton and 182 SCF/ton were obtained for the Pittsburgh and Upper Freeport coals near the study area. Similar gas content values (100-150 SCF/ton) were reported by Hunt and Steele (1991) for Pittsburgh coal from the Northern Appalachian coal basin. Reports also show that these gas content values may be functions of depth and degree of coalification (Kelafant and Boyer, 1998). Discussion related to variation of gas content values at different depths and for different coal ranks of Northern Appalachian coal basin can be found elsewhere (Kelafant and Boyer, 1988). Permeability values and gas content values for different coal groups of northern Appalachian coals can be found in published literature (Bruner, 1995). Moreover, anisotropic ratio (face cleat to butt cleat ratio) of 3.4 within the Upper Freeport coal formations has been found (McCoy et al, 2006). 


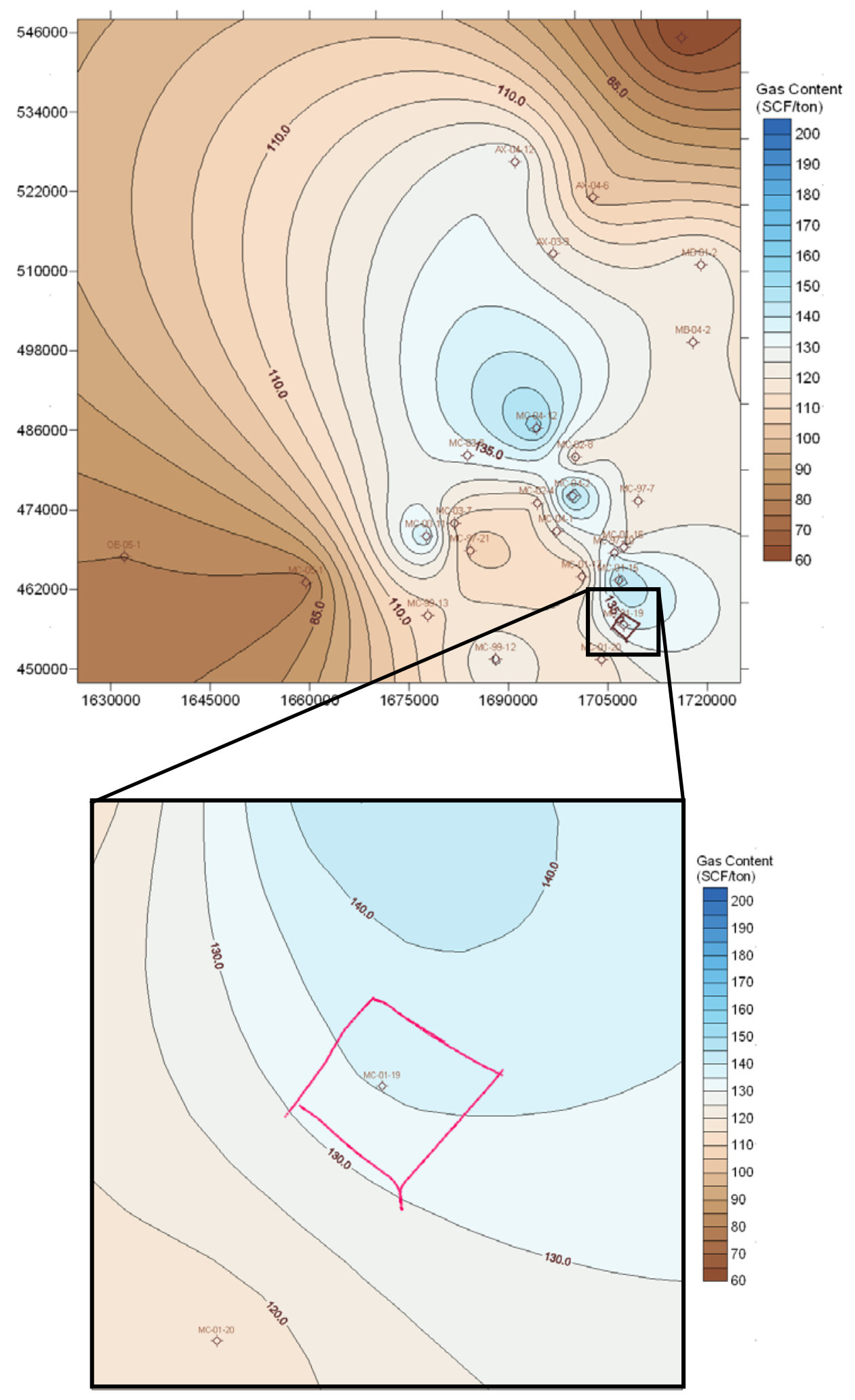

Note: Figure was generated based on available field data from CONSOL Energy (Winschel, 2009; Winschel, 2010).

Figure 3.16: Gas Content map for Pittsburgh coal seam (SCF/ton) 


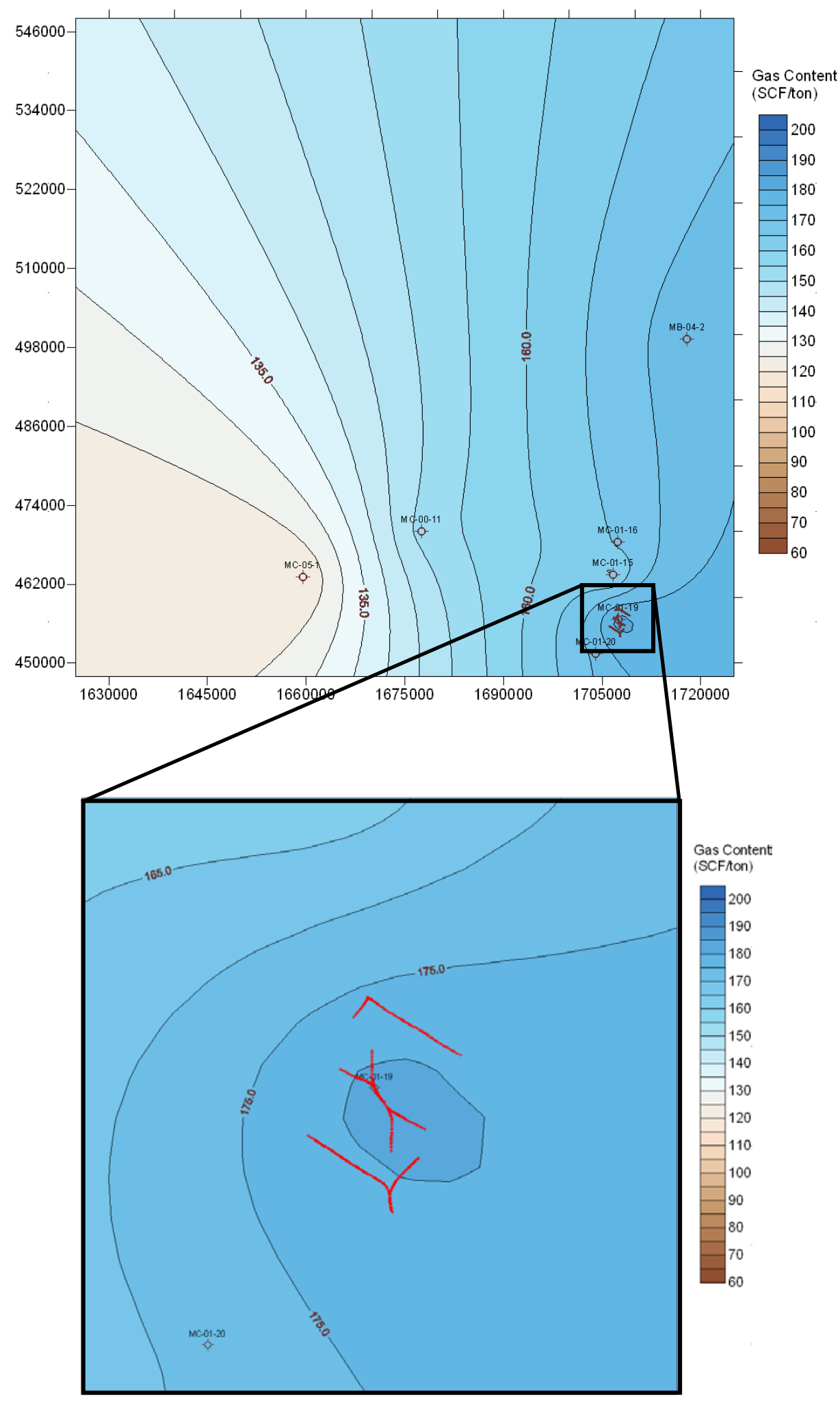

Note: Figure was generated based on available field data from CONSOL Energy (Winschel, 2009; Winschel, 2010).

Figure 3.17: Gas Content map for Upper Freeport coal seam (SCF/ton) 
Adsorption studies on coal samples from nearby core holes of both the Pittsburgh coal seam and Upper Freeport coal seam were performed by Consol Energy (Winschel, 2009). Adsorption isotherm tests similar to Mavor (1990) were performed at constant temperature conditions by exposing the coal samples to methane gas due to different pressure regimes until equilibrium was achieved. Adsorption tests were conducted on two nearby core hole samples of the Pittsburgh coal seam (MC-05-01 and MC-04-12). Figures 3.18 and 3.19 show the isotherm curves and adsorption plots for coal samples of the Pittsburgh coal seam. Methane isotherm curves and methane adsorption plots of these samples appear to give similar results with slight variations as seen in Figures 3.18 and 3.19. Only one core sample (MC-05-01) was available in the Upper Freeport coal layer near the area of interest. Similar methane adsorption tests were performed and the results are plotted in Figures 3.20 and 3.21. The effect of sorption isotherms on the methane production from horizontal wells and $\mathrm{CO}_{2}$ sequestration into horizontal wells can be found elsewhere (Bromhal et al, 2005).

Limited information was available on initial reservoir pressure. Therefore, a pressure gradient of $0.41 \mathrm{psi} /$ foot was selected to compute the initial reservoir pressure of Pittsburgh coal and Upper Freeport coal. A geothermal gradient of $1.5{ }^{0} \mathrm{~F} / 100$ foot and a mean annual temperature of $53.6{ }^{0} \mathrm{~F}$ was selected to estimate the formation temperatures of Pittsburgh and Upper Freeport coal. Initial reservoir conditions show that the coals are under-saturated and a delay in the desorption of gas was expected. Canister tests were performed on the samples of Pittsburgh coal and Upper Freeport coal and data was made available by Consol Energy. This data was helpful in estimating the delay in the desorption, desorption time or desorption coefficients. Behavior of gas transport and gas sorption in Pittsburgh coals can also be found in the literature (Jikich et al, 2009 ${ }^{\mathrm{a}}$ ). 


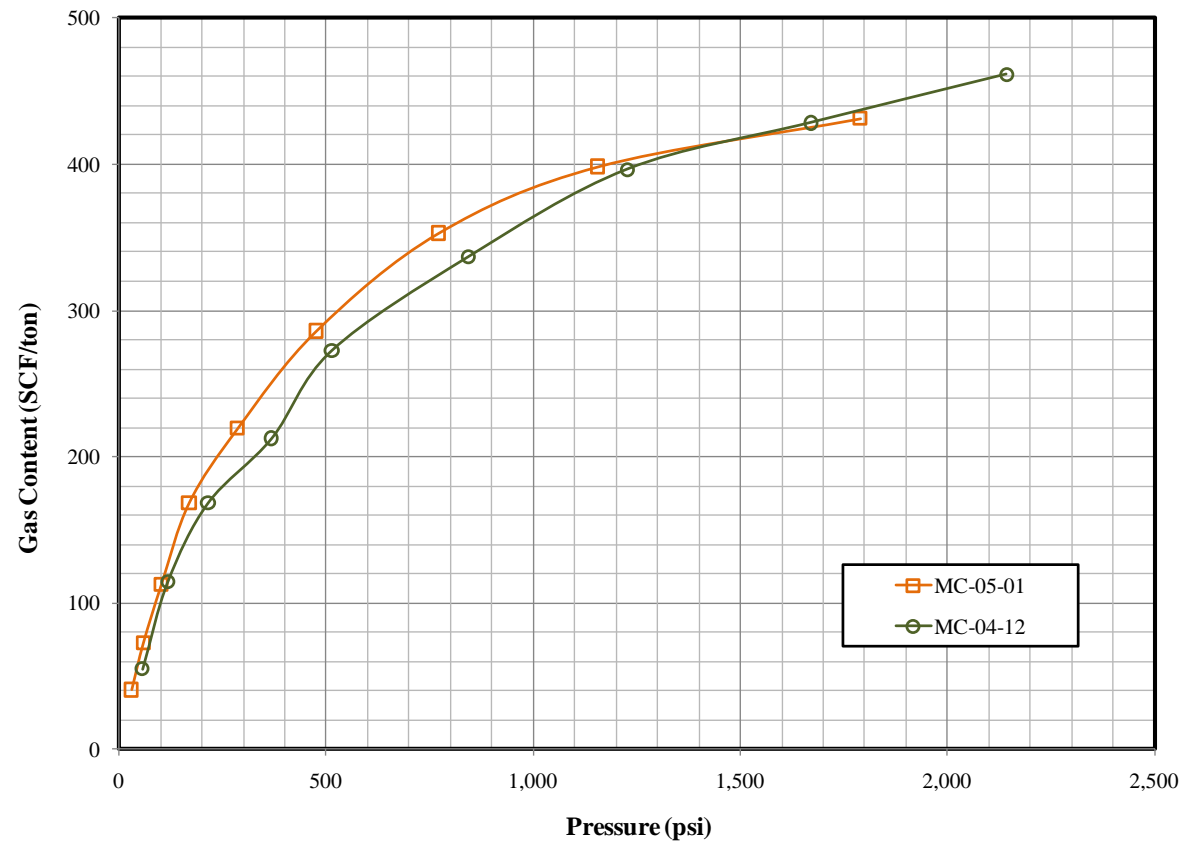

Note: Figure was generated based on available field data from CONSOL Energy (Winschel, 2009).

Figure 3.18: Isotherm curves of Pittsburgh coal seam

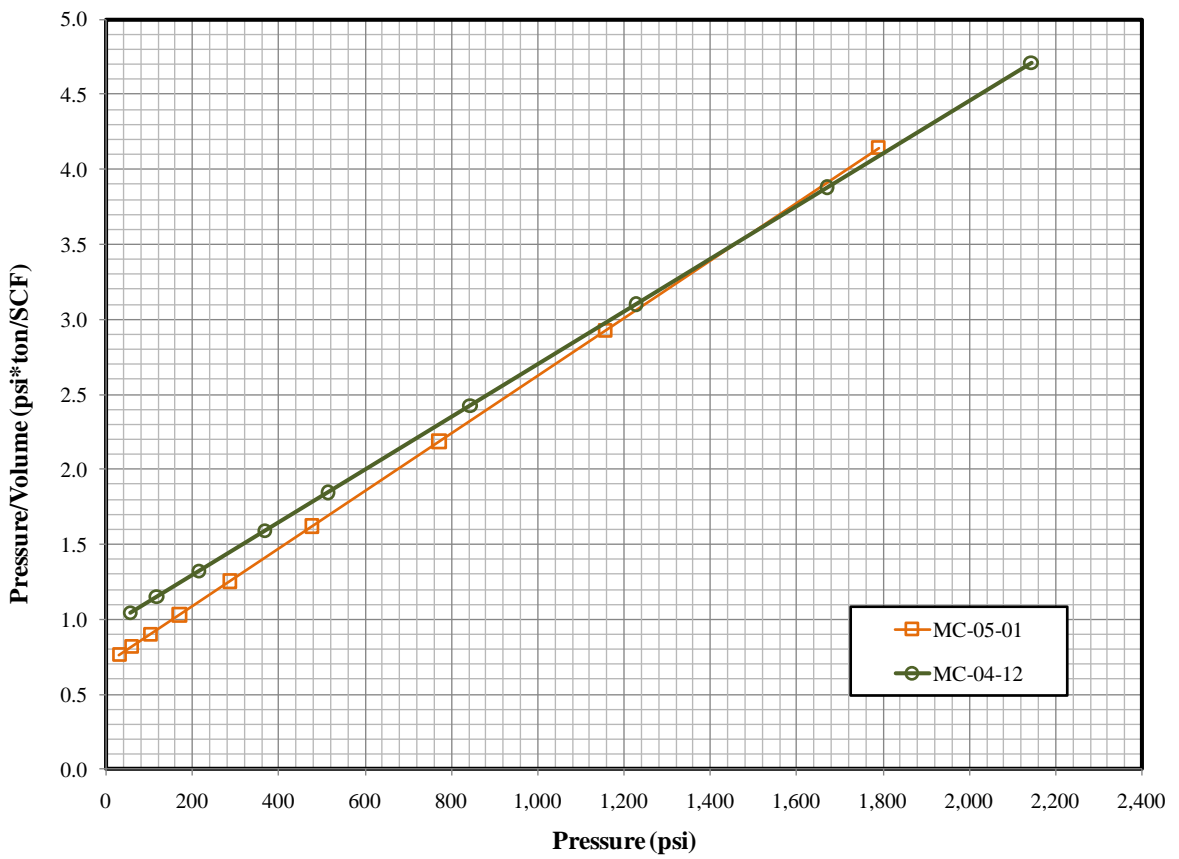

Note: Figure was generated based on available field data from CONSOL Energy (Winschel, 2009).

Figure 3.19: Adsorption curves of Pittsburgh coal seam 


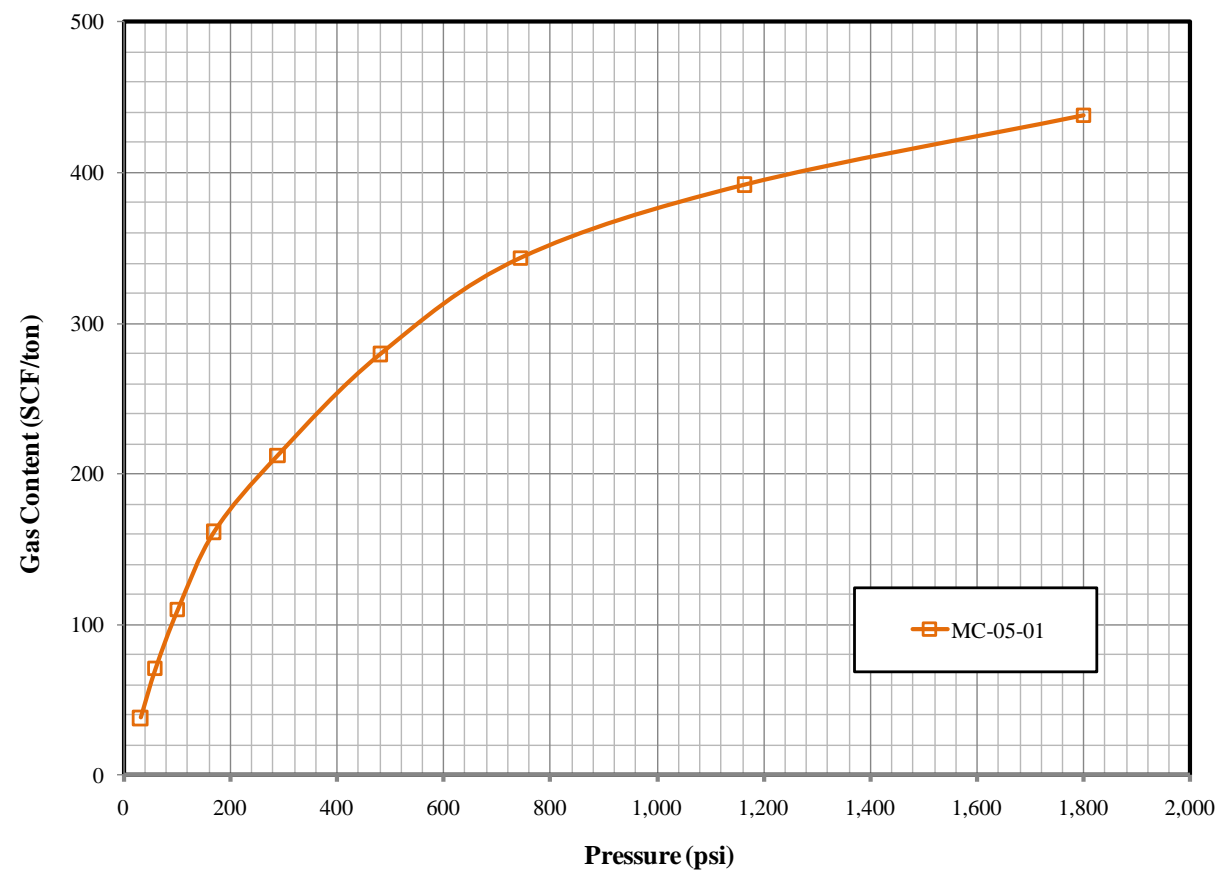

Note: Figure was generated based on available field data from CONSOL Energy (Winschel, 2009).

Figure 3.20: Isotherm curves of Upper Freeport coal seam

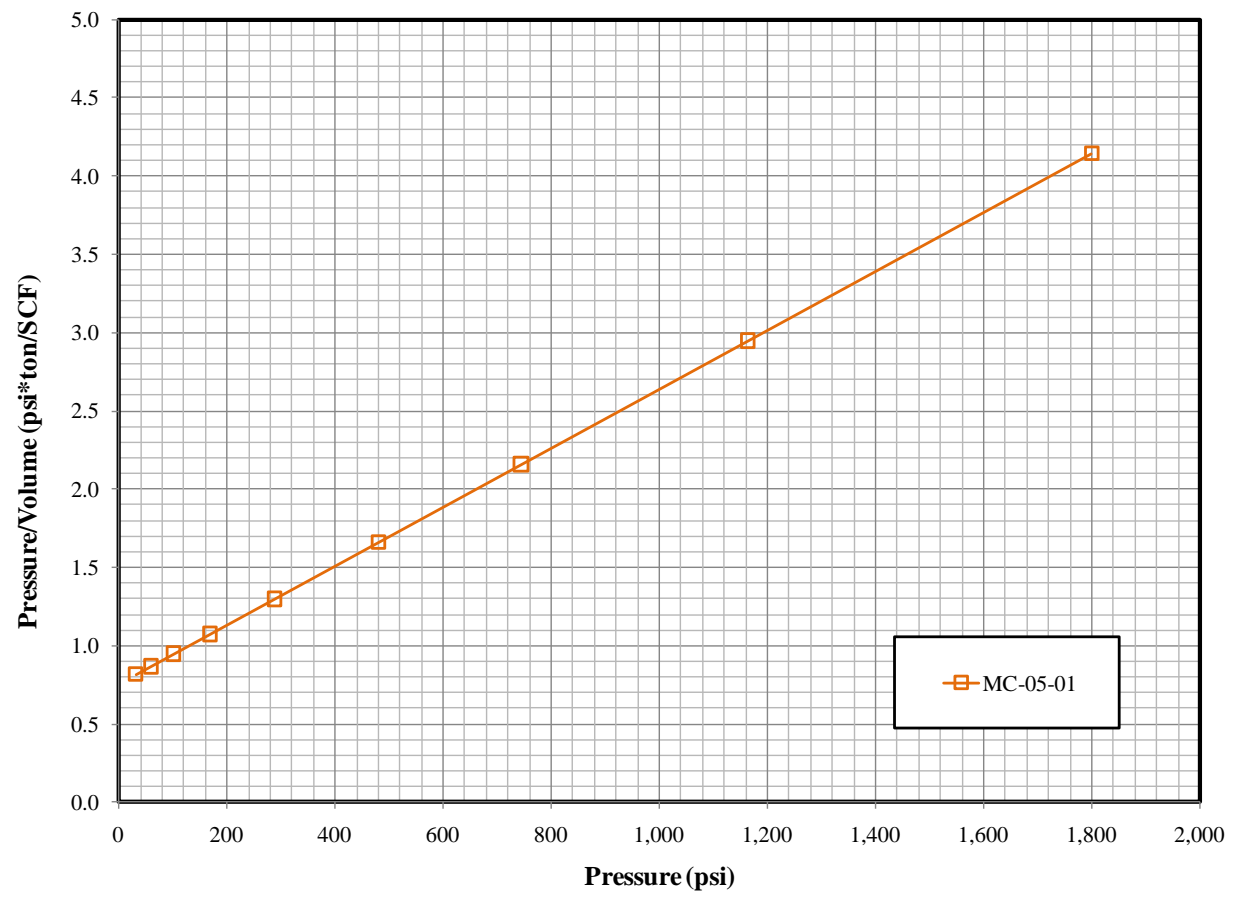

Note: Figure was generated based on available field data from CONSOL Energy (Winschel, 2009).

Figure 3.21: Adsorption curves of Upper Freeport coal seam 


\subsection{Production and injection details}

At the site, coalbed methane is being recovered from both coal seams. Figure 3.22 presents the comparison of gas production for all production wells (from both coal seams) based on the gas production data available at the field site.

MH-3 and two legs of MH-12 are active producers of the Pittsburgh coal seam with MH12 being a major producer as shown in Figure 3.22. Production from MH-12 started in 2004 with almost constant production rates of $400 \mathrm{MCF}$. The production well, MH-12 is still active with an current average production of approximately 200 MCF per day (Winschel et al, 2010). Production from MH-3 started in 2006, and production rates are much lower than MH-12. Production from MH-3 and MH-4 of Pittsburgh coal seam were periodic.

MH-11, MH-18 and MH-20 of Upper Freeport coal seam started producing in 2005, and MH-5 of Upper Freeport coal became active in 2006 with periodic shut-in's. In 2007, production from the central production wells of the Upper Freeport coal seam ( $\mathrm{MH}-18$ and $\mathrm{MH}-20)$ was ceased. Later, these wells (MH-18 and MH-20) were converted to injection wells after sufficient reservoir depletion with $\mathrm{CO}_{2}$ injection beginning September 2009 (Winschel et al, 2010). Figure 3.23 represents the time line chart of the production and injection in both coal seams. Limited data was available for reservoir pressure.

In the current project, about 20,000 tons of liquid $\mathrm{CO}_{2}$ was planned to inject using centrally located injection wells (MH-18 and MH-20) into lower unmineable Upper Freeport coal seam. $\mathrm{CO}_{2}$ injection began in September 2009, and as of now, about 1,000 tons of $\mathrm{CO}_{2}$ has been injected at maximum injection pressures of 700 psi (Winschel et al, 2010). Figure 3.24 and 3.25 show the injection pressures and injection volumes of $\mathrm{MH}-18$ and $\mathrm{MH}-20$. Future plans are to increase the injection pressure to 933 psi and inject $\mathrm{CO}_{2}$ at a rate of 27 short tons per day to meet the goal of the project (Winschel et al, 2010). More details on the field operations can be found elsewhere (Winschel et al, 2010). 


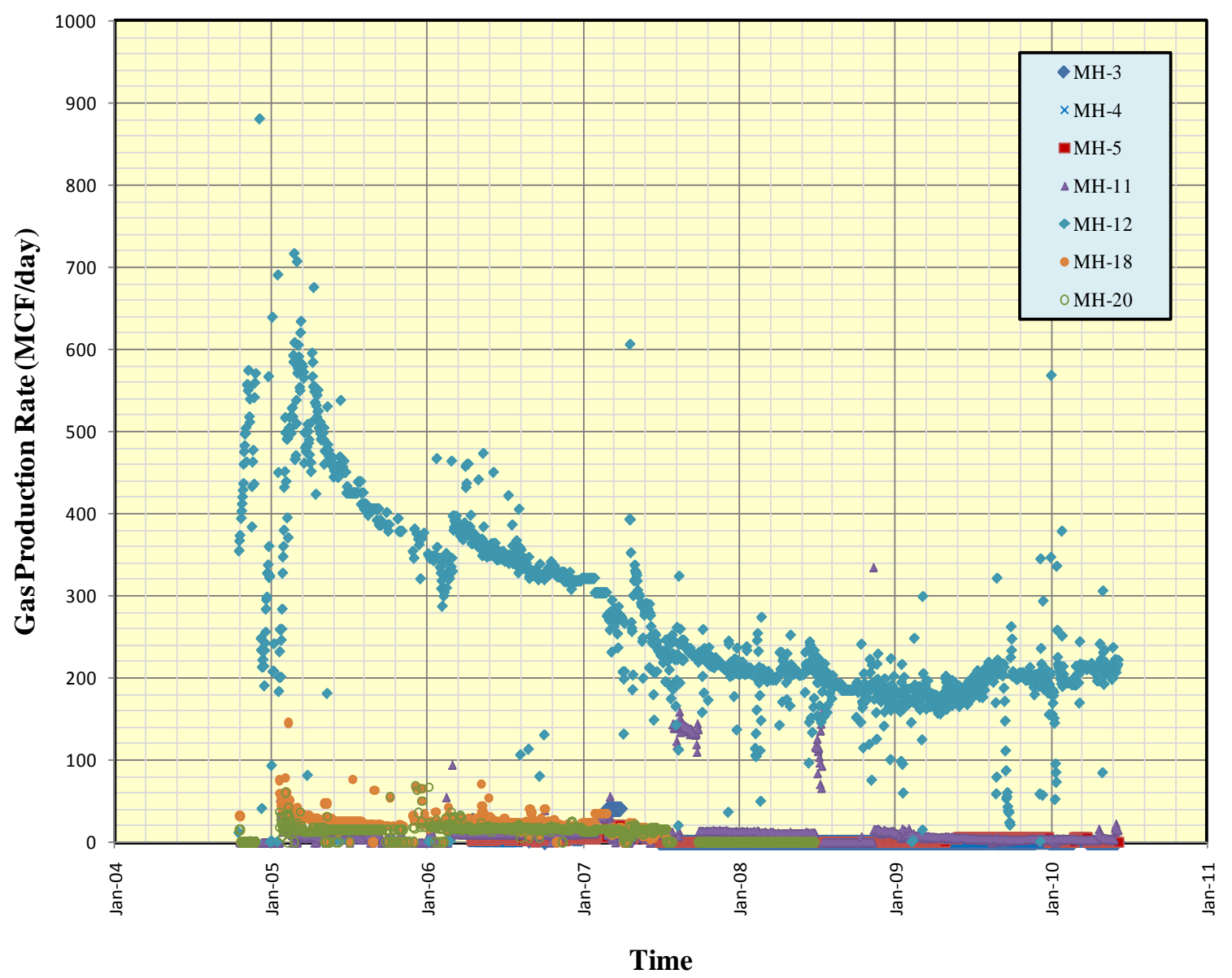

Note:

1. Gas production data was available from CONSOL Energy (Winschel, 2009; Winschel, 2010).

2. MH-12 of Pittsburgh coal seam has higher gas production rates compared to other wells

3. Production from MH3, MH-4 and MH-5 were sporadic or periodic.

Figure 3.22: Comparison of gas production for all wells 
Pittsburgh coal seam (Upper Coal Seam)

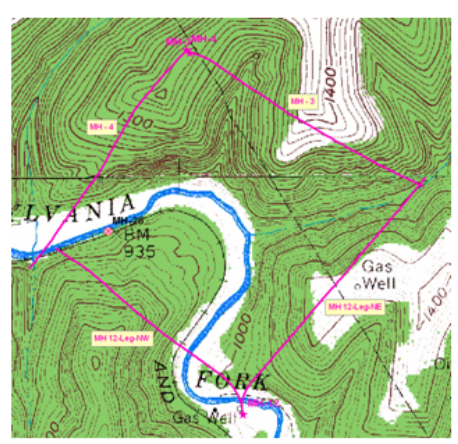

\begin{tabular}{|c|c|c|c|c|c|c|c|}
\hline \multirow{2}{*}{$\begin{array}{l}\text { \# Recurrent } \\
\text { Items }\end{array}$} & 2004 & 2005 & 2006 & 2007 & 2008 & 2009 & 2010 \\
\hline & 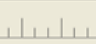 & 1111 & $\mid$ & 1111 & 11111 & 11111 & $\left.\perp_{1,1}\right|_{1,}$ \\
\hline \multicolumn{8}{|l|}{ Wells } \\
\hline MH-12 & & & & & & & 1 \\
\hline MH-3 & & & $\bullet$ & & & & 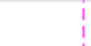 \\
\hline & & & & & & & 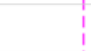 \\
\hline
\end{tabular}

CBM Production

$\mathrm{CO}_{2}$ Injection began on September 08, 2009

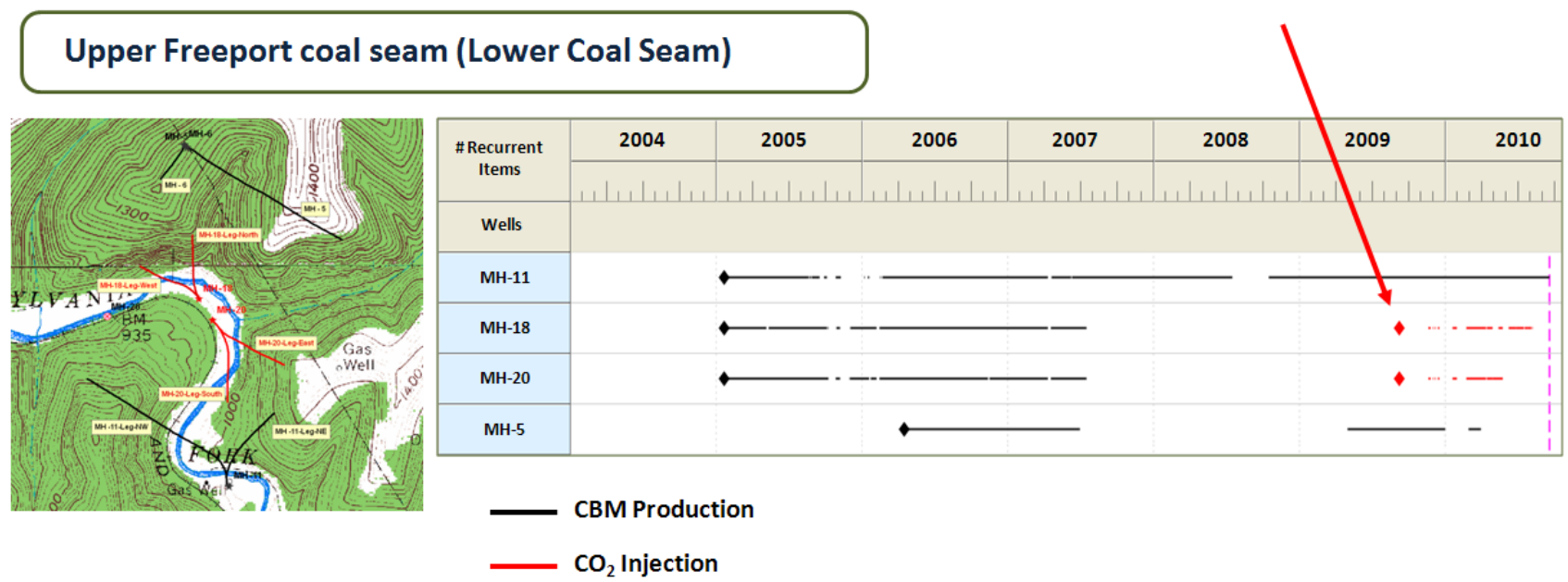

Note:

1. Gas production and $\mathrm{CO}_{2}$ injection data was available from CONSOL Energy (Winschel, 2009; Winschel, 2010).

2. Gas production from MH-12 was consistent when compared to other production wells

3. MH-4 is shut-in well and therefore not included.

4. $\mathrm{CO}_{2}$ injection began on September 08, 2009 with periodic shut-in's.

Figure 3.23: Time-line of $\mathrm{CBM}$ production and $\mathrm{CO}_{2}$ injection 


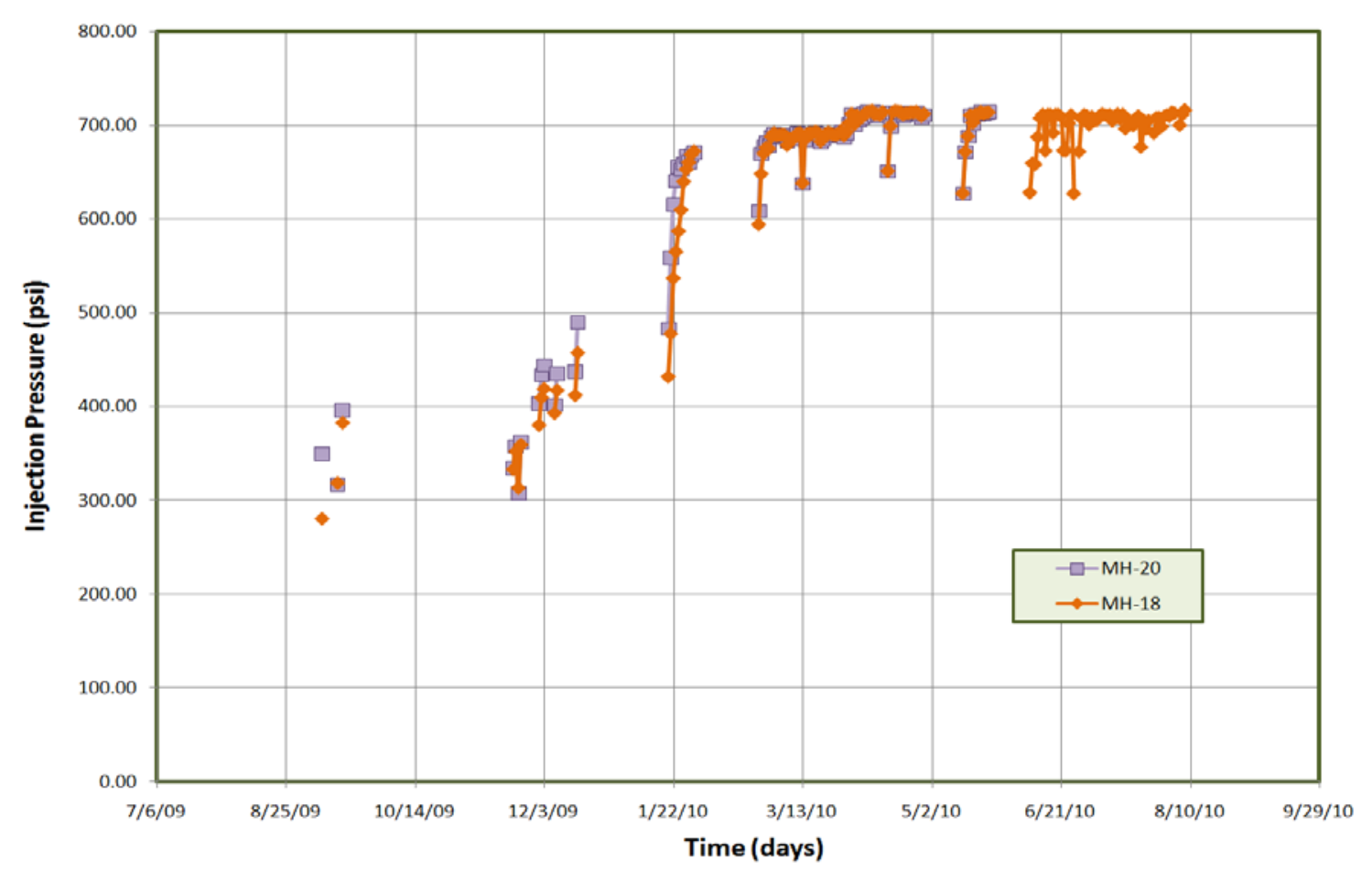

Note: Data was made available by CONSOL Energy (Winschel, 2009; Winschel, 2010).

Figure 3.24: Injection pressures of $\mathrm{MH}-18$ and $\mathrm{MH}-20$

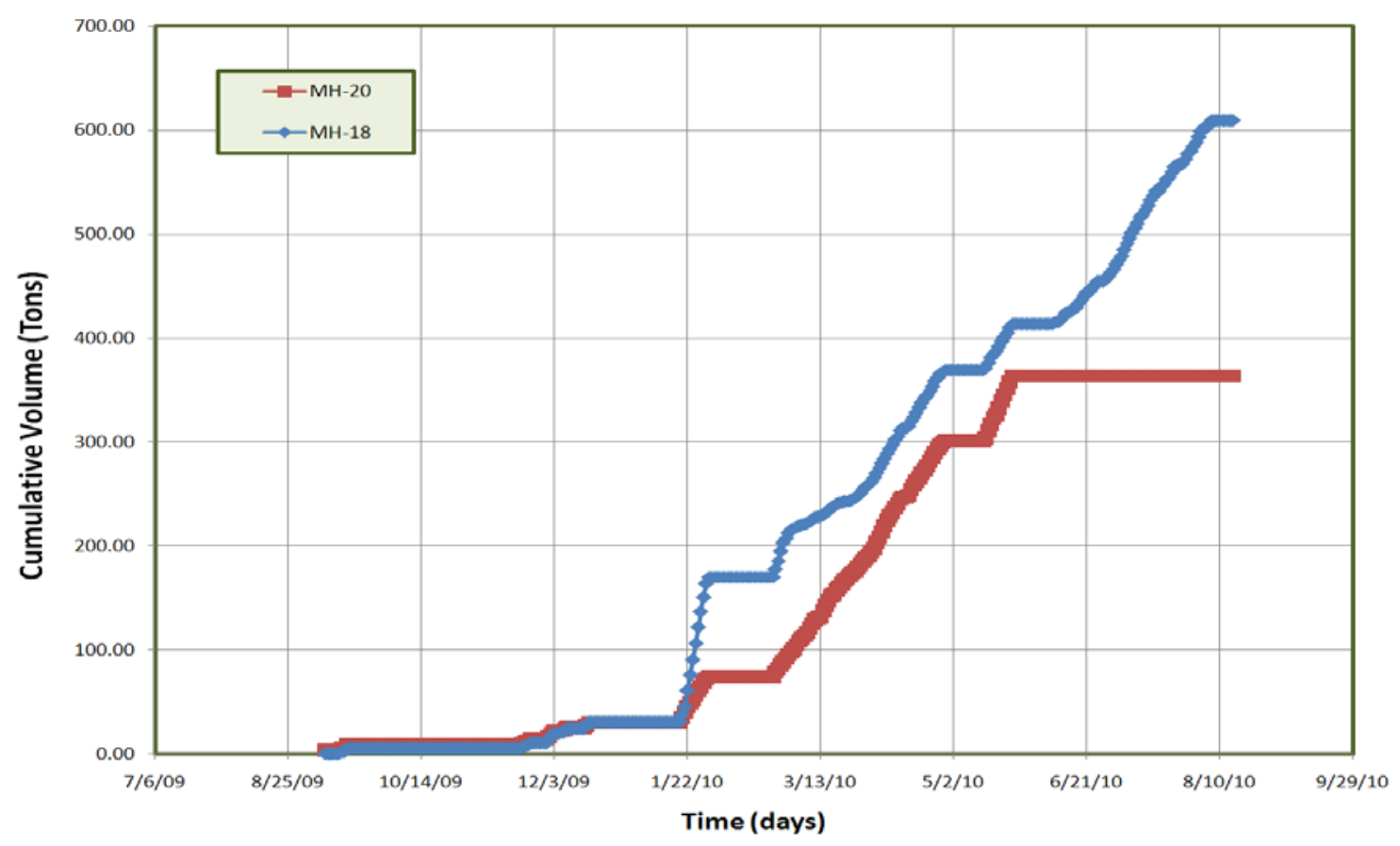

Note: Data was made available by CONSOL Energy (Winschel, 2009; Winschel, 2010).

Figure 3.25: Injection volumes of $\mathrm{MH}-18$ and $\mathrm{MH}-20$ 


\section{CHAPTER 4: FIELD MONITORING OF SURFACE DEFORMATIONS DURING $\mathrm{CO}_{2}$ INJECTION}

\subsection{Introduction to monitoring technologies}

Monitoring is important to geologic sequestration of carbon dioxide for several reasons. It helps in identifying any potential $\mathrm{CO}_{2}$ leaks and provides sequestration stability and feasibility by providing an understanding of the overall response of the system. Monitoring also helps in determining the longevity of $\mathrm{CO}_{2}$ storage in underground repositories. Several monitoring technologies are available to monitor physical and chemical reactions, fluid flow, leakage pathways, structural integrity and storage potential in published literature. Also, the use of near surface monitoring techniques such as groundwater monitoring, tracer isotopes and $\mathrm{CO}_{2}$ flux accumulations have been reported in $\mathrm{CO}_{2}$ sequestration projects (Koperna et al, 2009). Recently, surface and sub-surface monitoring techniques such as use of tiltmeters and InSAR have also been reported to study the ground response and the behavior of fluid flow. But, limited information is available on the use of such high-precision tools during geologic sequestration of $\mathrm{CO}_{2}$. In the current research study, high-precision titlmeters and GPS units were installed at the

field site (discussed in Chapter 3) to monitor ground deformations caused by $\mathrm{CO}_{2}$ injection and to investigate the migration of $\mathrm{CO}_{2}$ in the reservoir. Details of tiltmeters, site survey, installation, array design, data collection and methodology are presented in this chapter. Also, field monitoring results with a comparison to previous studies have been reported.

\subsection{Advantages and disadvantages of InSAR and tiltmeters}

Use of leading technologies such as InSAR and high-precision surface and subsurface tiltmeters have now become common in the oil and gas industries for real-time monitoring of fluid flow, overburden response and hydrofracturing (Wright et al, 1998; Meyerhofer et al, 2000; Davis et al, 2000; Davis et al, 2005; Mirnov et al, 2008). Their use along with integration of GPS stations has also been reported in several ground monitoring studies (Rutqvist et al, 2010; Maxwell et al, 2008; Du et al., 2007). Techniques such as conventional surveying, GPS surveying and trilateration can be used to measure ground elevations. However, it has been 
reported in the literature that the use of surface monitoring tools such as high-precision tiltmeters and InSAR have cut down data acquisition costs, enhanced the precision and improved the reporting time (Davis et al, 2000; Du et al, 2005; Davis et al, 2005; McColpin, 2009). Advantages and disadvantages of InSAR and tiltmeters are presented below to identify the suitable technology that is best fit for the field site used in this study.

\subsubsection{InSAR}

InSAR (Interferrometric Synthetic Aperture Radar) provides an incredible advantage to field sites with large areal extents and long-term monitoring plans (McColpin, 2009). One of biggest advantages of InSAR's data collection process is that no tools or equipment are required to be placed on the surface or subsurface. The deformation measurements are directly collected using satellites, therefore, reducing the noise and equipment installation time due to drilling. InSAR based measurements can extend across vast areas with pixel resolutions of up to 30 feet (10 meters) using RADARSAT or 100 feet (30 meters) using ENVISAT and ERS satellites. Electromagnetic radiation emitted through these satellite sources are recorded and checked for any changes in the signal strength and delay time (McColpin, 2009; Davis et al, 2005). The path difference in the satellites and recorded difference in phase shifts is reported to capture any interference between the two phase signals obtained between satellite passes. These changes in interference images can be used to measure surface deformations over a period of time using multiple passes or by combining InSAR technology with georeferencing or with integration of a few GPS instruments (Davis et al, 2005). In order for this technique to work accurately, a good surface correlation and coherence of interference acquisition images was suggested (Davis et al, 2005). Usually, correlations of these images are not believed to be accurate with seasonal changes and dense vegetation. Also, they can be very effective in covering large areal extents with long-term monitoring objectives. More details on the use of InSAR in real-time monitoring of geologic sequestration of carbon dioxide can be found in published literature (Onuma et al, 2008; Koperna et al, 2009; Davis et al, 2005). 


\subsubsection{Tiltmeters}

Tiltmeters are very sensitive tools capable of measuring tilts with a precision of up to one nano-radian. A network of tiltmeters can be used to measure displacements in the sub-millimeter range for surface expansion or subsidence caused due to fluid injection or fluid extraction. In the past, high precision tiltmeters have been extensively used in studies related to earthquakes, volcanoes, landslides, oil and gas applications, hydraulic fractures and structures influenced by stresses and settlements (www.Pinntech.com, Wright et al, 1998; Meyerhofer et al, 2000; Mirnov et al, 2008). For example, in hydraulic fracturing, these instruments deliver large signals as the injected fluid migrates towards the ground surface. In another example, during steam injection studies, these high-precision deformation monitoring tools have proven to provide constant updates on fluid movements and notify warnings of any fluid intrusion into inadvertent regions (Kramn et al , 2005; Walser et al, 2009). In addition to surface tiltmeters, downhole tiltmeters have also been used to determine reservoir-level strains. Ground displacements are caused due to geomechanical strains associated with changes in volume, stresses, temperature, or pore pressure.

In order to investigate the flow of injected fluid and ground response caused by $\mathrm{CO}_{2}$ injection, a tiltmeter technology similar to the steam injection method was proposed in the literature (Davis et al, 2005). Usually, a set of tiltmeters are deployed to capture the ground measurements caused due to fluid injection in this field monitoring method. Data on tilts and elevation changes are usually collected and processed on a regular basis with a central processing unit located at the field site. Field monitoring using tiltmeters could be an expensive task, especially for covering large areas. However, the precision of tiltmeters is high compared to InSAR and can be installed at sites that are expected to cause minimal ground changes. Given below are some criteria for selecting the best fit ground monitoring technology at the field site used in the current research work:

- The surface deformations obtained from InSAR technology are less precise when compared to measurements obtained from integration of high-precision tiltmeters and GPS units. 
- InSAR may not be best suitable technology in areas with thick vegetation and seasonal changes. Seasonal changes and thick vegetation may provide bad coherence and record discrepancies. Such discrepancies associated with ground reflectivity are reported to cause a de-correlation between contributing SAR images on interferrogram leading to InSAR's failure (Davis et al, 2005).

- Continuous ground deformation measurements may not be available as InSAR measurements are obtained only when the satellite is overhead of the field site.

\subsection{Ground monitoring objectives at the field site}

Monitoring of fluid flow and ground response due to injection is critical for optimization of any $\mathrm{CO}_{2}$ storage reservoir. In the current study, the primary objective is to monitor any fieldscale ground deformations caused by injection of $\mathrm{CO}_{2}$ in the depleted Upper Freeport coal seam. A tiltmeter study was performed to interpret overburden response of the reservoir due to injection of $\mathrm{CO}_{2}$ at the field site and to investigate the migration or flow of injected $\mathrm{CO}_{2}$ in the reservoir. Factors such as hilly ground terrain, thick vegetation and seasonal changes made the site extremely difficult and challenging to work with. Therefore, the use of tiltmeters integrated with a few GPS units was identified as the best suitable monitoring technology to investigate the overburden response of the field site used in the present study. Thirty-six high precision tiltmeters and two GPS units have been installed at the field site to record deformation measurements with a precision of up to the sub-millimeter range. Such sensitivity of these instruments allow them to pick-up earth tides and other events related to ground movement. For example, Figure 4.1 presents the earth tides recorded by one of the tiltmeters installed at the field site in the current study. The installation and monitoring of these tiltmeters and differential GPS units was carried out with the help of Pinnacle Technologies. 


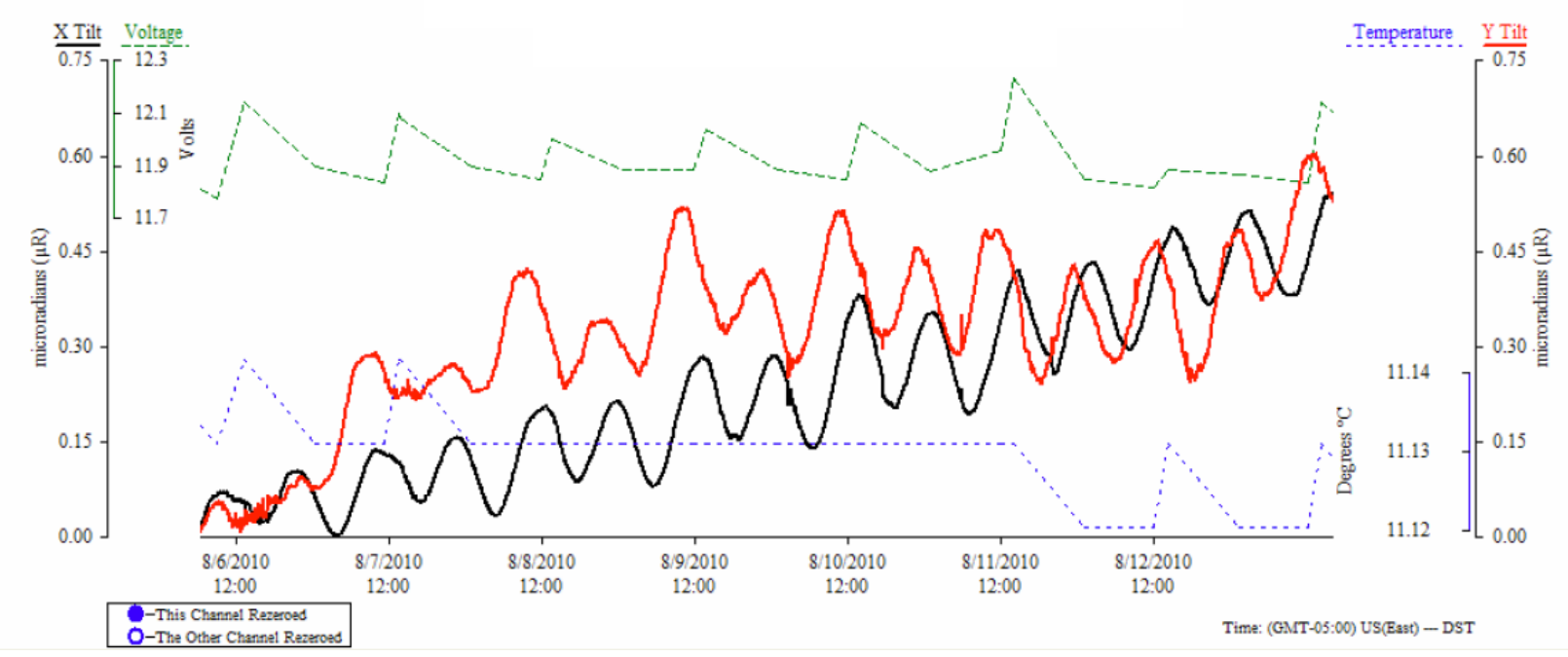

(Courtesy: Pinnacle Technologies)

Figure 4.1: Tilt measurements due to earth tides

The network of high-precision tiltmeters and different GPS stations installed at the field site can be used to monitor:

1. changes in surface gradients (or elevations) with respect to time due to $\mathrm{CO}_{2}$ injection

2. migration of injected $\mathrm{CO}_{2}$ covering the injection region and extending towards the periphery of lateral production wells

3. any reservoir-level strains caused due to surface expansions or subsidence during CBM extraction or $\mathrm{CO}_{2}$ injection, and

4. upward or horizontal fracture growth, if any

In order to interpret the results and accurately analyze the surface deformations obtained by tiltmeters, the tilt data is integrated with field operational data and reservoir data such as production rates, injection rates, and injection volumes. 


\subsection{Overview of surface tiltmeters}

Tiltmeters are the most sensitive available technology to map any surface or sub-surface elevation changes. A tiltmeter is very sensitive tool designed to record any changes in surface or subsurface tilts with abilities to measure tilts up to one nanoradian (Du et al, 2005; Du et al, 2008). A tilt changes of up to one nanoradian could be equivalent to measuring a quarter inch between New York and San Francisco as reported elsewhere (www.Pinntech.com). Surface deformations can be measured in the sub-millimeter range by calibrating these instruments by mapping out earth tides as suggested (Davis et al, 2005). Typically, they measure their own tilt on two orthogonal axes. It consists of a glass tube with a gas bubble contained within a conductive liquid as shown in the Figure 4.2. The air bubble contained in the conductive fluid moves to maintain its alignment with the local gravity vector when the electronic instrument tilts (Du et al, 2005). As the bubble moves, the sensors in the instrument get activated to record the resistivity between electrode changes (Du et al, 2005; www.Pinntech.com).

\subsection{Monitoring array of surface tiltmeters}

In general, an array of surface tiltmeters is deployed covering an injection region and boundary of interest to monitor surface deformations caused due to any strains associated with changes in volume, stresses, temperature, or pore pressure in the underground geologic system. Figure 4.3 shows a schematic diagram of a network of tiltmeters integrated with absolute and remote GPS stations deployed near a injection point. As each project is different, an adapted array design may be required depending on the project's unique requirements, site accessibility and tradeoff's. Surface deformations caused due to injection of fluid in the underground reservoir may not only be confined to injection region at all times, but also expand outside the boundary of the injection region. Mostly, surface deformations are expected to spread out over a larger area with greater injection depths (Davis et al, 2005). Hence, these instruments are placed covering the injection region and extended area. 


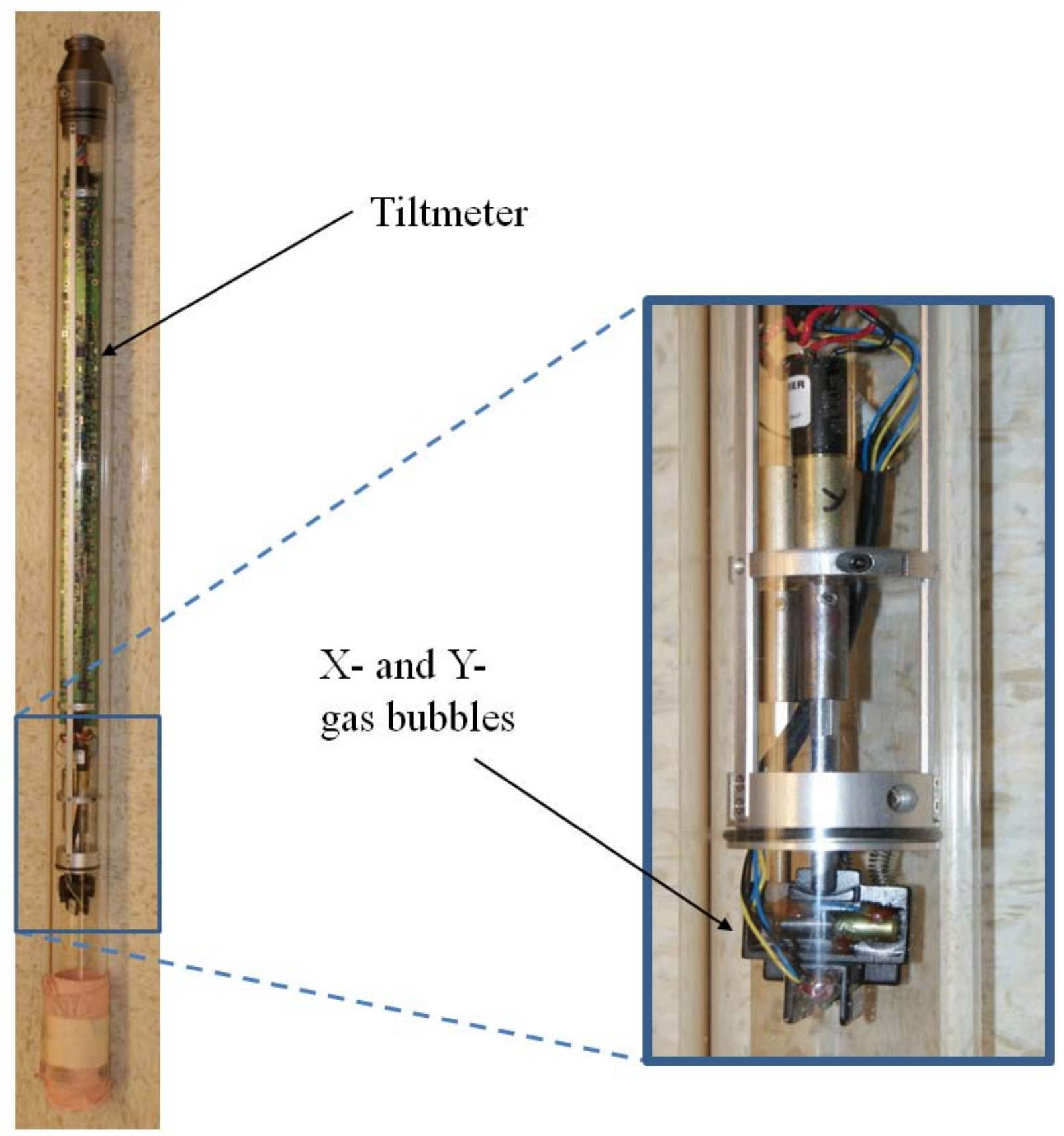

Figure 4.2: A detailed view of tiltmeter 


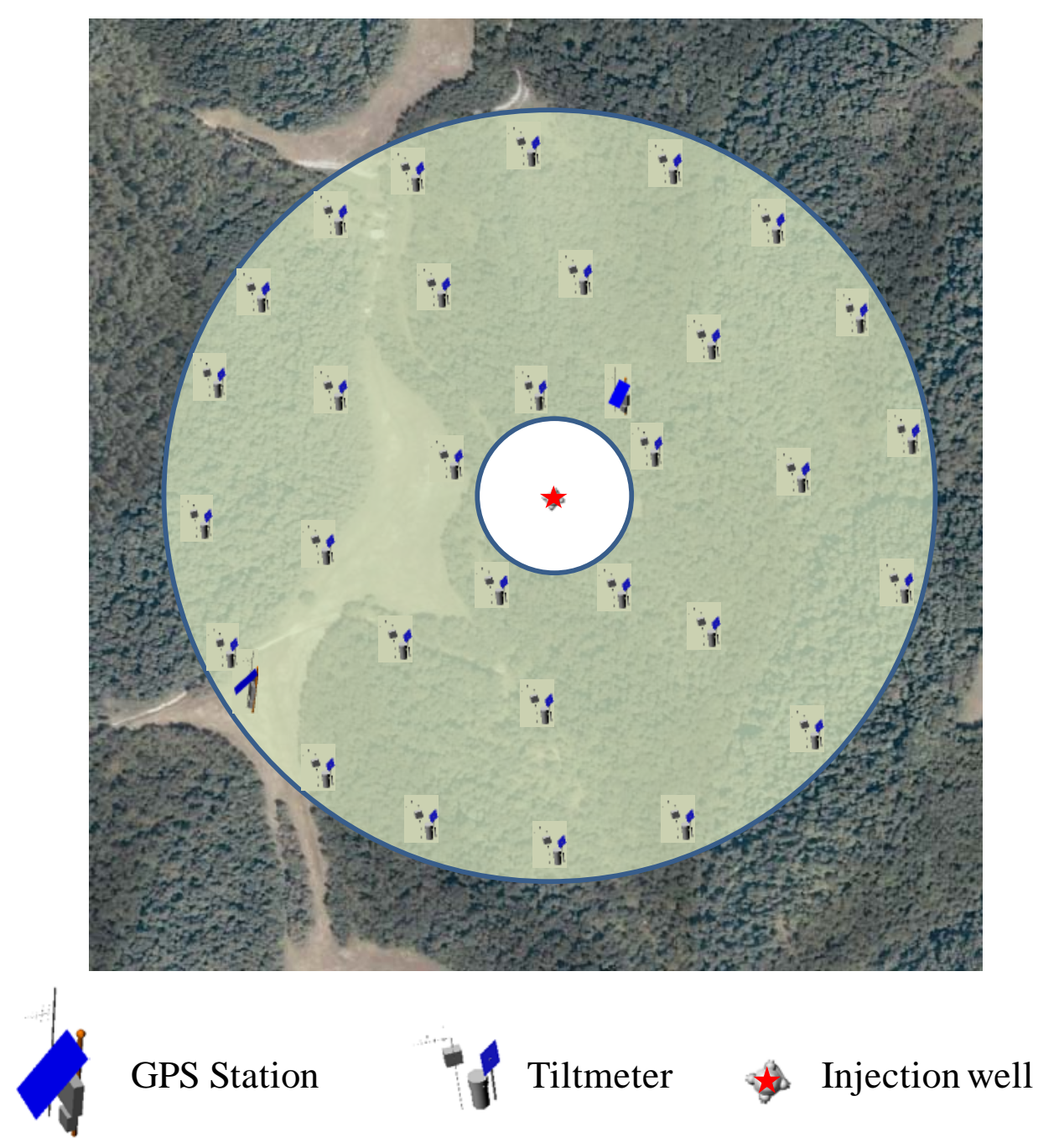

Figure 4.3: A schematic diagram of tiltmeter monitoring array

Published literature shows that the injection depth is proportional to aerial spread and inversely proportional to deformation magnitudes (Davis et al, 2005). In other words, surface deformations caused due to deep injection sources will result in small magnitudes but will spread out over a larger area. Conversely, surface deformations caused due to shallow injection sources may result in larger magnitudes but spread out to a smaller area. The spacing and density of tiltmeter stations and GPS units within the monitoring array is reported as a function of near monitoring depth, not necessarily the injection depth (Davis et al, 2005). In general, the tiltmeter spacing is reported to be roughly about one third of the shallowest monitoring depth (Davis et al, 2005). 
During the idealization and the customization of the monitoring array for the specific project site, it is also imperative to consider the overall density and any voids in the array. Several different lay-out's of the network are configured and ultimately a reasonable pattern is chosen to ensure sufficient density of tiltmeters to capture changes in tilts and elevations at the field site. Limited information is available in the literature on the quantification of the required number of tiltmeters and GPS stations.

Since most of the tiltmeters use electrolytic sensors that undergo some degrees of drift, it is believed uncertainty in tiltmeter based elevation changes is a function of tiltmeter spacing and time (Davis et al, 2005). Such uncertainties in tilt measurements may be much higher in longterm monitoring projects (Davis et al, 2005). Hence, GPS units are integrated with tiltmeter array to reduce these uncertainties. Figure 4.3 illustrates an example a base and a remote GPS station located in the monitoring array. Other possible solutions such as short-term shut-in's during long-term injections are also reported (Davis et al, 2005). Since GPS units are more expensive than tiltmeters, only a few GPS stations are deployed at the field site. The GPS locations were picked in such a way that the maximum distance from any point in the tiltmeter monitoring array to the nearest GPS location is minimized, thereafter reducing the uncertainties associated with measurements of ground deformations as a whole (Davis et al, 2005).

\subsection{Installation of tiltmeters and GPS units}

In the current research work, a total of 36 tiltmeters and two GPS stations (absolute/base reference and remote) were installed near the central site of the $\mathrm{CO}_{2}$ injection region at the field site. The monitoring array was customized and idealized to the project site based on the site accessibility, topography and array requirements. The first step of the installation procedure was to come up with a tentative plan to locate potential tiltmeters in and around the injection region based on ground topography and other known constraints. Wooden stakes were placed into ground at the surveyed locations of 36 tiltmeters and two GPS units as shown in the Figure 4.4. The rough terrain and dense woods at the field site made the installation of these equipment extremely difficult. Figures 4.5 and 4.6 show the rough terrain at the field site. 

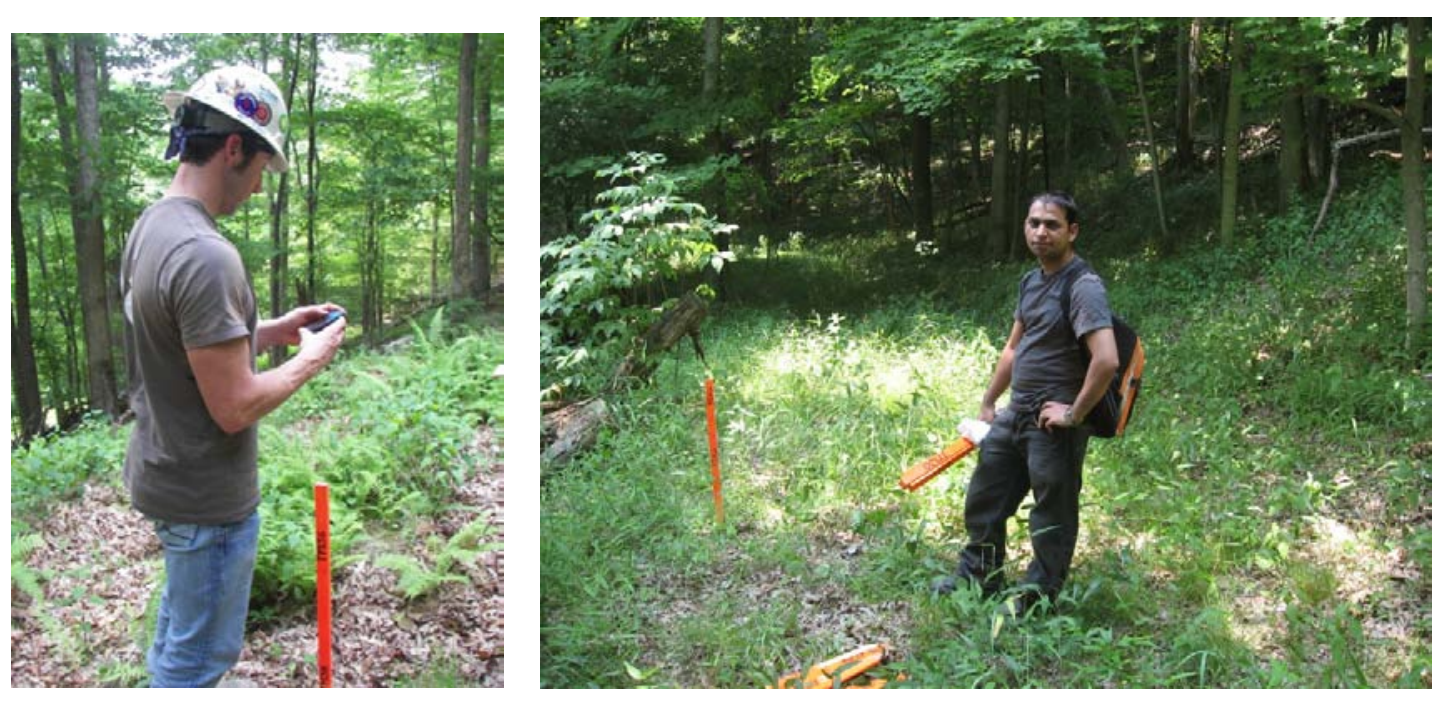

Figure 4.4: Surveying and positioning of potential tiltmeter locations

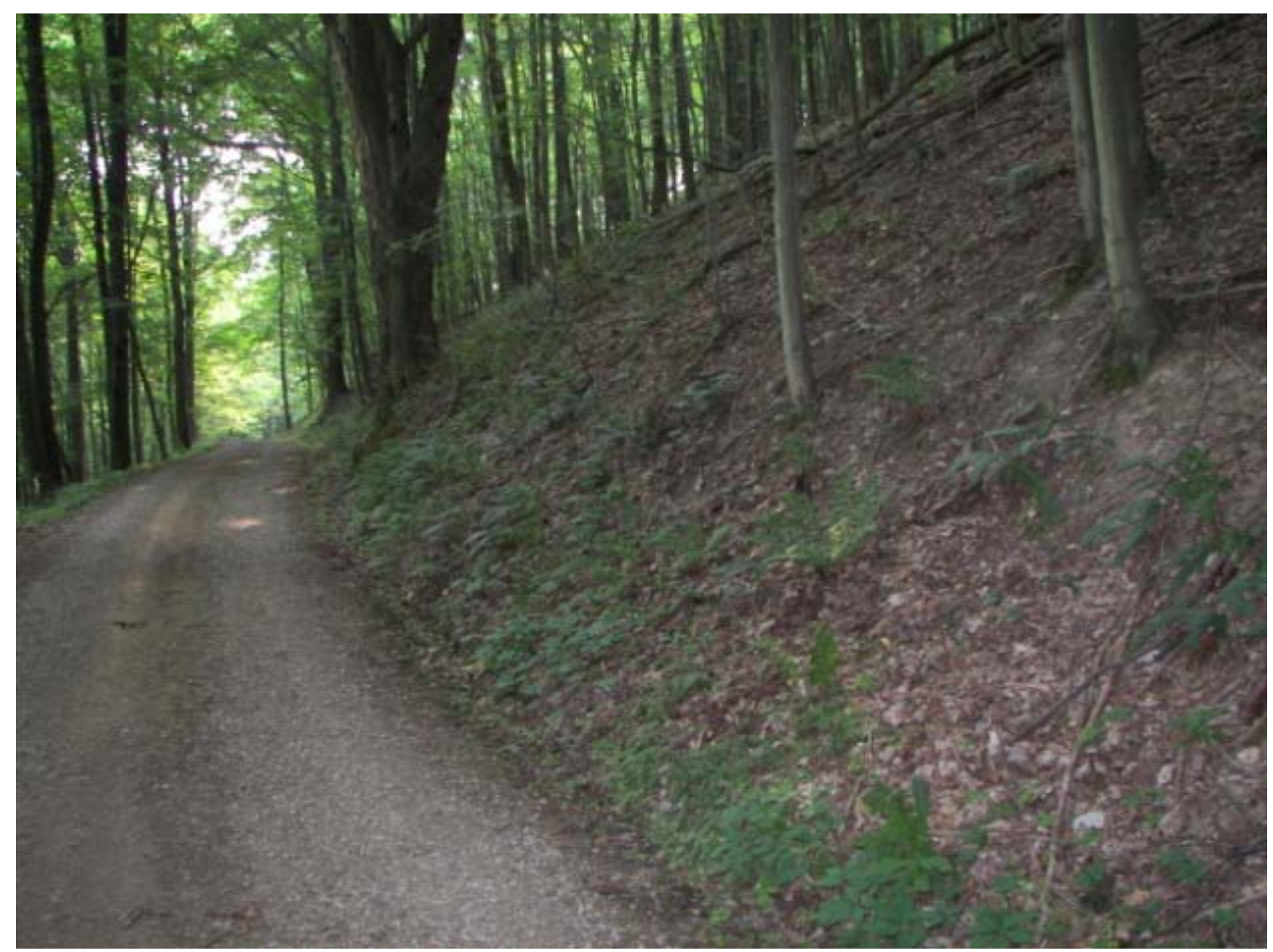

Figure 4.5: Rough terrain at the field site 


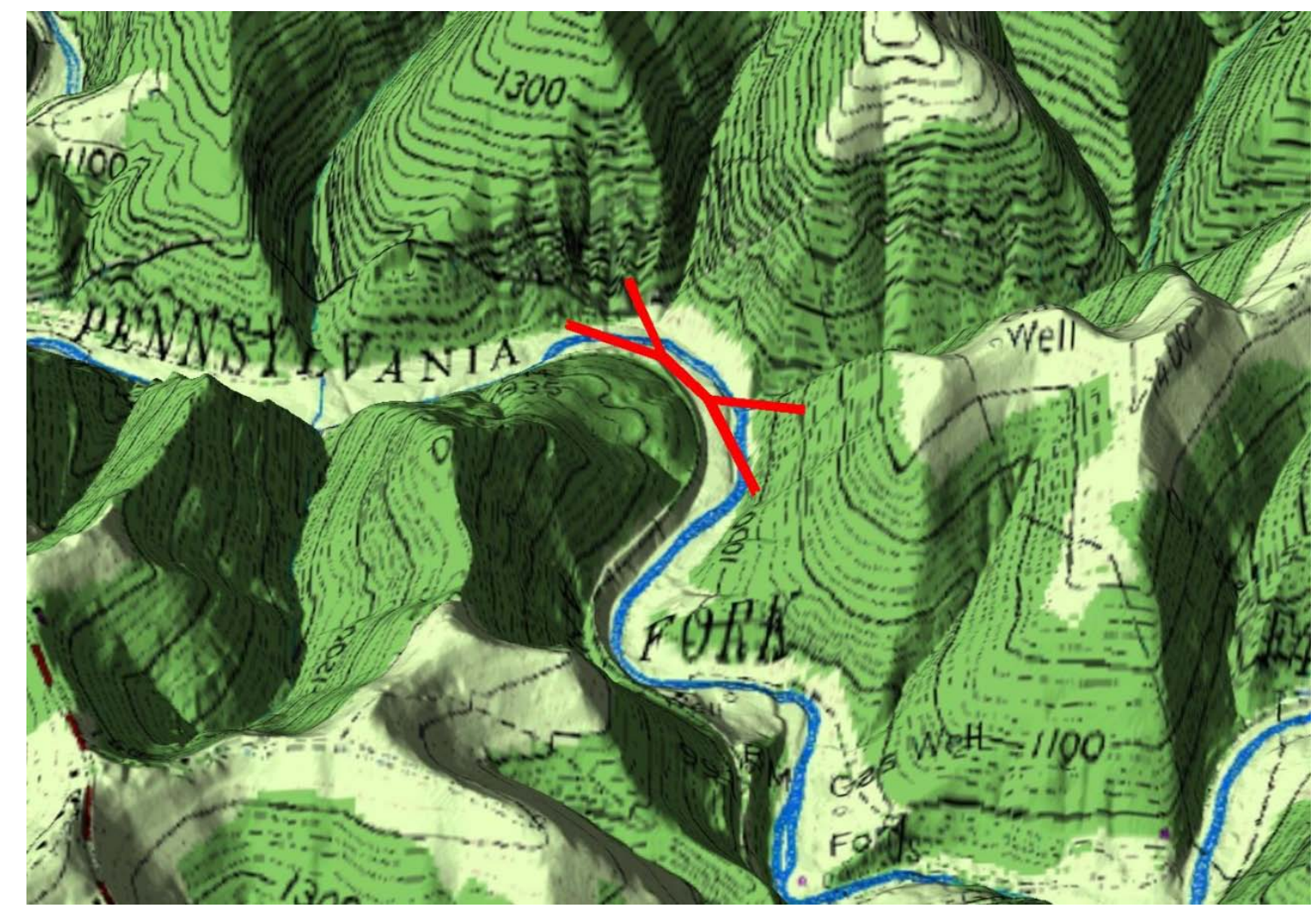

Note:

1. This figure was generated based on the field data and field details provided by CONSOL Energy at the field site (Winschel, 2009; Winschel et al, 2010).

2. GIS data was obtained from West Virginia GIS Technical Center (www.wvgis.wvu.edu).

Figure 4.6: Ground topography around the injection wells

Some earth mobilization work was carried out and 40-feet deep holes were drilled at 36 locations to mount surface tiltmeters. Figures 4.7 shows drilled locations of 36 tiltmeters and two GPS units. The southern part (south of MH-18 laterals) of the injection region has fewer tiltmeters due to restrictions in site accessibility. Figure 4.8 is a projected view of both wells and the finished tiltmeter array. These figures also the locations of absolute and remote GPS stations. The location of absolute/base GPS station is farther from injection region and can be seen in Figures 4.7 and 4.8. However, the remote GPS lies in a pelican box near the injection site with the central processing unit (purple square near tiltmeter T8 as shown in Figures 4.8 and 4.9), and is not seen on the ground surface. 


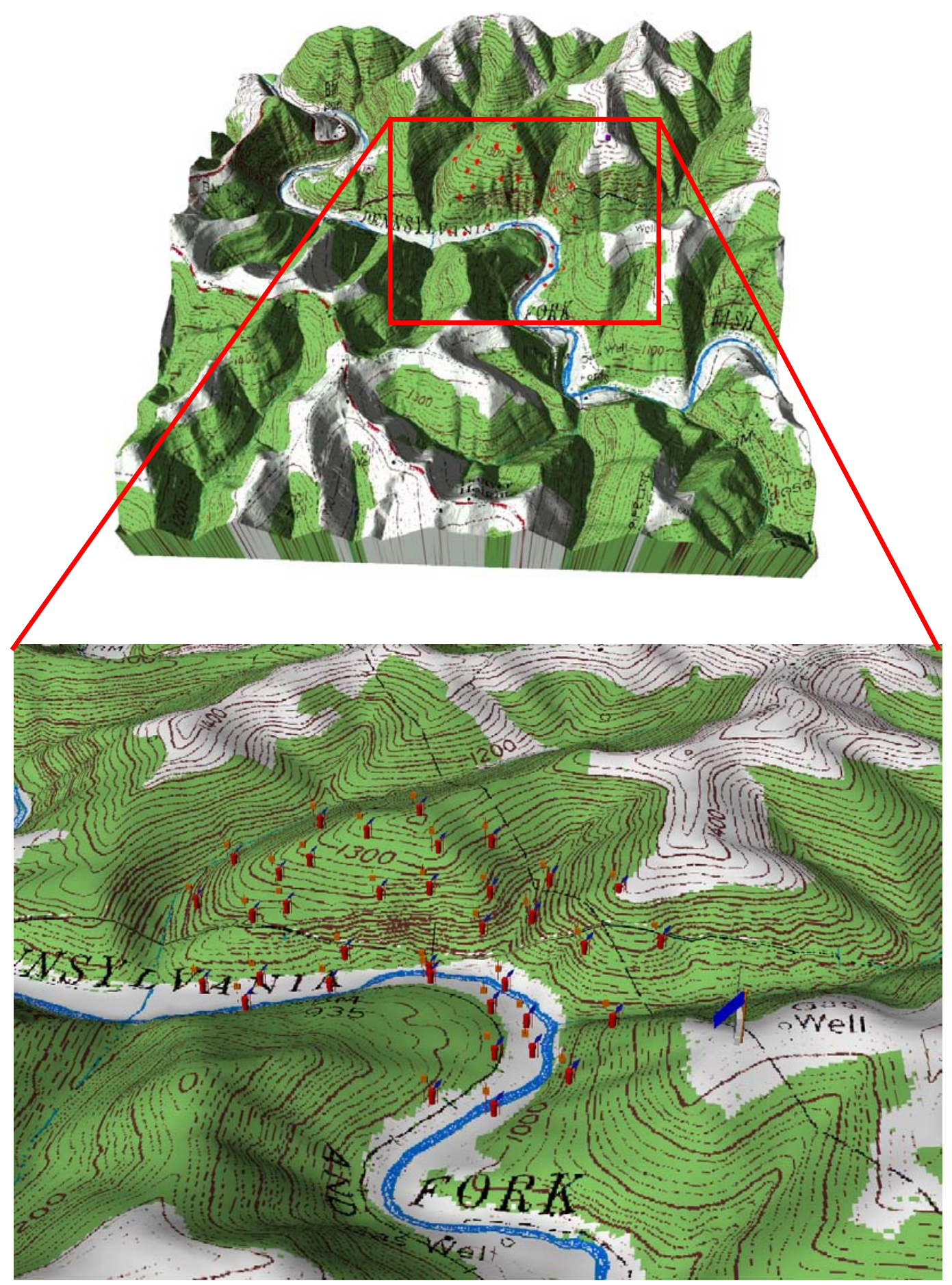

Note:

1. This figure was generated based on the field data provided by CONSOL Energy (Winschel, 2009; Winschel et al, 2010).

2. GIS data was obtained from West Virginia GIS Technical Center (www.wvgis.wvu.edu).

Figure 4.7: 3D-view of installed tiltmeters at the field site 


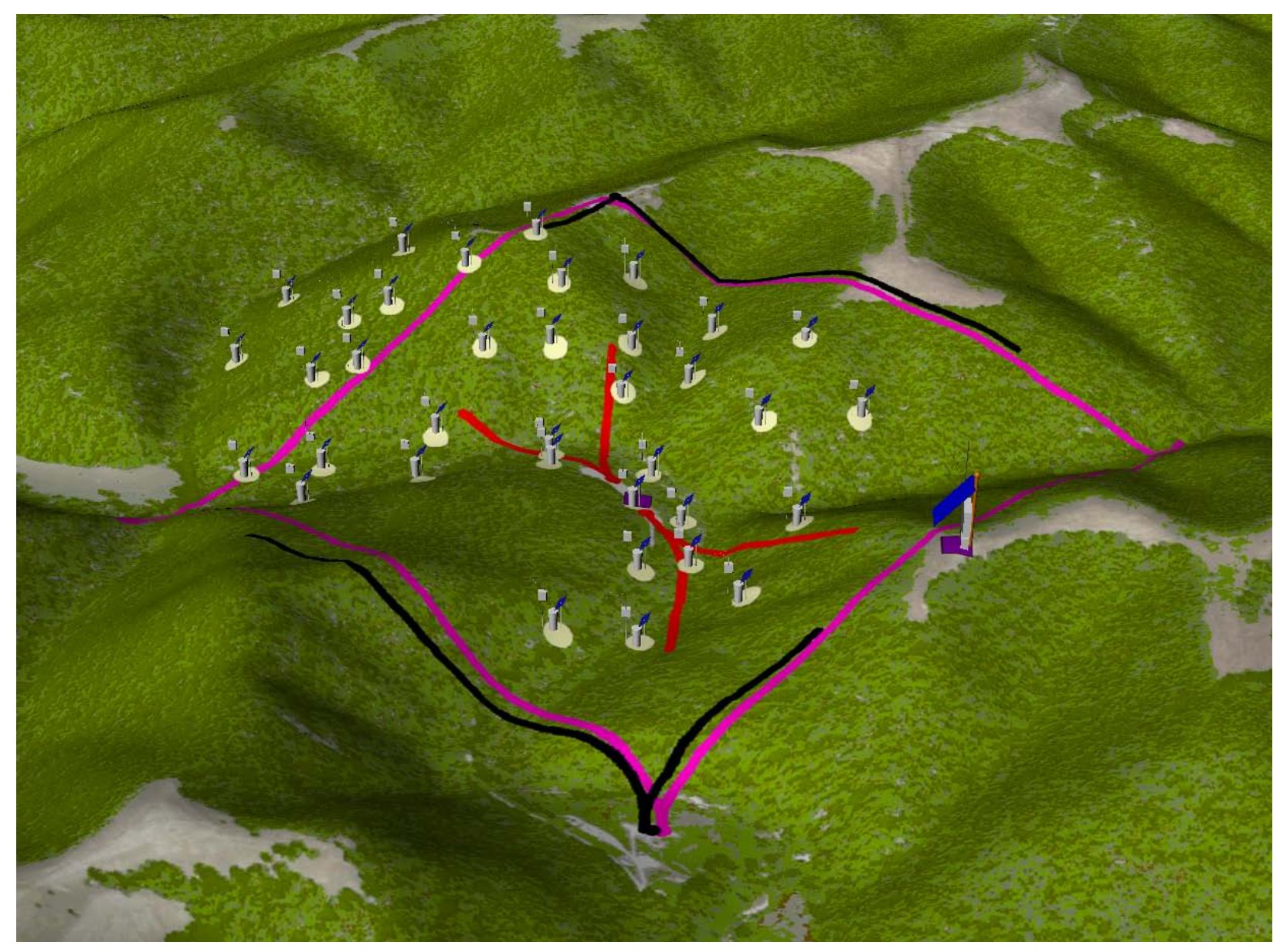

Note:

1. This figure was generated based on the field data and field details provided by CONSOL Energy at the field site (Winschel, 2009; Winschel et al, 2010).

2. GIS data was obtained from West Virginia GIS Technical Center (www.wvgis.wvu.edu).

Figure 4.8: Tiltmeter monitoring array with a projected view of wells on the ground surface

An aerial view of the 36 tiltmeters and 2 GPS stations installed at the field site can be seen in Figure 4.9 with the ground topography. The figure also represents the well configuration projected on the ground surface. Figure 4.10 describes the naming convention followed for 36 tiltmeters and 2 GPS units located at the field site in the current study. All these figures show that the injection region is bounded by a network of these tiltmeters and GPS units. Also, two GPS stations are shown. Remote GPS located closer to the injection zone and absolute/base GPS located farther from the injection zone. 


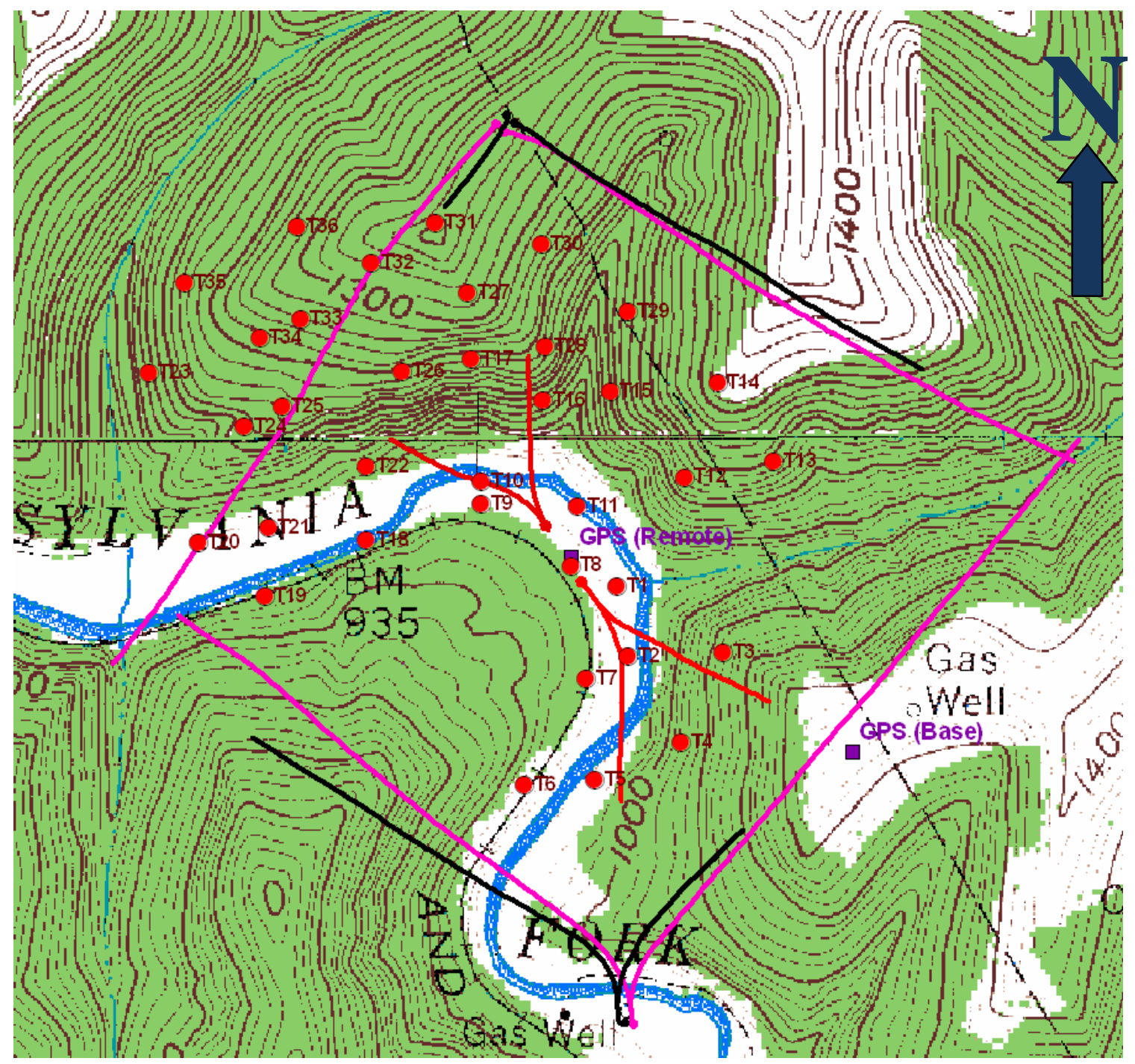

- 36 Tiltmeter locations

2 GPS Units - absolute and autonomous

_ Injection Wells (Upper Freeport Coal)

— Production Wells (Pittsburgh Coal)

\section{— Production/Injection Wells (Upper Freeport Coal)}

Note:

1. This figure was generated based on the field data and field details provided by CONSOL Energy at the field site (Winschel, 2009; Winschel et al, 2010).

2. GIS data was obtained from West Virginia GIS Technical Center (www.wvgis.wvu.edu).

Figure 4.9: Aerial view of 36 tiltmeters and 2 GPS receivers installed at the field site 


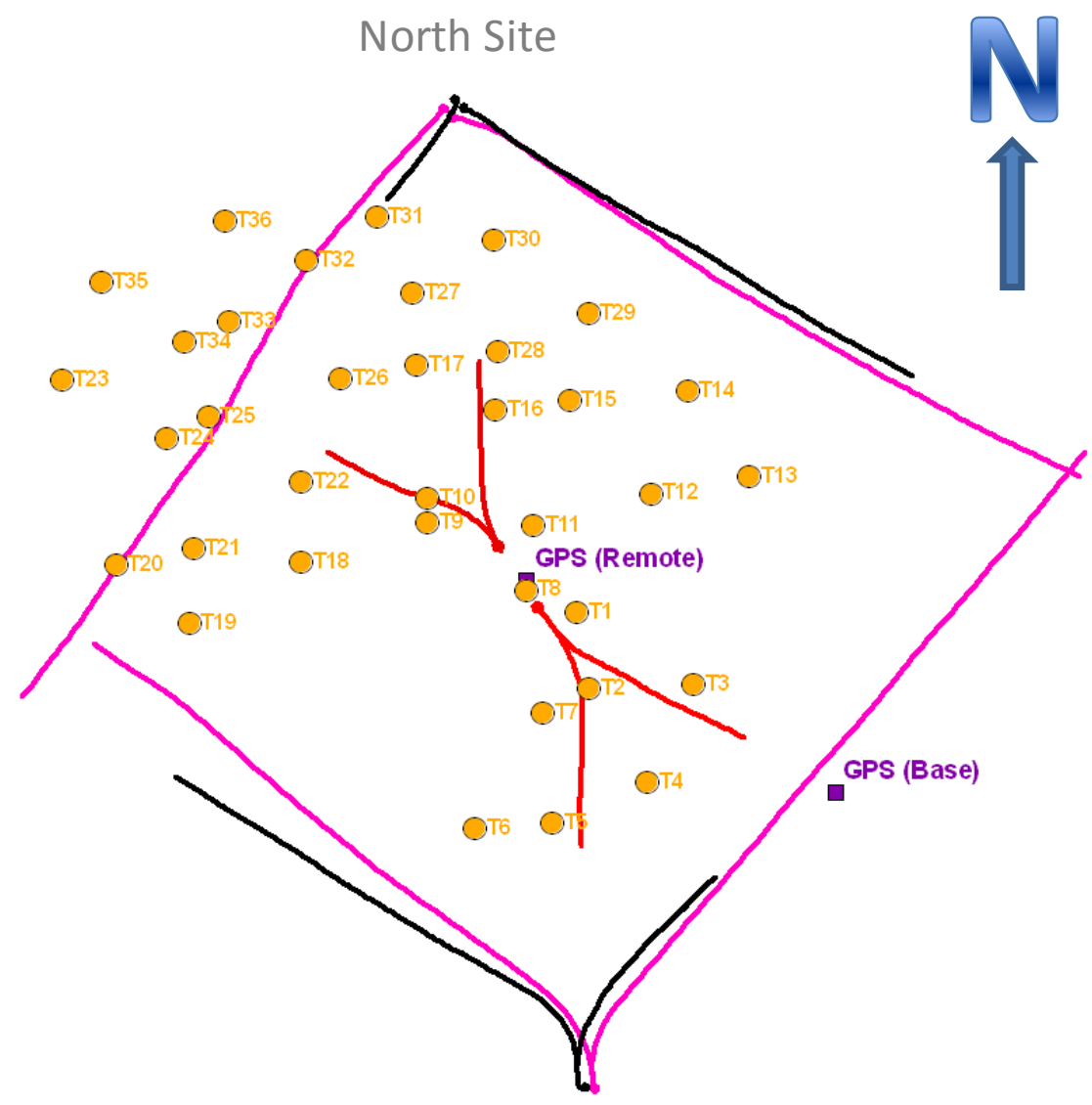

South Site

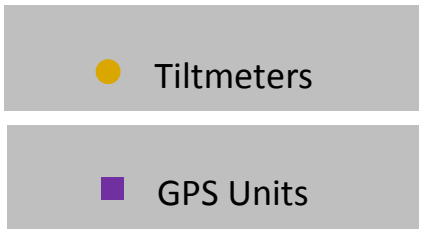

36 Tiltmeter locations

2 GPS Units - absolute and autonomous

- Injection Wells (Upper Freeport Coal)

- Production Wells (Pittsburgh Coal)

\section{_ Production/Injection Wells (Upper Freeport Coal)}

Note:

1. This figure was generated based on the field data and field details provided by CONSOL Energy at the field site (Winschel, 2009; Winschel et al, 2010).

2. GIS data was obtained from West Virginia GIS Technical Center (www.wvgis.wvu.edu).

Figure 4.10: Details of 36 tiltmeters and 2 GPS units 
Figure 4.11 illustrates a tiltmeter installed at the field site with installation details. Each instrument was installed by drilling a borehole in the subsurface (40 feet) and was placed in a bed of dry sand within a cemented PVC pipe (4 inch diameter) as shown in the Figure 4.11. Moreover, the tiltmeter is coupled to the cemented PVC pipe up to certain depth. As seen in the Figure 4.11, an outer PVC pipe (8 inch diameter) surrounds the inner PVC pipe up to a depth of 2 or 3 feet and extends on the surface. It is believed that this installation method helps reduce the noise and decouples the sensitive instrument from the surface (personal communications, Pinnacle Technologies).

Figure 4.12 shows a installed surface tiltmeter at field site. For the communication of tiltmeter data, a radio telemetry box was also housed in addition to the tiltmeter and connected to a antenna $(13 \mathrm{~dB})$ as shown in Figures 4.11 and 4.12. The on-site radios operate and maneuver to penetrate through the thick vegetation at low frequency signals of $465.4 \mathrm{MHz}$. Tiltmeters and radio's operate using a heavy-duty battery that is placed in a lockable, weather-proof case at each tiltmeter station as shown in Figures 4.11 and 4.12.

In addition to 36 tiltmeters, remote/autonomous and base/absolute GPS stations were installed in two different locations as shown in Figure 4.9 and Figure 4.10. The GPS base station (absolute location) is located farther from the injection point and installed on top of the hill as shown in Figure 4.9. Another GPS receiver is placed closer to the injection site, which is considered as remote GPS station as shown in Figures 4.9 and 4.10. Installed differential GPS receivers offer high-resolution, three-dimensional point-source deformation measurements. Figure 4.13 shows a reference GPS unit located at the field site. A 5-foot steel pole was cemented into the ground to provide stability to the GPS measurements as shown in the Figure 4.13. The GPS antenna (white disc situated at the top of the steel pole) collects signals from the GPS satellite constellations, and communicates with the central processing computer that is colocated at the central site (between injection wellheads $\mathrm{MH}-18$ and $\mathrm{MH}-20$ ) with the field equipment of the operating company, Consol Energy. Figure 4.14 shows the central processing computer co-occupied with other Consol Energy's field equipment. 


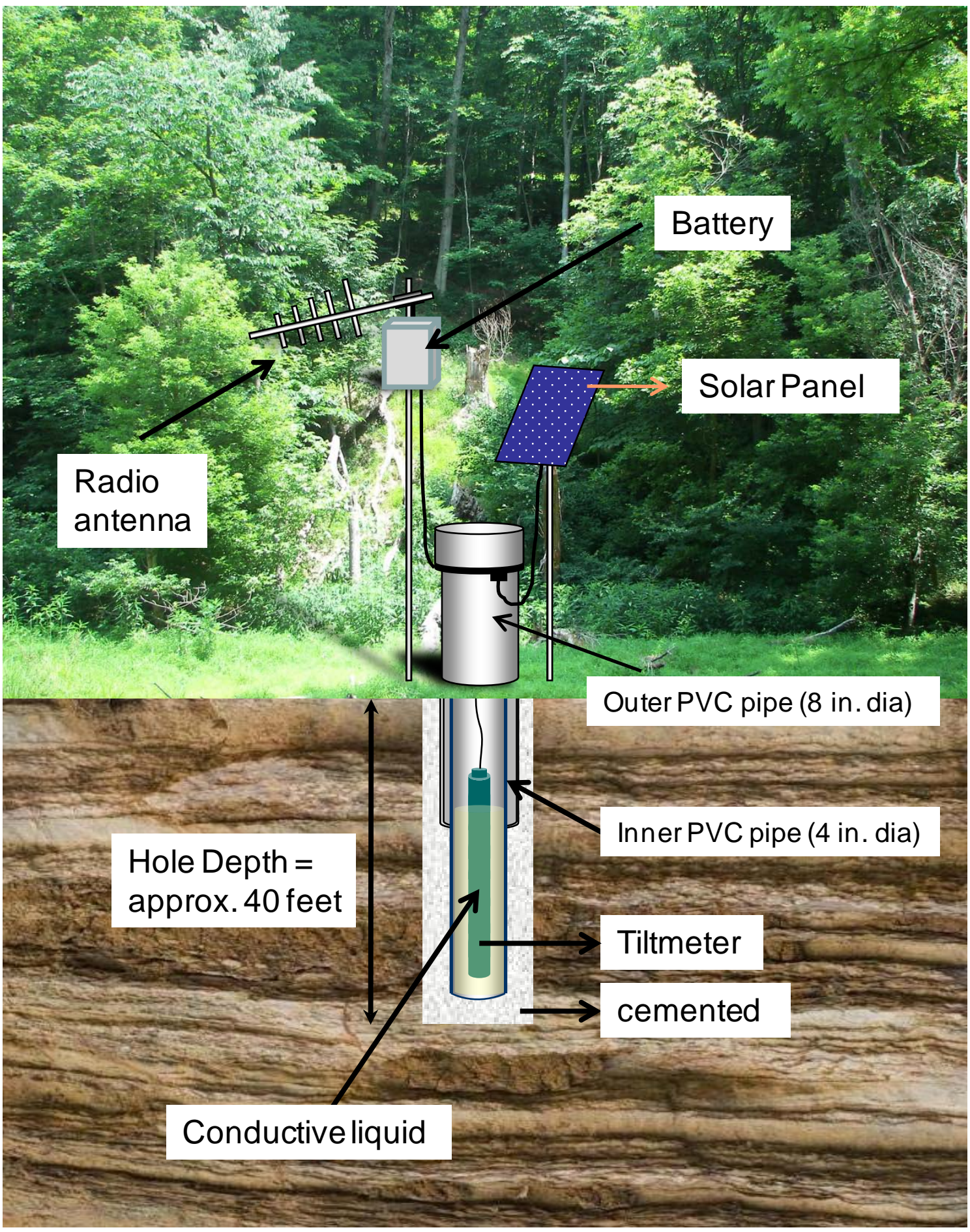

Note:

1. This figure was generated based on the assistance provided by Pinnacle Technologies.

Figure 4.11: Installation details of a tiltmeter at the field site 

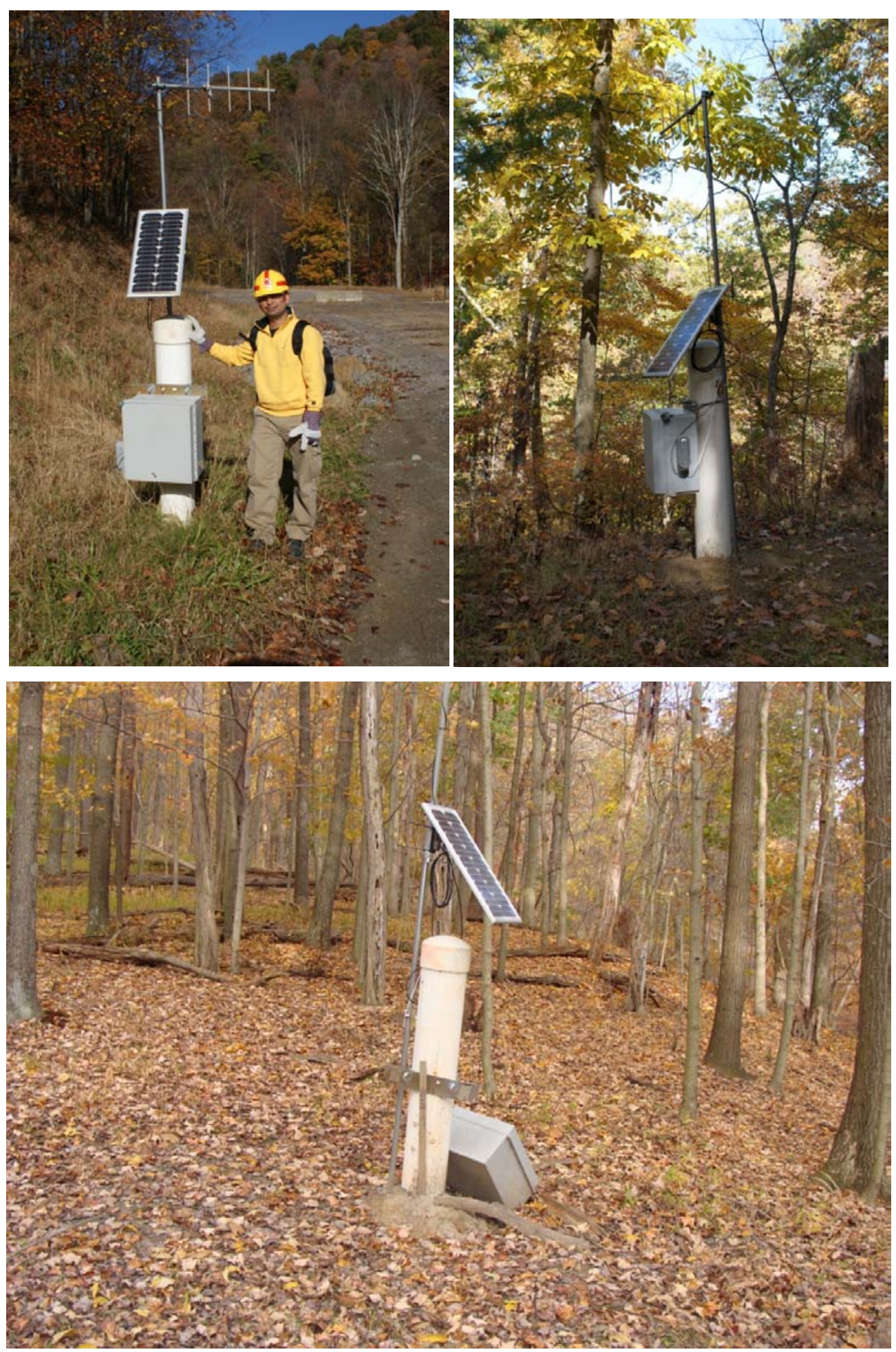

Note: Thanks to Pinnacle Technologies for their assistance in the installation of these tiltmeters.

Figure 4.12: A few tiltmeter stations located at the field site 

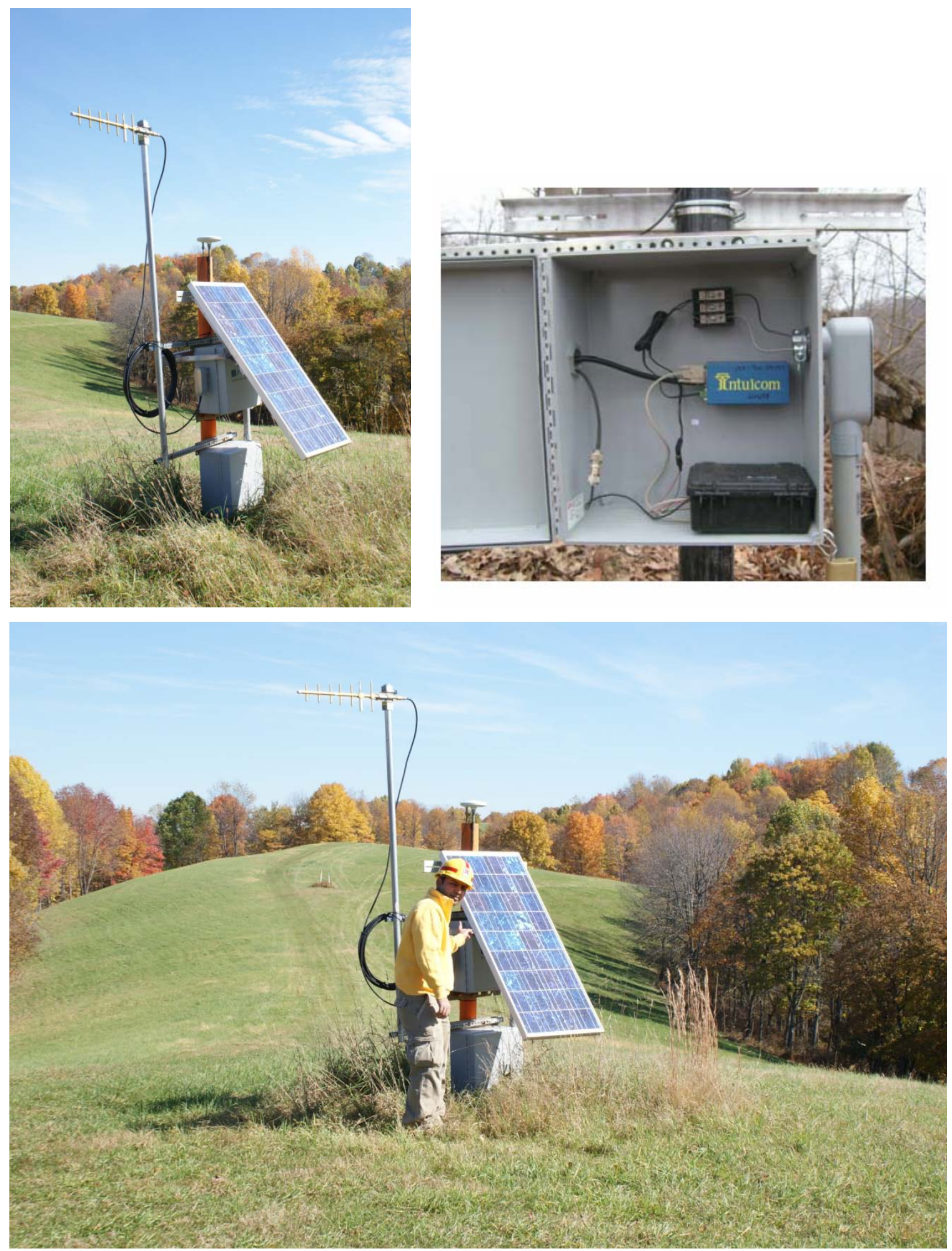

Note: Thanks to Pinnacle Technologies for their assistance in the installation of these GPS Stations.

Figure 4.13: Detailed view of absolute GPS station at the field site 

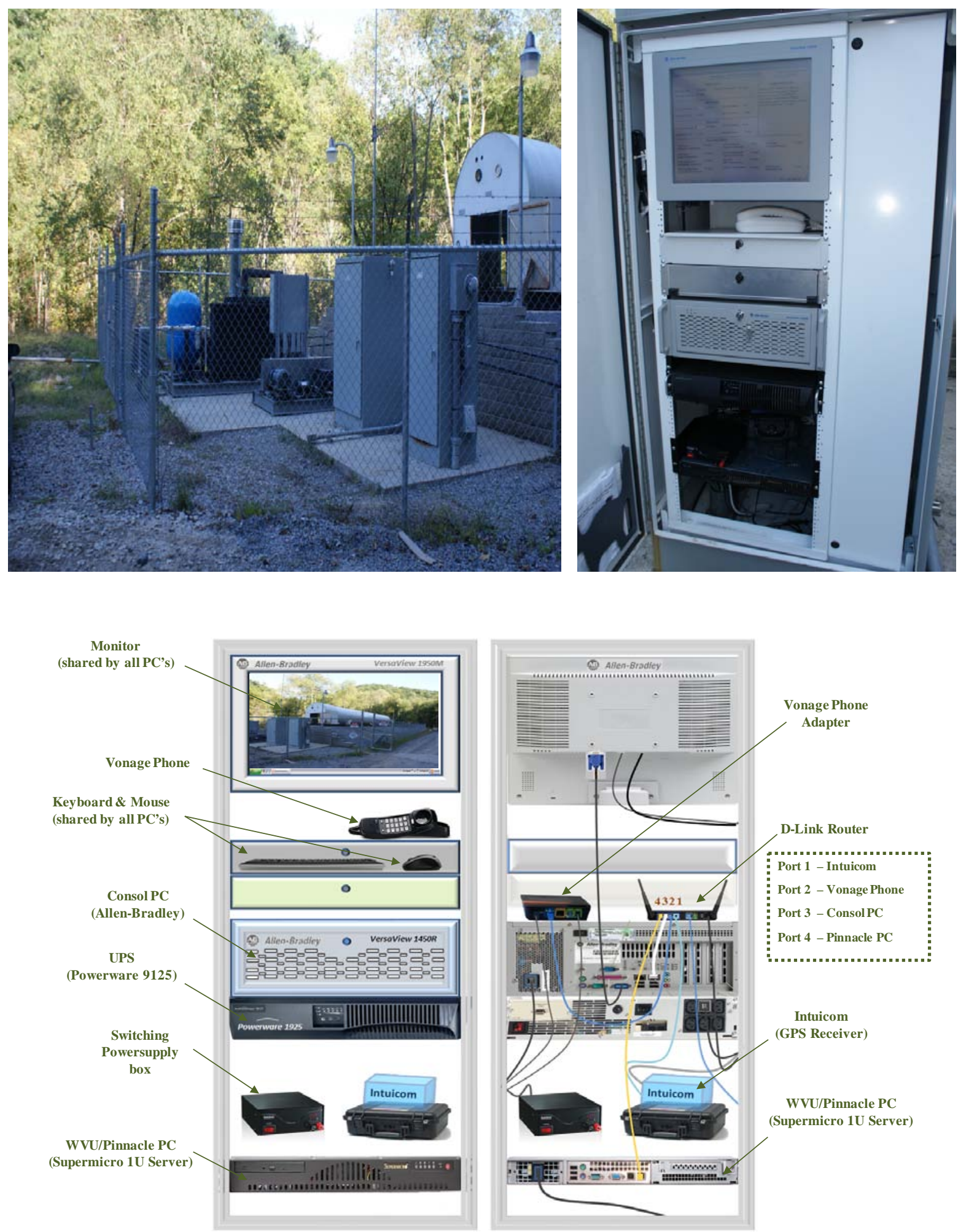

Note: Thanks to Pinnacle Technologies and CONSOL Energy for their assistance in setting up this equipment.

Figure 4.14: Central processing computer located with other field equipment 


\subsection{Data collection and processing}

The 36 tiltmeters and two GPS receivers have been calibrated prior to the commencement of $\mathrm{CO}_{2}$ injection. Calibration of these instruments is also routinely conducted by mapping out earth tides as shown in Figure 4.1. Real-time data is collected once a day by this on-site central processing computer from both the remote and reference GPS receivers, and all the 36 tiltmeters. The data obtained from 36 tiltmeters and two GPS receivers are transferred via an automated collection protocol to a computer system located for differential processing of the data. The system updates the surface deformations measured from tiltmeters on a weekly basis. Automated collection and analysis of data enhances the quality of the results and can be a cost-effective approach. Furthermore, the GPS data is updated frequently.

It has been reported that GPS provides minimal accuracy for vertical resolution with typical noise levels of approximately $11 \mathrm{~mm}$ with multiple differencing methods (Zumberge, 1997; Davis et al, 2005). However, it has also been reported that these noise levels of $11 \mathrm{~mm}$ can be reduced to $2 \mathrm{~mm}$ by long period filtering (Davis et al, 2005). The time period in which GPS measurements are collected is also a key element of integration of GPS measurements with tilt measurements (Davis et al, 2005). The integration of GPS measurements with tilt measurements is meaningful only if GPS measurements are collected when the ground deformations enter within the sensitivity range of GPS (Davis et al, 2005). If they are not collected during these particular time intervals, the integration of GPS measurements may mess-up the deformation magnitudes by adding noise to surface deformations recorded by high-precision tiltmeters in the monitoring array.

\subsection{Tiltmeter data analyses}

While each project is modified using a customized monitoring array, the design solution is reported to depend on a few generalized models that are based on underground sources of tilt and expected elevation changes (Davis et al, 2005). For example, the Okada model (Okada, 1985) is one such commonly used model to design the monitoring array by providing analytical solutions to estimate surface tilts and surface displacements from a given geometry. This simple 
dislocation models from Okada (Okada, 1985; Okada 1992) helps predict the lateral extents of fluid flow and maximum elevation changes (Davis et al, 2005). More complicated poroelastic models that can be used to incorporate changes in fluid pressures are found elsewhere (Green and Sneddon, 1950; Segall, 1985; Vasco et al, 1998; Geertsma,1974; Du and Olson, 2001).

In the current project, the surface deformations caused due to injection of $\mathrm{CO}_{2}$ in the lower coal seam are expected to be captured by installing tiltmeters and GPS stations at the field site. Tiltmeters measure only the magnitudes of tilts corresponding to $\mathrm{X}$ and $\mathrm{Y}$ bubbles in microradians. These magnitudes are then integrated with orientation of each tilt site and magnetic declination of the field site to compute the easing and northing tilts of each tiltmeter location in microradians. A vector sum of this easting and northing tilts provides the resultant tilt at each site. While the tilt measures change in elevation gradient, a GPS records the position of the receiver. At this particular site, tilt measurements are recorded and processed on a daily basis. In order to interpret elevation changes from above measured tilt values, it is necessary to integrate this data with gradient change measurements (Davis et al, 2001; Davis et al, 2005; personal communication; Pinnacle Technologies).

Many solutions are possible, but the best of all would be the smoothest surface that fits the measurements, which is known as minimum curvature surface solution in the published literature (Davis et al, 2005). Reports show that smooth surfaces obtained from closely spaced tiltmeters not only provide a desired solution, but also help capture deformations caused due to sources below the monitoring depth (Davis et al, 2005). Moreover, reports also show that Briggs (1974) has demonstrated a closed solution for determining the surface of minimum curvature through a bunch of elevation points. But no such closed or analytical solutions are reported to determine the minimum curvature surface through a group of surface gradients (Davis et al, 2005). Therefore, an iterative procedure is used to come-up with a minimum curvature surface that satisfies both the elevation points and surface gradient measurements (Davis et al, 2005).

If the tilts and elevations are known at the tilt locations, a Delauney triangulation is then constructed through the point cloud as reported in the published literature (Davis et al, 2005). Figure 4.15 shows the Delauney triangulation used for the injection site in the current study with 
assistance from Pinnacle Technologies. Furthermore, if the elevation is unavailable or unknown at a few of these tilt sites, the Delauney triangulation can be reduced to known elevation and tilt values as reported (Davis et al, 2005). However, if no measurement of elevation is available at the site due to the absence of GPS equipment, a tiltmeter site located farther from the injection source can be selected as reference tiltmeter with zero elevation change. The monitoring array is enlarged in such cases to cover an area of minimal ground motion (Davis et al, 2005).

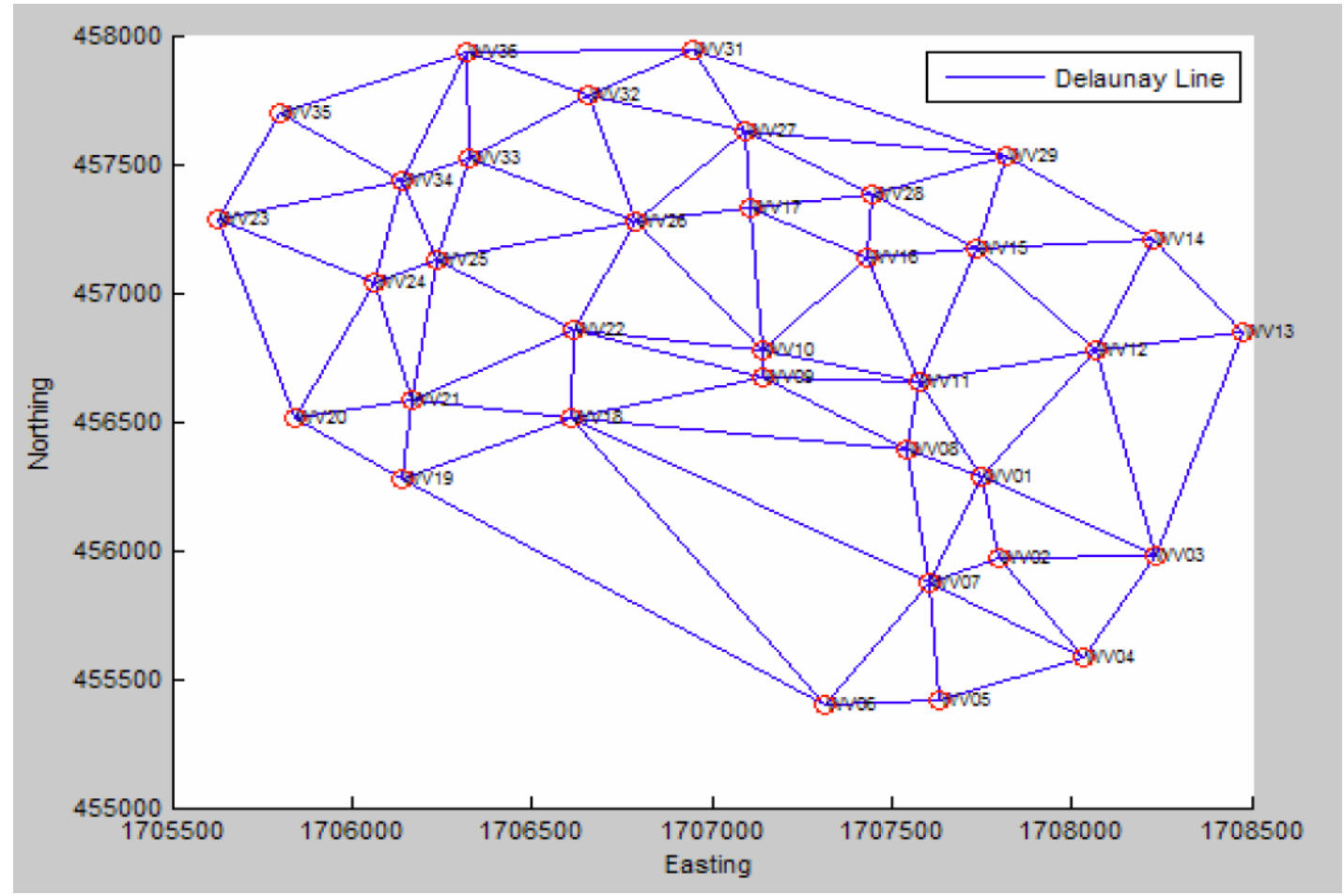

(Courtesy: Pinnacle Technologies)

Figure 4.15: An example of Delauney triangulation

One of the reduced set of Delauney triangulation lines is then selected randomly and is applied to fit the spline curve using a polynomial expression as given below in Equation (4.1) (Davis et al, 2005). $\alpha_{1}$ through $\alpha_{4}$ are coefficients that change depending on whether elevations are known at one end (Equations (4.1a)) or both ends (Equations 4.1b) of the Delauney triangulation line (Davis et al, 2005). 


$$
f(x)=\alpha_{1} x^{3}+\alpha_{2} x^{2}+\alpha_{3} x+\alpha_{4}
$$

where

$\mathrm{L}=$ length of the Delauney triangulation line

$\theta=$ tilt oriented in the direction of Delauney triangulation line

$\mathrm{H}_{\mathrm{i}}=$ elevation

Subscripts 1 and 2 correspond to start and end of Delauney triangulation line (Davis et al, 2005).

If elevations are known at one end of Delauney triangulation line,

$$
\alpha_{1}=0, \alpha_{2}=\frac{\theta_{1}-\theta_{2}}{2 L}, \alpha_{3}=-\theta_{1}, \alpha_{4}=H_{2}
$$

If elevations are known at both ends of Delauney triangulation line,

$$
\alpha_{1}=\frac{2\left(H_{1}-H_{2}\right)-2 \theta_{1} L+\left(\theta_{1}-\theta_{2}\right) L}{L^{3}}, \alpha_{2}=\frac{\theta_{1}-\theta_{2}}{2 L}-\frac{3}{2} \alpha_{1} L, \alpha_{3}=-\theta_{1}, \alpha_{4}=H_{2}
$$

Equation (4.1b)

Equation (4.2) describes the curvature of the line as given below (Davis et al, 2005). The curvature of the line is reported to be the integrated square of the second derivative of the spline polynomial along the length of the line (Davis et al, 2005). The process is believed to be continued until all the lines of the Delauney triangulation are fit with spline curves (Davis et al, 2005).

$$
C_{D}=12 \alpha_{1}^{2} L^{3}+12 \alpha_{1} \alpha_{2} L^{2}+4 \alpha_{2}^{2} L
$$


where

$\mathrm{L}=$ length of the Delauney triangulation line

$\theta=$ tilt oriented in the direction of Delauney triangulation line

$\mathrm{H}=$ elevation

$\mathrm{C}_{\mathrm{D}}=$ curvature of the Delauney triangulation line

Subscripts 1 and 2 correspond to start and end of Delauney triangulation line (Davis et al, 2005).

A single curvature of the entire surface is calculated by summing the curvature of individual lines and details of which can be found elsewhere (Davis et al, 2005). The standard deviation of computed elevations is calculated to manage the number of iterations for possible series of minimal curvature surface (Davis et al, 2005). The procedure is reported to help the coherence of tilt signals. Reports show that this optimum minimal curvature may still contain some surface undulations and can be corrected based on experience by keeping the coherent section and averaging out the incoherent sections (Davis et al, 2005). Once these sequences are formulated, interpolation is pursued to compute elevation change at any point on the ground surface (Davis et al, 2005).

In some cases, de-convolution of overburden may also be required to interpret reservoir level strains from the ground deformation results (Du et al, 2005; Walser et al, 2008; Walser et al, 2009). The de-convolution process requires surface displacements to be predicted and compared with measurements (Du et al, 2005; Walser et al, 2008; Walser et al, 2009). As discussed earlier, the prediction of surface displacements is possible with any one of the displacement models proposed by Okada (1985 and 1992) or Green and Sneddon (1950) or Segall (1985) or Vasco (1998). If the predictions are not good, the assumptions are modified and the inversion process is continued until a best fit is attained or predicted displacements match reasonably well with measured surface displacements (Vasco et al, 1998; Davis et al, 2005; Du et al, 2005; Walser et al, 2008; Walser et al, 2009). A Monte Carlo approach or brute force error mapping approach can also be followed to perform sensitivity studies to determine the uncertainties in the model (Davis et al, 2005). However, such displacement models are reported to be inaccurate. In such cases, poroelastic models demonstrated by Segall (1985) or Vasco (1998) are suggested useful in predicting ground deformations (Davis et al, 2005). Surface 
displacements caused due to changes in the pore fluid volume are calculated based on the Equation (4.3) as explained in many other research papers (Vasco et al, 1998; Davis et al, 2005; Du et al, 2005; Du et al, 2007; Walser et al, 2008; Walser et al, 2009).

$$
u_{i}(x)=\frac{K_{u}}{\mu} \int_{V} B_{s} \Delta v(\varsigma) g_{i}^{*}(x, \varsigma) d V_{\varsigma}
$$

Surface tilts are computed by taking the gradient of vertical displacements and can be presented as shown in Equation (4.4) (Vasco et al, 1998; Davis et al, 2005; Du et al, 2005; Du et al, 2007; Walser et al, 2008; Walser et al, 2009):

$$
T_{i}(x)=\frac{\partial u_{i}(x)}{\partial x_{j}}=\frac{K_{u}}{\mu} \int_{V} \frac{B_{s} \Delta v(\varsigma)}{\rho_{0}} \frac{g_{i}^{*}(x, \varsigma)}{\partial x_{j}} d V_{\varsigma}
$$

where,

$\mathrm{u}_{\mathrm{i}}=$ surface displacements caused due to change in the pore fluid volume

$\mathrm{T}_{\mathrm{i}}=$ surface tilts caused due to change in the pore fluid volume

$\mathrm{i}=1$ or 2

$\mathrm{x}_{\mathrm{i}}=\operatorname{vector}\left(\mathrm{x}_{1}, \mathrm{x}_{2}, \mathrm{x}_{3}\right)$

$\mathrm{B}=$ Skempton's pore pressure coefficient

$\mu$ = shear modulus; $\mathrm{K}_{\mathrm{u}}=$ bulk modulus at undrained condition

$\Delta v(\varsigma)=\frac{\Delta m}{\rho_{0}}=$ ratio of mass change per unit volume to fluid density at reference state

$g_{i}^{*}(x, \varsigma)=$ Green's function due to point source response function or center of dilation source in half space as described in literature (Okada,1992; Segall, 1985). 
In the above equations (Equations (4.3) and (4.4)), the first term $B \Delta v(\varsigma)$ represents a part of the total volumetric strain proposed by Segall (1985). The volumetric strain is proportional to the mean stress and change in mass of the pore fluid as expressed in Equation (4.5) (Segall, 1985):

$$
B_{s} \Delta v(\varsigma)=\varepsilon_{k k}-\frac{\sigma_{k k}}{3 K_{u}}
$$

where,

$\mathrm{B}=$ Skempton's pore pressure coefficient

$\mathrm{K}_{\mathrm{u}}=$ bulk modulus at undrained condition

$\sigma_{k k}=$ mean stress

$\varepsilon_{k k}=$ volumetric strain

$\Delta v(\varsigma)=\frac{\Delta m}{\rho_{0}}=$ ratio of mass change per unit volume to fluid density at reference state

Moreover, inversion models are needed to estimate volumetric changes in the reservoir (Vasco, 1998; Du et al, 2007; Du et al, 2008; Walser, 2008; Walser et al, 2009). The first step is to discretize the reservoir into a number of blocks. By assuming constant volumetric changes within each block, the above equations for surface displacements and surface tilts (Equation 4.3 and Equation 4.4) are numerically integrated over each discretized block to compute surface displacements and surface tilts (Vasco, 1998; Du et al, 2007; Du et al, 2008; Walser, 2008; Walser et al, 2009). Surface displacements are then computed based on the inversion process and superimposed on the surface deformations caused due to changes in the pore fluid volume.

The next step in the inversion process is to construct a discrete Green's function using the poroelastic forward model (Vasco, 1998; Du et al, 2007; Du et al, 2008; Walser et al, 2009). This discrete Green's function relates the surface deformation and surface tilts with volumetric changes due to a dilation source or a point source. Given a set of tilt observations, each of which is corresponding to volumetric changes due to a point source in the subsurface, a system of ' $m$ ' 
equations in 'n' unknowns is formed which can be expressed as a vector in the inversion problem as shown in Equation 4.6 (Vasco, 1998; Du et al, 2007; Du et al, 2008; Walser et al, 2009 ):

$$
d=G_{s}
$$

where

$\mathrm{d}$ = vector containing ' $\mathrm{m}$ ' tilt observations for the measured surface deformations $\mathrm{G}=$ discrete Green's function from the poroelastic forward model, $\mathrm{m}$ x n matrix

(Note: this Green's function depicts tilt or displacement at a specified point in the reservoir block due to changes in pore fluid volume)

Equation 4.6 can be solved to provide inverted volume estimates by minimizing the sum of the squares of the residuals. The solution to Equation 4.6 is not stable, and it requires a robust approach (Vasco, 1998; Du et al, 2007; Du et al, 2008; Walser et al, 2009 ). Two inversion methods have been reported ( $\mathrm{Du}$ et al, 2005; Du et al, 2008). The first method is the penalty function with smoothness proposed by Du et al (2001) as shown in Equation (4.7) The penalty function is the error reduction function and determines inverted changes in the pore fluid volume from the measured surface deformation map. The inverted distribution of changes in the pore fluid is presented in Equation 4.8 (Du et al, 2005; Du et al, 2008).

$$
\begin{gathered}
F(s)=\left\|G_{s}-d\right\|^{2}+\beta^{2}\left\|H_{S}\right\|^{2} \\
\Delta v_{\text {est }}=s_{\text {est }}=\left(G^{T} G+\beta^{2} H^{T} H\right)^{-1}\left(G^{T} d\right)
\end{gathered}
$$

where

$\mathrm{G}=$ discrete Green's function from the poroelastic forward model.

$\mathrm{d}=$ vector for the measured surface deformations 
$\mathrm{s}=$ vector for changes in the pore fluid volume of the individual reservoir block

$\beta^{2}=$ smoothness factor

$\Delta v_{\text {est }}=$ inverted distribution of fluid volume changes

$\mathrm{H}=$ finite difference approximation of the Laplace operator.

The second method for the penalty function is reported based on the smoothness and positive/negative constraints for geophysical inversions of injection and production cycles (Du et al, 2005; Du et al, 2008). Equation (4.9) describes this penalty function with smoothness and positive/negative constraints (Du et al, 2005; Du et al, 2008):

$$
\left(\begin{array}{c}
G \\
\beta^{2} H
\end{array}\right) s=\left(\begin{array}{l}
d \\
0
\end{array}\right)
$$

The above inversion process is solved for a series of smoothness factors until a best fit solution is available for measurements of surface tilts with volumetric estimates of pore fluid in individual cuboid blocks (Du et al, 2005; Du et al, 2008). Furthermore, it is reported that the following equation (Equation 4.10) can be used to determine total volumetric strains of the reservoir (Du et al, 2005; Du et al, 2008):

$$
\varepsilon_{k k}=\frac{K_{u}}{\mu} \int_{V} \Delta v(\varsigma)_{b e s-f i t} \frac{g_{i}^{*}(x, \varsigma)}{\partial x_{k}} d V_{\varsigma}
$$

More details on theoretical models, mathematical correlations, inversion problems and solutions to these analyses can be found elsewhere (Green and Sneddon, 1950; Okada, 1985; Okada, 1992; Segall, 1985; Vasco et al, 1998; Davis et al, 2005; Du et al, 2005; Du et al, 2007; Walser et al, 2008; Walser et al, 2009). 


\subsection{Previous ground monitoring studies}

Use of ground monitoring technologies is increasing in real-time monitoring of fluid migration, ground response, water and steam injection and any stress induced fractures or hydraulic fractures (Rutqvist et al, 2010; Onuma et al ,2008; Walser et al, 2008; Maxwell et al, 2008; Du et al., 2007; Davis et al, 2005; Davis et al, 2000; Kramn et al, 2005). However, their use in $\mathrm{CBM}$ extraction and $\mathrm{CO}_{2}$ sequestration is still underway. During the course of this research work, InSAR and high-precision tiltmeters integrated with a few GPS units were deployed at another real-time sequestration demonstration site by a research team from Southwest Regional Partnership (Koperna et al, 2009).

The Pump Canyon pilot site is located in the CBM fairway region of San Juan basin of northern New Mexico (Koperna et al, 2009). The objective at this pilot study was to demonstrate $\mathrm{CO}_{2}$ injection into a deep unmineable coal and produce CBM simultaneously. The target coal seam located at this Pump Canyon site was about 60 feet thick and is fairly deep ( 3,000 feet). As of June 2009, about 300 MMSCF ( 17,000 tons) of $\mathrm{CO}_{2}$ were injected into this coal seam with injection rates of up to $3.5 \mathrm{MMSCF} / \mathrm{day}$ ( 200 tons/day) (Koperna et al, 2009). More details on the field operations, geologic characterization or reservoir characterization can be found elsewhere (Koperna et al, 2009; Oudinot et al, 2008). 36 high-precision tiltmeters and two GPS stations were deployed at the field site. InSAR technique was also used to monitor any changes in the surface elevations at the site due to $\mathrm{CO}_{2}$ injection. Figures 4.16 and Figure 4.17 shows the results of tiltmeter and InSAR studies reported in the published literature (Koperna et al, 2009). Subsidence (due to reservoir shrinkage or reservoir compaction) was considered to be negative displacement and surface uplift (due to change in the effective stress or coal swelling) was considered as positive in the Figure 4.16. Results from Figure 4.16 are reported show no significant uplifts, no fracture developments, and spread of injected $\mathrm{CO}_{2}$ near the area of interest (Koperna et al, 2009). Surface displacements with very small magnitudes were observed. Also, some subsidence was noticed near the EPNG COM A 300 production well. More details on the ground monitoring results of this study can be found elsewhere (Koperna et al, 2009). Results

from InSAR (as shown in Figure 4.17) also reported to have seen no significant deformations in the area of interest or surrounding surface area. 


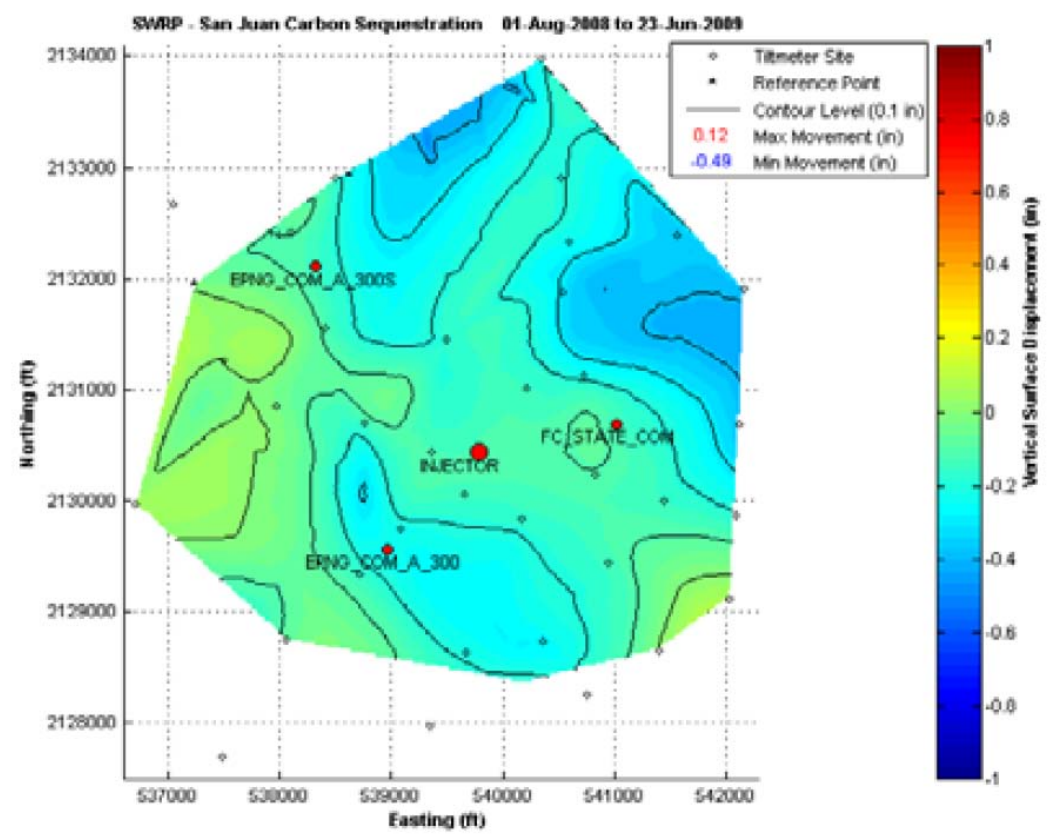

Figure 4.16: Results of tiltmeter study reported at the Pump Canyon $\mathrm{CO}_{2}$ sequestration site (Koperna et al, 2009)

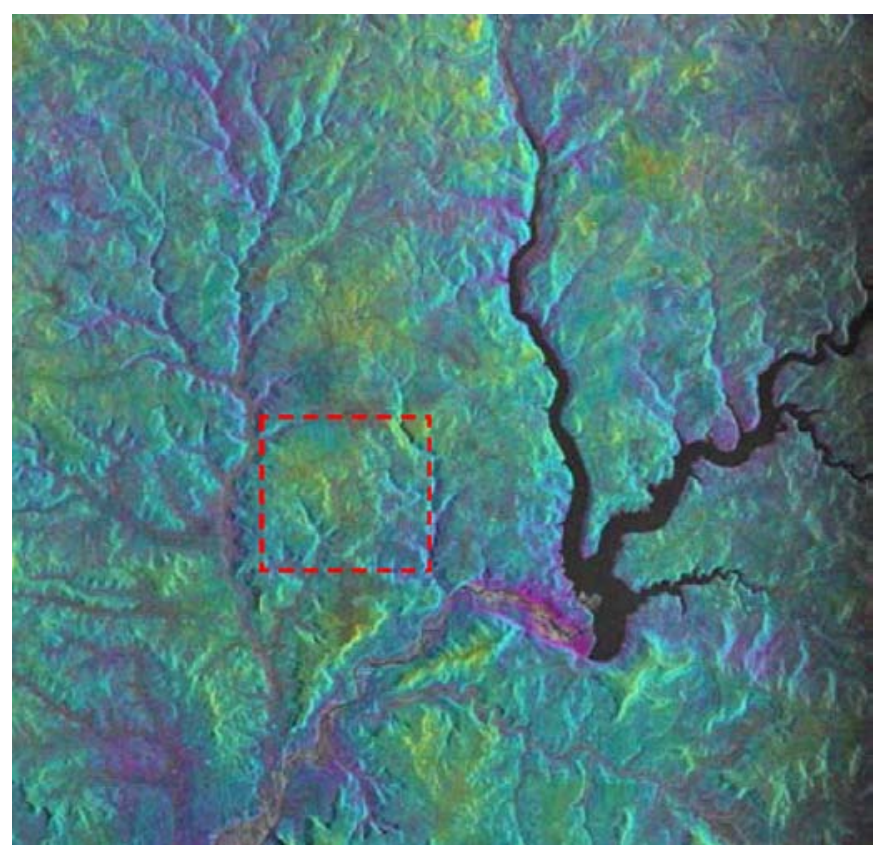

Figure 4.17: InSAR results reported at the Pump Canyon $\mathrm{CO}_{2}$ sequestration site (Kopema et al, 2009) 
In another study (Onuma et al, 2008; Rutquist et al, 2009; Rutquist et al, 2010), nearly one million tons of $\mathrm{CO}_{2}$ injection per year was reported to have taken place for four years (since August, 2004) in the InSalah gas project located in central region of Algeria. The $\mathrm{CO}_{2}$ was injected into water-filled sandstone at depths as low as 6,000 feet $(\sim 1800 \mathrm{~m})$. More details on the In Salah project can be found elsewhere (Onuma et al, 2008; Rutquist et al, 2009; Rutquist et al, 2010). InSAR technology was used for the four year $\mathrm{CO}_{2}$ injection period and surface deformations of up to $5 \mathrm{~mm}$ per year were observed above the injection region (Rutquist et al, 2009). Figure 4.18 shows surface elevation changes at the InSalah site after 3 years as reported in the published literature (Rutquist et al, 2009; Rutquist et al, 2010). The surface uplifts were reported to have extended several kilometers on the surface beyond the target injection area (Onuma et al, 2008; Rutquist et al, 2009). More details on the monitoring of this project can be found elsewhere (Onuma et al, 2008; Rutquist et al, 2009; Rutquist et al, 2010).

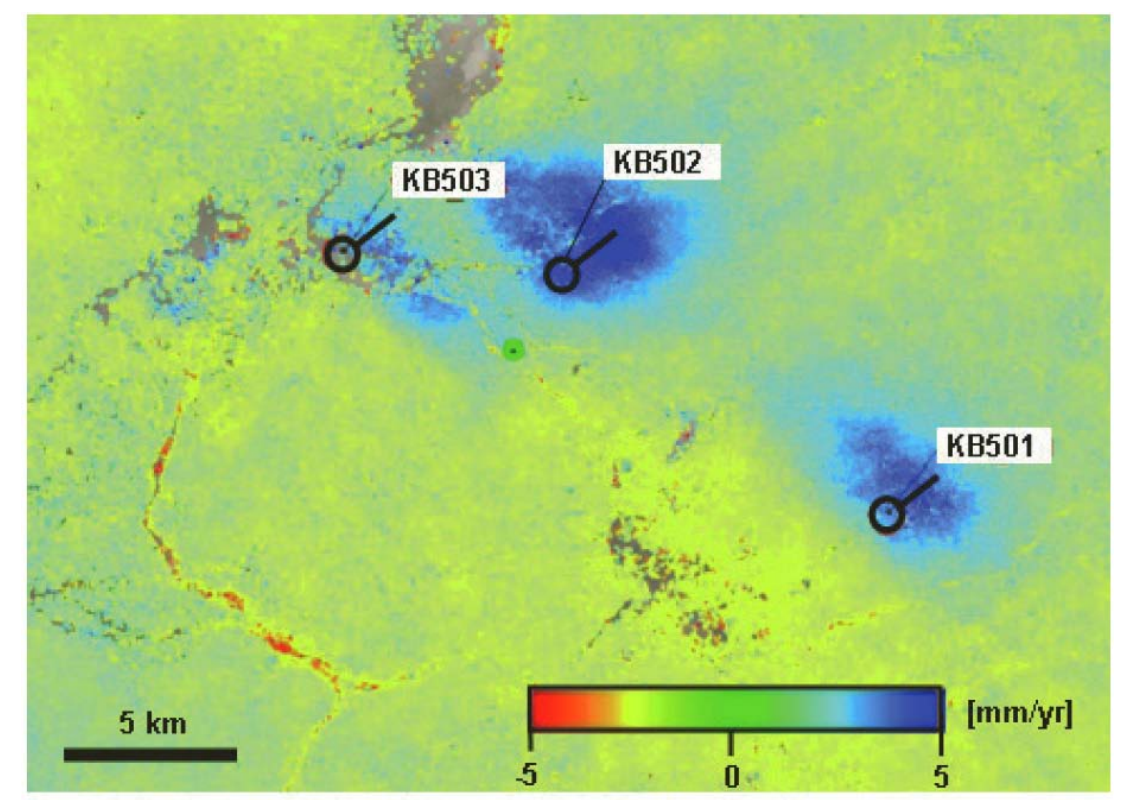

Figure 4.18: InSAR results reported at the InSalah $\mathrm{CO}_{2}$ sequestration site (Rutquist et al, 2009; Rutquist et al, 2010) 


\subsection{Tiltmeter monitoring results at the field site}

Tiltmeters measure only the magnitudes of tilts corresponding to $\mathrm{X}$ and $\mathrm{Y}$ bubbles in microradians. Figure 4.19a and 4.19b show typical samples of raw tilt information collected by tiltmeters. The difference in the tilts at particular time intervals is the amount of surface tilt within this period. These magnitudes of tilts at each site are integrated with the orientations of each tilt site and magnetic declination of the field site to compute the overall easting and northing tilts of each tiltmeter location in microradians. A vector sum of this easting and northing tilts provides the resultant tilt at each site. In the current research work, tilt measurements at the field site are recorded and processed on a daily basis. Data collection and data processing was done with the assistance of Pinnacle technologies.

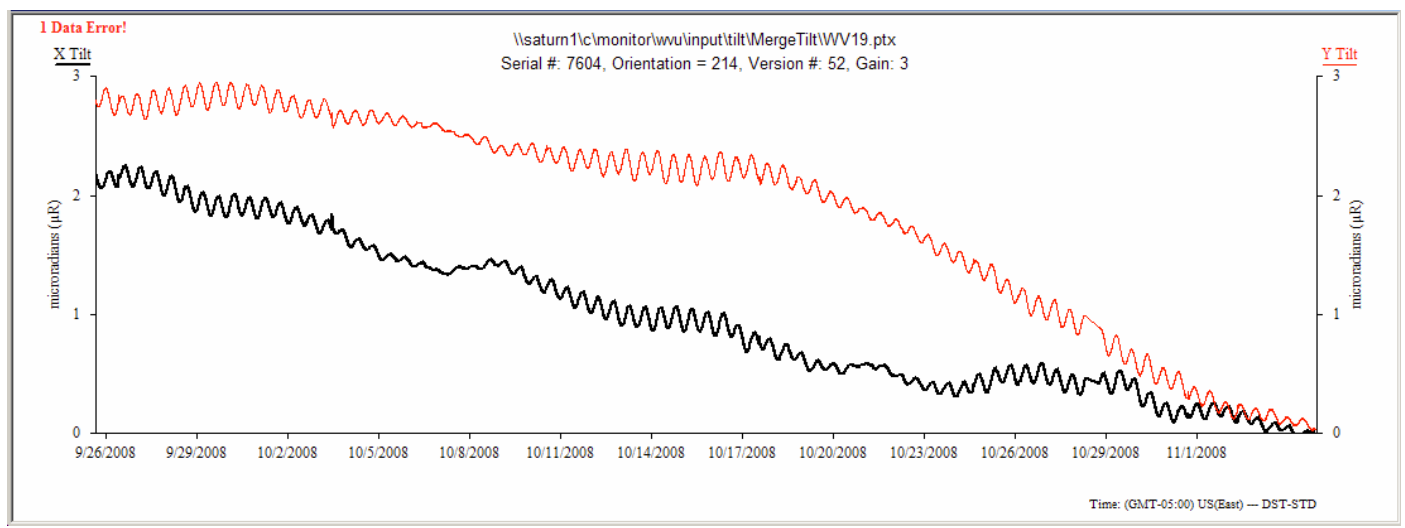

(a) raw data from tiltmeter 19

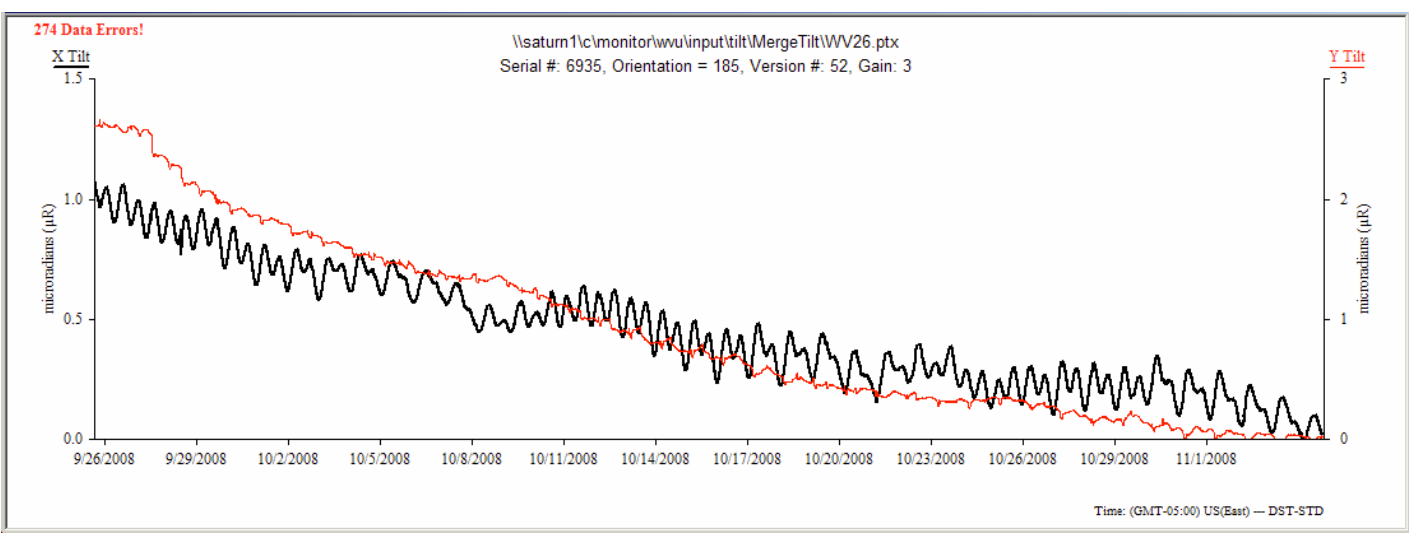

(b) raw data from tiltmeter 26

Figure 4.19: Raw data obtained from Tiltmeter 26 
In order to interpret elevation changes from above measured tilt values, it is also necessary to integrate this data with gradient change measurements (Davis et al, 2005). While the tilt measures change in elevation gradient, GPS records the position of receiver. Figure 4.20 show a typical example of the elevation data collected from GPS stations from September 07, 2009 to August 30, 2010 using a 96 hour filter. Plots in the figure (Figure 4.20) show a gradual uplift for the past several months, that has tapered off in the last few weeks.
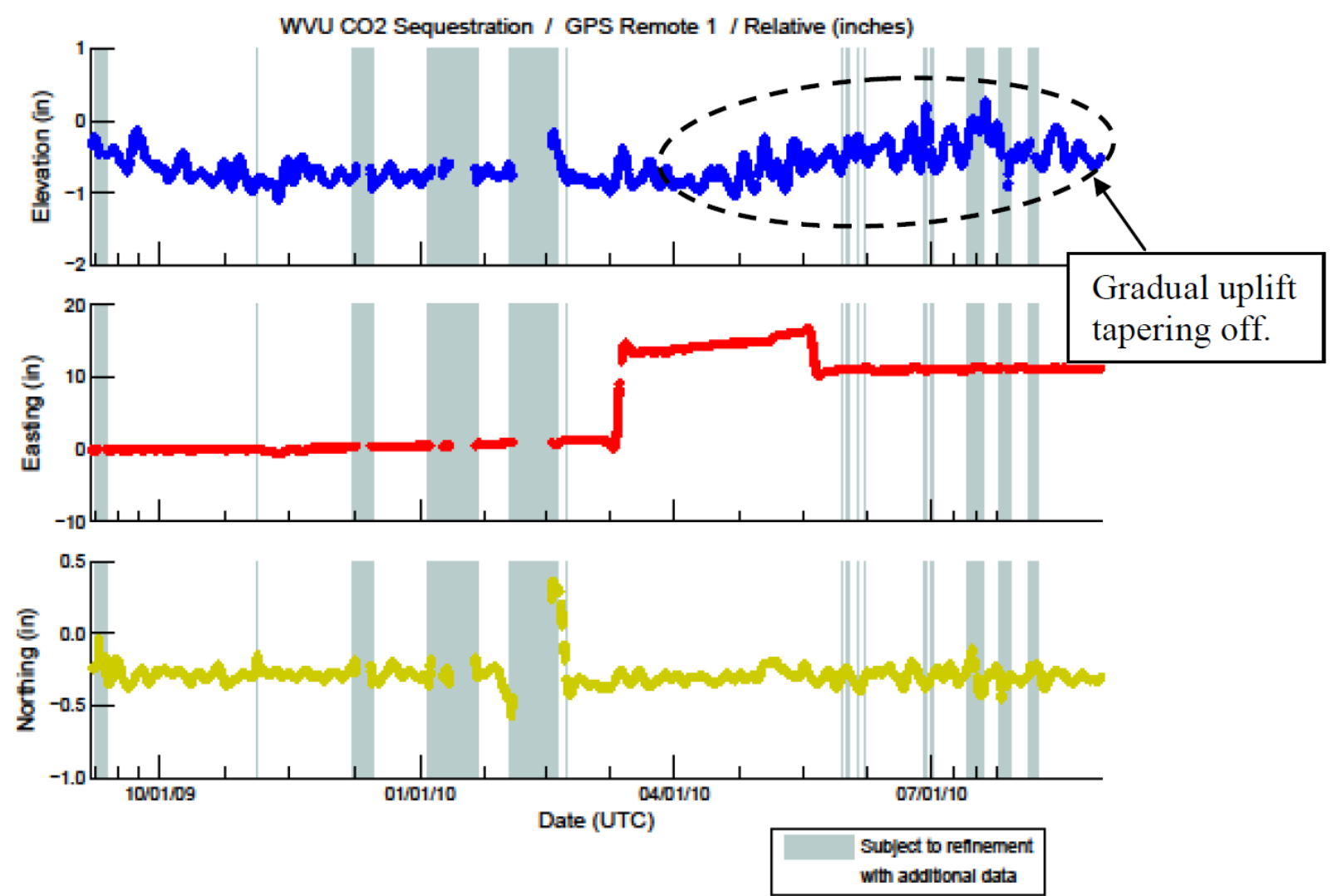

(Courtesy: Pinnacle Technologies)

Figure 4.20: GPS elevation profile

After the installation of tiltmeters and during the monitoring period of $\mathrm{CO}_{2}$ injection, several events such as earthquakes took place around the world. The instruments installed at this particular site could record disturbance due to most of these earthquakes with a delay of few minutes to several minutes depending on the location of the natural occurrence. Figure 4.21 
shows an typical example of tilt records for the earthquake that took place in Nicobar Islands on June 12, 2010. This indicates that tiltmeters were fully operational during the monitoring period.
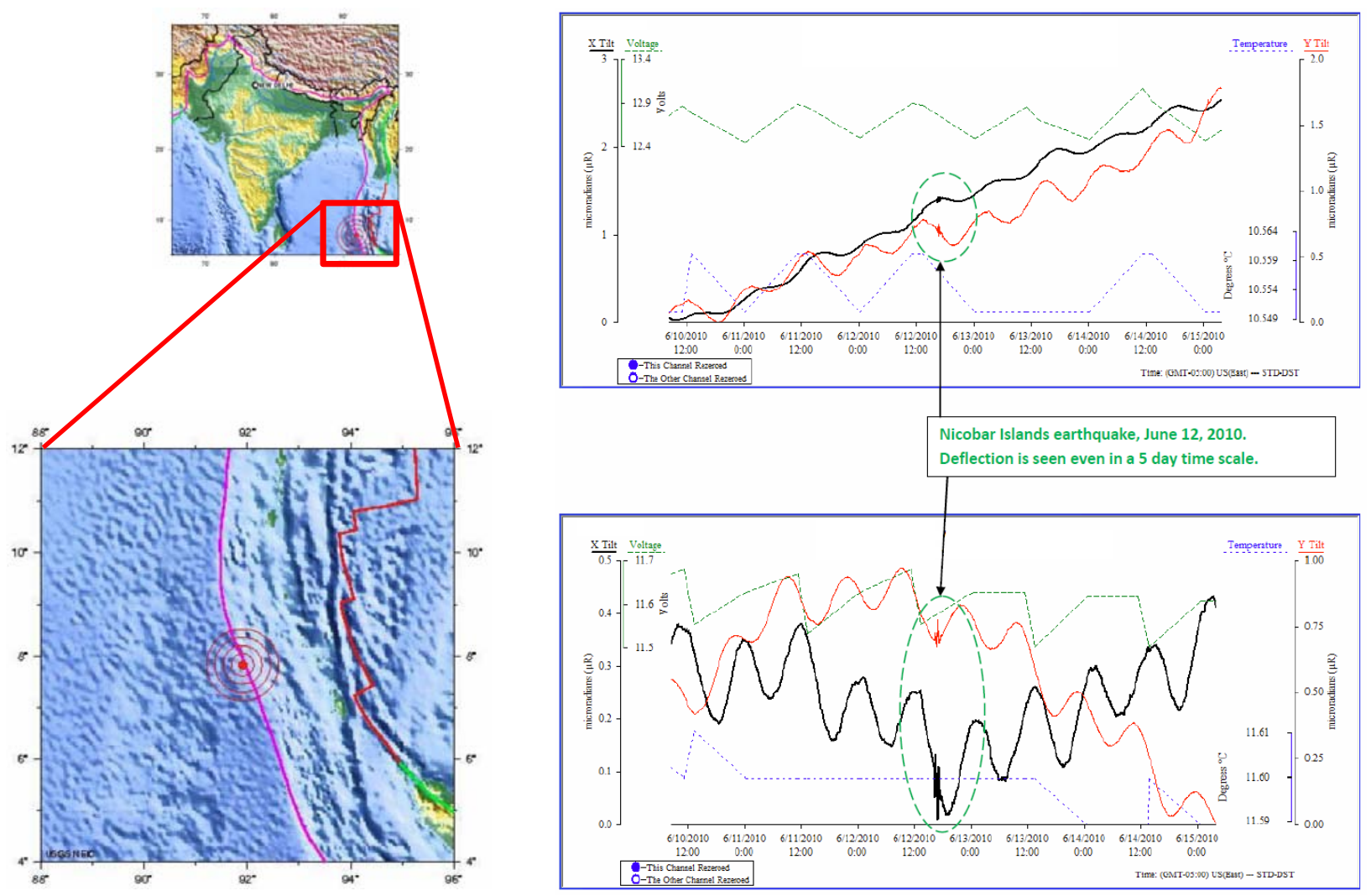

(Courtesy: Pinnacle Technologies)

Figure 4.21: GPS elevation profile

In the current sequestration project, the objective is to inject 20,000 tons of $\mathrm{CO}_{2}$ into the lower unmineable coal seam (Upper Freeport coal). Injection of $\mathrm{CO}_{2}$ began on September 08, 2009 and is continued for more than a year with periodic shut-in's. All 36 tiltmeters and two GPS receivers had been calibrated and fully functional prior to the commencement of $\mathrm{CO}_{2}$ injection. Figure 4.22 shows the surface deformations prior to injection. Results from Figure 4.22 show that no measureable ground displacements took place during the pre-injection monitoring period. Several interruptions to the injection schedule were noticed in the early part of $\mathrm{CO}_{2}$ injection. As a result, quiet conditions were observed at the site for the first few days. As of now, about 1,000 
tons of $\mathrm{CO}_{2}$ have been injected into the coal seam at an average pressure of nearly $700 \mathrm{psi}$. In the current research work, results are plotted only up to August 30, 2010. All of the 36 tiltmeters and two GPS units have been continuously recording and collecting data during the injection operations. Figures 4.23a and 4.23b present surface deformations for a typical two week period (08/16/2010 to 08/30/2010) at different deformation and time scales.

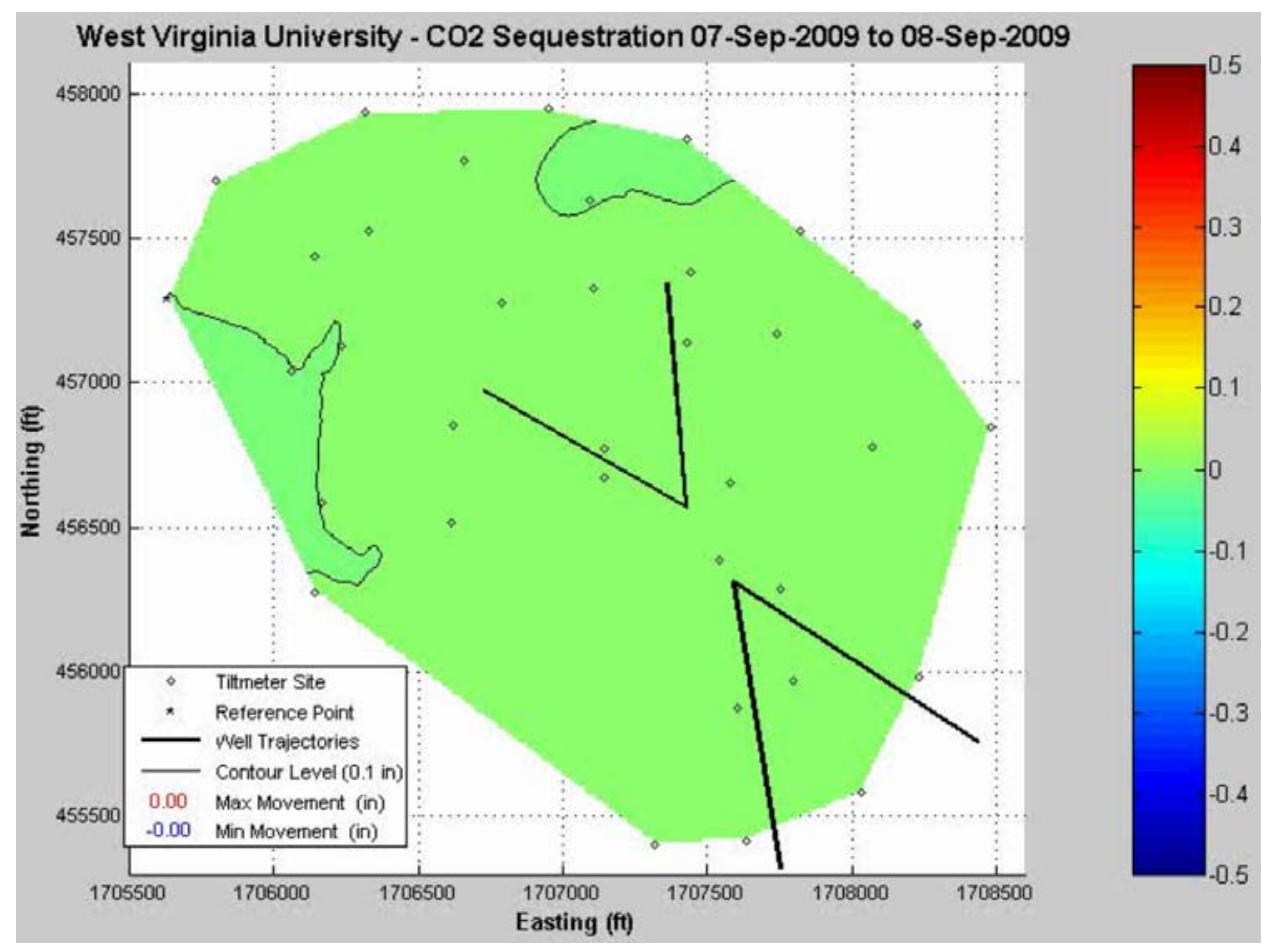

(Note: Thanks to Pinnacle Technologies for their assistance)

Figure 4.22: Surface deformation prior to injection of $\mathrm{CO}_{2}$ at the field site

Results from Figures 4.23(a) and 4.23(b) show very small surface displacements for the two week period of 08/16/2010 to 08/30/2010. In the current study, positive deformations are treated as surface uplifts and negative deformations are considered as subsidence. In Figure 4.23(b) (small-deformation scale image), an uplift in the surface deformations can be noticed along the heel sections of the north and west legs of MH-18. Also, some positive deformations are noticed in the east portion of these legs. Some subsidence can also be seen to the north of MH-18 and west of MH-20. However, the deformation magnitudes are very small, and could be due to methane production around the periphery of these lateral wells. 


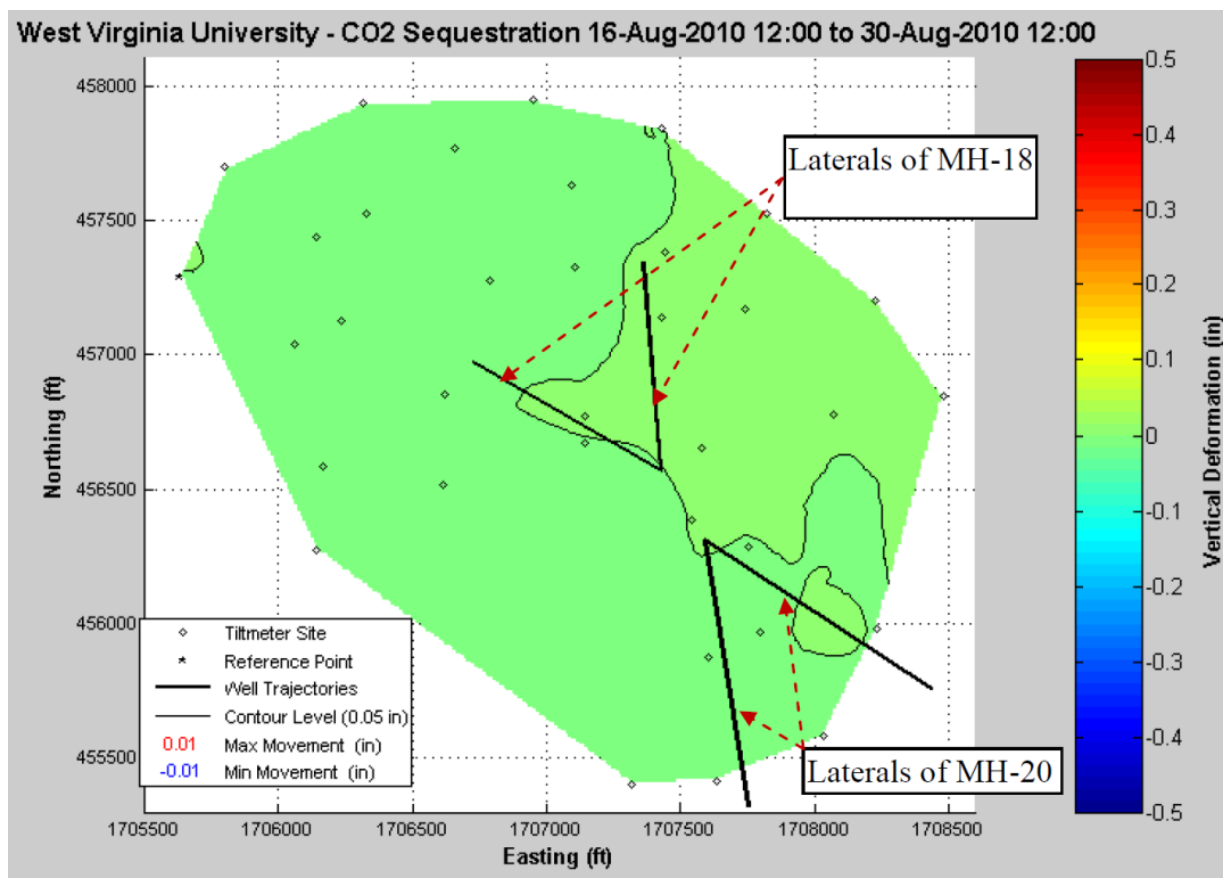

(a) large-deformation scale

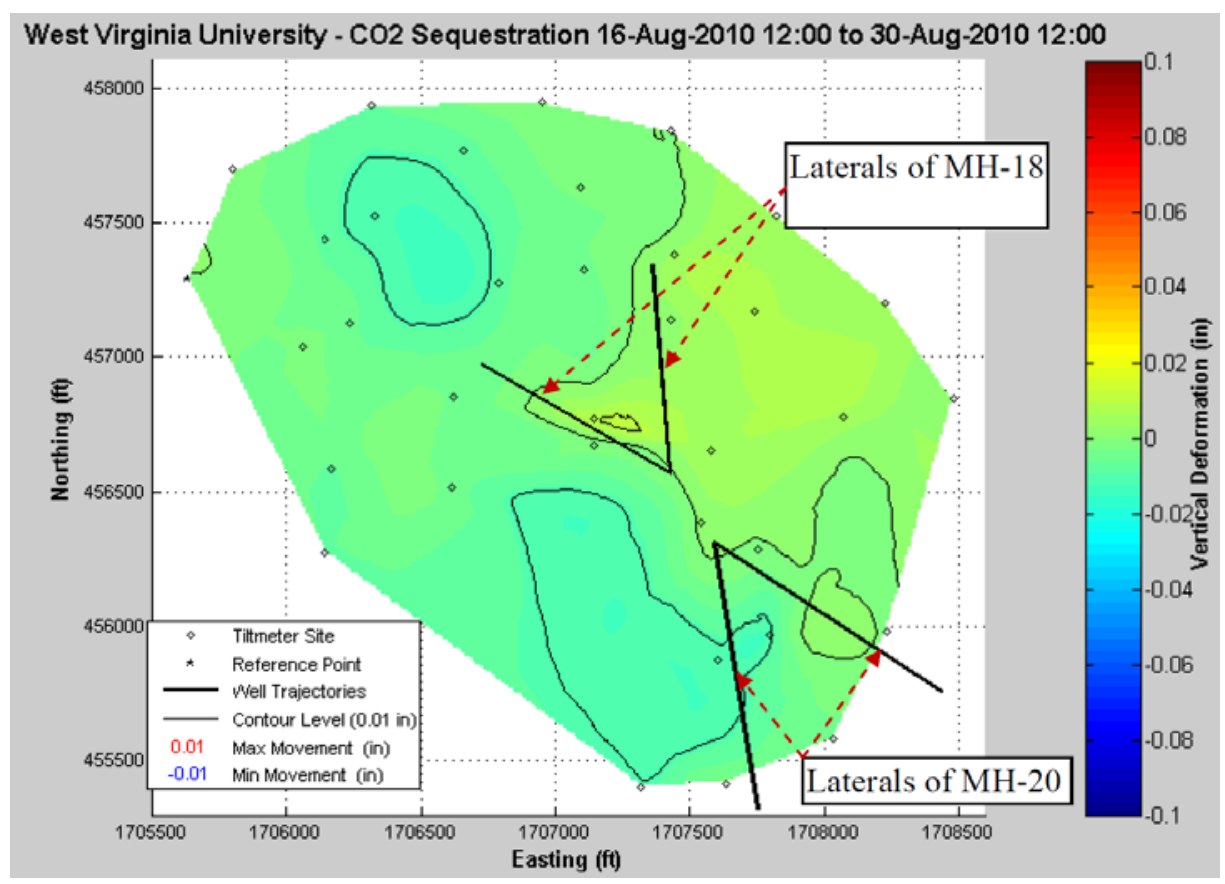

(b) small deformation scale

(Note: Thanks to Pinnacle Technologies for their assistance)

Figure 4.23: Surface deformation for a two week period of $08 / 16 / 2010$ to $08 / 30 / 2010$ 
Figure 4.24 shows the cumulative surface deformations from the beginning of $\mathrm{CO}_{2}$ injection (September 08, 2010) for about an year (08/30/2010). Long-term cumulative surface deformations show some surface uplifts (positive deformations) along the well trajectories of MH-18. Moreover, results show some fluid movements along the well trajectories. So far, measured data shows some uplift near the heel sections and northeast sections of legs of MH-20. Also, the maximum surface uplift recorded is about 0.13 inches. These surface uplifts may be due to increase in the reservoir pressure or due to swelling of coal during the injection of $\mathrm{CO}_{2}$. Hence, results of the field monitoring show that tiltmeters with integration of GPS technology can be used effectively to monitor migration of $\mathrm{CO}_{2}$ and measure ground deformations caused by injection of $\mathrm{CO}_{2}$ into coal seams. 

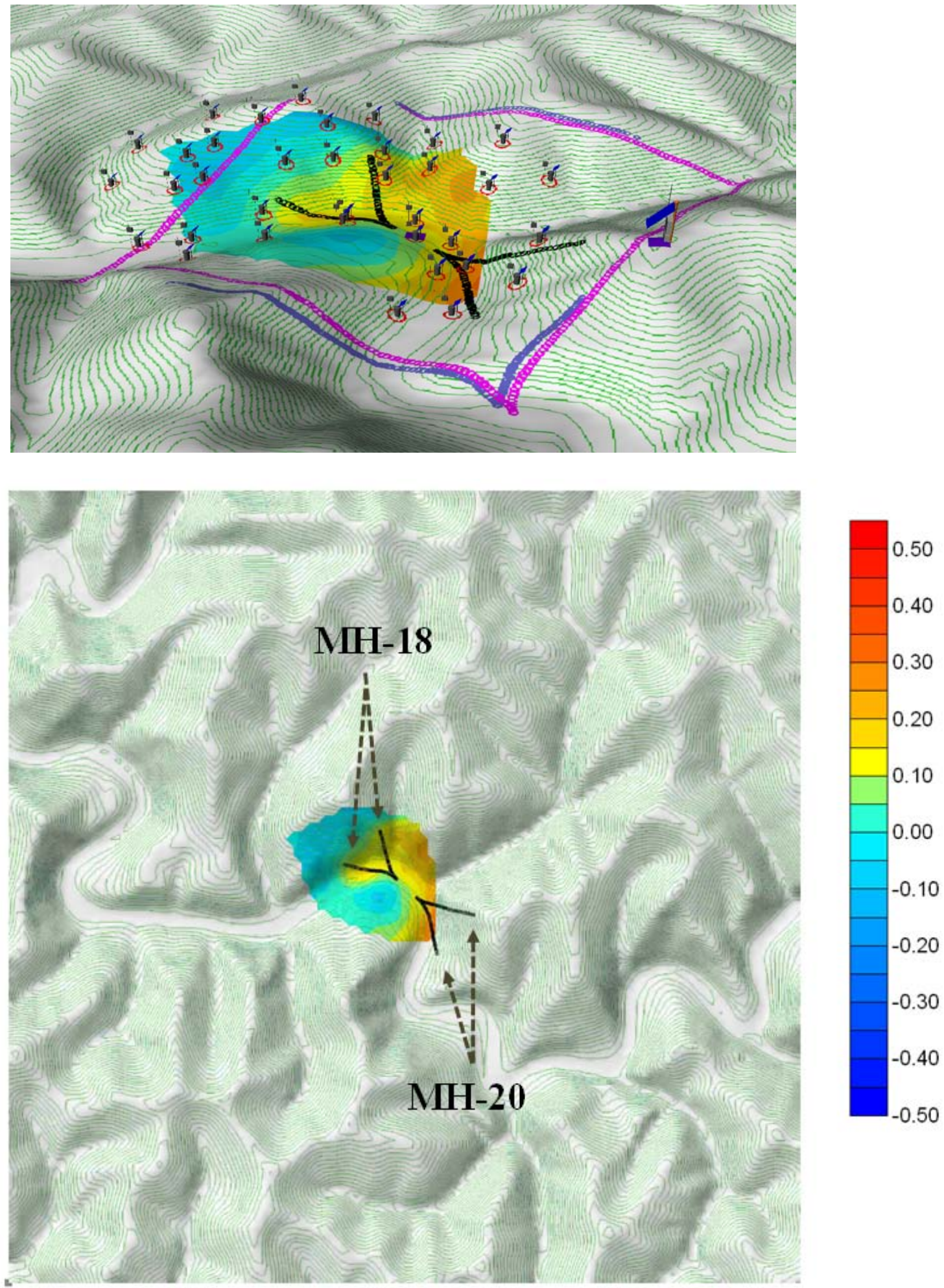

Figure 4.24: Long-term cumulative surface deformations from the beginning of $\mathrm{CO}_{2}$ injection (09/07/2009 to $08 / 30 / 2010$ ) 


\section{CHAPTER 5: NUMERICAL MODELING OF $\mathrm{CO}_{2}$ INJECTION}

\subsection{Objectives of numerical modeling}

In addition to the field monitoring of ground deformations using tiltmeters, numerical modeling of flow and overburden response during $\mathrm{CO}_{2}$ injection is carried out in the current research work. When a fluid is pumped into a reservoir, the pressure response of the system may change due to change in the fluid pressure and cause deformations in the reservoir layer and overburden rocks. The overall pressure response in the system therefore may not only be based on the reservoir characteristics but also depend on the geomechanical properties of the reservoir and overburden layers. The objective of numerical modeling in the present study is to investigate the migration of injected $\mathrm{CO}_{2}$ into the lower coal seam and to compute ground deformations caused by injection. Moreover, model results are compared with field measurements over a period of time to calibrate numerical models and understanding of reservoir changes.

In brief, the objectives of numerical modeling in the current research work are given below:

- Simulate $\mathrm{CBM}$ production and $\mathrm{CO}_{2}$ injection by performing multiphase flow modeling to investigate reservoir properties of both coal seams

- Investigate the influence of reservoir properties and geomechanical properties on the fluid pressure distribution

- Perform geomechanical modeling of ground response and fluid flow during $\mathrm{CO}_{2}$ injection at the field site

- Compute ground deformations and investigate the overburden response due to gemechanical properties

- Compare field measurements due to $\mathrm{CO}_{2}$ injection with model results

- Investigate the influence of injection pressures and injection volume on ground deformations at the field site 


\subsection{Numerical methodology}

In the current study, numerical modeling of $\mathrm{CO}_{2}$ injection was carried out by performing reservoir simulations and geomechanical modeling to investigate the behavior of fluid flow and to compute ground deformations caused by injection. Reservoir calculations for CBM production and $\mathrm{CO}_{2}$ injection were performed by using a compositional reservoir simulator provided by Computer Modeling Group (CMG, 2009). Solutions from simple to very complex engineering problems can be simulated using CMG's simulation software (CMG, 2009). Three-dimensional multiphase flow modeling of CBM production in both coal seams and $\mathrm{CO}_{2}$ injection in the lower coal seam was performed to history match and investigate the reservoir properties. The results of these reservoir calculations were used as input to three-dimensional couple flow and deformation geomechanical finite element models constructed specifically for the field site. The finite element modeling was performed by using a commercially available unified finite element analysis package, which is known as 'ABAQUS', a product of Simulia (ABAQUS, 2009). This finite element package provides exceptionally powerful solutions and is used in a wide variety of industrial applications. Finite element modeling and reservoir modeling were used in conjunction

with several other visualizing and data input software's to construct quality geologic models. More details on the numerical methodology of reservoir modeling and finite element modeling are discussed in sections described below:

\subsubsection{Reservoir modeling}

Reservoir simulations were performed on both coal reservoirs, the Pittsburgh coal and the Upper Freeport coal to investigate the behavior of fluid flow and to determine the pressure distribution at the reservoir level. These simulations were performed by using a compositional reservoir simulator (CMG, 2009). CMG's simulation software 'Builder/Results', 'GEM', and 'CMOST' were used for the purpose of this study. 'Builder' is pre-processing tool for CMG's reservoir simulators to construct single and dual porosity reservoirs for modeling applications such as primary and enhanced oil and natural gas recoveries (CMG, 2009). The use of 'Builder' has several advantages and few of these are described below (CMG, 2009): 
- allows the ability to create and import a modeling grid with complex geometries

- add/delete/import from simple to complex well trajectories

- define/import fluid flow models

- define/change rock-fluid properties and initial conditions

- import/create production or injection information related to gas, water or other multicomponent mixtures

- validate and allow to be used by other reservoir simulators

'Results' is a post-processing software allowing exceptionally sophisticated tools to visualize and plot results obtained after performing reservoir simulations (CMG, 2009). 'GEM' is a advanced compositional and GHG reservoir simulator that can be used to perform reservoir calculations related to single and dual porosity formations (CMG, 2009). GEM is ideal for simulation of compositional effects in primary CBM production and enhanced CBM production (CMG, 2009). The equation of state is already built into the software and allows the multi-component gas and fluid flow modeling along with geomechanics of the reservoir. 'CMOST' is CMG's extremely competent software which provides efficient tools for sensitivity analysis, history matching, optimization and uncertainty analysis (CMG, 2009).

Three-dimensional reservoir models of individual coal layers were constructed based on the available field and geologic details. Models of both reservoirs incorporate complex geometries with such varying coal thickness and varying top depth as shown in Figure 5.1. Since the boundary of the model was selected not only to cover the periphery of the wells but also to cover the area outside this region, a few geometric data points in these models have been interpolated and extrapolated with well log data. The reservoir model dimensions are 12,000 feet x 12,000 feet with $\mathrm{CO}_{2}$ injection pursued at the center. These reservoir calculations incorporate multiphase flow, a dual porosity system, anisotropy, stress-dependent permeability, sorption/desorption and coal swelling/shrinkage. 


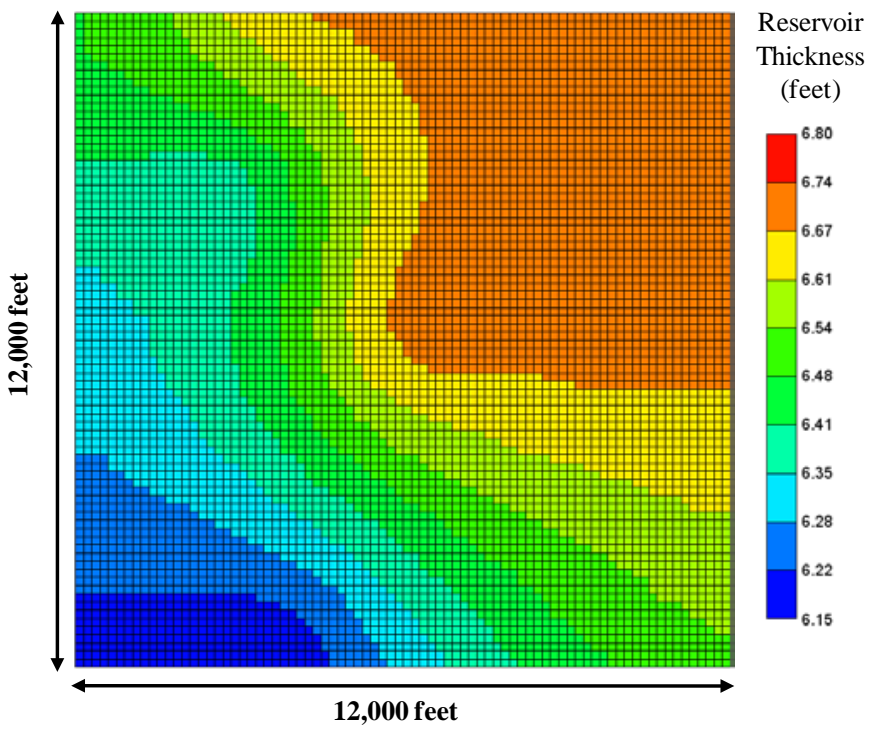

(a) Pittsburgh Freeport coal
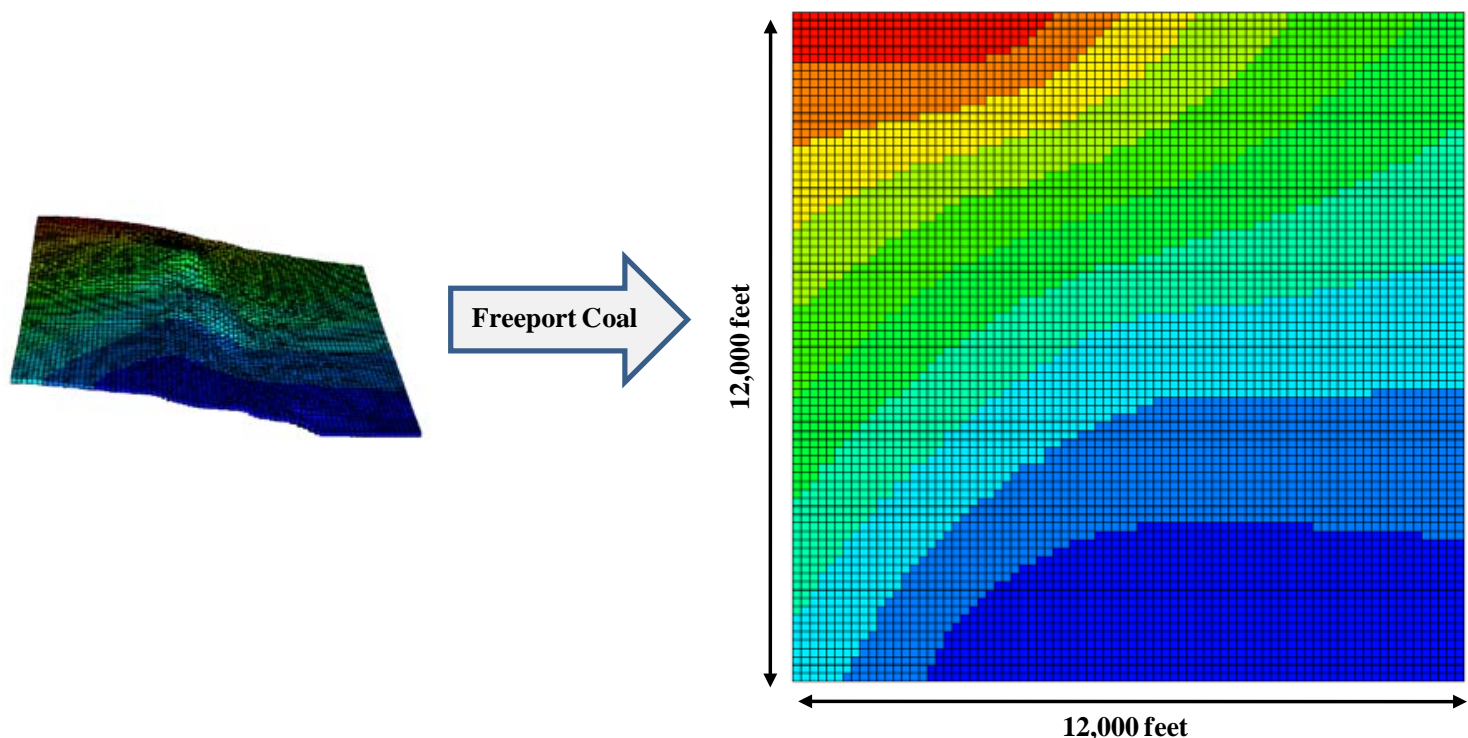

Reservoir Thickness (feet)

(b) Upper Freeport coal

Figure 5.1: Reservoir geometry of Pittsburgh coal and Upper Freeport coal used in the study 
$\mathrm{CBM}$ production from both coal seams and $\mathrm{CO}_{2}$ injection into the lower coal seam were performed by considering actual trajectories of horizontally drilled production and injection wells as shown in Figure 5.2. The well configuration in each reservoir layer is different. Figure 5.2(a) illustrates the projected view of wells on the ground topography. Figure 5.2(b) shows the well configuration in the Pittsburgh coal reservoir. $\mathrm{MH}-3, \mathrm{MH}-4$ and $\mathrm{MH}-12$ are the lateral wells of the Pittsburgh coal seam. MH-12 is a major active producer of coalbed methane in the coal seam since October 2004. Production of CBM from MH-3 started in October 2004 and was shutin in 2007. MH-4 has been sealed and is not an active producer. Therefore, MH-4 has been considered as a dormant well for modeling purposes. Figure 5.2(c) shows the well configuration used in the reservoir model of the Upper Freeport coal. Starting October 2004, CBM was produced from all the lateral wells (MH-5, MH-18, MH-20 and two legs of MH-11) present in the coal seam except MH-6, which was sealed. MH-5, MH-6 (sealed) and two legs of MH-11 are completed on the periphery and legs of MH-18 and MH-20 form a V-shaped and inverted Vshaped well patterns at the center of the site. While the legs of $\mathrm{MH}-18$ extend toward the north and west, the legs of MH-20 extend towards the south and east as shown in Figures 3.4 and 3.5. These central wells (MH-18 and MH-20) had been major producers. Later, they were converted from production wells to injection wells after sufficient reservoir depletion.

These reservoir models also account for the highest permeability in the face cleat direction. Cleat orientation allows directional permeability and better understanding of the migration of fluid. In the current study, the reservoir models for both coal seams have been oriented in the $\mathrm{N} 76^{0} \mathrm{~W}$, the direction in which face cleats are believed to be oriented near the field site. Moreover, the reservoir models also incorporate permeability anisotropy, which is common to coalbed reservoirs. A permeability anisotropy ratio of 3 has been assumed in these models based on the anisotropic values reported in the literature (McCoy et al, 2006). Cleat spacing was varied from 0.025 feet to 0.25 feet based on the published information for coal seams (Law, 1993; Steidl, 1977; Levine, 1996). 


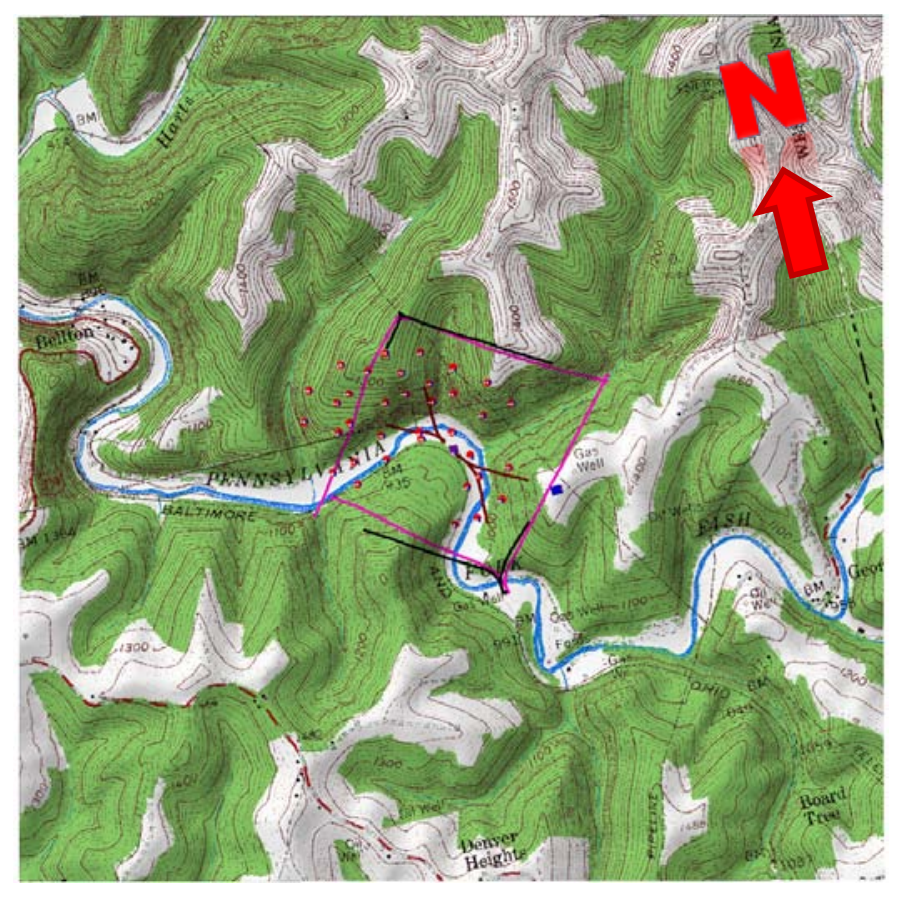

(a) Projected view on ground surface

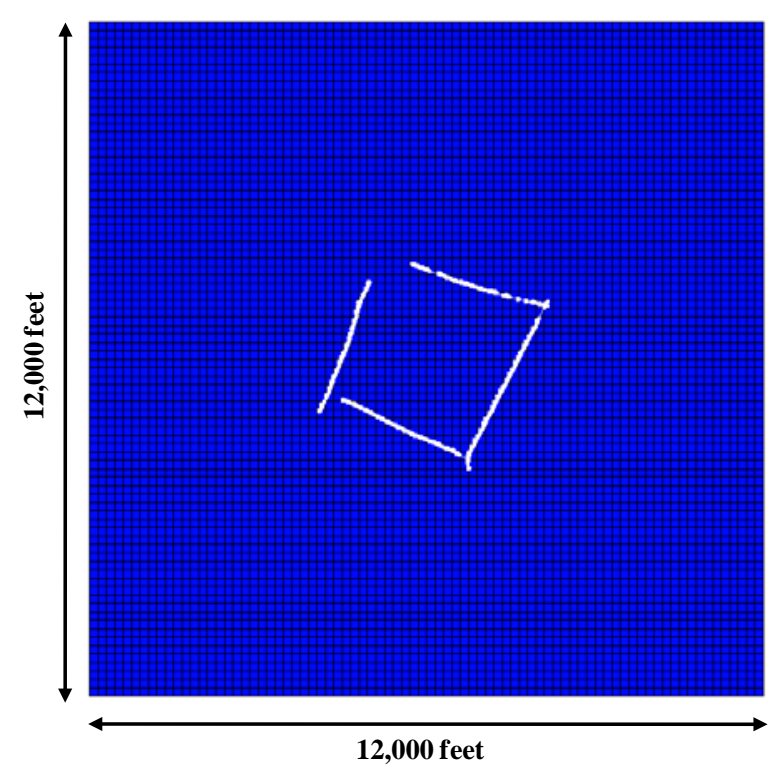

(b) Pittsburgh coal seam

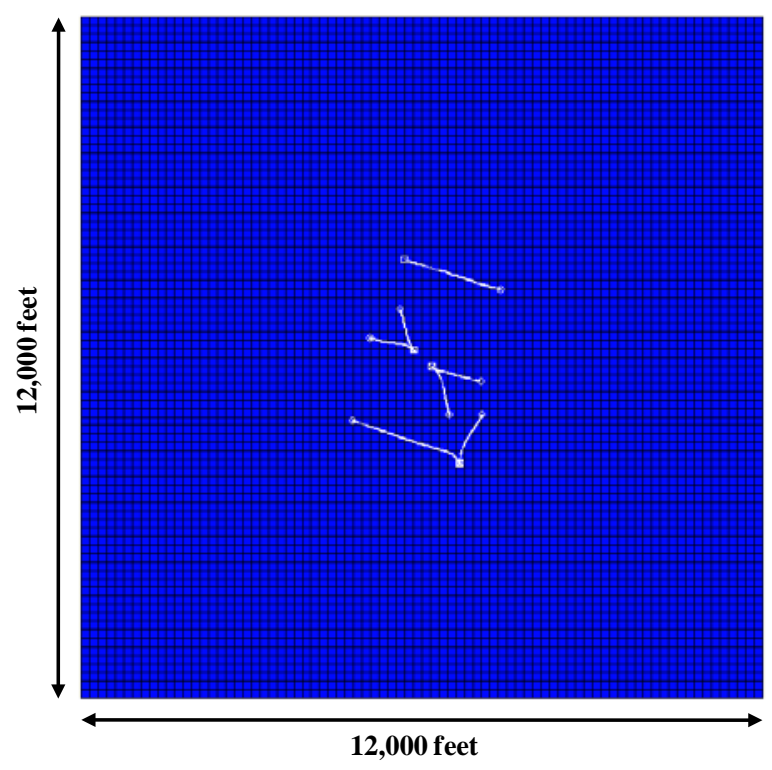

(c) Upper Freeport coal seam

Figure 5.2: Well configurations considered in the reservoir modeling study 
The reservoir models presented in the current study incorporate multi-phase fluid flow and gas transport by considering relative permeability. Initially, both coal seams have been considered as under-saturated reservoirs for reservoir simulations. Table 5.1 presents the comparison of conventional and unconventional properties used in the study for both coal seams. Conventional properties such as cleat porosity, absolute and reservoir permeability were obtained based on the literature. Unconventional reservoir properties such as initial gas content, initial gas composition, initial reservoir pressure, initial reservoir temperature, desorption times, Langmuir volumes and Langmuir pressures were used based on available field data. Since ground topography varies spatially, stress-dependent permeability was also considered in the reservoir modeling. For example, Figure 5.3 shows the stress-dependent permeability used in the reservoir modeling for the lower coal seam. Values of initial cleat permeability have been used by reviewing published literature (Bruner, 1995; Smith and Jikich, 2009; Jikich and Smith, 2009).

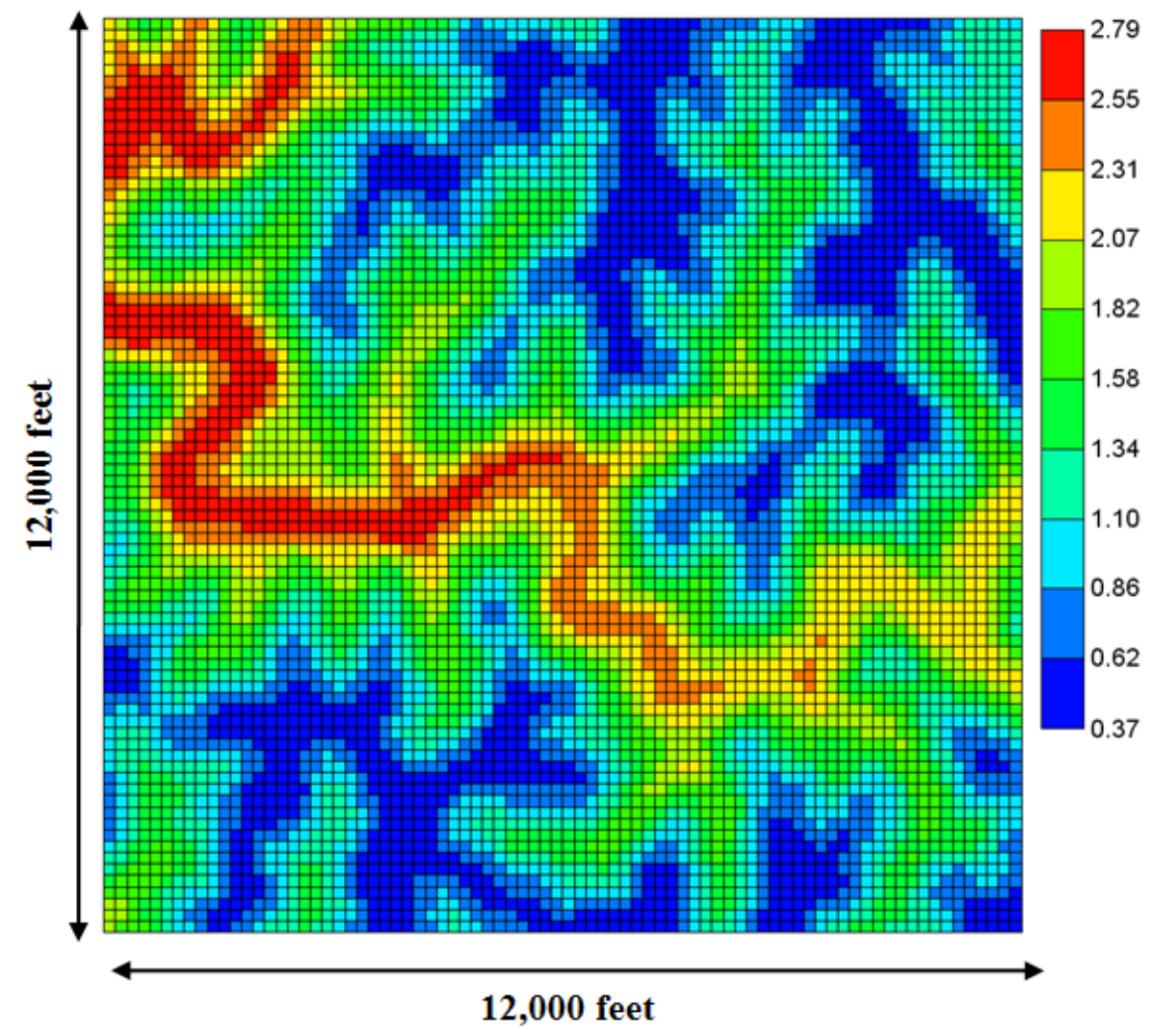

Figure 5.3: Stress-dependent permeability used in the study 
Table 5.1: Conventional and unconventional reservoir properties used in the study

\begin{tabular}{|c|c|c|}
\hline Reservoir Input & Pittsburgh Coal Seam & Upper Freeport Coal Seam \\
\hline Reservoir Grid (I, J, K) & $80,80,1$ & $80,80,1$ \\
\hline Individual Grid Block Size (feet) & 150 & 150 \\
\hline Reservo ir Depth (feet) & Variable Spatially & Variable Spatially \\
\hline Reservo ir Thickness (feet) & Variable Spatially & Variable Spatially \\
\hline Cleat Spacing (feet) & 0.025 & 0.025 \\
\hline Cleat Porosity (\%) & 1.0 & 0.5 \\
\hline Cleat Permeability (mD) & 1 & Stress-Dependent Permeability \\
\hline Coal Density (pcf) & 89.5 & 89.5 \\
\hline Coal Compressibility (1/psi) & $1.00 \mathrm{E}-06$ & $1.00 \mathrm{E}-06$ \\
\hline Poisson's Ratio & 0.34 & 0.34 \\
\hline Elas tic Modulus (psi) & 400,000 & 400,000 \\
\hline \multirow{2}{*}{ Strain at Infinite Pressure } & 0.0065 at 725 psi for $\mathrm{CH}_{4}$ & 0.0065 at 725 psi for $\mathrm{CH}_{4}$ \\
\hline & - & 0.025 at 480 psi for $\mathrm{CO}_{2}$ \\
\hline Palmer and Mansoori exponent & 3 & 3 \\
\hline Initial Reservo ir Temperature $\left({ }^{0} \mathrm{~F}\right)$ & $53.6+1.5{ }^{0} \mathrm{~F} / 100$ foot & $53.6+1.5{ }^{0} \mathrm{~F} / 100$ foot \\
\hline Initial Reservoir Pressure (psi/foot) & 0.42 & 0.42 \\
\hline Initial Water Saturation (\%) & 100 & 90 \\
\hline Water Viscosity (cp) & 0.7 & 0.7 \\
\hline Water Density (pcf) & 62.4 & 62.4 \\
\hline Gas Composition, \% $\left(\mathrm{CH}_{4}, \mathrm{CO}_{2}\right)$ & $(100,0)$ & $(100,0)$ \\
\hline Average Initial Gas Content (SCF/ton) for $\mathrm{CH}_{4}$ & $136 \mathrm{SCF} /$ ton & $182 \mathrm{SCF} / \mathrm{ton}$ \\
\hline Average Initial Gas Content (SCF/ton) for $\mathrm{CO}_{2}$ & Unknown & Unknown \\
\hline Langmuir Parameters for $\mathrm{CH}_{4}\left(\mathrm{~V}_{\mathrm{L}}, \mathrm{P}_{\mathrm{L}}\right)$ & (544.65 SCF/ton, 452 psi) & (531.3 SCF/ton, 402.8 psi) \\
\hline Langmuir Parameters for $\mathrm{CO}_{2}\left(\mathrm{~V}_{\mathrm{L}}, \mathrm{P}_{\mathrm{L}}\right)$ & (987.3 SCF/ton, 239.9 psi) & (700 SCF/ton, 450 psi) \\
\hline Coal Desorption Time (days) & 10 & 10 \\
\hline
\end{tabular}

Note:

1. Reservoir depth and reservoir thickness were selected based on the isopach maps generated based on the field data available by CONSOL Energy (Winschel, 2009; Winschel, 2010).

2. Isotherm data and sorption desorption data was provided by CONSOL Energy (Winschel, 2009).

3. Most of these values are averaged based on the published literature for the field site. 
Moreover, these reservoir models for the Pittsburgh and Upper Freeport coal also consider swelling and shrinkage of coal. Swelling and shrinkage of coal was modeled based on the Palmer and Mansoori model built into the software package. There have been several reported values in the literature for volumetric strains at varying pressures related to $\mathrm{CH}_{4}$ and $\mathrm{CO}_{2}$ for various coals (Roberston and Christiansen, 2005; Levine, 1996; Harpalani and Schraufnagel, 1990; Mitra and Harpalani, 2007; Clarkson et al, 2008). Average strain values of 0.0065 and 0.0175 at pressure of 725 psi and 480 psi have been considered for $\mathrm{CH}_{4}$ and $\mathrm{CO}_{2}$, respectively. Geomechanical properties such as elastic modulus, poisson's ratio, coal compressibility, coal density and strain at infinite pressures can also be seen in Table 5.1. These properties have been identified from the reported literature. Sorption properties were made available for $\mathrm{CH}_{4}$, however, the sorption properties related to $\mathrm{CO}_{2}$ were ambiguous. Recent studies provide values of $\mathrm{CO}_{2}$ sorption properties in the Upper Freeport coal (Smith and Jikich, 2009; Jikich et al, 2009). However, sorption values for $\mathrm{CO}_{2}$ have been adjusted in the reservoir modeling to match injection pressures and injection volumes at the field site.

Sensitivity analyses were performed (using CMOST) for both coal reservoirs to study the influence of unconventional reservoir properties and geomechanical properties. History matching was then performed on these reservoirs to determine best-fit properties. Gas production rates and cumulative gas production were matched. Along with $\mathrm{CBM}$ production, $\mathrm{CO}_{2}$ is being injected into central wells of the Upper Freeport coal. Field injection pressures were used as input to match field injection volumes in the history matching of $\mathrm{CO}_{2}$ injection in the Upper Freeport coal seam.

\subsubsection{Finite element modeling}

A multi-layered, three dimensional, coupled flow and deformation finite element model was constructed to investigate the fluid flow and overburden response at the field site. Since the primary interest of the current research work was to identify any ground movements caused due to $\mathrm{CO}_{2}$ injection, the finite element modeling was limited to $\mathrm{CO}_{2}$ injection. The models cover a spatial area of 12,000 x 12,000 square feet. The size of the coverage area was selected not only to cover the periphery of the horizontal wells, but was also extended to capture any deformations 
far away from injection region. The finite element model consists of five layers - overburden rock, upper coal seam, sandwich layer, lower coal seam and floor rock as shown in Figure 5.4. The finite element mesh used for the current research work is shown in Figure 5.4. The discretization of the geologic model was made using 10-noded quadratic tetrahedron elements and 20-noded quadratic brick elements, which are capable of handling stress and pore fluid. The finite element model incorporates flow, ground topography, horizontal well configuration and complex reservoir geometry. Figure 5.5 shows the idealized well configuration of injection wells used in the finite element model. Furthermore, the finite element model is oriented in the face cleat direction and accounts for permeability anisotropy.

The upper coal seam is located at a depth of 800 feet (approximately 246 feet above mean sea level), and the lower coal seam is located at depth of 1,400 feet (approximately 348 feet below mean sea level), separated by nearly 600 feet as shown in the Figure 5.4. Average thicknesses of the Upper Freeport coal and the Pittsburgh coal are about 4.2 feet and 6.6 feet, respectively. Other layers include shale and impermeable rocks as presented in preceding chapters. Table 5.2 shows the geomechanical properties used in the study. These geomechanical properties were calculated based on the average values of elastic modulus of geologic strata present in respective layers. Also, these values were consistent and similar to results obtained from geophysical studies performed and suggested at the site (Wilson, 2009).

Table 5.2: Geomechanical properties used in the study

\begin{tabular}{|c|c|c|c|}
\hline Layer & Density (pcf) & Elastic Modulus (psf) & Poisson's Ratio \\
\hline Overburden & 158 & $8.6 \mathrm{E}+008$ & 0.23 \\
\hline Pittsburgh Coal & 142 & $7.4 \mathrm{E}+008$ & 0.28 \\
\hline Sandwich & 158 & $1.078 \mathrm{E}+009$ & 0.18 \\
\hline Upper Freeport Coal & 142 & $7.4 \mathrm{E}+008$ & 0.28 \\
\hline Under burden & 158 & $8.6 \mathrm{E}+008$ & 0.23 \\
\hline
\end{tabular}



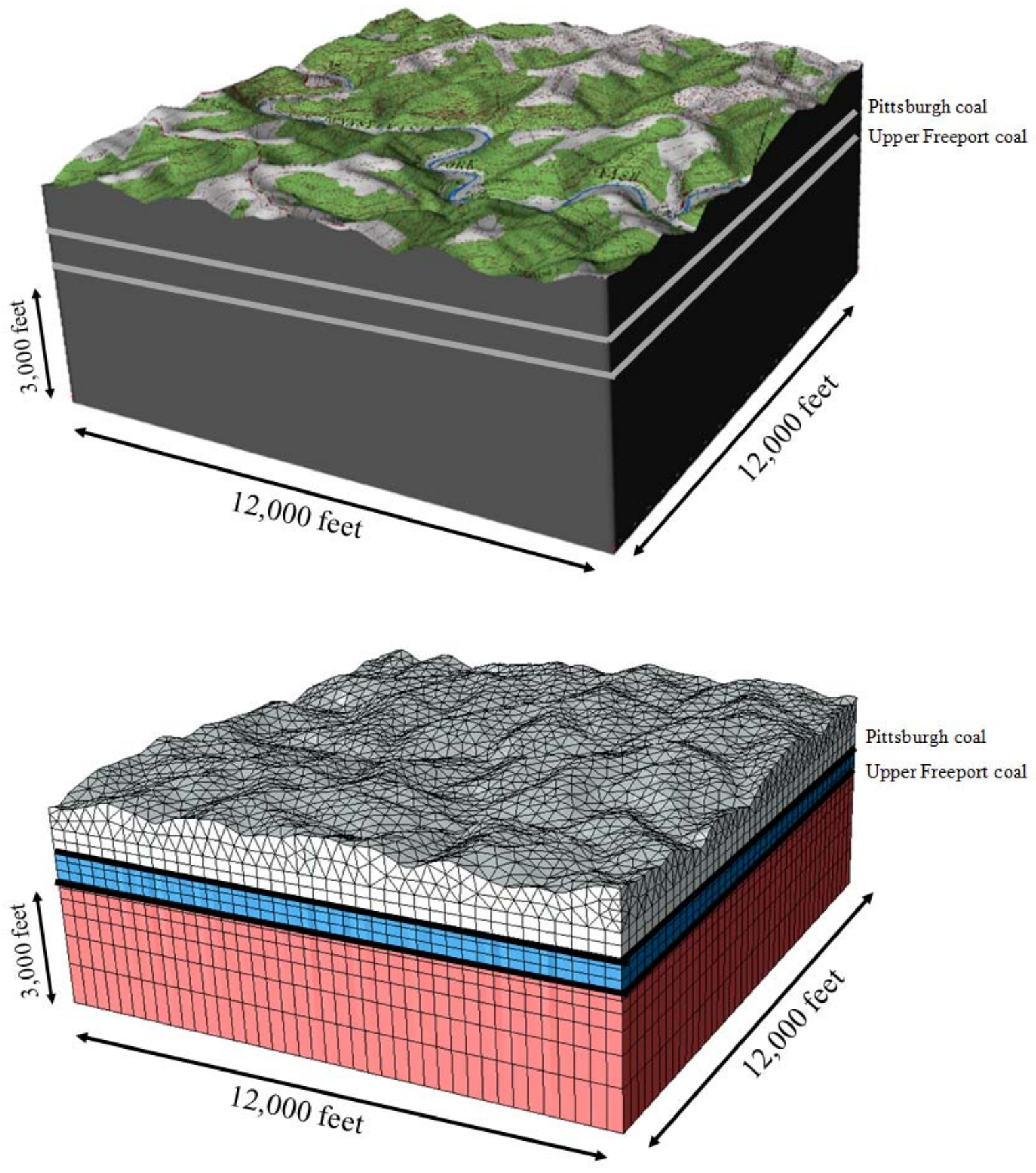

Figure 5.4: Geometry and mesh of the finite element model 

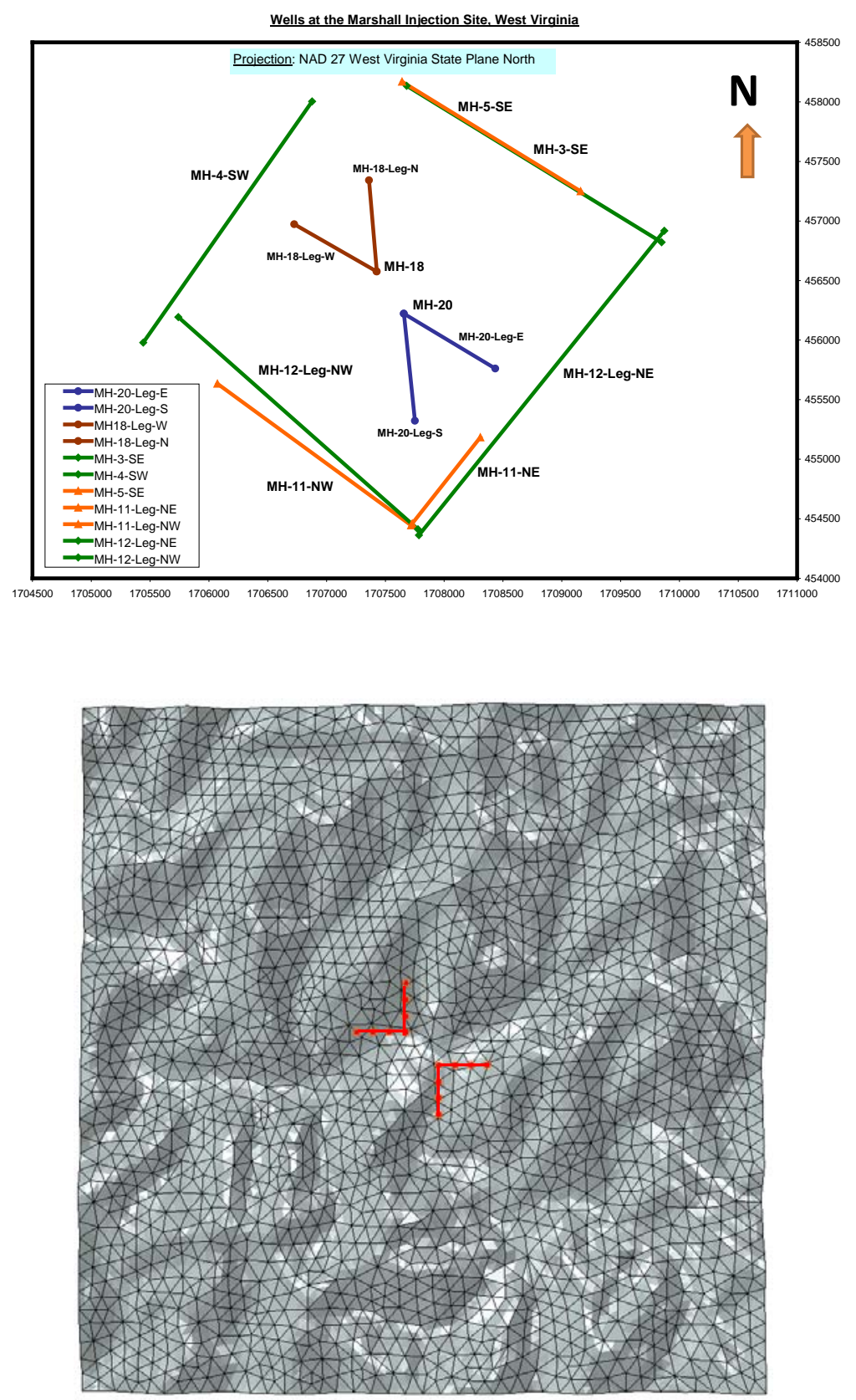

Figure 5.5: Idealized well configuration of $\mathrm{CO}_{2}$ injection wells 


\subsection{Mathematical formulations for coupled flow-deformation analyses}

Mathematical formulations in deformable porous medium depends on conservation of mass and energy, and Darcy's law for the fluid flow. The constitutive equations related to mathematical formulations of single-phase and multi-phase fluid flow in a deformable reservoir can be found extensively in published literature (Biot, 1955; Biot, 1956a; Biot, 1956b; Biot and Wills, 1957; Geerstma, 1973; Geerstma, 1974; Hassanizadeh, 1986ª ; Hassanizadeh, 1986 Settari and Mourits, 1998; Tran et al, 2002; Cook et al, 2004; Nghiem et al, 2004; Du and Wong, 2005; Tran et al, 2005; Settari et al, 2005; Chen et al, 2006; Nordbotten and Celia, 2006; Yin et al, 2007; Tran et al, 2008; Pan and Sepehrnoori, 2009). However, the mathematical details of coupled flow-deformation finite element analyses using ABAQUS is present in this study.

It has been reported that the deformation in a porous geologic media mainly depends on the effective stresses (ABAQUS, 2009). Moreover, these effective stresses may change depending on the saturation of the porous media and can be computed based on relationships described in the literature as given below (in Equations 5.1 and 5.2) (ABAQUS, 2009):

$$
\sigma_{v}^{\prime}=\sigma_{v}-u_{w} \text { (for a fully saturated porous media) }
$$

$$
\sigma_{v}^{\prime}=\left(\sigma_{v}-u_{a}\right)+\chi\left(u_{a}-u_{w}\right) \quad \text { (for a partially saturated porous media) }
$$

where:

$\sigma_{v}{ }^{\prime}=$ effective vertical stress

$\sigma_{v}=$ total vertical stress $=\mathrm{z} \gamma$

$u_{w}=$ pore pressure

$u_{a}=$ pore-air pressure

$\chi=$ factor dependent on degree of saturation of the porous media (0 - dry; 1 - fully saturated) 
Equilibrium equations have also been derived in the published literature by using the principle of virtual work (ABAQUS, 2009). Equation 5.3 presents these equilibrium equations (ABAQUS, 2009).

$$
\int_{V} \sigma: \delta \varepsilon d V=\int_{V} \hat{f} \cdot \delta v d V+\int_{S} t \cdot \delta v d S
$$

where

$\delta v$ = virtual velocity field $=N^{N} \delta v^{N}$ ( $N^{N}$ represents interpretation functions)

$\delta \varepsilon=$ virtual rate of deformation, $=\frac{\partial \delta v}{\partial x}=\beta^{N} \delta v^{N}$, where $\beta^{N}=\frac{\partial \delta N^{N}}{\partial x}$

$\sigma=$ true stress (Cauchy stress)

$t=$ surface tractions per unit area, and

$\hat{f}=$ body forces per unit volume

The body forces per unit volume, $\hat{f}$ in the above mathematical formulation is included by the weight of wetting liquid as expressed in Equation (5.4) (ABAQUS, 2009):

$$
f_{w}=\left(s n+n_{t}\right) \rho_{w} g
$$

where

$n=$ porosity of the porous media

$n_{t}=$ ratio of trapped wetting liquid to total volume of porous media

$\rho_{w}=$ density of the wetting liquid

$g=$ acceleration due to gravity

Therefore, Equation (5.5) presents the modified equation (ABAQUS, 2009): 


$$
\int_{V} \sigma: \delta \varepsilon d V=\int_{V} f \cdot \delta v d V+\int_{V}\left(s n+n_{t}\right) \rho_{w} g \cdot \delta v d V+\int_{s} t \cdot \delta v d S
$$

Equation (5.5)

It has also been reported that Equation (5.5) can be modified by combining virtual deformation rates and velocity fields, and written as shown in Equation (5.6) given below (ABAQUS, 2009):

$$
\delta v^{N} \int_{V} \beta^{N}: \sigma d V=\delta v^{N}\left[\int_{V} N^{N} \cdot f d V+\int_{V}\left(s n+n_{t}\right) \rho_{w} N^{N} \cdot g d V+\int_{s} N^{N} \cdot t d S\right]
$$

The 'terms' conjugate to $\delta v$ on the left hand side and right hand side of Equation (5.6) are referred to as internal load array $\left(I^{N}\right)$ and external load array $\left(P^{N}\right)$ in the literature (ABAQUS, 2009). The balanced expression reported is shown in Equation (5.7) (ABAQUS, 2009):

$$
I^{N}-P^{N}=0
$$

In the finite element mathematical formulation of porous media, the modeling of porous media is reported by assuming a finite element mesh attached to the solid substance, and allowing fluid to pass through the finite element mesh (ABAQUS, 2009). Hence, a continuity equation is suggested to balance the rate of fluid mass stored at a point and flowing into a point within a small time increment (ABAQUS, 2009). Consider a fixed amount of solid substance, V with surface S. At any time, $t$, if the amount of fluid flowing through this volume is expressed as $V_{w}$ and the volume of fluid trapped is expressed as $V_{t}$, the amount of total fluid contained in this controlled volume can be calculated using Equation (5.8) as discussed in the literature (ABAQUS, 2009):

$$
\int_{V} \rho_{w}\left[d V_{w}+d V_{t}\right]=\int_{V} \rho_{w}\left(n_{w}+n_{t}\right) d V
$$


where

$\rho_{w}=$ fluid density

$n_{w}=$ porosity of free fluid at a point, $=\frac{d V_{w}}{d V}$

$n_{t}$ - porosity of fluid trapped, $=\frac{d V_{t}}{d V}$

Also, the rate of volume change can be expressed as given below (ABAQUS, 2009):

$$
\frac{d}{d t}\left(\int_{V} \rho_{w}\left(n_{w}+n_{t}\right) d V\right)=\int_{V} \frac{1}{J} \frac{d}{d t}\left(J \rho_{w}\left(n_{w}+n_{t}\right)\right) d V
$$

Equation (5.9)

where

$\mathrm{J}=$ ratio of current volume to original volume, $J=\left|\frac{d V}{d V^{0}}\right|$

$V=$ volume in the current state

$V^{0}=$ original reference volume

As reported, according to mass conservation, the time rate of fluid change in the controlled volume should be same as the rate of fluid mass passing through this volume (right hand side of Equation (5.10)) as shown below (ABAQUS, 2009):

$$
\int_{V} \frac{1}{J} \frac{d}{d t}\left(J \rho_{w}\left(n_{w}+n_{t}\right)\right) d V=-\int_{S} \rho_{w} n_{w} n \cdot v_{w} d S
$$

Equation (5.10)

Overall, the governing equations for the coupled fluid flow and deformation are derived and more details can be found elsewhere (ABAQUS, 2009). Equation (5.11) and (5.12) are examples of such governing equations (ABAQUS, 2009): 


$$
\begin{gathered}
K^{M N} \bar{C}_{\delta}^{N}-L^{M P} \bar{C}_{u}^{P}=P^{M}-I_{\text {(equilibrium equation) }}^{M} \\
\left(\widehat{B}^{M Q}\right)^{T_{\bar{v}} M}+\widehat{H}^{Q P_{\bar{u}} P}=Q_{\text {(po...... Equa fluid equation) }}^{Q}
\end{gathered}
$$

Equation (5.12)

\subsection{Modeling results}

Results from reservoir modeling and finite element modeling have been separated out in sub-sections and is presented below.

\subsubsection{Results of reservoir modeling study}

Sensitivity analyses were performed for both coal reservoirs to understand the influence of individual reservoir and geomechanical properties. Results from the sensitivity study show that porosity and permeability of reservoir has tremendous influence on the reservoir behavior, along with the swelling and shrinkage of coal. History matching was then performed on individual reservoirs to determine optimized and best-fit properties for each reservoir. CBM was produced from both coal seams and $\mathrm{CO}_{2}$ was injected into lower coal seams according to field conditions. Figure 5.6 shows the comparison of measured data and computed gas production data of periphery wells, MH-12, MH-5 and MH-11. MH-12 was a major and constant producer of all. Computed results show an excellent comparison to measured gas production data from MH-12. Gas production from MH-5 and MH-11 were sporadic, and Figure 5.6 shows the history match. 

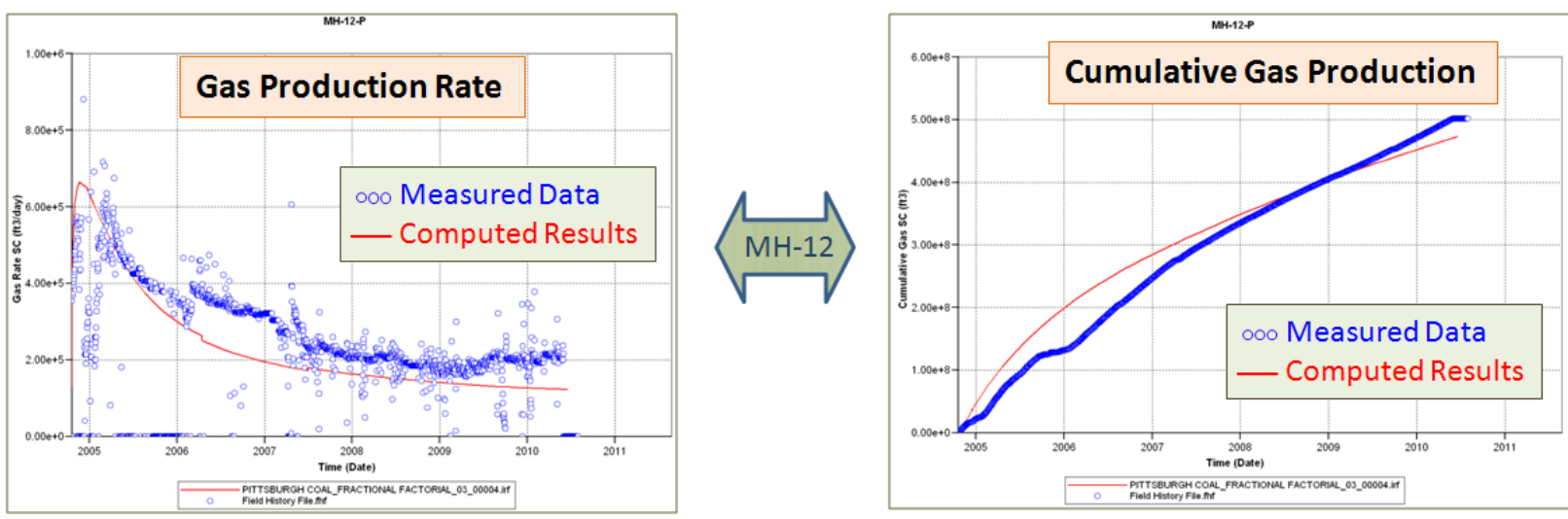

(a) Gas production of $\mathrm{MH}-12$
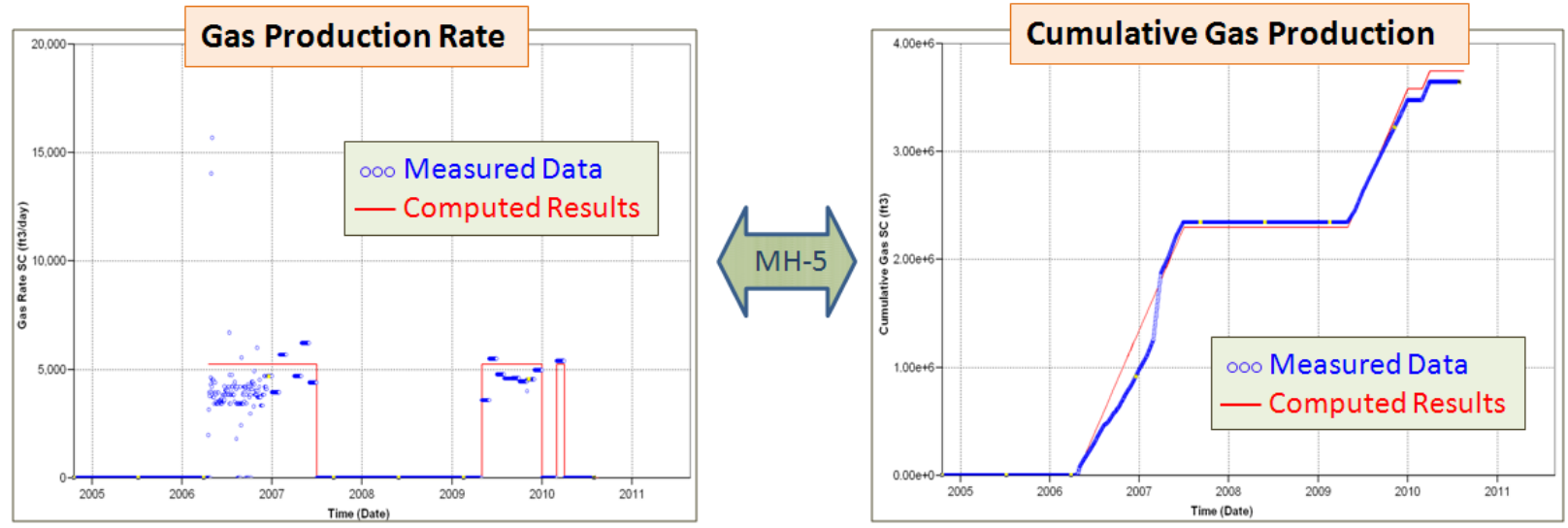

(b) Gas production of $\mathrm{MH}-5$
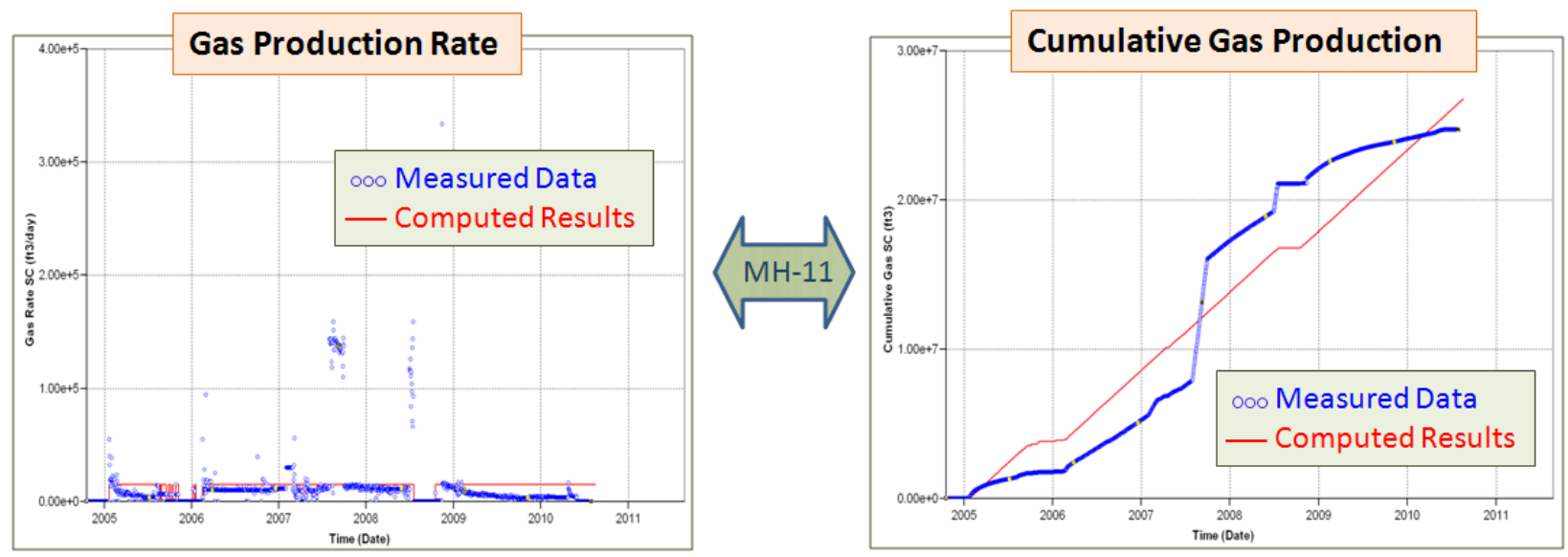

(c) Gas production of $\mathrm{MH}-11$

Note: Measure data was provided by CONSOL Energy (Winschel, 2009; Winschel et al, 2010).

Figure 5.6: History matching results of CBM production from $\mathrm{MH}-12, \mathrm{MH}-5$ and $\mathrm{MH}-11$ 
MH-18 and MH-20 were producing CBM until 2007. After sufficient CBM depletion in the reservoir, these central wells (MH-18 and $\mathrm{MH}-20)$ were ceased and converted from production wells to injection wells. About 20,000 tons of $\mathrm{CO}_{2}$ injection is planned into the lower coal seam (Winschel et al, 2010). However, as of now, about 1,000 tons of $\mathrm{CO}_{2}$ has been injected with about 640 tons going into the north and west legs of $\mathrm{MH}-18$ and 360 tons of $\mathrm{CO}_{2}$ going into the south and east legs of $\mathrm{MH}-20$. In the reservoir modeling, field injection pressures were used as input to match field injection volumes. History matching results of $\mathrm{CBM}$ production and $\mathrm{CO}_{2}$ injection in MH-18 and MH-20 can be seen in Figure 5.7. Results from Figure 5.7 show a good match with measured data.

Moreover, Figure 5.8 shows the reservoir pressure distribution in Pittsburgh coal seam and Upper Freeport coal seam due to $\mathrm{CBM}$ depletion and $\mathrm{CO}_{2}$ injection at certain periods of time. Results from Figure 5.8 show reduced reservoir pressures due to CBM extraction in both coal seams prior to $\mathrm{CO}_{2}$ injection. Figure 5.8a shows major pressure depletion along the well trajectories of legs of $\mathrm{MH}-12$ since $\mathrm{MH}-12$ is a major producer in the region. Due to CBM depletion, an increase in the cleat permeability was observed in both coal seams due to shrinkage of coal. Since the $\mathrm{CO}_{2}$ injection, an increase in the reservoir pressure was noticed along the legs of MH-18 and MH-20 as shown in Figure 5.8b. The pressure increase along the legs of MH-18 was higher (compared to $\mathrm{MH}-20$ ) due to fact that more volume of $\mathrm{CO}_{2}$ was injected into northwest legs of $\mathrm{MH}-18$. Coal swelling parameters and $\mathrm{CO}_{2}$ sorption properties had significant influence in the history matching process of $\mathrm{CO}_{2}$ injection. Furthermore, the pressure distribution in the lower coal seam shows that injection is a localized phenomenon and was confined near well trajectories. 

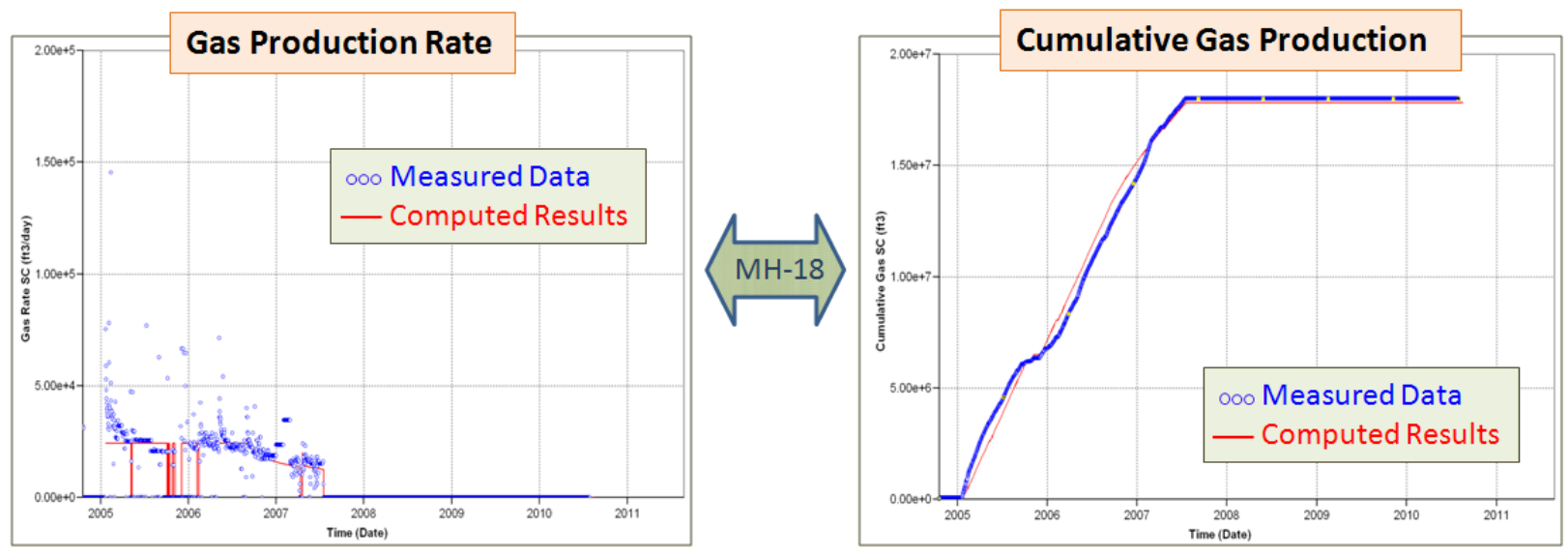

(a) Gas production of $\mathrm{MH}-18$
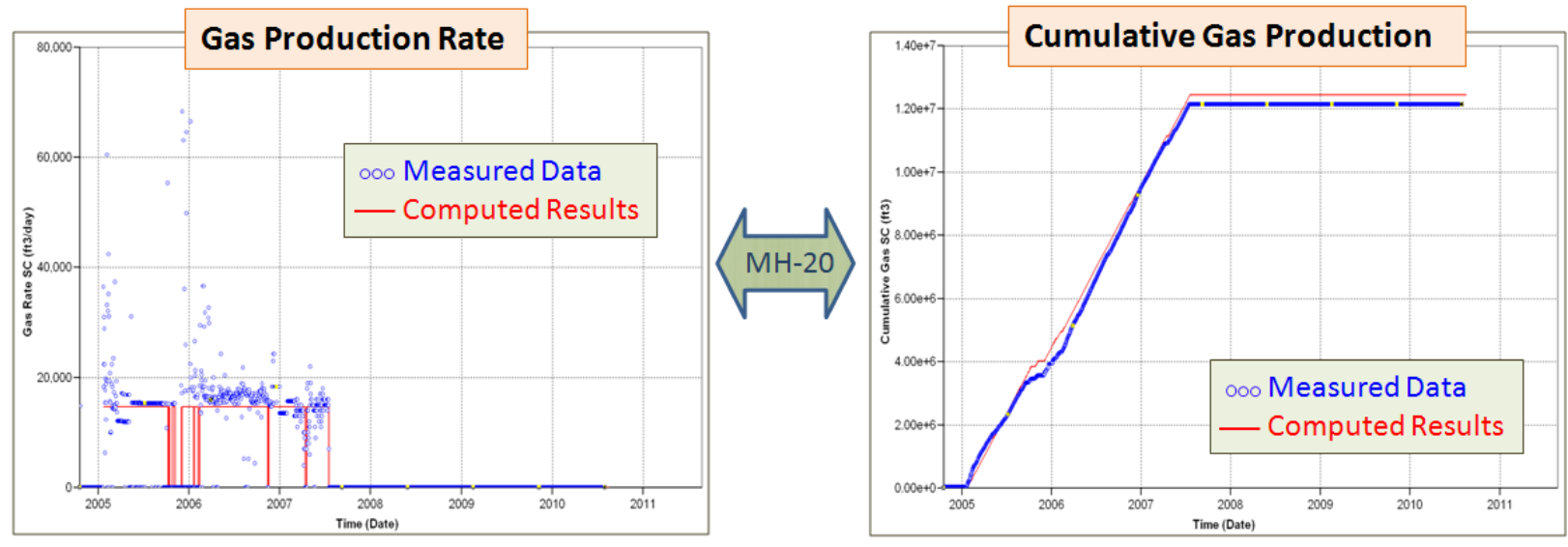

(b) Gas production of $\mathrm{MH}-20$
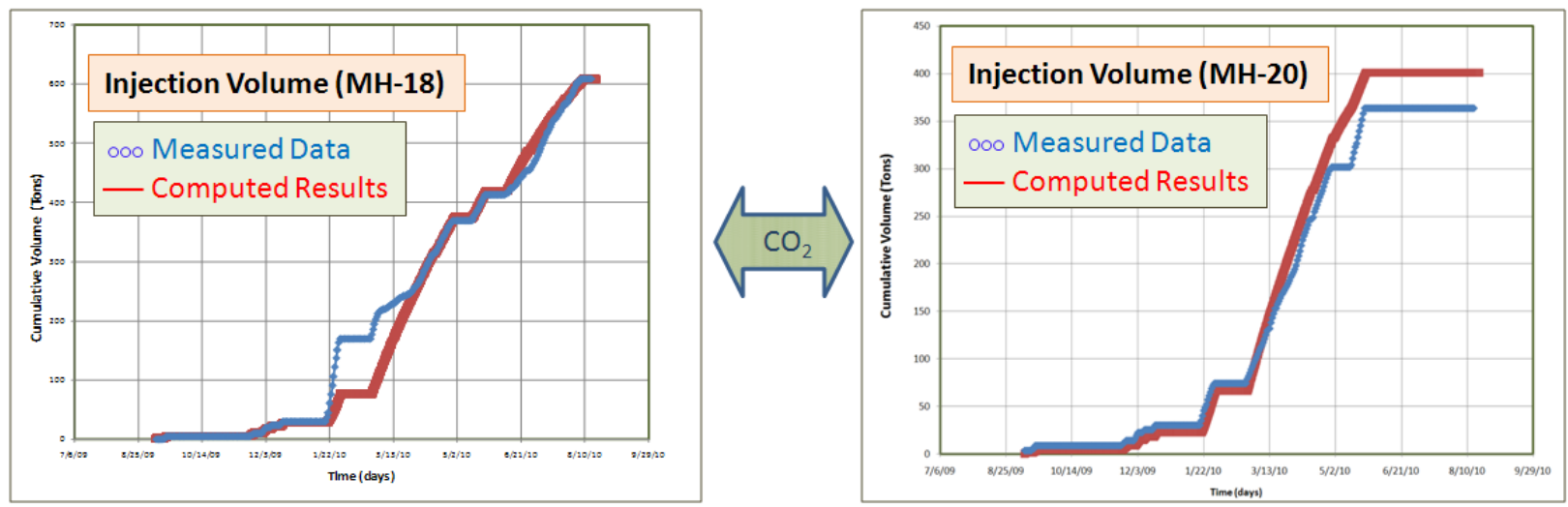

(c) Injection volumes of $\mathrm{MH}-18$ and $\mathrm{MH}-20$

Note: Measure data was provided by CONSOL Energy (Winschel, 2009; Winschel et al, 2010).

Figure 5.7: History matching results of production and $\mathrm{CO}_{2}$ injection of $\mathrm{MH}-18$ and $\mathrm{MH}-20$ 


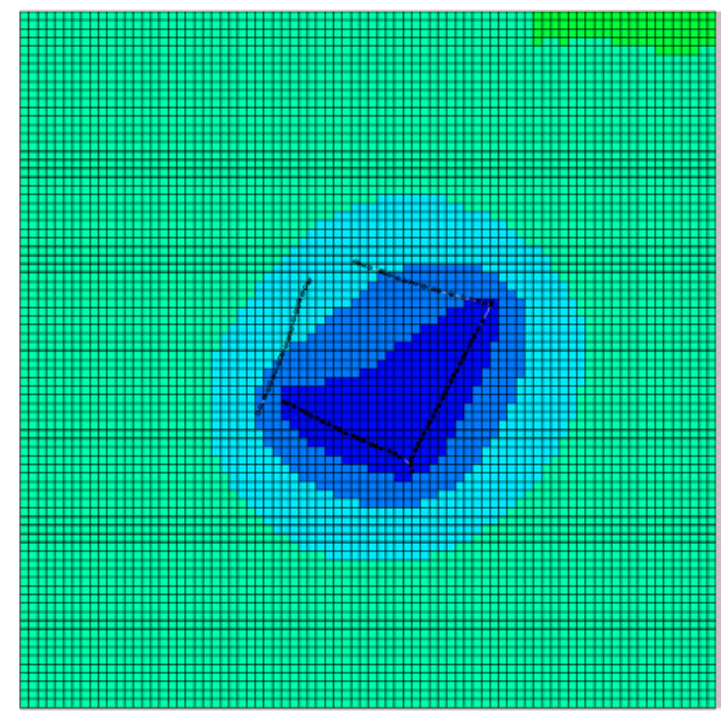

September 08, 2009

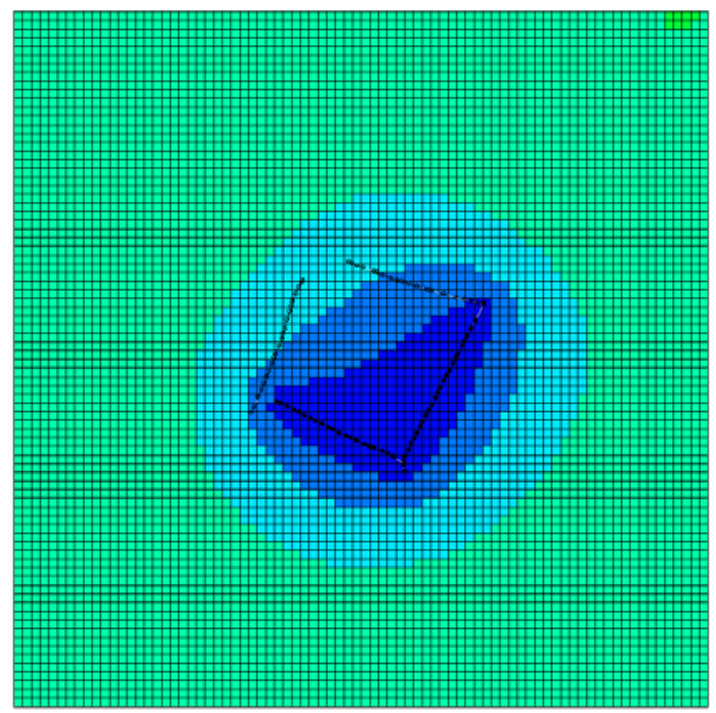

June 19, 2010
Reservoir

Pressure (psi)

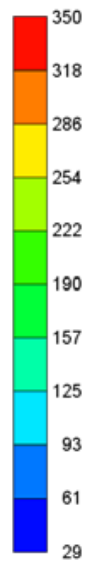

(a) upper coal seam (Pittsburgh coal seam)

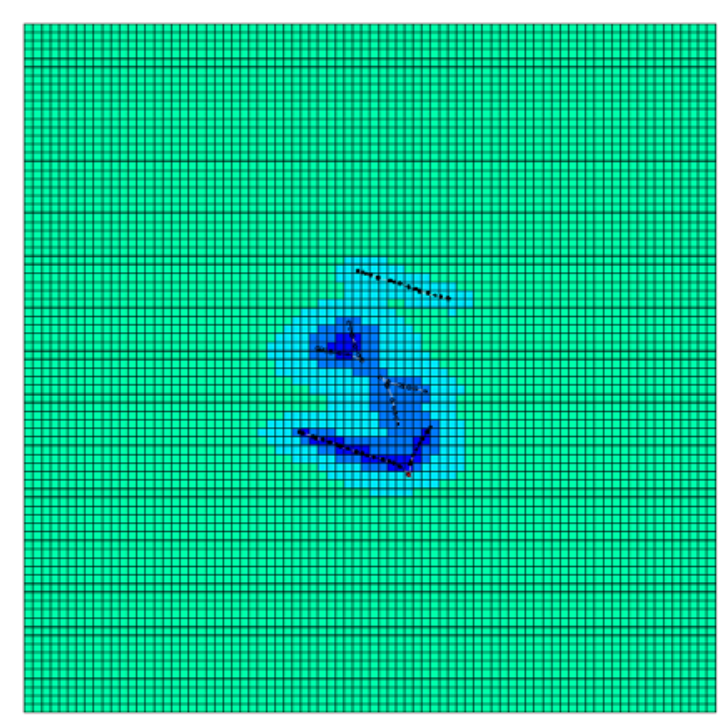

September 08, 2009

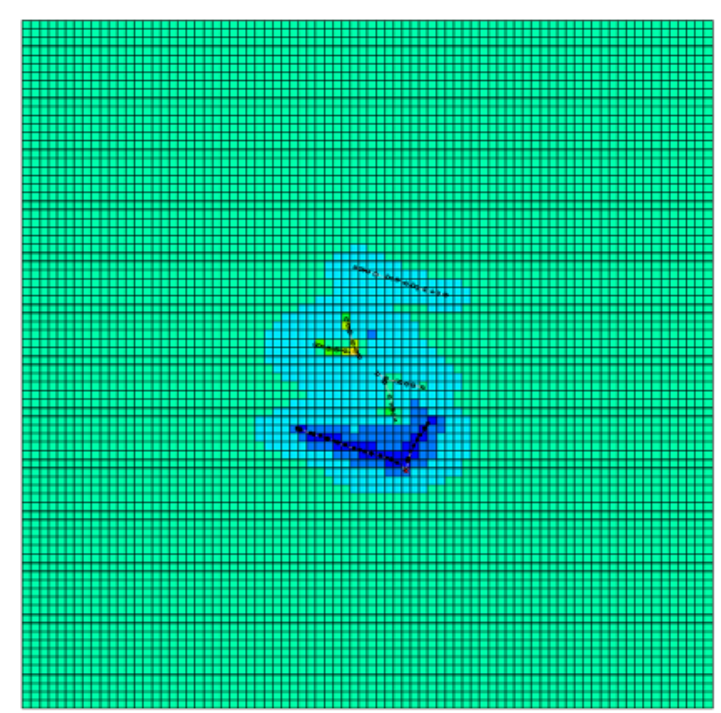

August 19, 2010

(b) lower coal seam (Upper Freeport coal seam)

Figure 5.8: Reservoir pressure distribution 


\subsubsection{Finite element results}

Coupled flow-deformation finite element analyses were performed to investigate the fluid flow and overburden response due to injection of $\mathrm{CO}_{2}$ into the lower coal seam. The finite element model incorporates a horizontal well configuration and challenges due to surface topography. Injection of $\mathrm{CO}_{2}$ began on September 08, 2009 and as of now, about 1,000 tons of $\mathrm{CO}_{2}$ was injected into lower coal seam. Figure 5.9 shows the pressure response in the lower coal seam at the end of injection period. It can be observed from the figure that the fluid pressure distribution is highly localized in the reservoir layer, and is consistent with results from the reservoir modeling study. Figure 5.10 shows the variation of fluid pressure with depth using the same scale. Pressure response on the ground surface was insignificant due to limited injection volumes. However, the distribution of fluid pressure in overburden layers is interesting.
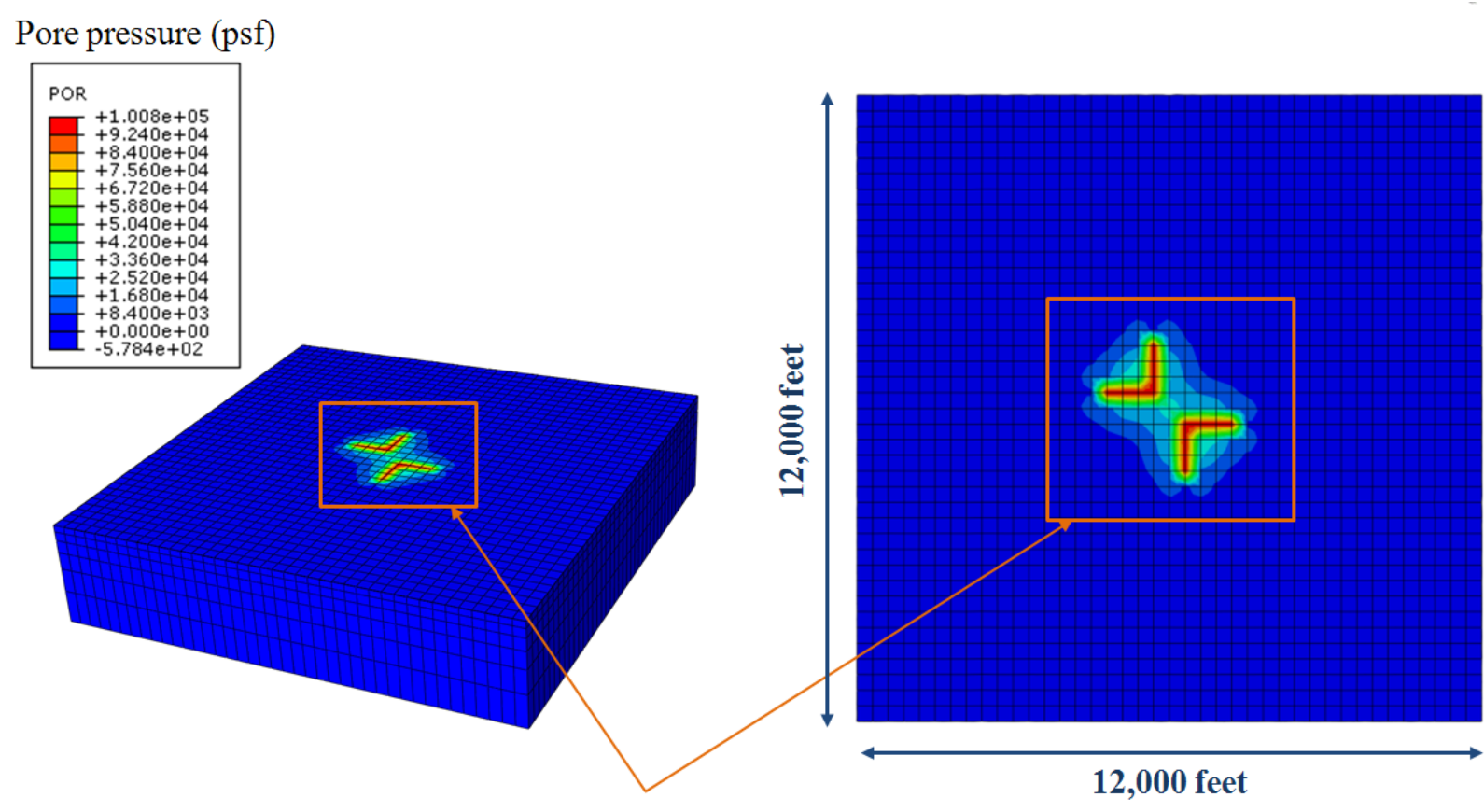

12,000 feet

Pressure distribution

Figure 5.9: Fluid pressure distribution in the lower coal seam at the end of injection period 

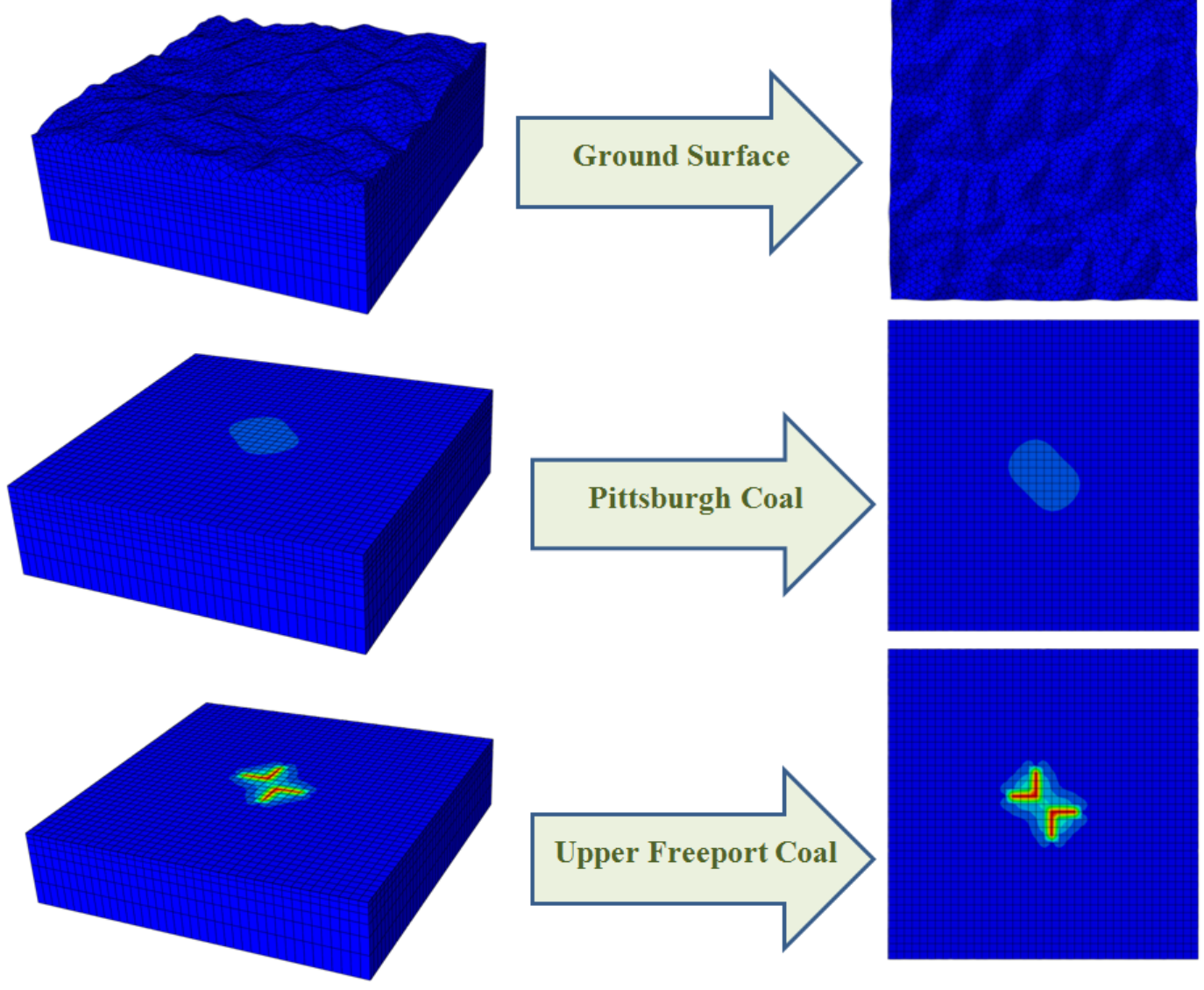

Pore pressure

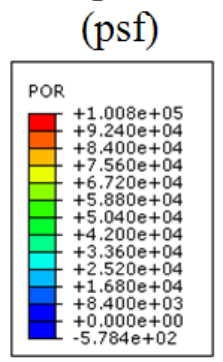

Figure 5.10: Fluid pressure distribution in the reservoir and overburden layers

Figure 5.11 shows the computed ground deformations caused due to $\mathrm{CO}_{2}$ injection. Results show that computed surface displacements vary in the range of 0.14 inches to 0.18 inches. Computed ground deformations show higher displacements right above the injection zone in low lying areas at the field site may be because of the difference in the overburden. Large deformations in such low lying areas could possibly change the stream flow. Figure 5.12 shows the computed deformations in the overburden layers. Results indicate that surface deformations are less predominant when compared to the upper coal seam, but may be useful in understanding the overburden response of the system. Figure 5.13 shows the displacements and stress changes in the overall system. The stress patterns and deformations patterns are significantly different, and can be used in investigation of high stress zones. 


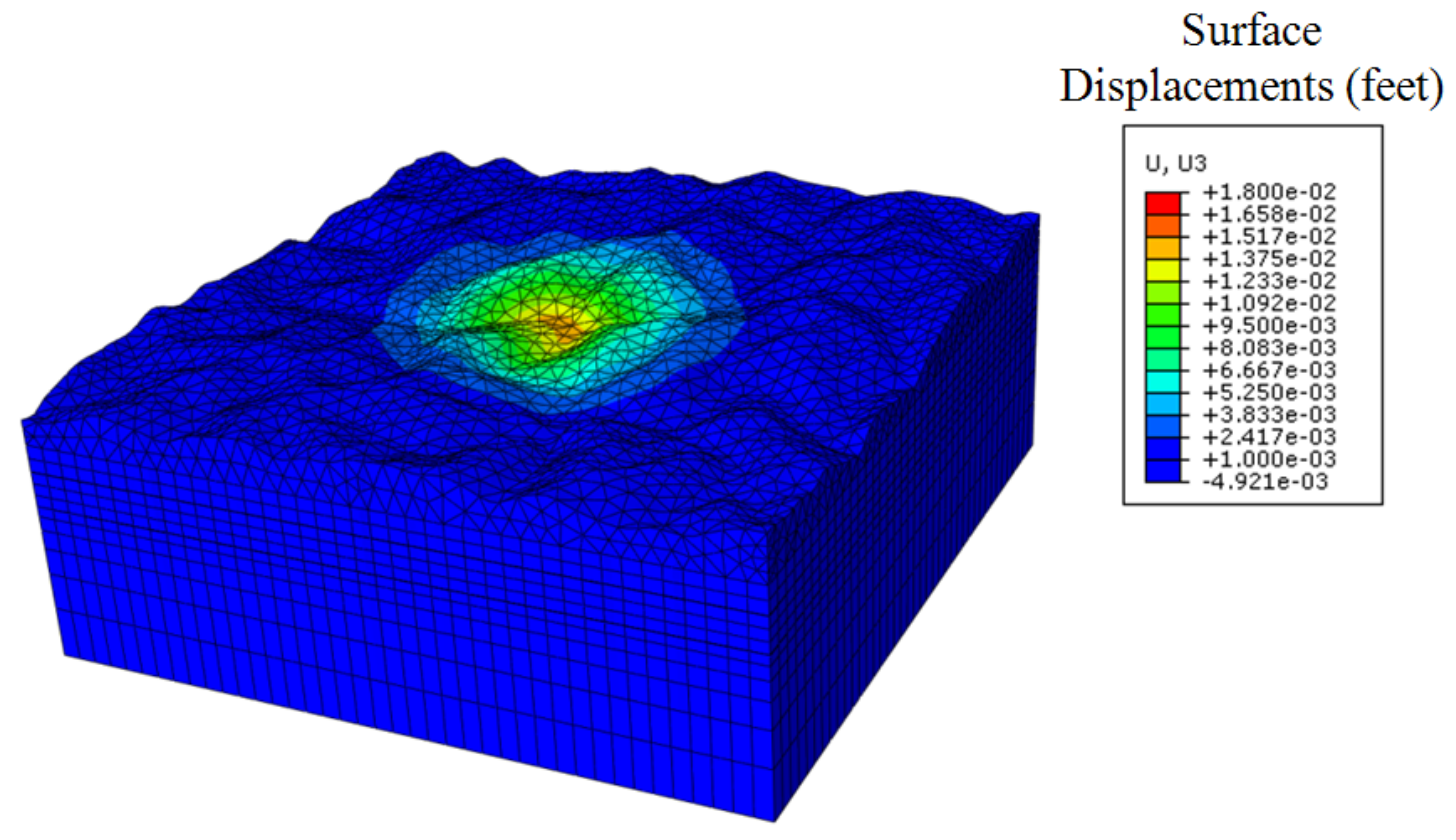

(a) perspective view

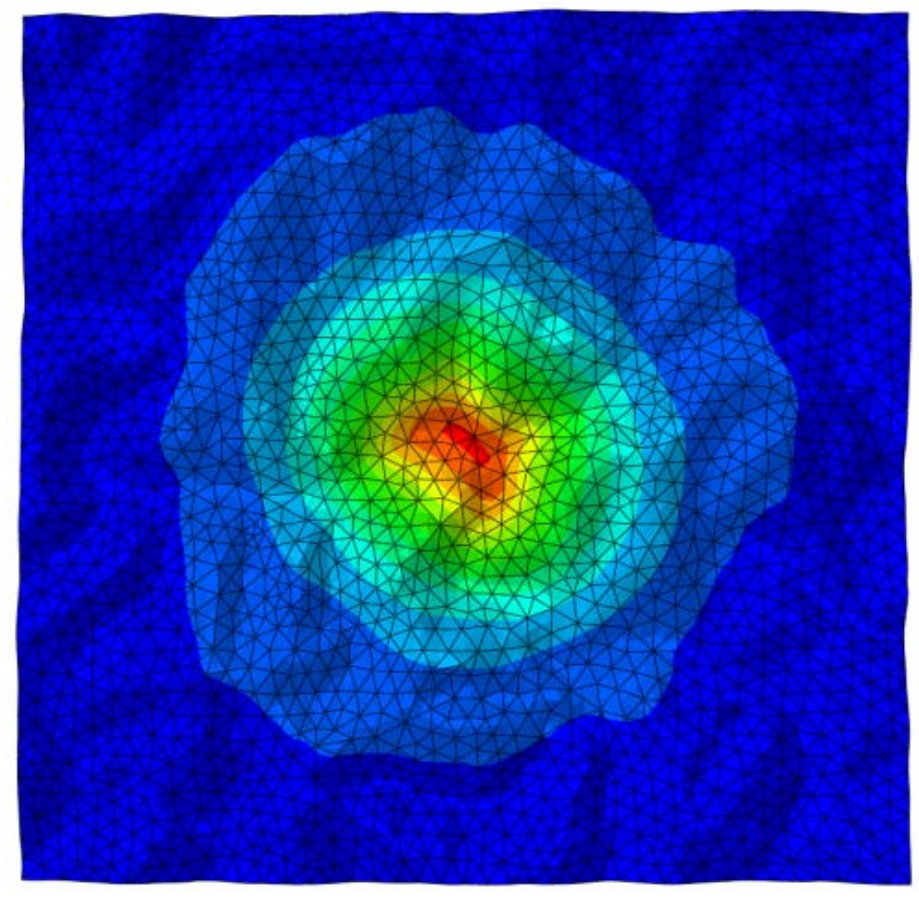

(b) aerial view

Figure 5.11: Computed surface displacements 

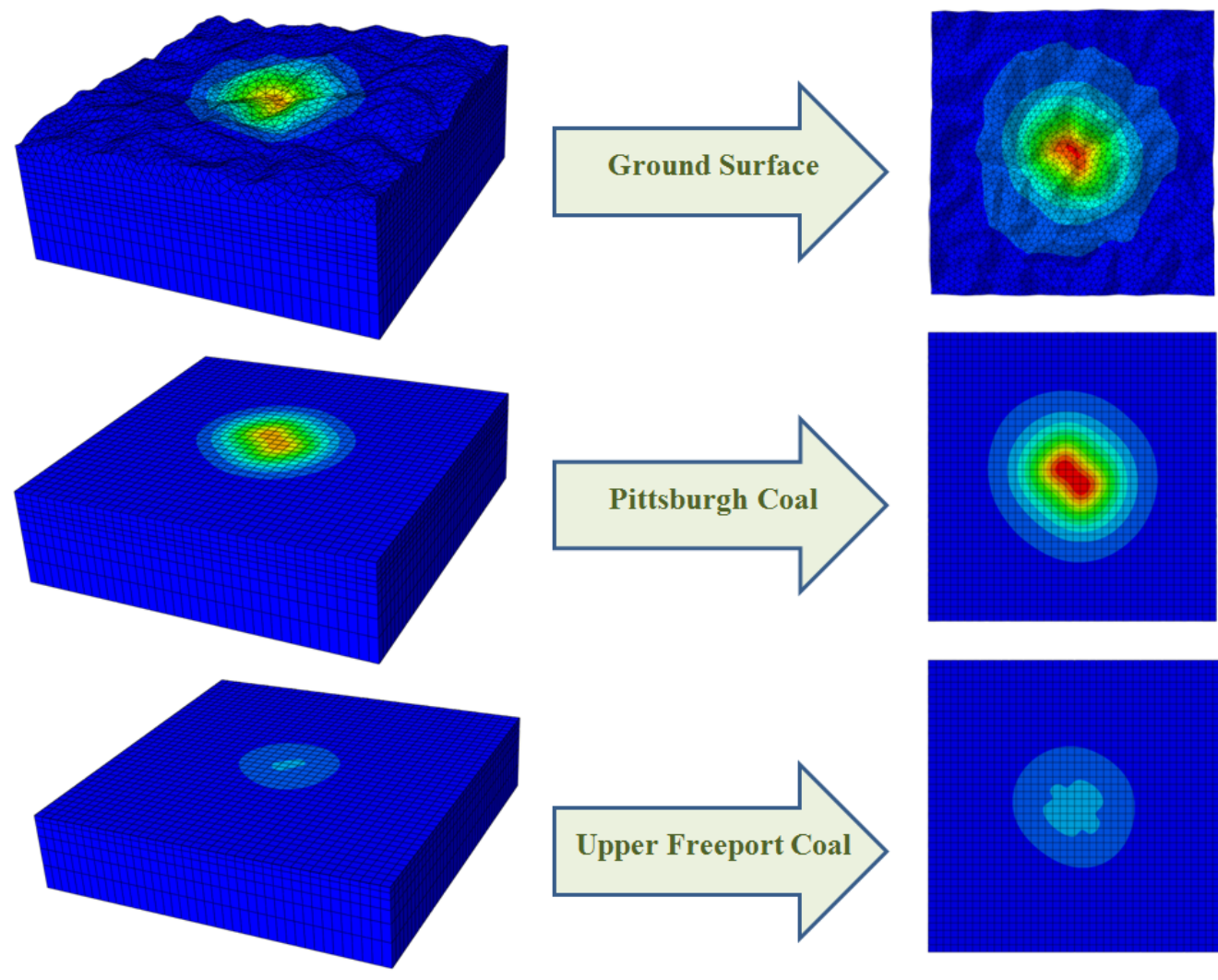

Surface

Displacements
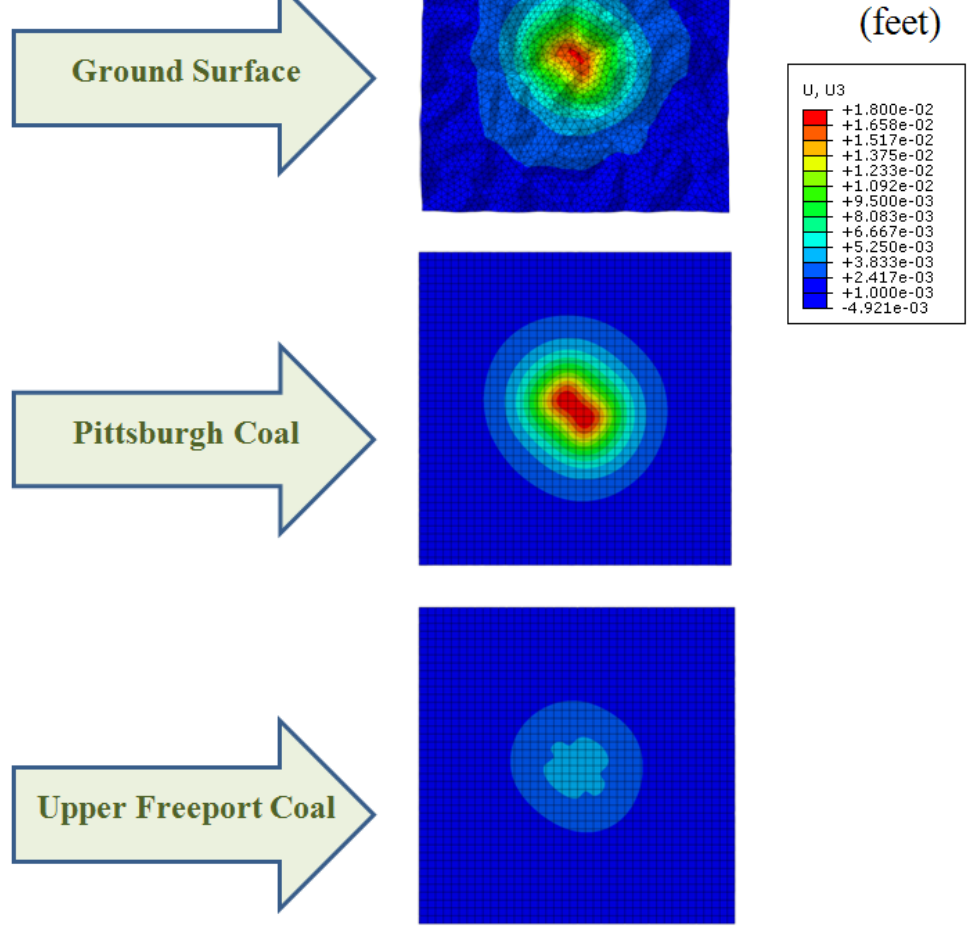

Figure 5.12: Vertical displacements in overburden layers
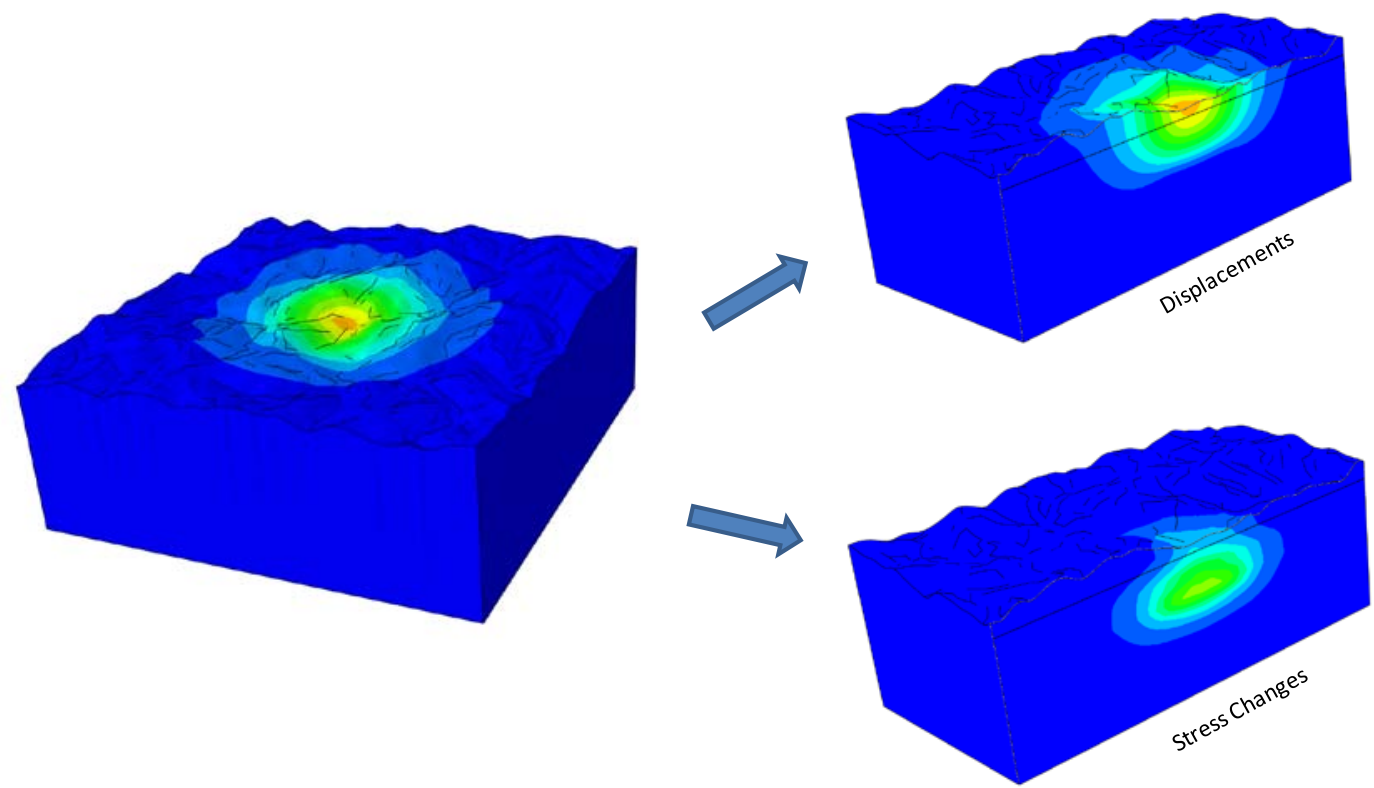

Figure 5.13: Displacement and stress changes 


\subsubsection{Comparison of computed and measured surface displacements}

Figure 5.14 presents the comparison of computed surface displacements with field measurements projected on the surface topography. Results show a good match between computed and measured surface displacements. Also, signs of fluid movement could be noticed along the trajectories of injection wells. Production of CBM along lateral well in northwest may be a reason for subsidence in surface displacement. However, this is not a major producer and is very premature to draw any conclusions as not much of $\mathrm{CO}_{2}$ was injected and no significant deformations have been observed.

\subsubsection{Correlation of measured and computed ground displacements}

Since large volumes of $\mathrm{CO}_{2}$ were injected more consistently into north-west legs of $\mathrm{MH}$ 18, surface displacements near the well trajectories of $\mathrm{MH}-18$ were used to investigate the correlation between measured data and computed results. Figure 5.15 represents the correlation between measured and computed surface displacements. Results from numerical modeling show similar trends to field measurements. The correlation plot shows a good linear match between field measurements and computed values with $\mathrm{R}^{2}$ value of nearly 0.7 .

5.4.5 Pressure comparison from reservoir modeling and finite element modeling

Pressure distributions from reservoir modeling and finite element modeling were compared (similarly near the well trajectories of MH-18) and can be seen in Figure 5.16. Pressure changes caused due to $\mathrm{CO}_{2}$ injection were confined along the well trajectories. Results from Figure 5.16 show that the pressure distribution was similar in reservoir modeling and finite element modeling. However, pressure values from finite element analyses were slightly higher. A linear trend in the pressure correlation was observed. 

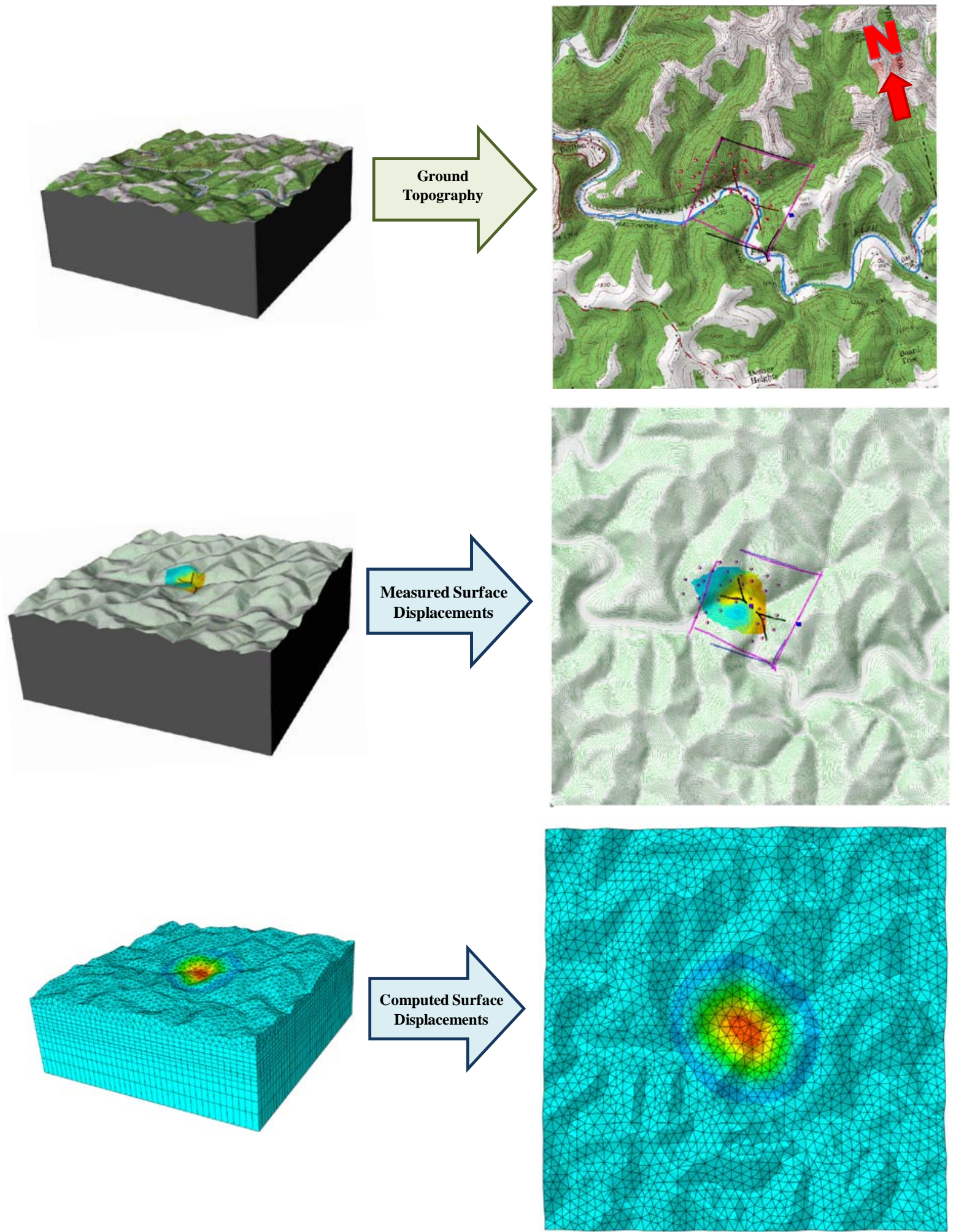

Figure 5.14: Ground topography, field measurements and computed surface displacements 


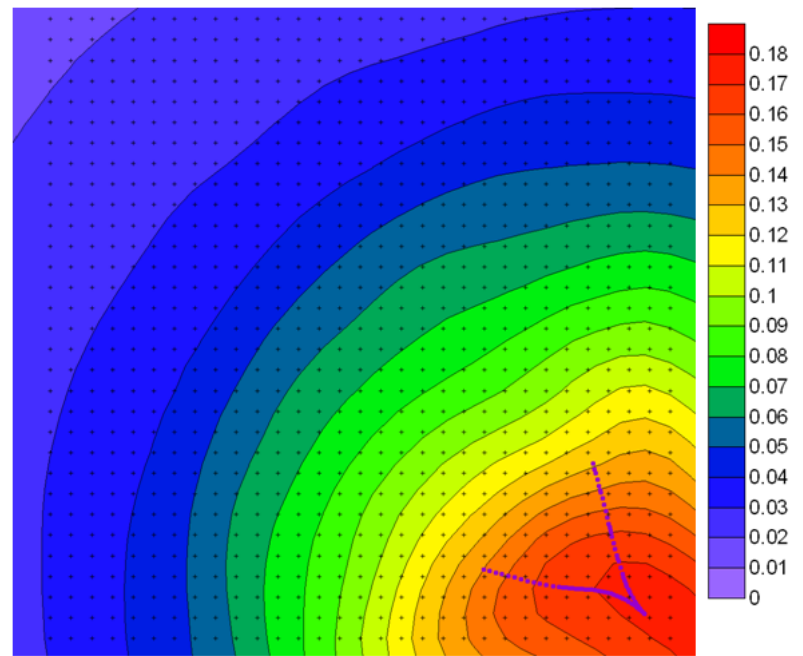

Computed Surface Displacements (inches)

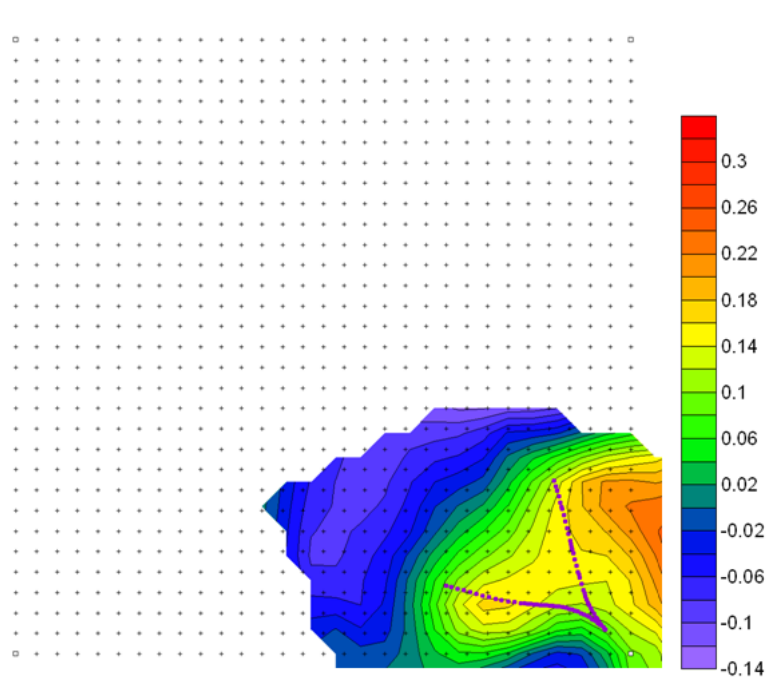

Measured Surface Displacements (inches)

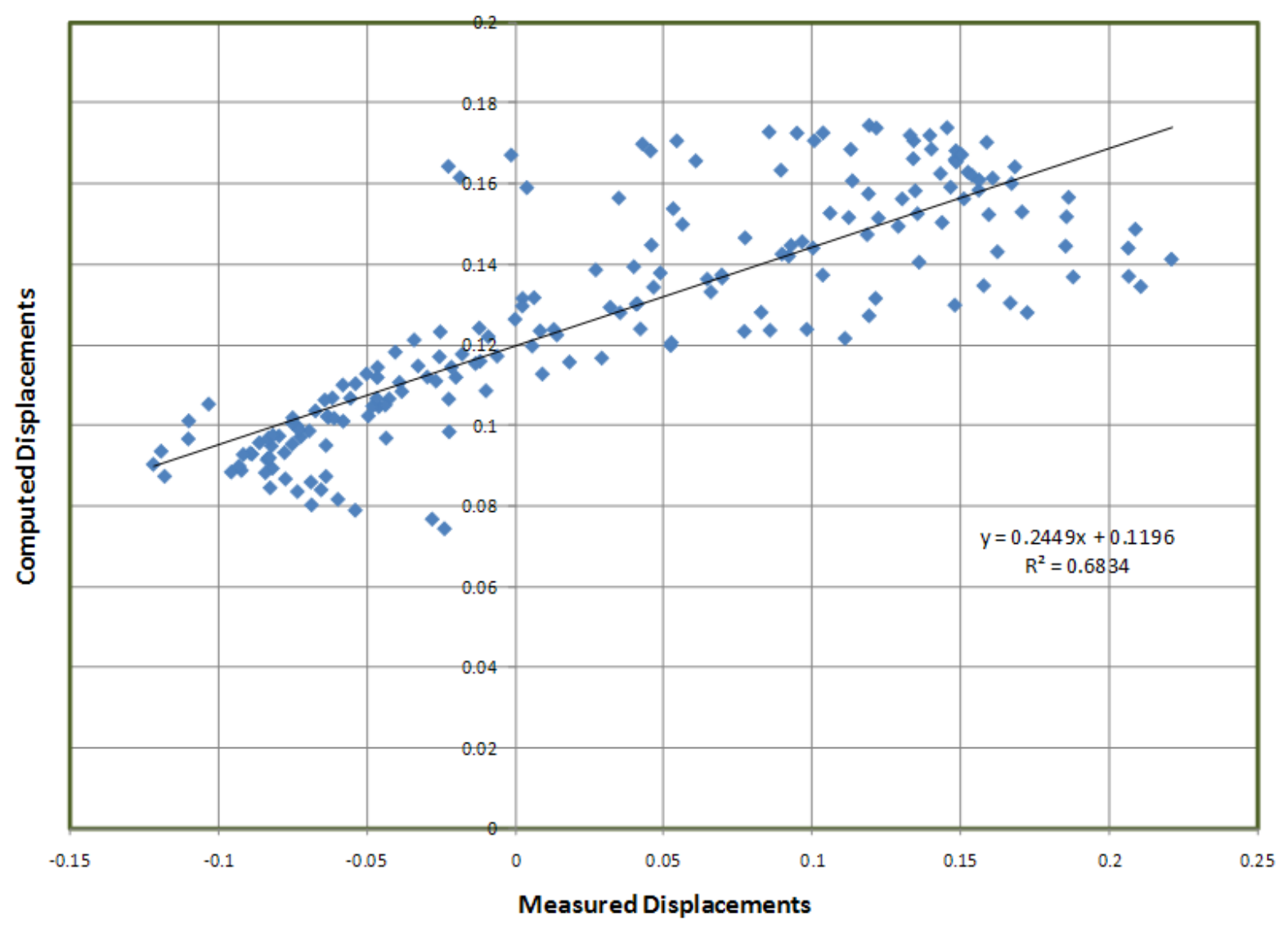

Figure 5.15: Correlation of measured and computed surface displacements 


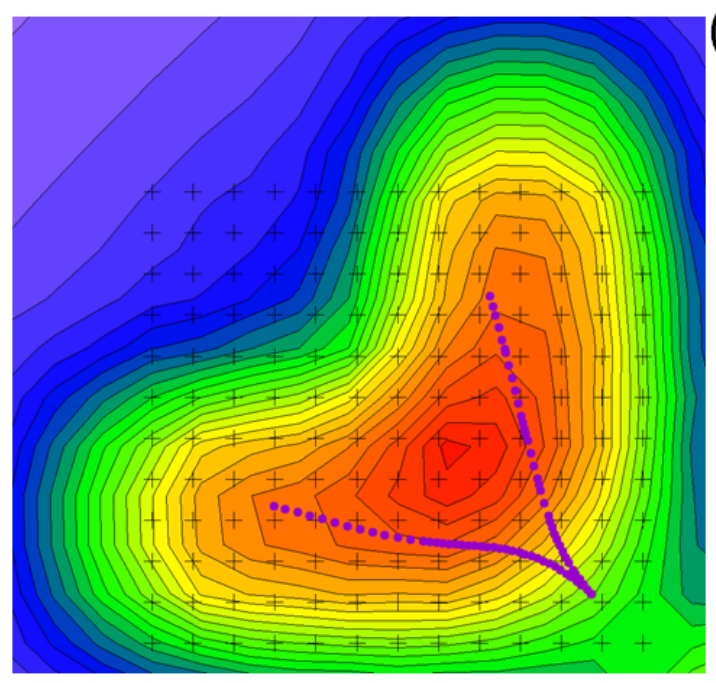

Finite Element Method
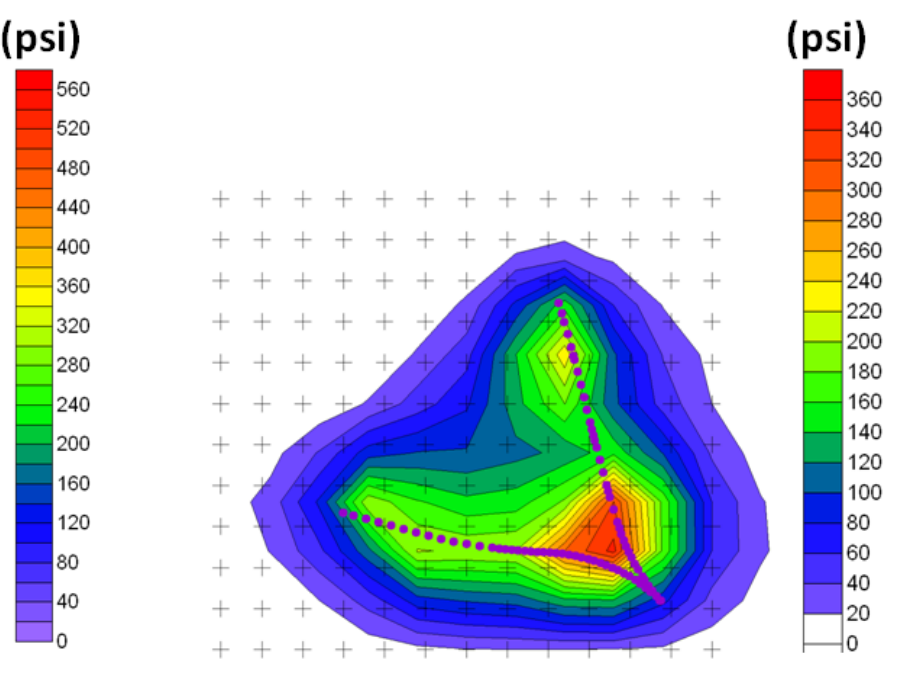

Reservoir Modeling

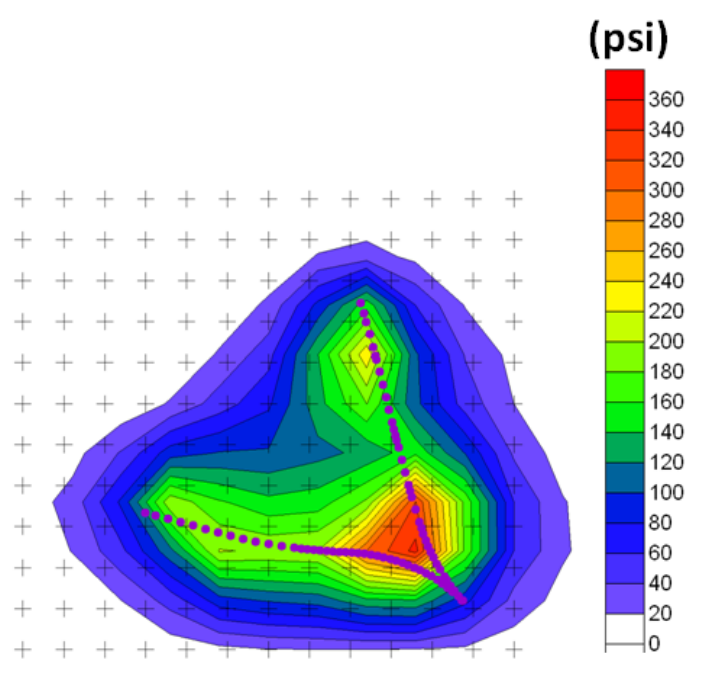

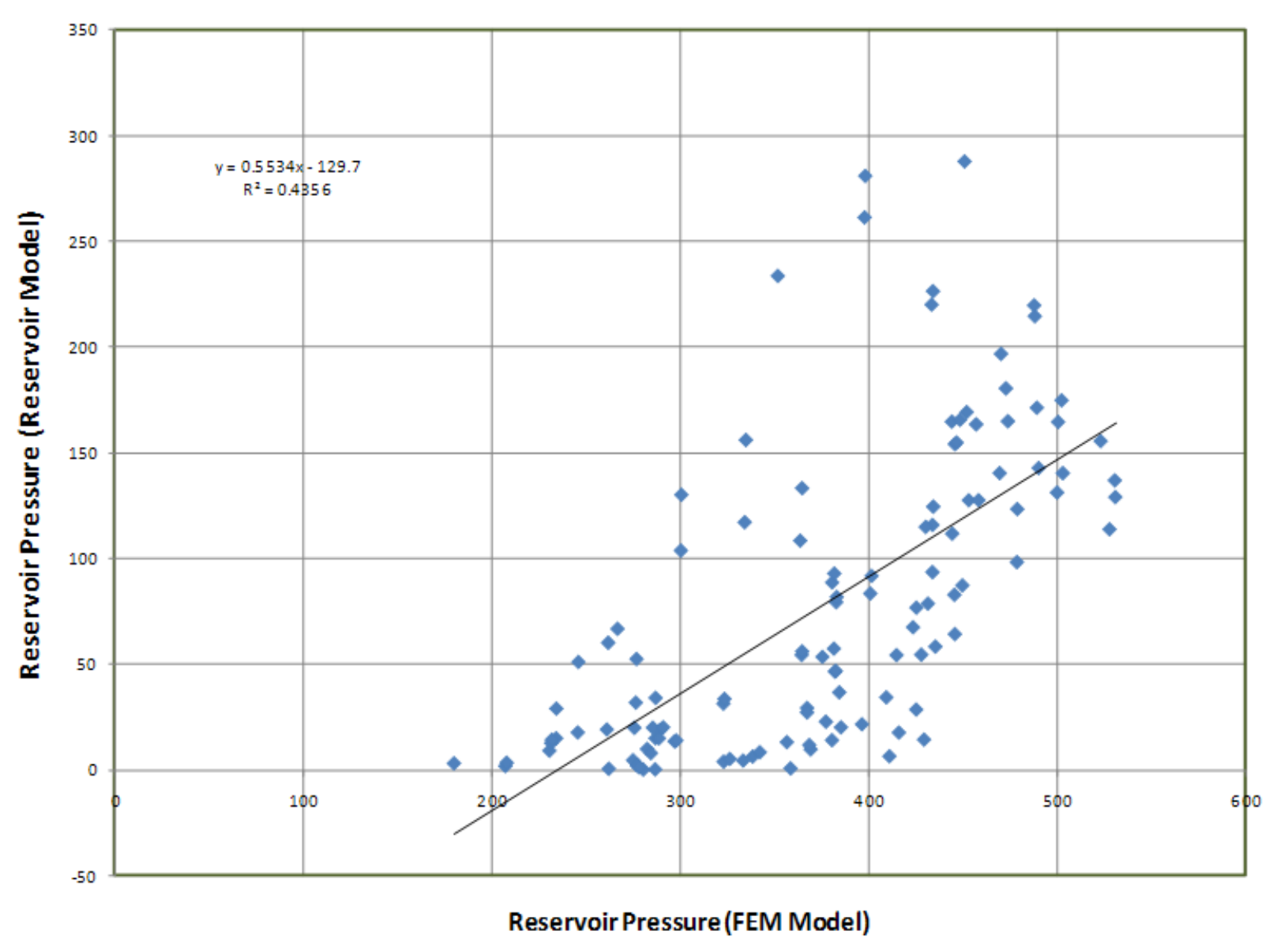

Figure 5.16: Comparison of pressure from reservoir modeling and finite element modeling 


\section{CHAPTER 6: PRESSURE RESPONSE IN A OVERBURDEN MONITORING LAYER}

\subsection{Monitoring technologies}

One of the key elements for the success of large-scale sequestration projects is the development of monitoring technologies to interpret the possible communication/interaction of injected fluid with overlying or underlying geologic formations (Wilson et al, 2003). Any fracture in the tight caprock layer may act as a leakage pathway for injected fluid. Therefore, it is necessary to develop monitoring technologies to detect such leaks. In the current study, an effort has been made to investigate the influence of a hypothetical caprock fracture on the pressure response in an overburden monitoring layer during a hypothetical injection of carbon dioxide. The highly permeable layer above the caprock in the overburden is defined as 'monitoring layer' (Figure 5.1). Large pressure gradients near the injection region of $\mathrm{CO}_{2}$ or seepage through edges of the confined reservoirs may be potential leakage pathways in the vertical and lateral directions (Bruant et al, 2002). A significant leakage may be possible due to induced or natural fractures/faults (Bruant et al, 2002; Rutqvist et al, 2008). Mammoth Mountain in eastern California is a perfect example of natural $\mathrm{CO}_{2}$ release (Bruant et al, 2002).

When carbon dioxide is injected into a deep reservoir, the fluid pressure within the target reservoir and surrounding geologic strata change depending on the geomechanical properties and the permeability of the target formation and surrounding formations. The changes in the overburden pressure response in the monitoring layer may depend on many factors such as:

- Permeability and compressibility of caprock

- Permeability and compressibility of reservoir rock

- Fracture permeability

- Permeability of the monitoring layer

It is anticipated that signatures of pressure response in the monitoring layer will vary depending on the number of fractures and their respective locations in the caprock layer. 


\subsection{Numerical methodology used in the caprock fracture study}

In the present study, several hypothetical scenarios of fractures in the caprock were considered to investigate the influence of a caprock fracture, fracture location, and fracture permeability on the pressure response in the overburden monitoring layer. Figure 6.1 shows a multi-layered geologic profile of a hypothetical $\mathrm{CO}_{2}$ injection site that was used in the current work. The hypothetical $\mathrm{CO}_{2}$ injection was carried out in the target reservoir for a period of one year at an injection pressure of 1,500 psi $(10,342 \mathrm{kPa})$. The thickness of each layer including the permeability values are shown in the figure. The carbon sink (reservoir) is assumed to be located 3,280 feet $(1,000 \mathrm{~m})$ below ground level.

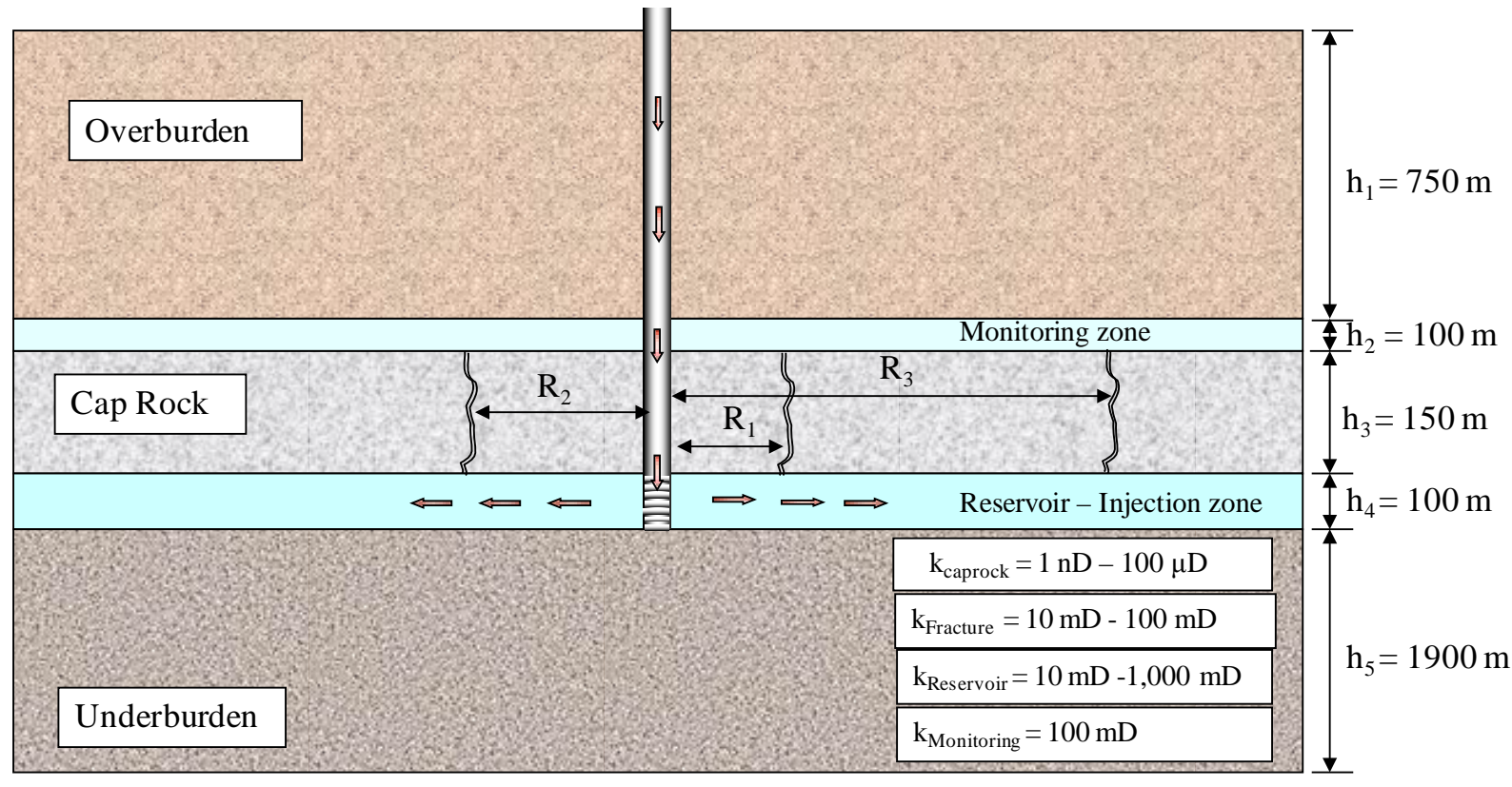

Figure 6.1: Multi-layered geologic profile of hypothetical $\mathrm{CO}_{2}$ injection site

Finite element method was used as a simulation tool to develop monitoring techniques for evaluating the long-term storage potential of sequestration sites. The injection of carbon dioxide was simulated by considering coupled flow-deformation analyses. Two-dimensional and three-dimensional finite element models were developed and tested with and without a fault in the caprock layer. Figure 6.2(a) and 6.2(b) show two-dimensional and three-dimensional finite 
element models that were constructed with different layers with respective properties as illustrated in Figure 6.1. Figure 6.3 illustrates $\mathrm{CO}_{2}$ injection into the reservoir layer with a simulated fracture in the caprock layer. Figures 6.2(a) and 6.2(b) show fractures/faults located in the caprock layer at $100 \mathrm{~m}, 500 \mathrm{~m}$, and $1000 \mathrm{~m}$ away from the injection point. The variations of pressure signatures for different cases are presented in the paper together with results on the influence of fracture locations.

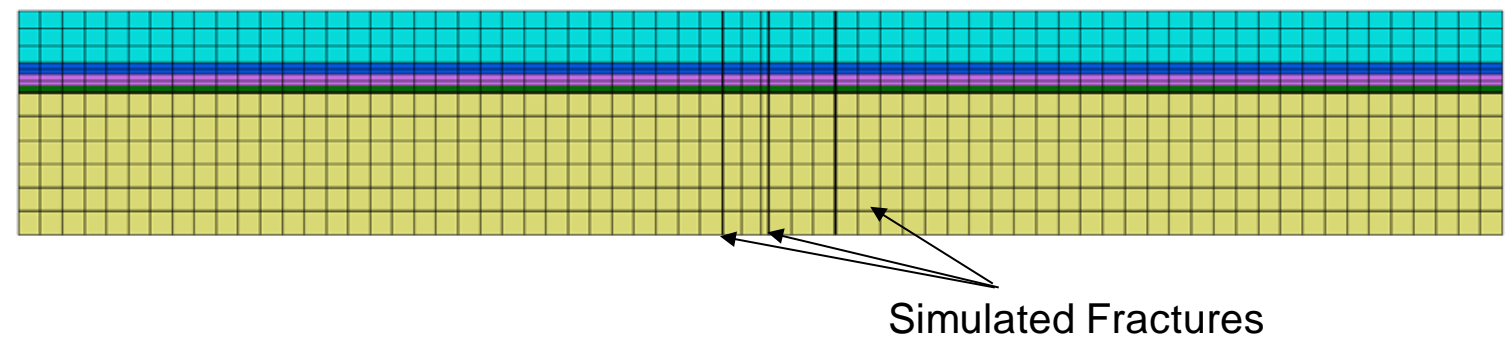

(a) 2-D FEM model

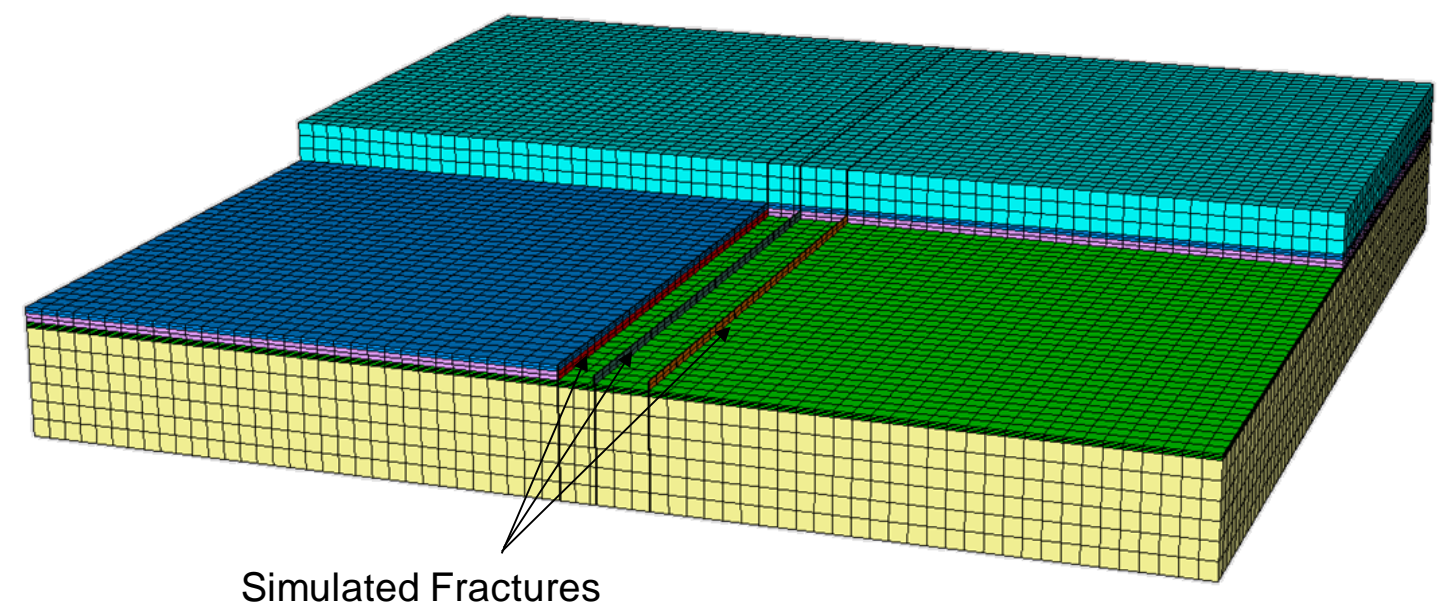

(b) 3-D FEM model

Figure 6.2: 2-D and 3-D finite element models with multiple fractures 


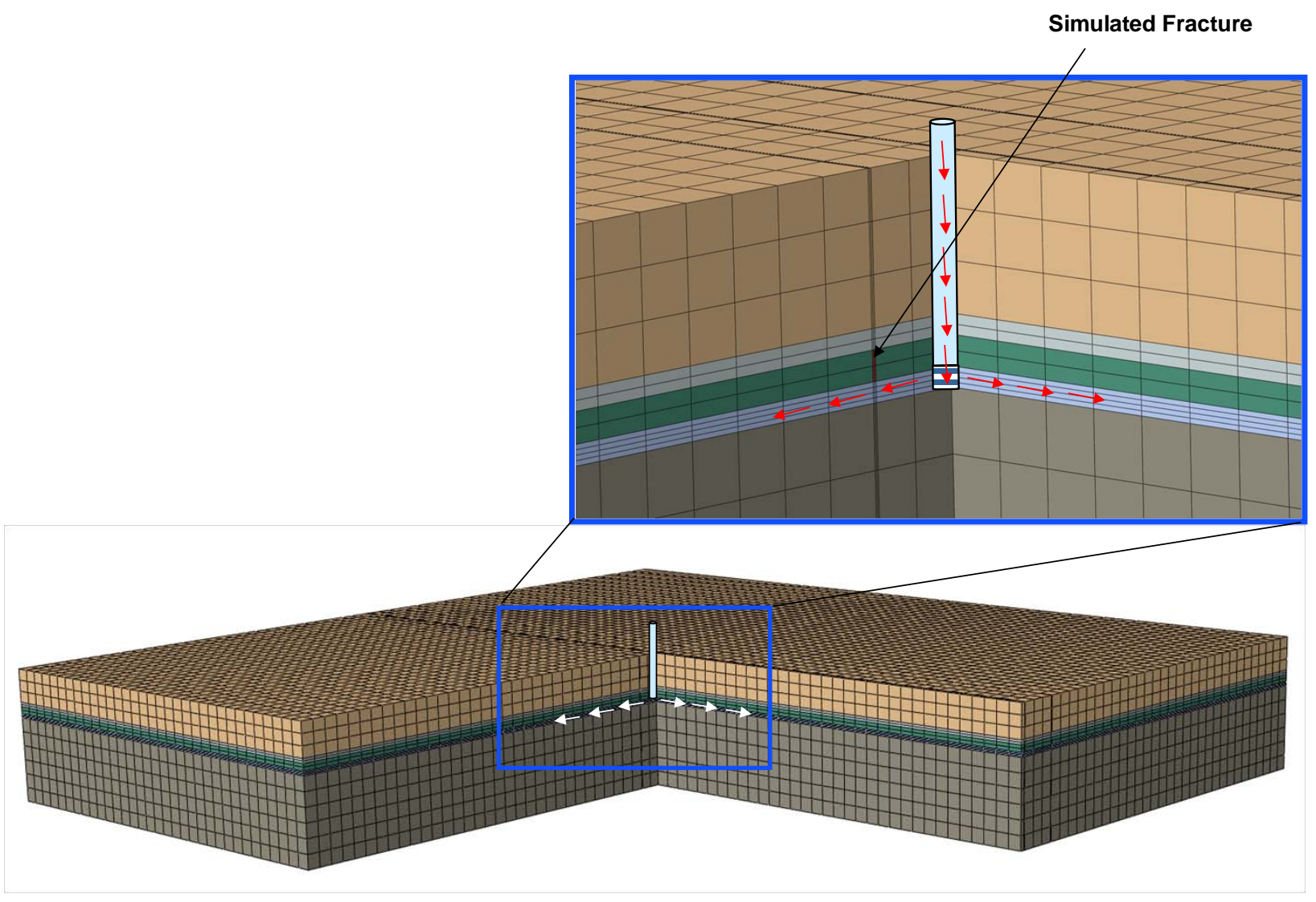

Figure 6.3: Finite element mesh and location of fault in the caprock

\subsection{Results and discussion}

Figure 6.4 shows the contours of ground deformations for cases with and without a fault in the caprock layer. Surface deformations due to the faults are significantly different and show a non-uniformity in the contour pattern due to the presence of the fault. This suggests that surface monitoring technologies may be useful in detecting the presence of faults or fractures. The surface displacements are plotted along the distance to locate the fracture as shown in Figure 6.5. Results in this figure clearly show signal change in surface deformations with time. 


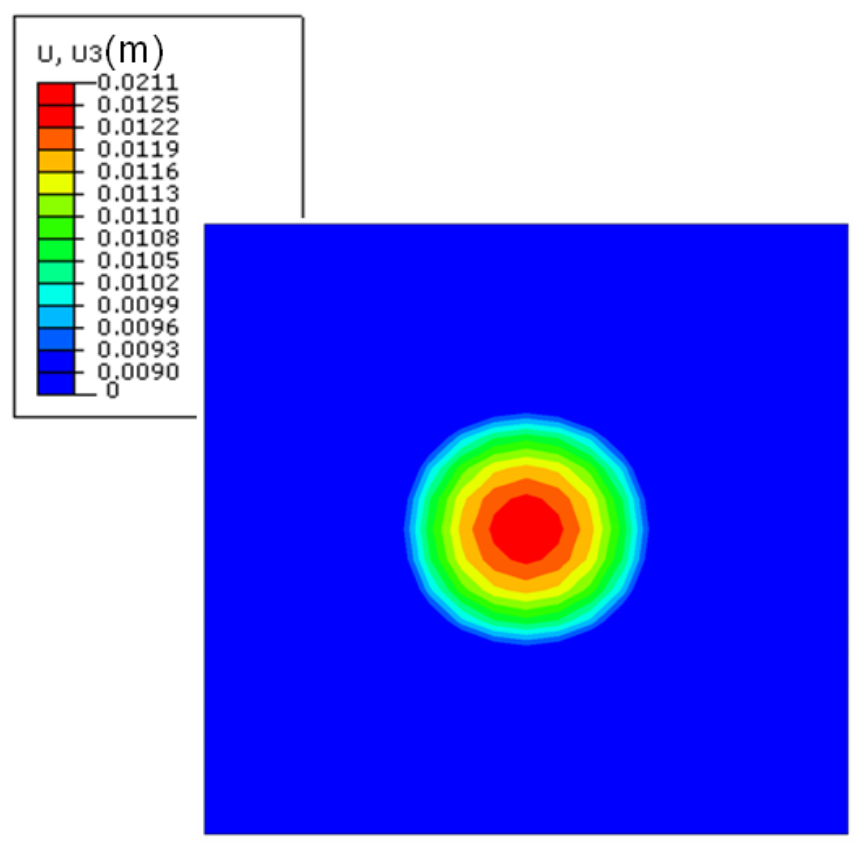

Without Fracture

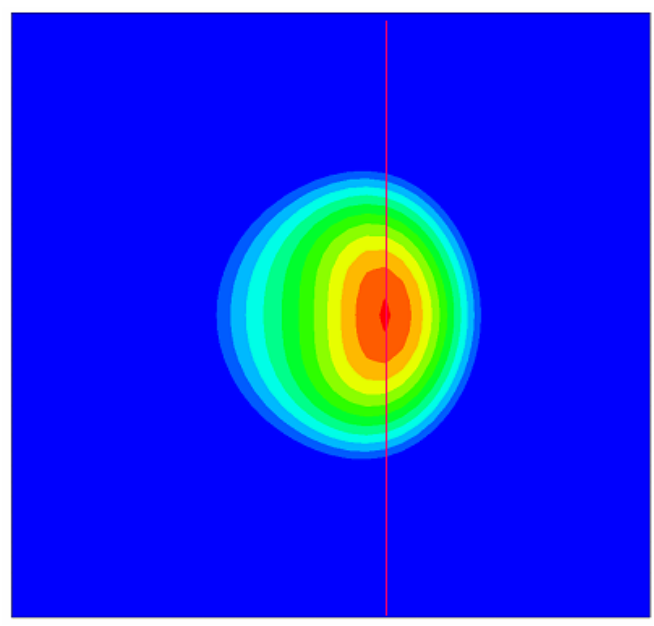

With Fracture

Figure 6.4: Surface displacements with and without fracture

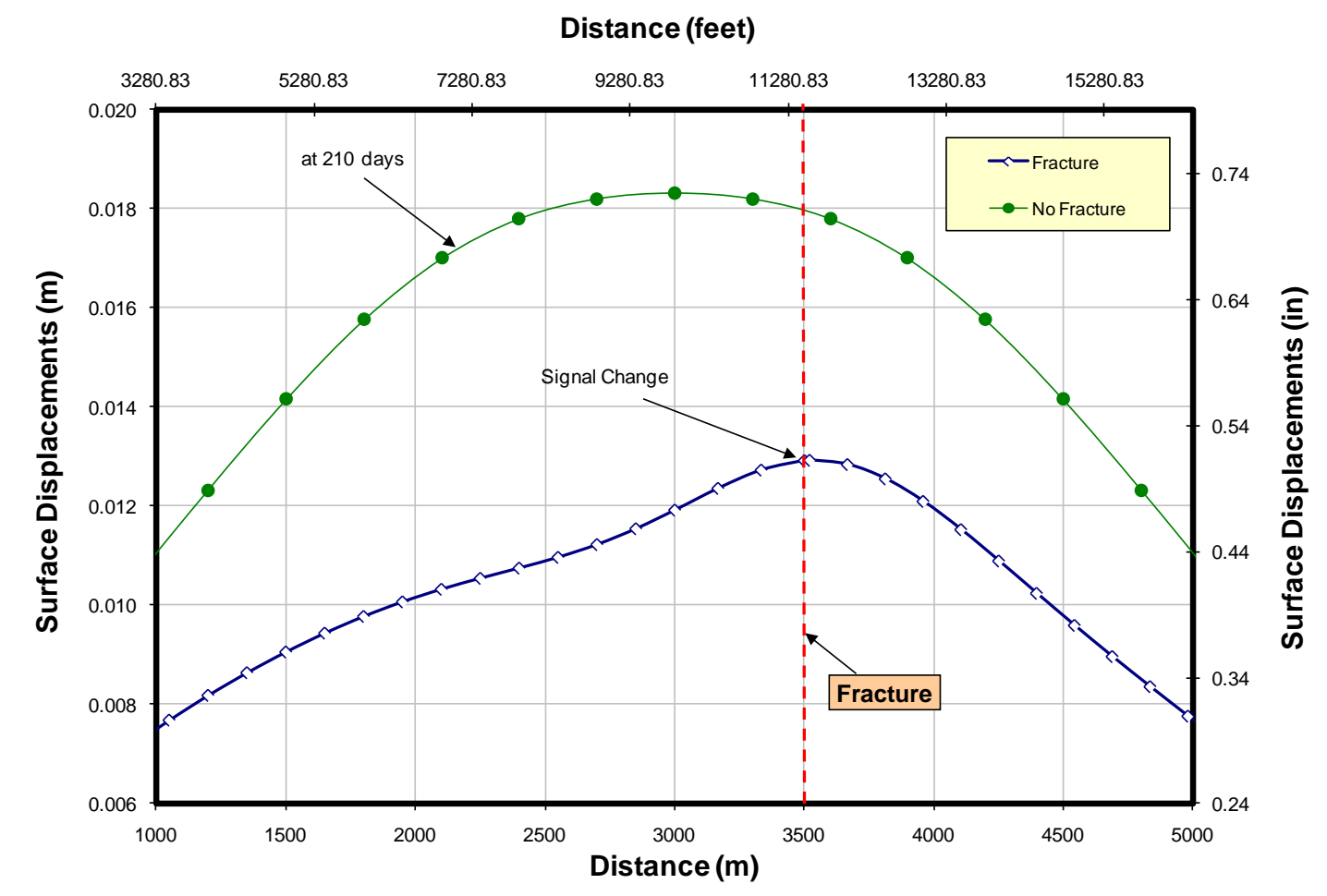

Figure 6.5: Signal change in surface deformations with time (at 210 days) 
Figures 6.6(a) and 6.6(b) show the pressure response in the overburden monitoring layer with and without fracture. Results show significant changes in the signatures of fluid pressure. In the case without a fracture, the pressure response in the monitoring layer is more uniform and the magnitude of signal increases with an increase in the permeability. However, when a fracture is induced the signatures of fluid pressure are more closely concentrated at the location of the fracture in the monitoring layer. The significant variation of pressure signatures in an overlying monitoring zone may more likely be an indicator of the presence of fractures in the caprock that could act as leakage pathways for migration of injected fluid.

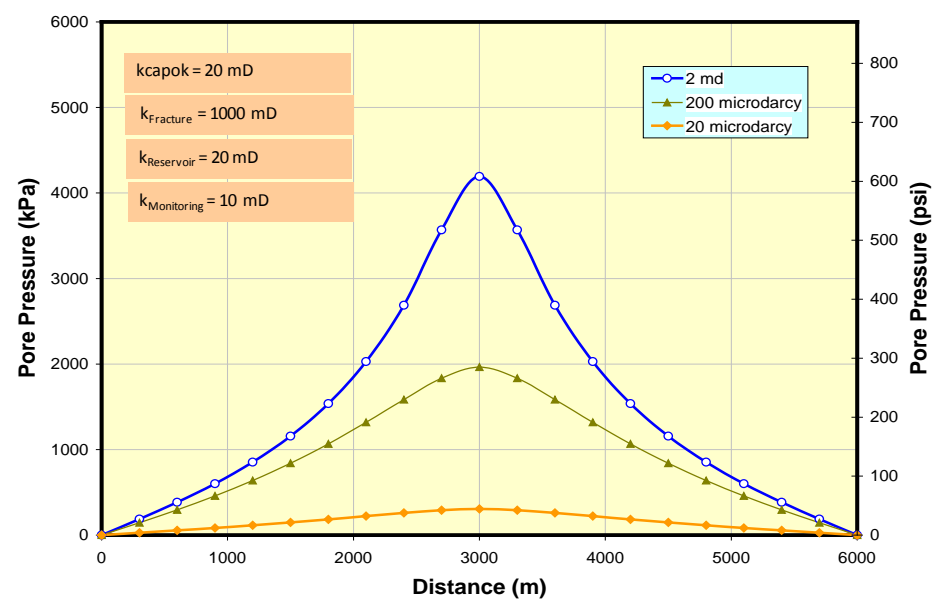

(a) without fracture

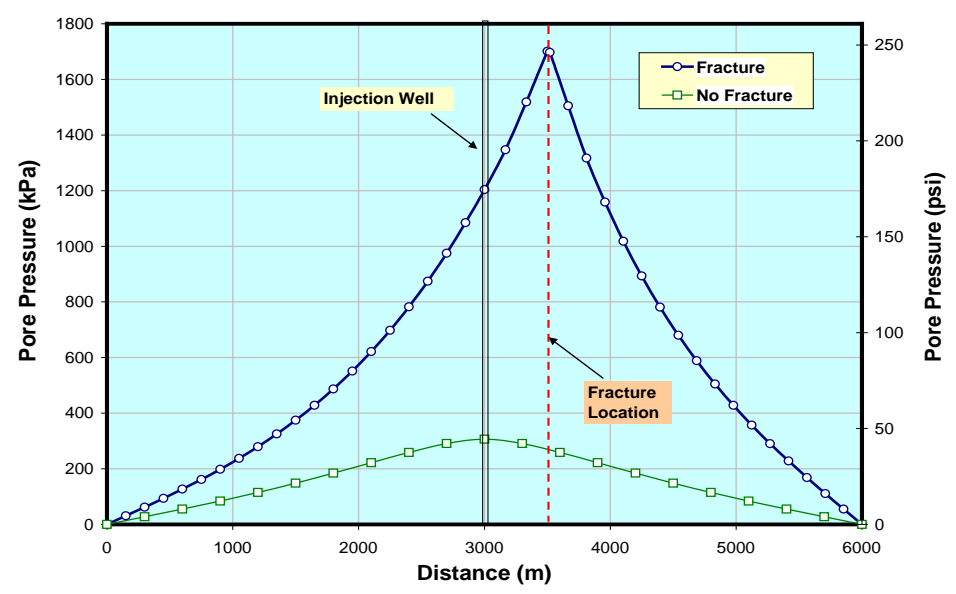

(b) with fracture

Figure 6.6: Pressure response in the monitoring layer with and without fracture 
Figure 6.7 shows the influence of caprock permeability on the overburden pressure response in the monitoring layer. It can be inferred from the results that no significant changes in the pressure signal were observed in a relative permeable caprock. Also, it can be observed that noticeable signals can be seen in an impermeable caprock when a fracture is introduced.

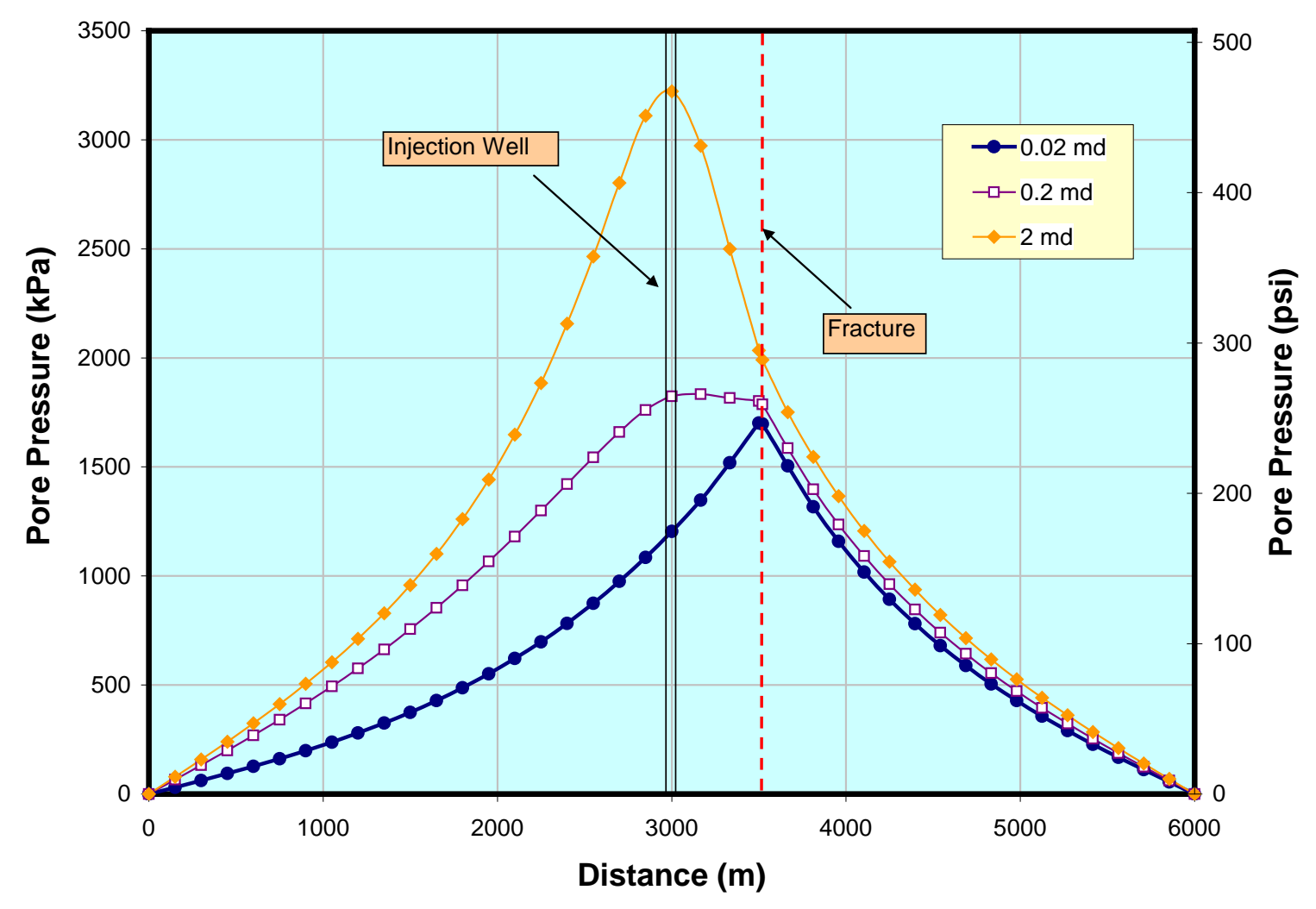

Figure 6.7: Influence of caprock permeability on overburden pressure response

It is difficult to identify the location of fractures and variations of pressure signatures over a large area. In another event, the overburden pressure response at various locations in the monitoring layer was compared. Figure 6.8 shows the locations of various monitoring points in the monitoring region. Figure 6.9 shows the comparison of pressure response at various locations in the monitoring layer with the presence of a fracture. The response of overburden monitoring pressure seems to be significantly different at various locations in the monitoring zone, which will be useful in identifying fractures in the caprock. 


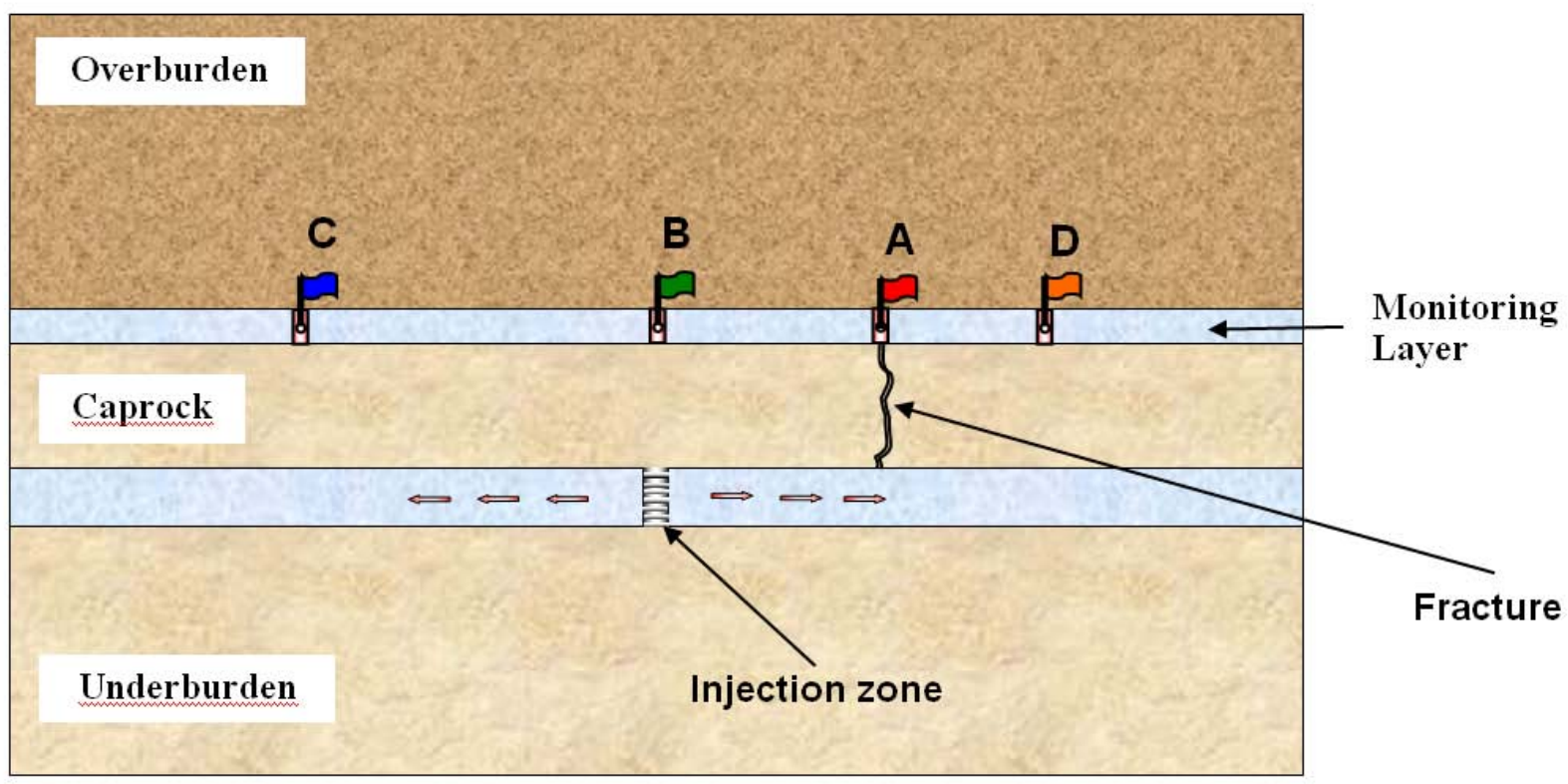

- Point A - Located in the Monitoring layer above the fracture

- Point B - Located in the Monitoring layer above the injection point

- Point C - Located 900m left of injection point in the Monitoring layer

- Point D - Located 958m right of injection point in the Monitoring layer

Figure 6.8: Monitoring points above the caprock layer

The variation of fluid pressure in different layers is shown in Figure 6.10. The presence of a fracture can be identified from these figures. Figure 6.11 shows the pore pressure response of the overburden monitoring layer with and without a fault. The fluid seems to migrate through the caprock fracture to above layers. Figures 6.12 and 6.13 show the influence of different fracture locations on the surface deformations and pore pressure response. These figures clearly illustrate different trends, and are more influential right above the fracture. Therefore, monitoring at different locations on top of the reservoir or on ground surface will help in understanding the location of the fracture. 


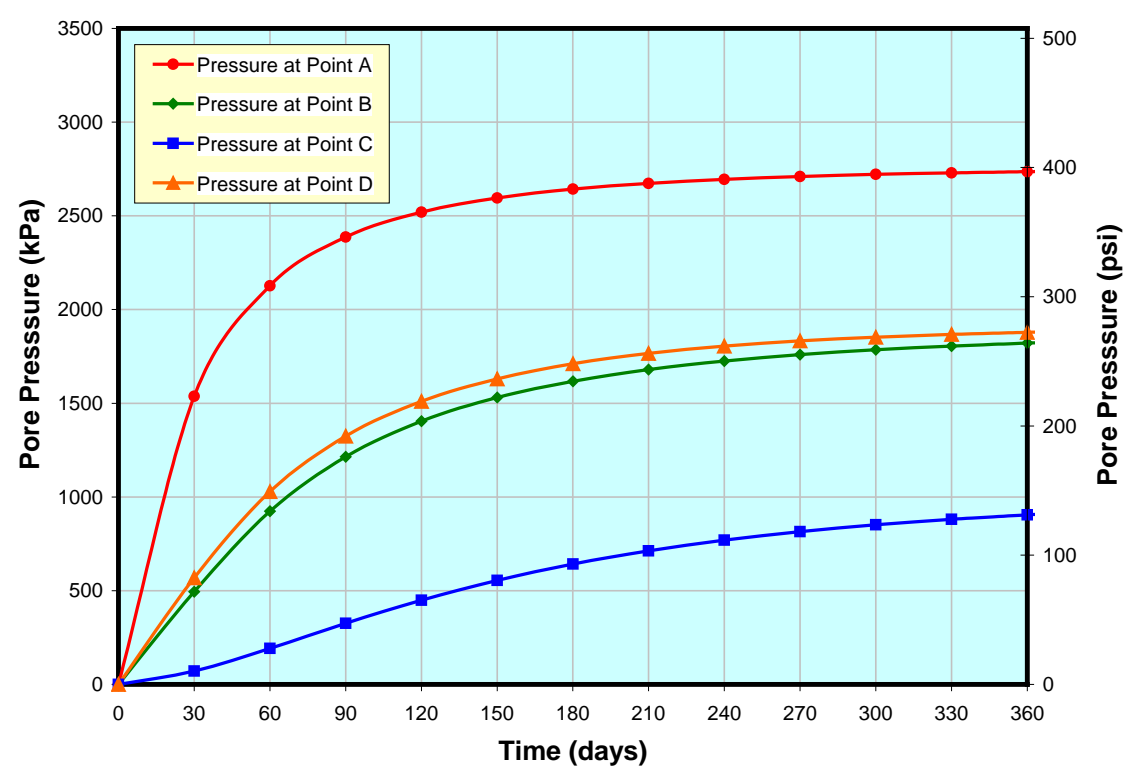

Figure 6.9: Variations of pore pressure at various locations (points A, B, C and D as shown in Figure 6.8) in the monitoring zone

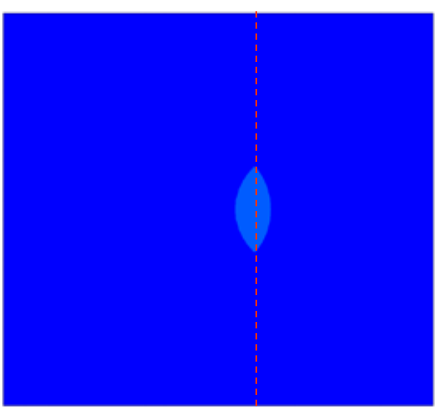

Monitoring Laye

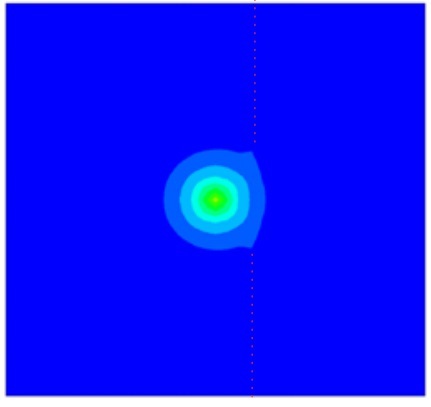

Cap Rock
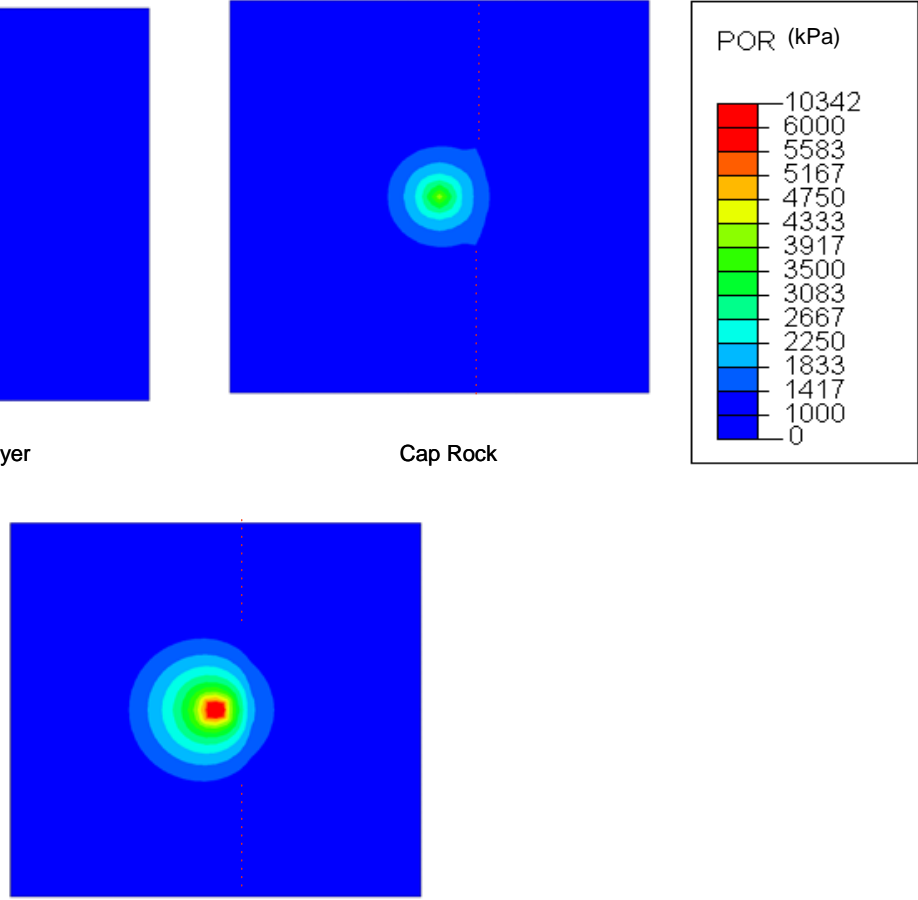

Reservoir

Figure 6.10: Variation of pore pressure in different layers 


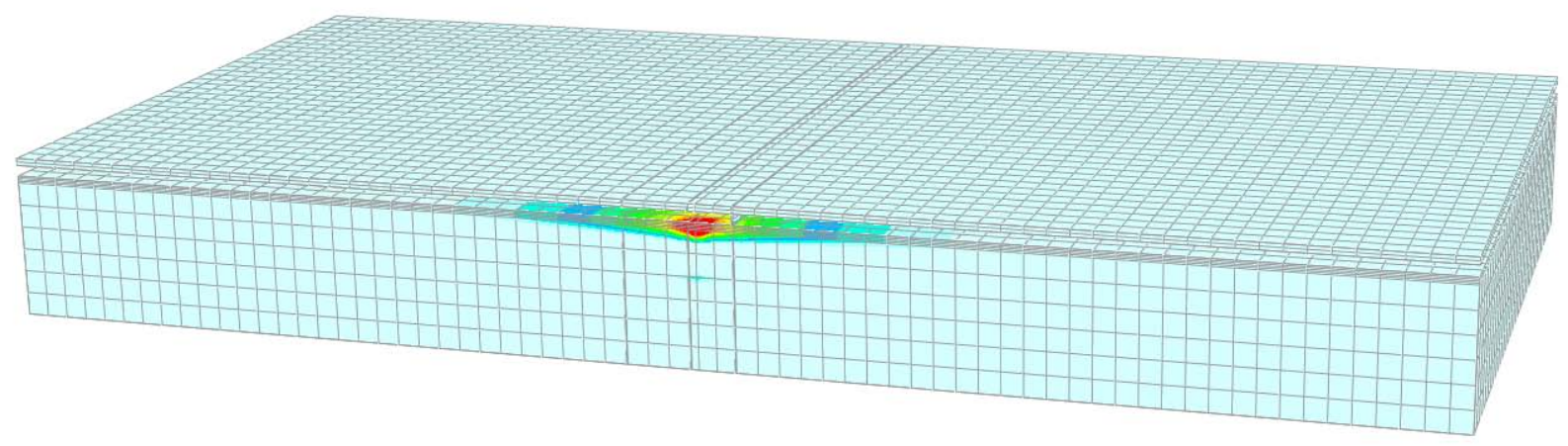

(a) Without any fault in the caprock

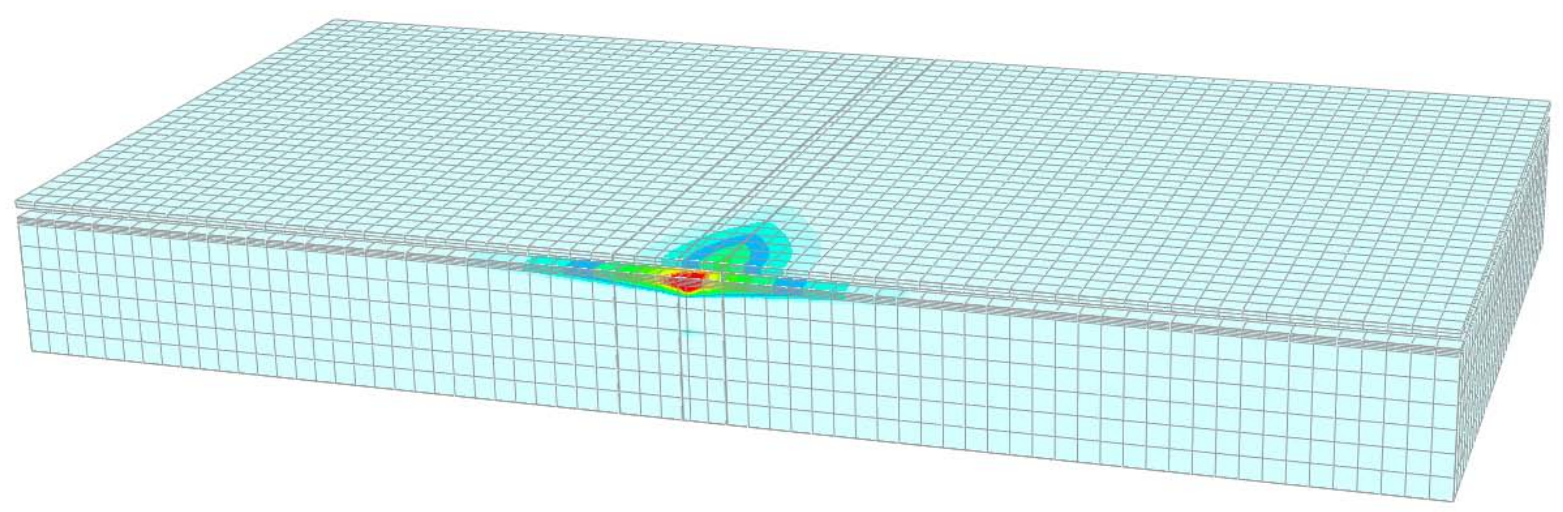

(a) With a fault in the caprock

Figure 6.11: Influence of a fault on the pore pressure response in the monitoring layer 


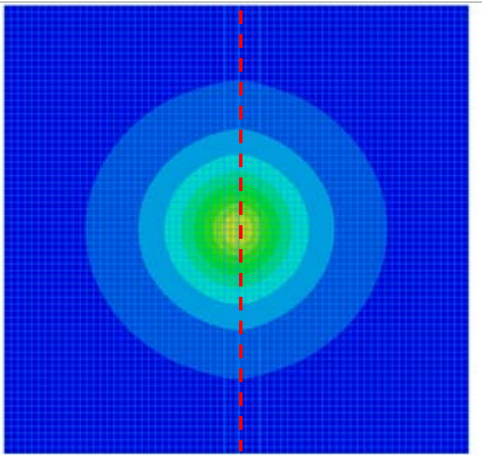

Fracture at $100 \mathrm{~m}$

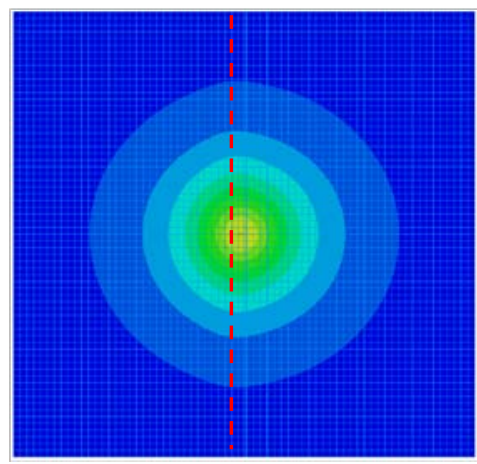

Fracture at $500 \mathrm{~m}$

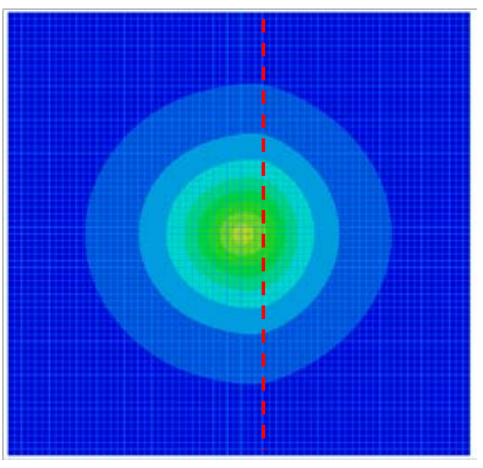

Fracture at $1,000 \mathrm{~m}$
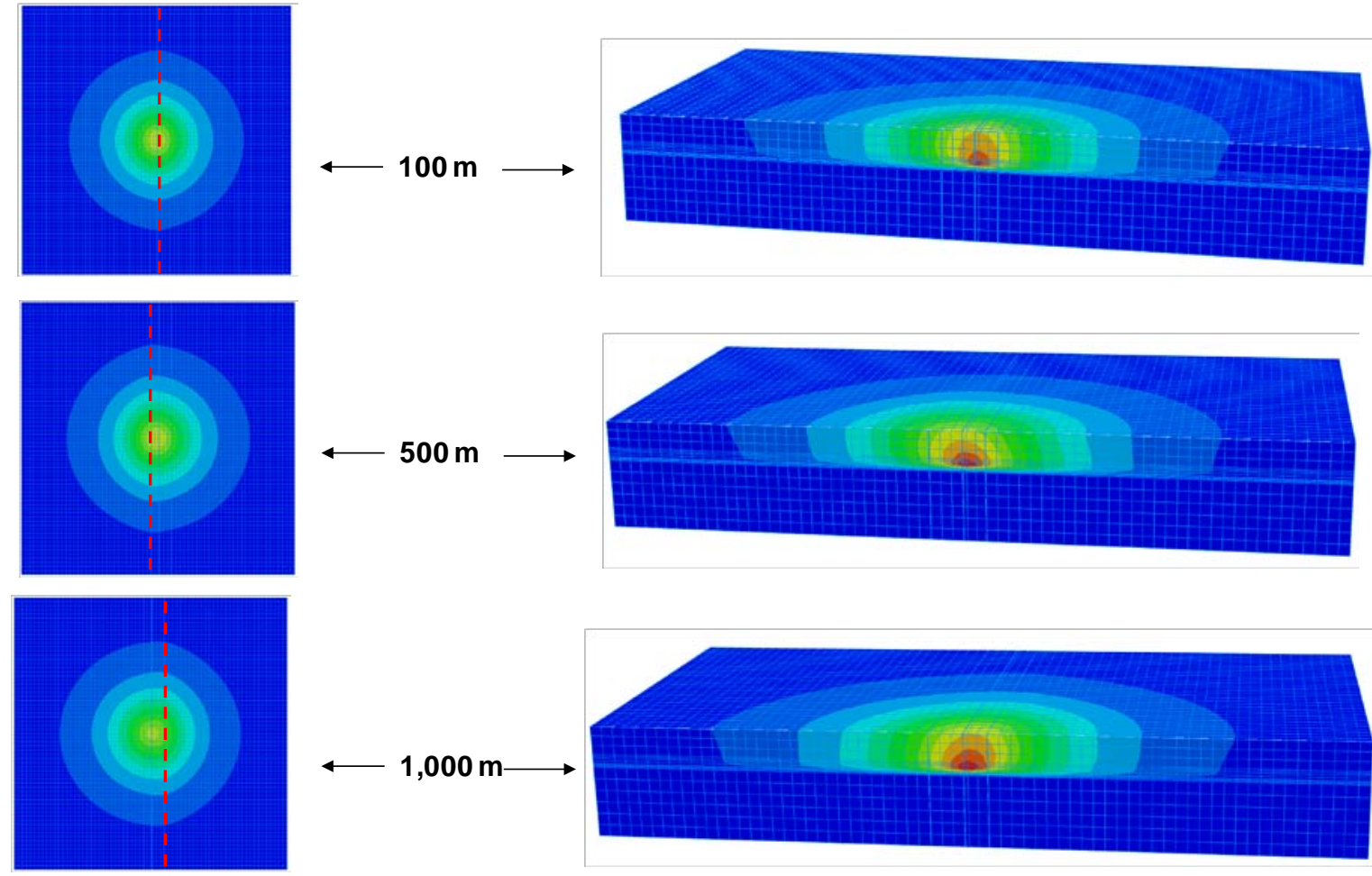

Figure 6.12: Influence of different fractures on the ground response 


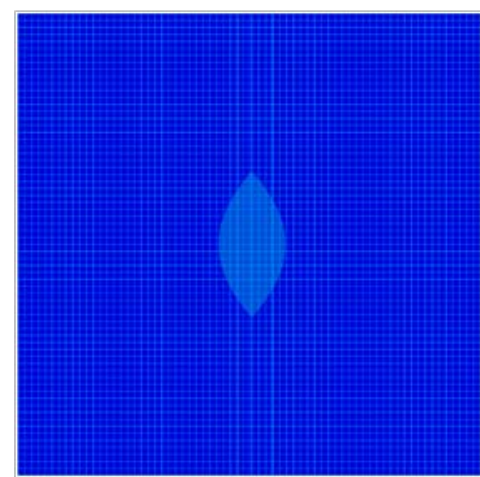

$100 \mathrm{~m}$

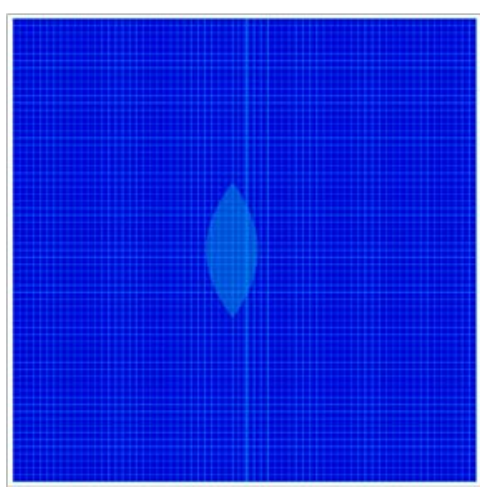

$500 \mathrm{~m}$

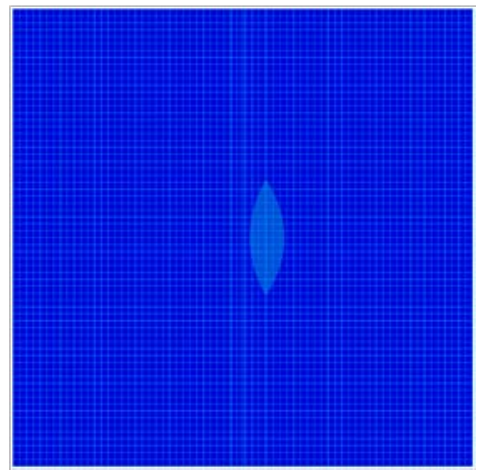

$1,000 \mathrm{~m}$

Figure 6.13: Influence of different fractures on the pressure response

Some modeling attempts have also been made to study the overburden pressure response of a fault activated by the injection of carbon dioxide. The results from this study can certainly be used in the development of smart technologies to evaluate the long-term potential of deep geologic formations. Two-dimensional and three-dimensional finite element models were considered to test the fault activation during injection of carbon dioxide. The two-dimensional finite element model with assumed properties of different layers is shown in Figure 6.14.
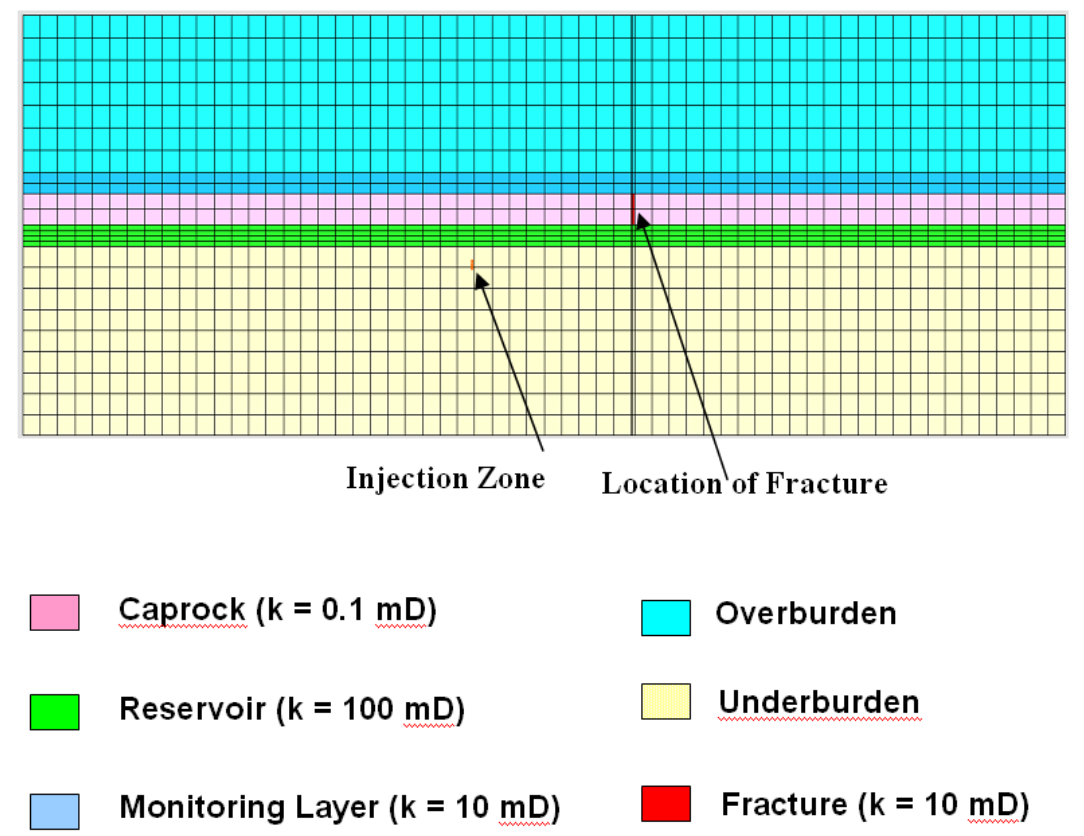

Overburden

Underburden

Figure 6.14: Two-dimensional finite element mesh used to simulate fault activation 
Figure 6.15 shows the pressure response due to activation of a hypothetical fault during injection of carbon dioxide at point A (located immediately above fracture in the monitoring layer) and at point B (located immediately above injection point in the monitoring layer). The models show a distinct change in the pressure signature in the overburden response in the monitoring layer due to activation of a hypothetical fault. Two-dimensional and threedimensional finite element results show similar patterns on the fracture/fault activation.

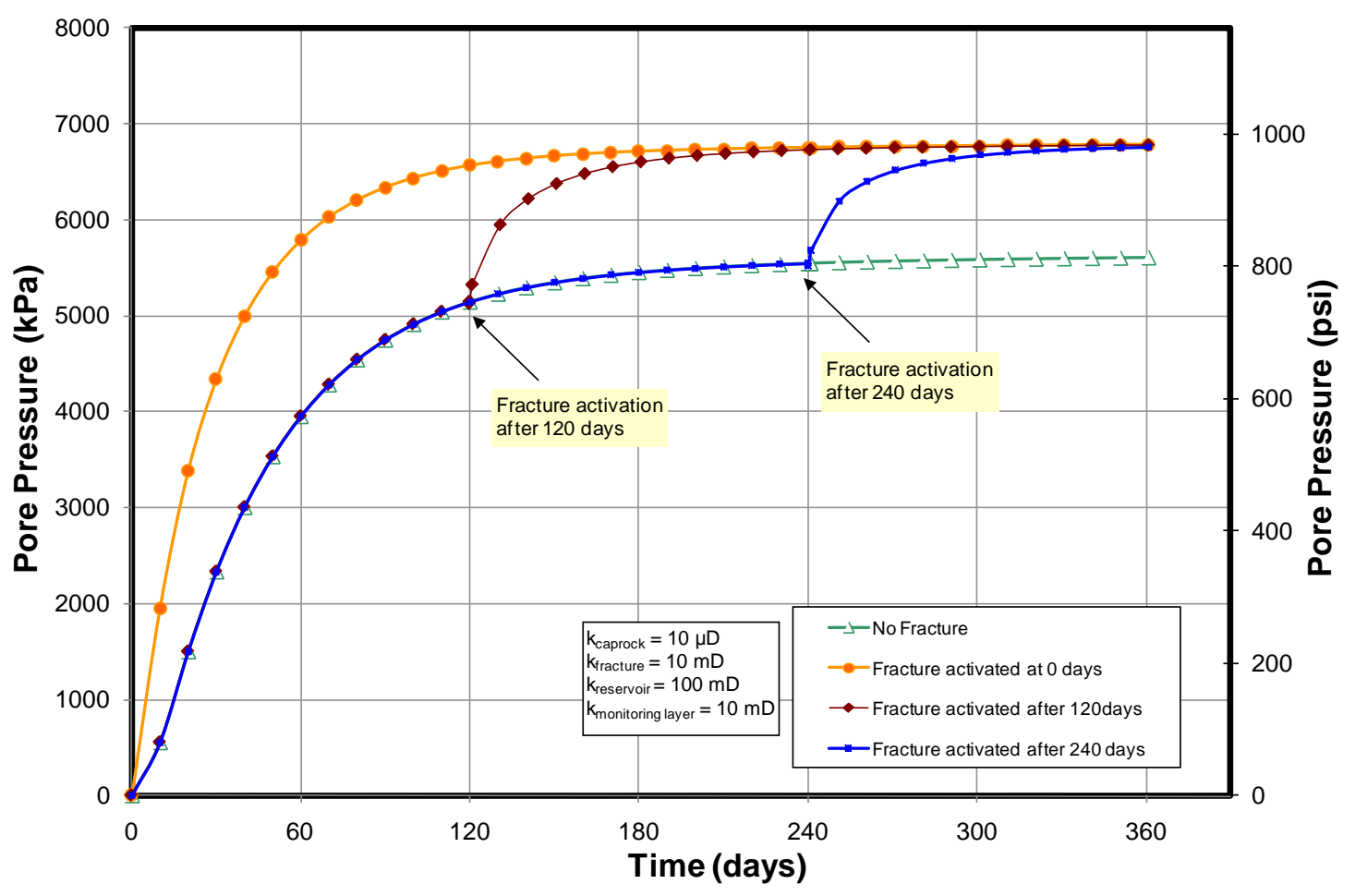

Figure 6.15: Pressure response due to activation of simulated fault during $\mathrm{CO}_{2}$ injection 


\section{CHAPTER 7: SUMMARY AND CONCLUSIONS}

\subsection{Summary}

The objectives of this research study were:

- to monitor field-scale ground deformations caused by the injection of $\mathrm{CO}_{2}$ at a field site by using a network of tiltmeters and GPS stations

- to investigate the influence of reservoir properties and geomechanical properties on the overall overburden response

- to perform numerical modeling to investigate the fluid flow in the reservoir

- to perform coupled flow-deformation geomechancial analyses to determine ground response caused due to $\mathrm{CO}_{2}$ injection

- $\quad$ to compare field measurements with numerical modeling results

- to investigate the influence of a hypothetical fault/fracture in the caprock on the pressure response in a monitoring layer and the displacements at the ground surface

A sequestration field site located in the northern Appalachian basin and in Marshall County, West Virginia, U.S.A. was selected to study the behavior of fluid flow in the reservoir and overburden response due to injection of $\mathrm{CO}_{2}$ into a unmineable coal. The field site encompasses hilly ground terrain and dense vegetation with a creek passing through the low lying areas of the site. The objective of the field site is to evaluate enhanced coalbed methane (CBM) recovery and sequestration potential of $\mathrm{CO}_{2}$ in an unmineable coal seam. The sequestration field site consists of two coal seams, a lower unmineable coal seam (Upper Freeport coal seam) and a upper mineable coal seam (Pittsburgh coal), separated by shale and other impermeable rocks. Coalbed methane is extracted by using horizontally drilled wells from both coal seams with majority of CBM production coming from the Pittsburgh coal seam. A total volume of 20,000 tons of $\mathrm{CO}_{2}$ is planned for injection into the lower coal seam using centrally located lateral injection wells as discussed in Chapter 3. 
The objective of this research work was to investigate the flow of injected fluid in the reservoir and to monitor any field-scale ground deformations caused by pressure changes in the lower coal seam due to injection of $\mathrm{CO}_{2}$. Thirty six high-precision tiltmeters and two GPS receivers were installed at the field site to monitor ground surface deformations caused due to $\mathrm{CO}_{2}$ injection and to investigate the migration of injected $\mathrm{CO}_{2}$ in and around the injection region. These tiltmeters installed at the field site are very sensitive and capable of measuring tilts up to one nano-radian. Such instruments have been used in the past in real-time applications related to oil and gas reservoirs to monitor fluid fronts and potential of fracture growth due to surface expansion or subsidence. However, the use of such monitoring techniques in processes related to geologic sequestration of $\mathrm{CO}_{2}$ is limited. In order to understand the $\mathrm{CO}_{2}$ induced reservoir changes, the tiltmeter data was integrated with available field data such as gas production data, injection rates and injection volumes.

The tiltmeter array was calibrated and fully functional prior to $\mathrm{CO}_{2}$ injection and during the injection of $\mathrm{CO}_{2}$. Measurements were recorded on a daily basis and were transferred and processed using a central processing unit located at the field site. Data shows that no measurable surface displacements took place during the pre-injection monitoring period. The $\mathrm{CO}_{2}$ injection began in September 2009, and about 1,000 tons of $\mathrm{CO}_{2}$ has been already injected into the lower coal seam. Tiltmeter measurements so far indicate some surface uplifts (positive ground deformations) along the trajectories of injection wells. A maximum surface uplift of about 0.13 inches was measured so far indicating fluid movement along the legs/trajectories of the central located lateral injection wells.

In addition to the field monitoring by tiltmeters and GPS units, numerical modeling was performed to investigate the movements of injected $\mathrm{CO}_{2}$ and to compute ground deformations caused by the injection. Numerical modeling of $\mathrm{CO}_{2}$ injection is useful in the understanding of overall response of the system during and after injection. Reservoir simulations were performed by using a compositional reservoir simulator. Three-dimensional reservoir models of individual coal layers were constructed to investigate the influence of reservoir properties such as reservoir permeability and porosity on fluid flow. These reservoir models were oriented in the primary cleat direction and incorporate factors such as multiphase flow, dual porosity, complex reservoir 
geometry, permeability anisotropy, sorption/desorption and coal swelling/shrinkage. CBM production from both coal seams and $\mathrm{CO}_{2}$ injection into the lower coal seam were simulated by considering actual trajectories of horizontally drilled wells. Reservoir history matching was performed on the $\mathrm{CBM}$ production and $\mathrm{CO}_{2}$ injection to investigate reservoir properties and geomechanical properties such as permeability, porosity, and parameters related to coal swelling and shrinkage. These multiphase reservoir simulations helped in the development of an understanding of $\mathrm{CO}_{2}$ movement and pressure distribution that can be used in the computations of ground deformations.

In order to investigate the ground response caused by $\mathrm{CO}_{2}$ injection, a multilayer threedimensional coupled flow-deformation geomechanical model was constructed by using the finite element method. The finite element model accounts for cleat orientation, permeability anisotropy and topographical challenges, as well as fluid flow. Results from reservoir simulations were integrated with finite element models to compute surface displacements and provide useful information on migration of $\mathrm{CO}_{2}$ over a period of time. Results from finite element analyses show computed surface displacements in the range of 0.14 to 0.18 inches caused due to 1,000 tons of $\mathrm{CO}_{2}$ injection. These computed surface deformations are consistent with field measurements. Finite element models and reservoir models both show that the pressure response due to $\mathrm{CO}_{2}$ injection is highly localized in the lower coal seam. Moreover, results show that factors such as permeability anisotropy had an influence on the ground deformation pattern and pressure response of the system. Field monitoring techniques such as the use of tiltmeters is an expensive task, but with advanced numerical modeling (such as integration of finite element modeling and reservoir modeling) coupled with limited field monitoring can be a useful approach to investigate the ground response and the migration of fluid flow during the geologic sequestration of $\mathrm{CO}_{2}$.

Several different scenarios of hypothetical $\mathrm{CO}_{2}$ injections were considered to investigate the influence of a fault/fracture in the caprock on the overburden response. Two-dimensional and three-dimensional coupled single phase flow-deformation finite element models were constructed with simulated fractures at different locations in the caprock layer as discussed in Chapter 6. Several monitoring locations were selected in the monitoring layer above the caprock 
seal to investigate the pressure response due to fluid injection in the reservoir. Results show that surface displacement patterns and pressure signature in the overburden monitoring layer due to the presence of a caprock fracture are distinctly different. Such results can be useful in identifying the fracture locations in the caprock layer that could serve as leakage pathways.

Pressure changes in the reservoir due to injection of fluid may induce or activate existing dormant fractures/faults, if present. In the current study, a finite element approach was used to monitor the pressure response in an overlying monitoring layer due to activation of such dormant fractures/faults. Hypothetical activations of fracture/faults in the caprock layer were simulated in the model and results of the study show that pressure signatures at any point in the monitoring layer are significantly different. These pressure signatures can serve as a mechanism to identify the activation of leakage pathways through the caprock during $\mathrm{CO}_{2}$ injection in sequestration projects.

\subsection{Conclusions}

- Field measurements indicate some surface uplifts as a result of $\mathrm{CO}_{2}$ injection. The surface uplift is around the trajectories of horizontal injection wells. A maximum surface uplift of about 0.13 inches was measured after 1,000 tons of $\mathrm{CO}_{2}$ injection.

- Multiphase reservoir modeling helped in the development of an understanding of $\mathrm{CO}_{2}$ movement and pressure distribution in the reservoir layer.

- Geomechanical models such as multi-layered, three-dimensional coupled flowdeformation finite element models described in this study can be used to compute surface displacements and changes in fluid pressure. Results from the finite element analyses show that the computed surface displacements are in the range of 0.14 to 0.18 inches which is consistent with field measurements for 1,000 tons of $\mathrm{CO}_{2}$ injection. 
- Advanced numerical modeling (such as integration of reservoir modeling and finite element analyses) combined with limited field monitoring can be a useful method to investigate the overburden response and fluid migration during sequestration projects.

- Surface displacement patterns and pressure changes at various monitoring locations in a monitoring layer in the overburden are significantly different due to presence of a fracture in the caprock.

- Pressure signature is distinctly different due to a hypothetical activation of a dormant fracture/fault in the caprock during $\mathrm{CO}_{2}$ injection. Pressure signatures at various monitoring locations in the monitoring layer could be used as a mechanism to detect leakage pathways due to activation of such dormant fracture/faults.

\subsection{Recommendations}

The following tasks are recommended for future research work.

- Continuation of field monitoring by using tiltmeters and GPS stations is suggested for the planned injection of 20,000 tons of $\mathrm{CO}_{2}$ into lower coal seam at the field used in the current study.

- Installation of down-hole tiltmeters and instrumentation to investigate reservoir-level strains and micro-seismicity in future $\mathrm{CO}_{2}$ sequestration projects.

- Development of comprehensive monitoring technologies to identify activation of dormant fractures/faults during $\mathrm{CO}_{2}$ injection. 


\section{REFERENCES}

ABAQUS (2009). ABAQUS Manuals, ABAQUS version 6.9. Dassault Systemes Simulia Corp (SIMULIA).

Adams, M.A., Eddy, G.E., Hewitt, J.L., Kirr, J.N. and Rightmire, C.T. (1984). Geological overview, coal resources, and potential methane recovery from coalbeds of the Northern Appalachian coal basin -- Pennsylvania, Ohio, Maryland, West Virginia, and Kentucky, in Rightmire, C.T., Eddy, G.E., and Kirr, J.N., eds., Coalbed methane resources of the United States: American Association of Petroleum Geologists, AAPG Studies in Geology \#17, Tulsa, Oklahoma, U.S.A., 15-71.

Altunin, V. V. and Sakabetdinov, M. A. (1972). The viscosity of liquid and gaseous carbon dioxide at temperatures of 220-1300 K and pressures up to 1200 bar. Teploenergetika 19(8), 8589.

Audus, H. (1997). Greenhouse gas mitigation technology: an overview of the $\mathrm{CO}_{2}$ capture and sequestration studies and further activities of the IEA greenhouse gas R\&D programme. Energy $22(2 / 3), 217-221$.

Avuduevskii, V.S., Glebov, G.A. and Koshkin, V.K. (1973). Calculation of the thermodynamc and transport properties of carbon dioxide. Teplofizika Vysokikh Temperatur 11(1), 51-58.

Bachu S., Bonijoly D., Bradshaw J., Burruss R., Holloway S., Christensen N. and Mathiassen O. (2007). $\mathrm{CO}_{2}$ storage capacity estimation: methodology and gaps. International Journal of Greenhouse Gas Control 1 (4), 403-443.

Bachu, S. (2002). Sequestration of $\mathrm{CO}_{2}$ in geological media in response to climate change: Road map for site selection using the transform of the geologic space into the $\mathrm{CO}_{2}$ phase space. Energy Conversion and Management 43(1), 87-102.

Beecy, D. J. and Kuuskraa, V. A. (2001). Status of U.S. geologic carbon sequestration research and technology. Environmental Geosciences 8(3), 152-159.

Bennaceur K. and Gielen, D. (2010). Energy technology modelling of major carbon abatement options. International Journal of Greenhouse Gas Control 4, 309-315.

Bergman, P.D. and Winter, E. M. (1995). Disposal of carbon dioxide in aquifers in the U.S. Energy Conversion \& Management 36, 523-526.

Bhatt, S.K. (1995). Appalachian coal: an overview. Mining Engineering 47(12), 1089- 1090.

Biot, M.A. (1941). General theory of three-dimensional consolidation. Journal of Applied Physics 12, 426-430. 
Biot, M.A. (1955). Theory of elastic and consolidation of a porous anisotropic solid. Journal of Applied Physics 26(2), 182-185.

Biot, M.A. $\left(1956^{\mathrm{a}}\right)$. General solutions of the equations of elasticity and consolidation for a porous material. Journal of Applied Mechanics, 91-96, March.

Biot, M.A. $\left(1956^{\mathrm{b}}\right)$. Theory of deformation of a porous viscoelastic anisotropic solid. Journal of Applied Physics 27(5), 459-467.

Biot, M.A. and Wills, D.G. (1957). The elastic coefficients of the theory of consolidation. Journal of Applied Mechanics, 594-601, December.

Birkholzer J.T., Zhou, Q. and Tsang, C. (2009). Large-scale impact of $\mathrm{CO}_{2}$ storage in deep saline aquifers: A sensitivity study on pressure response in stratified systems. International Journal of Greenhouse Gas Control 3, 181-194.

Blunt, M., Fayers, F.J. and Orr, Jr., F.M. (1993). Carbon dioxide in enhanced oil recovery. Energy Conversion and Management 34 (9-11), 1197-1204.

Bradshaw, J. and Rigg, A. (2001). The GEODISC program research into geological sequestration of $\mathrm{CO}_{2}$ in Australia. Environmental Geosciences 8(3), 166-176.

Briggs I.C. (1974). Machine contouring using minimum curvature. Geophysics 39, 39-48.

Bromhal G.S., Sams N.W., Jikich S.A., Odusote O., Ertekin T. and Smith D.H. (2003). Reservoir simulation of the effects of anisotropy on ECBM production and $\mathrm{CO}_{2}$ sequestration with horizontal wells. Proceedings of 2003 International Coalbed Methane Symposium, Tuscaloosa, Alabama, U.S.A., 6-8 May.

Bromhal, G.S., Sams, N., Jikich, S.A., Ertekin T. and Smith, D.H. (2004). Assessing economics for sequestration $\mathrm{CO}_{2}$ in coal seams with horizontal wells. Third Annual Sequestration Conference, Alexandria, Virginia, U.S.A., 142-151.

Bromhal, G.S., Sams, W.N., Jikich, S., Ertekin, T. and Smith, D.H. (2005). Simulation of $\mathrm{CO}_{2}$ sequestration in coal beds: The effects of sorption isotherms. Chemical Geology 217, 201-211.

Bruant, R.G., Jr., Guswa, A.J., Celia, M.A. and Peters, C.A. (2002). Safe storage of $\mathrm{CO}_{2}$ in deep saline aquifers. Environmental Science \& Technology, 241-245, 1 June.

Bruner, K.R., Oldham, A.V. Repine, T.E., Markowiski, A.K. and Harper, J.A., (1995). Geological aspects of coalbed methane in the northern Appalachian coal basin, southwestern Pennsylvainia and north-central West Virginia. Topical Report (August 1990-August 1993): Gas Research Institute, Chicago, Illinois, U.S.A., 72. 
Burruss, R. C. (2003). $\mathrm{CO}_{2}$ adsorption in coal seams as a function of rank and composition: a new task in USGS research on geologic sequestration of $\mathrm{CO}_{2}$. Coal-Seq II, Washington, D.C., U.S.A.

Byrer, C.W., Mroz, T.H. and Covatch, G.L. (1987). Coalbed methane production potential in US basins. Journal of Petroleum Technology, 821, July.

Cairns, G.L. (2002). Enhanced coal bed methane production and sequestration of $\mathrm{CO}_{2}$ in unmineable coal seams. Semi-Annual Progress Report under Contractor No. DE- FC2601NT41148.

Carroll, R.E. and Pashin, J.C. (2003). Relationship of sorption capacity to coal quality: $\mathrm{CO}_{2}$ sequestration potential of coalbed methane reservoirs in the Black Warrior Basin. International Coal Bed Methane Symposium, Tuscaloosa, Alabama, U.S.A., 6-8 May.

Cervik, J. (1969). Behavior of coal-gas reservoirs. Bureau of Mines Technical Progress Report10, Methane Control Program, U.S. Department of the Interior, April.

Chen Z., Huan, G. and Ma, Y. (2006). Computational Methods for Multiphase Flows in Porous Media. Society for Industrial and Applied Mathematics.

Chu, S. (2009). Carbon capture and sequestration (editorial note), Science 325, 1599, September 25.

Chikatamarla L. Cui, X. and Bustin, R.M. (2004). Implications of volumetric swelling/shrinkage of coal in sequestration of acid gases. Proceedings of International Coalbed Symosium, Alabama, U.S.A.

Clarkson, C.R., Pan, Z., Palmer, I. and Harpalani, S. (2008). Predicting sorption-induced strain and permeability depletion for CBM reservoirs. SPE paper 114778. SPE Annual Technical Conference and Exhibition, Denver, Colorado, U.S.A., 21-24 September.

CMG (2009). Computer Modeling Group and manuals.

Cook, R.D., Malkus, D.S., Plesha, M.E. and Witt, R.J. (2004). Concepts and Applications of Finite Element. $4^{\text {th }}$ edition, John Wiley \& Sons, Inc., New York.

Cui, X. and Bustin, R. M. (2005). Volumetric strain associated with methane desorption and its impact on coalbed gas production from deep coal seams. AAPG Bulletin 89(9), 1181-1202.

Davis E. (2005). Uncertainty analysis of hydraulic fracture parameters measured by tiltmeter mapping. Pinnacle Technologies Newsletter, Summer 2004 \& Winter 2005.

Davis, E., Astakhov, D., Du, J., Marsic, S. and Roadarmel, W. (2005). Application of multicomponent deformation monitoring to $\mathrm{CO}_{2}$ sequestration. Proceedings of Fourth Annual Conference on Carbon Capture and Sequestration, 2-5 May. 
Davis, E., Astakhov, D. and Wright, C. (2001). Precise deformation monitoring by high resolution tiltmeters. Butsuri-Tsana, Society of Exploration Geophysicists of Japan, 54(6), 425432.

Davis, E., Wright, C., Demetrius, S., Choi, J., and Craley, G. (2000). Precise tiltmeter subsidence monitoring enhances reservoir management. SPE 62577 presented at the SPE/AAPG Western Regional Meeting, Long Beach, California, U.S.A., 19-23 June.

Diamond, W.P., LaScola, J.C. and Hyman, D.M. (1986). Results of direct-method determination of the gas content of U.S. coalbeds: U.S. Bureau of Mines Information Circular 9067, 95.

Du, J. and Wong, R.C.K. (2005). Development of a coupled geomechanics-thermal reservoir simulator using finite element method. Paper 027, Proceedings of Canadian International Petroleum Conference.

Du, J., Brissenden, S.J., McGillivray, P., Bourne, S., Hofstra, P., Davis, E.J., Roadarmel, W.H., Wolhart, S.L. and Wright, C.A. (2005). Mapping fluid flow in a reservoir using tiltmeter-basedsurface-deformation measurements. SPE paper 96897. Proceedings of SPE Annual Technical Conference and Exhibition, Dallas, Texas, U.S.A., October 9-12.

Du, J., Brissenden, S.J., McGillivray, P., Bourne, S., Hofstra, P., Davis, E.J., Roadarmel, W.H., Wolhart, S.L., Gusek, R. and Wright, C.A. (2008). Mapping reservoir volume changes during cyclic stam stimulation using tiltmeter-based-surface deformation measurements. SPE paper 97848. Proceedings of SPE International Thermal Operations and Heavy Oil Symposium, Calgary, Alberta, Canada, 1-3 November.

Du, J., Maxwell, S.C. and Warpinski, N.R. (2007). Fluid production and injection-Induced stress changes using reservoir volume changes inverted from tiltmeter-based surface deformations. SPE paper 110832. SPE Annual Technical Conference and Exhibition, Anaheim, California, U.S.A, 11-14 November.

Du, J. and Olson, J.E. (2001). A poroelastic reservoir model for predicting subsidence and mapping subsurface pressure fronts. Journal of Petroleum Science and Engineering 30, 181-197.

Gale, J. and Freund, P. (2001). Coal bed methane enhancement with $\mathrm{CO}_{2}$ sequestration: worldwide potential. Environmental Geoscience 8(3), 210.

Geerstma, J. (1973). Land subsidence above compacting oil and gas reservoirs. Journal of Petroleum Technology, 734-744.

Geertsma, J. (1974). Estimating the coefficient of internal resistance in fluid flow through porous media. SPE Paper No. 4706, SPE Journal, 445-450. 
Gorucu, F., Ertekin, T., Bromhal, G. S., Smith, D. H., Sams, W.N. and Jikich, S. (2005). Development of a neuro-simulation tool for coalbed methane recovery and $\mathrm{CO}_{2}$ sequestration. Proceedings of the International Coalbed Methane Symposium, Tuscaloosa, Alabama, U.S.A.

Gray, R.H., III. (1987). An overview of methane liberation from U.S. coal mines in the last 15 years: Third U.S. Mine Ventilation Symposium. University Park, Pennsylvania, Chapter 38, 251255.

Green, A.E. and Sneddon, I.N. (1950). The distribution of stress in the neighborhood of a flat elliptic crack in and elastic solid. Proceedings of Cambridge Philosophical Society 46, 159-163.

Harpalani, S. and Chen, G. (1997). Influence of gas production induced volumetric strain on permeability of coal. Geotechnical and Geological Engineering 15, 303-325.

Harpalani, S. and Schraufnagel, R.A.(1990). Shrinkage of coal matrix with release of gas and its impact on permeability of coal. Fuel 69, 551-556.

Hassanizadeh, S.M. $\left(1986^{\mathrm{a}}\right)$. Derivation of basic equations of mass transport in porous media, Part-1. Macroscopic balance laws. Advances in Water Resources 9, 207-222.

Hassanizadeh, S.M. $\left(1986^{\mathrm{b}}\right)$. Derivation of basic equations of mass transport in porous media, Part-2. Generalized Darcy's and Fick's laws. Advances in Water Resources 9, 196-206.

Holt, T., Jensen, J.-I. and Lindeberg, E. (1995). Underground storage of $\mathrm{CO}_{2}$ in aquifers and oil reservoirs. Energy Conversion and Management 36 (6-9), 535-538.

Hunt, A.M. and Steele, D.J. $\left(1991^{\mathrm{a}}\right)$. Coalbed methane development in the northern and central Appalachian basins -- past, present, and future, in Proceedings of the Coalbed Methane Symposium: University of Alabama, Tuscaloosa, Alabama, U.S.A., 127-141.

IPCC. (2007). Intergovernmental Panel on Climate Change, www.ipcc.ch.

Jikich, S., McLendon, T.R. and Smith, D.H. (2009 ${ }^{a}$. Permeability variations in an Upper Freeport coal core due to changes in effective stress and sorption. SPE paper 124348. Proceedings of the SPE Annual Technical Conference and Exhibition, New Orleans, Louisiana, U.S.A., 4-7 October.

Jikich, S.A., McLendon, T.R., Seshadri, K., Irdi, G. and Smith, D.H. (2009 ${ }^{\mathrm{b}}$ ). Carbon dioxide transport and sorption behavior in confined coal cores for carbon sequestration. SPE paper 109915.

Karacan, C. O. (2007). Swelling induced volumetric strains internal to a stressed coal associated with $\mathrm{CO}_{2}$ sorption. International Journal of Coal Geology 72, 209-220. 
Kelafant, J.R. and Boyer, C.M. (1988). A geologic assessment of natural gas from coal seams in the central Appalachian basin: Topical Report (January 1988 - November 1988) prepared under Contract No. 5084-214-1066, Gas Research Institute, Chicago, Illinois, U.S.A., 66.

Kelemen, S. R., Kwiatek, L. M. and Lee, A. G. K. (2006). Swelling and sorption response of selected argonne premium bituminous coals to $\mathrm{CO}_{2}, \mathrm{CH}_{4}$, and $\mathrm{N}_{2}$. Proceedings of the International Coalbed Methane Symposium, Tuscaloosa, Alabama, U.S.A.

King G.R., Ertekin T. and Schwerer F.C. (1986). Numerical simulation of the transient behavior of coal-seam degasification wells. SPEFE (April 1986) 165, Transactions of AIME, 281.

King, G.R.(1990). Material balance techniques for coal seam and Devonian shale gas reservoirs. SPE paper 20730, Proceedings of the 65th SPE Annual Technical Conference and Exhibition of Society of Petroleum Engineers, New Orleans, Louisiana, U.S.A., September 23-26.

Koide, H., Tazaki, Y., Noguchi, Y., Nakayama, S., Iijima, M., Ito, K. and Shindo, Y. (1992). Subterranean containment and long-term storage of carbon dioxide in unused aquifers and in depleted natural gas reservoirs. Energy Conversion and Management 33 (5-8), 619-626.

Koperna, G., Oudinot, A. Y., McColpin, G.R., Liu, N., Heath, J.E., Wells, A. and Young, G.B. (2009). $\mathrm{CO}_{2}$-ECBM/storage activities at the San Juan basin's Pump Canyon test site. SPE paper 124002, Proceedings of the SPE Annual Technical Conference and Exhibition, New Orleans, Louisiana, U.S.A., October 4-7.

Kramn, R.C., Griffin, L.G., Apruzzes, J., Stanley, G.R., Flaten, D.W., Bradshaw, M.K. and Lucas, B.C. (2005). Mapping preferential flow in a West Texas water flood. SPE Paper 95566. Proceedings of the SPE Annual Technical Conference and Exhibition, Dallas, Texas, U.S.A., 912 October.

Kulander, B.R., Dean, S.L. and Williams, R.E. (1980). Fracture trends in the Allegheny plateau of West Virginia: West Virginia geological and economic survey, publication MAP - WV11 (2 sheets), 1:250,000.

Langmuir, I. (1918). The adsorption of gases on plane surface of glass, mica, and platinum. Journal of American Chemical Society 40(9), 1361-1403.

Law, B.E. (1993). The relationship between coal rank and cleat spacing: Implications for the prediction of permeability in coal: Proceedings of the 1993 International Coalbed Methane Symposium ( The University of Alabama, Tuscaloosa, May 17-21, 1993), 435-441.

Levine J.R. (1996). Model study of the influence of matrix shrinking on absolute permeability of coal bed reservoirs. In: Gayer, R. Harris, I. (eds.) Coalbed Methane and Coal Geology, Geologic Society Special Publication 109, 197-212.

Lewis, C.A. and Shinn J.H. (2001). Global warming - An oil and gas company perspective: Prospects for Geologic Sequestration. Environmental Geosciences 8(3), 177-186. 
Liu, J., Chen, Z., Elsworth, D., Miao, X. and Mao, X. (2010). Evaluation of stress-controlled coal swelling process. International Journal of Coal Geology 83, 446-455.

Lyons, P.C. (1998). The central and northern Appalachian basin-a frontier region for coalbed methane development. International Journal of Coal Geology 38, 61-87.

Mavor, M.J., Owen, L.B. and Pratt, T.J. (1990) Measurement and evaluation of coal sorption isotherm data. SPE paper 20728, Proceedings of 65th Annual Technical Conference and Exhibition of the Society of Petroleum Engineers, New Orleans, Louisiana, U.S.A.

Mavor, M. J., Gunter, W.D. and Robinson, J. R. Alberta. (2004). Multiwell micro-pilot testing of CBM properties, enhanced methane recovery and $\mathrm{CO}_{2}$ storage potential. SPE 90256. Proceedings of the SPE Annual Technical Conference, Houston, Texas, U.S.A.

Maxwell, S.C., Du, J. and Shemeta, J. (2008). Passive seismic and surface monitoring of geomechanical deformation associated with steam injection. The Leading Edge, Special Section: Heavy Oil, 1176-1184.

Mazumder, S., Bruining, J. and Wolf, K. H. (2006 ${ }^{\mathrm{a}}$. Swelling and anomalous diffusion mechanisms of $\mathrm{CO}_{2}$ in coal. Proceedings of the International Coalbed Methane Symposium, Tuscaloosa, Alabama, U.S.A.

Mazumder, S., Karnik, A. and Wolf, K. H. (2006 ${ }^{\mathrm{b}}$ ). Swelling of coal in response to $\mathrm{CO}_{2}$ sequestration for ECBM and its effect on fracture permeability. SPE 97754. SPE Journal, 390398.

Mazumder, S., Siemons, N. and Wolf, K. H. $\left(2006^{\mathrm{C}}\right)$. Differential swelling and permeability changes of coal in response to $\mathrm{CO}_{2}$ injection for enhanced coalbed methane. Proceedings of the International Coalbed Methane Symposium, Tuscaloosa, Alabama, U.S.A.

McCoy, K.J., Donovan, J.J. and Leavitt, B.R. (2006). Horizontal hydraulic conductivity estimates for intact coal barriers between closed underground mines. Environmental and Engineering Geoscience XII(3), 273-282.

McCulloch, C.M. and Diamond, W.P.(1976). Inexpensive method helps predict methane content of coal beds. Coal age, June, 102-106.

McCulloch, C.M., Deul, M. and Jeran, P.W. (1974). Cleat in bituminous coalbeds: U.S. Bureau of Mines, Report of Investigations 7910, 23.

McElhiney, J.E., Koenig, R.A. and Schraufnagel, R.A. (1989). Evaluation of coalbed-methane reserves involves different techniques. Oil and Gas Journal, 63-72.

McColpin, G.R. (2009). Surface deformation monitoring as a cost effective MMV method. Energy Procedia 1, 2079-2086. 
Mayerhofer M., Demetrius, S., Griffin, L., Benzant, R.B., Nevans, J. and Doublet L. (2000). Tiltmeter hydraulic fracture mapping in the North Robertson field, West Texas. SPE paper 59715. Proceedings of SPE Permian Basin Oil and Gas Recovery Conference, Midland, Texas, U.S.A., 21-23 March.

Mirnov, V.S., Diyashev, I.R., Brovchuk, A.V., Stanley, G.R. and Davidson, B.M. (2008). Determination of fracture azimuth in Palnikovskoye field Western Siberia using tiltmeter technology. SPE paper 117097. Proceedings of the SPE Russian Oil \& Gas Technical Conference and Exhibition, Moscow, Russia, 28-30 October.

Mitra, A. and Harpalani, S. (2007). Modeling incremental swelling of coal matrix with $\mathrm{CO}_{2}$ injection in coalbed methane reservoirs. Proceedings of the SPE Eastern Regional Meeting, Lexington, Kentucky, U.S.A.

Nghiem, L., Sammon, P., Grabenstetter, J. and Ohkuma, H. (2004). Modeling $\mathrm{CO}_{2}$ storage in aquifers with a fully-coupled geochemical EOS compositional simulator. SPE paper 89474, Proceedings of Fourteenth Symposium on Improved Oil Recovery, Tulsa, Oklahoma, U.S.A., 17-21 April.

Nickelsen, R.P. and Hough, V.D. (1967). Jointing in the Appalachian plateau of Pennsylvania. The Journal of Geological Society of America bulletin 78, 609-630.

NIST. (2010). REFPROP, National Institute of Science and Technology, www.nist.gov.

Nordbotten, J.M. and Celia, M.A. (2006). Similarity solutions for fluid injection into confined aquifers. Journal of Fluid Mechanics 561, 307-327.

Okada, Y. (1985). Surface deformation due to shear and tensile faults in a half-space. Bulletin of the Seismological Society of America 75(4), 1135-1154, August.

Okada, Y. (1992). Internal deformation due to shear and tensile faults in a half-space. Bulletin of the Seismological Society of America 82(2), 1018-1040.

Onuma, T., Okada, K. and Ohkawa, S. (2008). Surface heave detection related with $\mathrm{CO}_{2}$ injection by DInSAR at In Salah, Algeria. IPTC paper 12294, Proceedings of International Petroleum Technology Conference, Kuala Lumper, Malaysia, 3-5 December.

Oudinot, A. Y., Schepers, K.C., Gonzalez R.J. and Reeves, S.R. (2008). An integrated reservoir characterization, geostatistical analysis, optimized history-matching and performance forecasting study of the 9-section, 30-well Pump Canyon $\mathrm{CO}_{2}$-ECBM/sequestration demonstration site, San Juan Basin, New Mexico. Paper 0804. Proceedings of International Coalbed and Shale Gas Symposium. 
Palmer, I. and Manosoori, J. (1996). How permeability depends on stress and pore pressure in coalbeds: A new model. SPE paper 36737. Proceedings of the SPE Annual Technical Conference and Exhibition, Denver, Colorado, U.S.A., October, 6-9.

Palmer, I. and Mansoori, J. (1998). How permeability depends on stress and pore pressure in coalbeds: a new model. SPE 52607. SPE Reservoir Evaluation Engineering 1(6), 539-544.

Pan, F. and Sepehrnoori, K. (2009). A new solution for a fully coupled geomechanics and compositional reservoir simulator. SPE paper 119029. Proceedings of the SPE Reservoir Simulation Symposium, Woodlands, Texas, U.S.A., 2-4 February.

Pan, Z. and Connell, L. D. (2005). Measurement and modelling of gas adsorption-induced coal swelling. Proceedings of the International Coalbed Methane Symposium, Tuscaloosa, Alabama, U.S.A.

Pan, Z. and Connell, L. D. (2007). A theoretical model for gas adsorption-induced coal swelling. International Journal of Coal Geology 69, 243-252.

Pashin J.C., Groshong R.H. and Carroll R.E. (2001). Carbon sequestration potential of coalbed methane reservoirs in black warrior basin: a preliminary look. Proceedings of the International Coalbed Methane Symposium, Tuscaloosa, Alabama, U.S.A., 14-18 May.

Pashin, J.C. and MccIntyre, M.R. (2003). Temperature-pressure conditions in coalbed methane reservoirs of the Black Warrior basin: Implications for carbon sequestration and enhanced coalbed methane recovery. International Journal of Coal Geology 54, 167-183.

Pekot, L.J. and Reeves, S.R. (2003). Modeling of effects of matrix and shrinkage and differential swelling on coalbed methane recovery and carbon sequestration. Paper 0328, Proceedings of International Coalbed Symposium.

Reeves, S R. (2001). Geological sequestration of $\mathrm{CO}_{2}$ in deep, unmineable coalbeds: in integrated research and commercial-scale field demonstration project. SPE Annual Technical Conference and Exhibition, New Orleans, Louisiana, 30 September - October 3.

Reeves, S. and Oudinot, A. (2005). The Allison $\mathrm{CO}_{2}$ - ECBM pilot, a reservoir and economic analysis coal. Proceedings of the International Coalbed Methane Symposium, Tuscaloosa, Alabama, U.S.A.

Reeves, S. R. (2003). Assessment of $\mathrm{CO}_{2}$ sequestration and ECBM potential of U.S. coalbeds. Topical Report. U.S. Department of Energy.

Reeves, S., Taillefert, A., Pekot, L. and Clarkson, C. (2003). The Allison Unit $\mathrm{CO}_{2}-$ ECBM pilot: a reservoir modeling study. Topical Report (DE-FC26-0NT40924), U.S. Department of Energy.

Reucroft, P.J. and Patel, H. (1986). Gas-induced swelling in coal. Fuel 65, 816-820. 
Roberston, E.P. and Christiansen, R.L. (2005). Measurement of sorption-induced strain. Proceedings of International Coalbed Symposium.

Roberston, E.P. and Christiansen, R.L. (2006). A permeability model for coal and other fractured, sorptive elastic media. Proceedings of Society of Petroleum Engineers Eastern Regional Meeting, October.

Rogers, R. E. (1994). Coalbed Methane: Principles and Practice. PTR Prentice Hall, New Jersey.

Ruppel, T.C., Grein, C.T. and Bienstock, D. (1973). Adsorption of methane on dry coal at elevated pressure. Fuel 51(4), 297-303.

Rutqvist, J., Vasco, D.W. and Myer L. (2009). Coupled reservoir-geomechanical analysis of $\mathrm{CO}_{2}$ injection at In Salah, Algeria. Energy Procedia 1, 1847-1854.

Rutqvist, J., Birkholzer, J.T. and Tsang, C.F. (2008). Coupled reservoir-geomechanical analysis of the potential for tensile and shear failure associated with $\mathrm{CO}_{2}$ injection in multilayered reservoir-caprock systems. International Journal of Rock Mechanics Mineral Science 45, 132143.

Rutqvist, J., Vasco, D.W. and Myer, L. (2010). Coupled reservoir-geomechanical analysis of $\mathrm{CO}_{2}$ Injection and Ground Deformations at In Salah, Algeria. International Journal of Greenhouse Gas Control 4, 255-230.

Saghafi, A., Faiz, M. and Roberts, D. (2007). $\mathrm{CO}_{2}$ storage and gas diffusivity properties of coals from Sydney basin, Australia. International Journal of Coal Geology 70, 240-254.

Sams, W.N., Bromhal, G., Jikich, S., Odusote, O., Ertekin, T. and Smith D. (2003). Using reservoir simulation to evaluate the effect of uncertainties in reservoir properties on the design of a pilot project for sequestration of carbon dioxide and enhanced coalbed methane production. Proceedings of the International Coalbed Methane Symposium, Tuscaloosa, Alabama, U.S.A., 78 May.

Sams, W.N., Bromhal, G., Jikich, S.A., Oduote, O., Ertekin, T. and Smith, D.H. (2002). Simulating carbon dioxide sequestration/ECBM production in coal seams: effects of coal properties and operational parameters, paper SPE 78691. Proceedings SPE Eastern Regional Meeting, Lexington, Kentucky, U.S.A., 23-26 October.

Segall, P. (1985). Stress and subsidence resulting from subsurface fluid withdrawal in the epicentral region of the 1983 Coalinga earthquake. Journal of Geophysical Research 90, 68016816. 
Seidle, J.P. and Huitt, L.G. (1995). Experimental measurement of coal matrix shrinkage due to gas desorption and implications for cleat permeabilty increases. SPE paper 30010. Proceedings of the International Meeting on Petroleum Engineering, Beijing, China, 14-17 November.

Seidle, J.P., Jeansonne, M.W. and Erickson, D.J. (1992). Application of matchstick geometry to stress dependent permeability in coals. SPE paper 24361. Proceedings of the SPE Rocky Mountain Regional Meeting, Casper, Wyoming, U.S.A., 18-21 May.

Settari, A.T., Bachman, R.C. and Walters, D.A. (2005). How to approximate effects of geomechanics in conventional reservoir simulation. SPE paper 97155, Proceedings of the SPE Annual Technical Conference and Exhibition, Dallas, Texas, U.S.A., 9-15 October.

Settari, A. and Mourits, F.M. (1998). A coupled reservoir and geomechanical simulation system. SPE paper 50939. SPE Journal, 219-226.

Shi, J. Q. and Durucan, S. (2004). A numerical simulation study of the Allison Unit $\mathrm{CO}_{2}-\mathrm{ECBM}$ pilot: the impact of matrix shrinkage and swelling on ECBM production and $\mathrm{CO}_{2}$ injectivity. Proceedings of the 7th International Conference on Greeenhouse Gas Control Technology, IEA Greenhouse Gas Programme.

Shi, J.Q. and Durucan, S. (2003). Modelling of enhanced methane recovery and $\mathrm{CO}_{2}$ sequestration in deep coal seams: The impact of coal matrix shrinkage/swelling on cleat permeability. Paper 0343, Proceedings of the International Coalbed Symposium.

Shi, J.Q. and Durucan, S. (2005). $\mathrm{CO}_{2}$ storage in deep unmineable coal seams. Oil and Gas Science and Technology 60(3), 547-558.

Siemons, N., Karl-Heinz, A. A. W. and Bruining, J. (2007). Interpretation of carbon dioxide diffusion behavior in coals. International Journal of Coal Geology 72, 315-324.

Siriwardane, H. J., Smith, D. H. and Gorucu, F. (2006). Shrinkage and swelling of coal during coalbed methane production or geologic sequestration of carbon dioxide. Proceedings of the international Coalbed Methane Symposium, Tuscaloosa, Alabama, U.S.A.

Siriwardane, H.J., Gondle, R. and Smith, D.H. (2009). Shrinkage and swelling of coal induced by desorption and sorption of fluids: theoretical model and interpretation of a field project. International Coalbed Journal of Coal Geology, Volume 77 (1-2), 188-202, January.

Smith, D.H. and Jikich, S.A. (2009). Permeability, elastic, and carbon dioxide-sorption properties of Upper Freeport coalbed cores from a carbon dioxide sequestration/enhanced coalbed methane field project. Paper 0908. Proceedings of International Coalbed and Shale Gas Symposium, 106-124.

Smith, D.H., Bromhal, G., Sams, W.N., Jikich, S. and Ertekin, T. (2004). Simulating carbon dioxide sequestration/ECBM production in coal seams: Effects of permeability anisotropies and 
the diffusion-time constant. SPE paper 84423. Proceedings for the SPE Annual Technical Conference and Exhibition, Denver, Colorado, U.S.A., October 5-8.

Steidl, P.F. (1977). Geology and methane content of the Upper Freeport coalbed in Fayette county, Pa. Bureau of Mines Report of Investigation-8226r, U.S. Department of the Interior.

Stevens, S.H., Kuuskraa, V.L., Gale, J. and Beecy, D. (2001). $\mathrm{CO}_{2}$ injection and sequestration in depleted oil and gas fields and deep coal seams: worldwide potential and costs. Environmental Geosciences 8(3), 200-209.

Terzaghi, K. (1936). The shear resistance of saturated soils. Proceedings of First International Conference on Soil Mechanics \& Foundation Engineering1, 54-56, Cambridge, Massachusetts, U.S.A.

Tran, D., Settari, A. and Nghiem, L. (2002). New iterative coupling between a reservoir simulator and a geomechanics module. SPE paper 78192. Proceedings of the SPE/ISRM Rock Mechanics Conference, Irving, Texas, U.S.A., October 20-23.

Tran, D., Settari, A. and Nghiem, L. (2004). New iterative coupling between a reservoir simulator and a geomechanics module. SPE paper 88989, SPE Journal, September, 362-369.

Tran, D., Nghiem, L. and Buchanan, L. (2005 ${ }^{\mathrm{a}}$ ). Improved iterative coupling between geomechanics with reservoir flow. SPE paper 93244. Proceedings of the SPE Reservoir Simulation Symposium, Houston, Texas, U.S.A., 31 January - 2 February.

Tran, D., Nghiem, L. and Buchanan, L. $\left(2005^{\mathrm{b}}\right)$. An overview of iterative coupling between geomechanical deformation and reservoir flow. SPE paper 97879. Proceedings of the SPE International Thermal Operations and Heavy Oil Symposium, Calgary, Alberta, Canada, 1-3 November.

Tran, D., Buchanan, L. and Nghiem, L. (2008). Improved gridding technique for coupling geomechanics to reservoir flow. SPE paper 115514. Proceedings of the SPE Annual Technical Conference and Exhibition, Denver, Colorado, U.S.A., 21-24 September.

U.S. D.O.E. (2006). Carbon Sequestration Technology Roadmap and Program Plan, Office of Fossil Energy, National Energy Technology Laboratory.

U.S. D.O.E. (2007). Carbon Sequestration Atlas of the United States and Canada. www.netl.doe.gov

U.S. D.O.E. (2008). Carbon Sequestration Atlas of the United States and Canada. www.netl.doe.gov

U.S. D.O.E. (2010). Carbon Sequestration Atlas of the United States and Canada. www.netl.doe.gov 
Van der Meer, L.G.H. (1992). Investigations regarding the storage of carbon dioxide in aquifers in Netherlands. Energy Conversion and Management 33 (5-8), 611-618.

Vasco, D.W., Karasaki, K. and Myer, L. (1988). Monitoring of fluid and soil consolidation using surface tilt measurements. Journal of Geotechnical and Geoenvironmental Engineering 124 (1), 29-37.

Viete, D. R. and Ranjith, P. G. (2006). The effects of $\mathrm{CO}_{2}$ on the geomechanical and permeability behavior of brown coal; Implications for coal seam $\mathrm{CO}_{2}$ sequestration. International Journal of Coal Geology 66, 204-216.

Viete, D. R. and Ranjith, P. G. (2007). The mechanical behavior of coal with respect to $\mathrm{CO}_{2}$ sequestration in deep coal seams. Fuel 86 (17-18), 2667-2671.

Wageningen, van, W.F.C. and Mass, J.G. (2007). Reservoir simulation and interpretation of the RECOPOL ECBM pilot in Poland, Paper 0702. International Coalbed Methane Symposium, Tuscaloosa, Alabama, U.S.A., 23-24 May.

Wageningen, van, W.F.C., Wentinck, H.M. and Otto, C. (2009). Report and modeling of the MOVECBM field tests in Poland and Slovenia, Energy Procedia 1, 2071-2078.

Walser, D.W., Aktahov, D.K. and Stanley, G.R. (2008). A new model for vertical leak detection in low to moderate permeability flooded reservoirs. SPE paper 113076, Proceedings of the SPE/DOE Improved Oil Recovery Symposium, Tulsa, Oklahoma, U.S.A., 19-23 April.

Walser, D.W., Aktahov, D.K. and Stanley, G.R. (2009). A new model for vertical leak detection in low to moderate permeability flooded reservoirs. SPE Reservoir Evaluation \& Engineering, 683-688.

White, Curt M., Smith, D.H., Jones, K.L., Goodman, A.L., Jikich, S.A., LaCount, R.B., DuBose, S.B., Ozdemir, E., Morsi, B.I. and Schroeder, K.T. (2005). Sequestration of carbon dioxide in coal with enhanced coalbed methane recovery - a review. Energy \& Fuels 19(3), 659-724.

Wilson, T.H. (2009). Personal Communications.

Wilson, T.H., Tallman, J., Rauch, H., Wells, A. and Smith, D. (2003). Reconnaissance studies of a pilot carbon sequestration site in the central Appalachians of West Virginia. Northeastern Geology \& Environmental Sciences 25(4), 330-345.

Winschel, R.A. (2009). Personal Communications.

Winschel, R.A. and Scandrol, R.O. (2007). Enhanced coal bed methane production and sequestration of $\mathrm{CO}_{2}$ in unmineable coal seams. Presentation at "Unconventional Plays and Research Needs for Appalachian Basin Small Producers" Meeting, NRCCE (WVU), Morgantown, West Virginia, U.S.A., 15 February. 
Winschel, R.A., Locke, J.E., Srivastava, R.S., Bajura, R.A., Wilson, T.H., Siriwardane, H.J., Rauch, H.W., Patchen, D.G., Hega, B.D. and Gondle R. (2010). $\mathrm{CO}_{2}$ sequestration in unmineable coal with enhanced coalbed methane recovery: The Marshall county project, Proceeding of the International Pittsburgh Coal Conference, Istanbul, Turkey, 11-14 October.

Wright, C.A., Davis, E.J., Minner, W.A., Ward, J.F., Weijers, L., Schell, E.J. and Hunter, S.P. (1998). Surface tiltmeter fracture mapping reaches new depths - 10,000 feet, and beyond?. SPE 39919. SPE Rocky Mountain Regional/Low-Permeability Symposium and Exhibition, Denver, Colorado, U.S.A. 5-8 April.

www. $\mathrm{CO}_{2} \mathrm{NOW}$.org

www.eia.doe.gov

www.geology.com

www.Pinntech.com

www.wvgis.wvu.edu

Yin, S., Dusseault, M.B. and Rothenburg, L. $\left(2007^{\mathrm{a}}\right)$. Analytical and numerical analysis of pressure drawdown in a poroelastic reservoir with complete overburden effect considered. Advances in Water Resources 30, 1160-1167.

Yin, S., Dusseault, M.B. and Rothenburg, L. (2007 $)$. Coupled multiphase poroelastic analysis of reservoir depletion including surrounding strata. International Journal of Rock Mechanics \& Mining Sciences 44, 758-766.

Zumberge, J.F., Heflin, M.B., Jefferson, D.C., Watkins and M.M., Webb, F.H. (1997). Precise point positioning, for the efficient and robust analysis of GPS data from large networks. Journal of Geophysical Research 102, 5005-5017. 